\title{
Making functional assessment functional
}

Citation for published version (APA):

Elings, J. (2021). Making functional assessment functional: application with patients before and after their total hip or total knee arthroplasty. [Doctoral Thesis, Maastricht University]. Maastricht University. https://doi.org/10.26481/dis.20210212je

Document status and date:

Published: 01/01/2021

DOI:

10.26481/dis.20210212je

Document Version:

Publisher's PDF, also known as Version of record

\section{Please check the document version of this publication:}

- A submitted manuscript is the version of the article upon submission and before peer-review. There can be important differences between the submitted version and the official published version of record.

People interested in the research are advised to contact the author for the final version of the publication, or visit the DOI to the publisher's website.

- The final author version and the galley proof are versions of the publication after peer review.

- The final published version features the final layout of the paper including the volume, issue and page numbers.

Link to publication

\footnotetext{
General rights rights.

- You may freely distribute the URL identifying the publication in the public portal. please follow below link for the End User Agreement:

www.umlib.nl/taverne-license

Take down policy

If you believe that this document breaches copyright please contact us at:

repository@maastrichtuniversity.nl

providing details and we will investigate your claim.
}

Copyright and moral rights for the publications made accessible in the public portal are retained by the authors and/or other copyright owners and it is a condition of accessing publications that users recognise and abide by the legal requirements associated with these

- Users may download and print one copy of any publication from the public portal for the purpose of private study or research.

- You may not further distribute the material or use it for any profit-making activity or commercial gain

If the publication is distributed under the terms of Article $25 \mathrm{fa}$ of the Dutch Copyright Act, indicated by the "Taverne" license above, 


\section{MAKING FUNCTIONAL ASSESSMENT FUNCTIONAL}

APPLICATION WITH PATIENTS BEFORE AND AFTER

THEIR TOTAL HIP OR TOTAL KNEE ARTHROPLASTY

$$
\text { J O R D I E I N G S }
$$
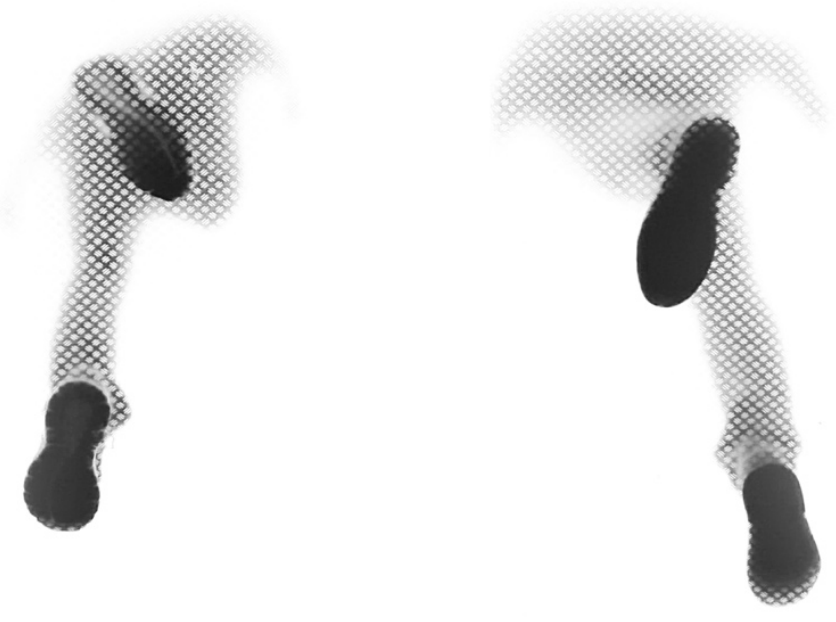
(c) Jordi Elings, Wageningen 2020

No parts of this book may be reproduced or transmitted in any form or by any means, without prior permission in writing by the author, or when appropriate, by the publisher of the publications.

$\begin{array}{ll}\text { Design cover } & \text { Joël Kouthoofd } \\ \text { Cover photo } & \text { John Robert Marasigan } \\ \text { Layout } & \text { Jordi Elings } \\ \text { Printed by } & \text { proefschriftenprinten.nl } \\ \text { ISBN/EAN } & 978-90-831117-8-0\end{array}$

The research presented in this thesis was conducted at the Department of Epidemiology, research line Functioning, Participation, and Rehabilitation of the Care and Public Health Research Institute (CAPHRI), Maastricht University.

The printing of this thesis was financially supported by (in alphabetical order): Anna Foundation|NOREF, Diakonessenhuis, and the Scientific college of Physical therapy (WCF) of the Royal Dutch Society for Physical Therapy (KNGF).

\section{Mastricht University}

(†) CAPHRI

\section{Diakonessenhuis}

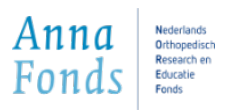

Koninklijk Nederlands
Genootschap voor Fysiotherapie 


\title{
MAKING FUNCTIONAL ASSESSMENT FUNCTIONAL
}

\author{
APPLICATION WITH PATIENTS BEFORE AND AFTER \\ THEIR TOTAL HIP OR TOTAL KNEE ARTHROPLASTY
}

PROEFSCHRIFT

ter verkrijging van de graad van doctor aan de Universiteit Maastricht,

op gezag van de Rector Magnificus, Prof dr. Rianne M. Letschert

volgens het besluit van het College van Decanen,

in het openbaar te verdedigen

op vrijdag 12 februari 2021 om 16.00 uur

door

JORDI ELINGS 


\section{Promotor}

Prof. dr. N.L. van Meeteren

\section{Copromotor}

Dr. T.J. Hoogeboom

Dr. S.M. van Gaalen (MD)

\section{Beoordelingscommissie}

Prof. dr. L.W. van Rhijn (voorzitter)

Prof. dr. R.A. de Bie

Prof. dr. A.M.C.F. Verbunt

Prof. dr. J.A.N. Verhaar

Prof. dr. P.J. van der Wees 


\section{TABLE OF CONTENTS}

$\begin{array}{llr}\text { Chapter } 1 \quad \text { General introduction } & 9\end{array}$

PART I

Chapter 2 What preoperative patient-related factors predict inpatient recovery of physical 25 functioning and length of stay after total hip arthroplasty? A systematic review

Chapter 3 Exploration and Conformation of Clinically Relevant Patient Profiles of Individuals 57 Awaiting Total Hip Arthroplasty

Chapter 4 Development of a Risk Stratification Model for Delayed Inpatient Recovery of 77 Physical Activities in Patients Undergoing Total Hip Replacement

\section{PART II}

Chapter 5 Advocacy for use of the modified lowa Level of Assistance Scale for clinical use 97 in patients after hip replacement: an observational study

Chapter 5.1 Letter to the editor

Chapter 5.2 Response to the editor

\section{PART III}

Chapter 6 Reference chart for knee flexion following total knee arthroplasty: a novel tool for monitoring postoperative recovery

Chapter $7 \quad$ General discussion

Chapter $8 \quad$ Valorization

Summary 

I have seen the healthcare system from many angles,

including as a patient.

Ron Williams, 2016 



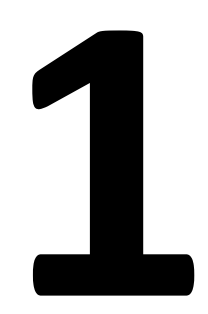

INTRODUCTION 
"We are all different."

L. Hood (founder of P4 medicine)

The purpose of this thesis is to improve the care process and outcomes for individual patients choosing total hip arthroplasty (THA) surgery through the development of clinical tools that aid patients and healthcare providers in their decision making. This introduction outlines the epidemiology, the changes in context in which this thesis is written, what changes are needed, and what this thesis adds to the current evidence. The introduction ends with the specific aims of this thesis.

\section{EPIDEMIOLOGY}

THA is one of the most common inpatient elective surgeries worldwide. In the USA in 2014 roughly 370,000 [1] and in the Netherlands in 2017 about 30,000 [2] THA surgeries were performed, and this number will almost double in 2030 [1]. Total joint arthroplasty of the hip or knee is considered to be a safe and effective surgical intervention to improve hip pain and functioning [3], [4]. Nevertheless, surgical interventions are not without risks nor are guaranteed for optimal outcome [5], [6]. There is evidence suggesting that in an older population, only half of the people undergoing THA will achieve a good outcome, defined as a clinically relevant improvement on pain and disability [7]. So evidently, there is still room for improvement in the outcome of THA.

\section{CHANGES IN (HEALTHCARE) CONTEXT}

\section{SHIFT IN SOCIETY}

The way society is arranged also shifted due to the aging of humanity. In the Netherlands, the welfare society is changing to a participatory society [8] in which citizens are depending less on the government. One of the goals is that the elderly would stay at their own home as long as possible, if necessary with home care to support. Thereby, more and more daily support is expected from family and friends, and skilled nursing homes are reduced in numbers, and the 
indications for admission are stricter. To be admitted to a skilled nursing home nowadays you need 24/7 intensive care [9].

\section{VIEW ON HEALTH}

The definition of health, by the WHO, dates back to 1948 where health was defined as "A state of complete physical, mental and social well-being and not merely the absence of disease or infirmity" [10]. This definition has not been amended by the WHO since. The life expectancy of men in the Western world has increased since the initial definition of health by 10 years [11] especially by declining late-life mortality [12]. Most fatal diseases in early 1900 are now evolved to chronic conditions, which led to a discussion on how we should manage disease. This resulted in a new insight on health defined as "the ability to adapt and manage physical, mental and social challenges throughout life" [13]. Vanderweele et al [14] stretches the definition even further into the patient's life. The "Flourishing" framework for health addresses 5 universally desired domains [happiness and life satisfaction; physical and mental health; meaning and purpose; character and virtue; close social relationships] and one domain [financial and material security] to securing the aforementioned (see Table 1.1). Both new definitions match the nature of health care professionals better, namely to empower the individual to cope with the consequences of their disease/illness.

\footnotetext{
"A scientist who experiences occasional psychotic symptoms is told that antipsychotic medication can suppress episodes but also could potentially impede his capacity for scientific work" T.J. Vanderweele (Flourishing statement)
}

\section{EVIDENCE BASED MEDICINE}

Evidence-based medicine (EBM) was first described in the early '90 as a new paradigm to practice medicine. EBM is all about making the best choices about the treatment of individual patients. EBM requires integrating the clinical expertise of the health care professionals with the best available evidence, adjusted together with the individual patient with his or her unique values 
Table 1.1. Flourishing Measure and Questions

\begin{tabular}{|c|c|}
\hline Domain & Question/Statement \\
\hline \multirow{2}{*}{ Happiness } & 1. Overall, how satisfied are you with life as a whole these days? \\
\hline & 2. In general, how happy or unhappy do you usually feel? \\
\hline Mental and & 3. In general, how would you rate your physical health? \\
\hline physical health & 4. How would you rate your overall mental health? \\
\hline \multirow{2}{*}{$\begin{array}{l}\text { Meaning and } \\
\text { purpose }\end{array}$} & 5. Overall, to what extent do you feel the things you do in your life are worthwhile? \\
\hline & 6. I understand my purpose in life. \\
\hline \multirow[t]{2}{*}{ Character } & $\begin{array}{l}\text { 7. I always act to promote good in all circumstances, even in difficult and challenging } \\
\text { situations. }\end{array}$ \\
\hline & 8. I am always able to give up some happiness now for greater happiness later. \\
\hline Close social & 9. I am content with my friendships and relationships. \\
\hline relationships & 10. My relationships are as satisfying as I would want them to be. \\
\hline Financial & 11. How often do you worry about being able to meet normal monthly living expenses? \\
\hline stability & 12. How often do you worry about safety, food, or housing? \\
\hline
\end{tabular}

and objectives [15]. EBM in combination with shared decision making (SDM) makes the best possible care possible for the individual patient. However, the integration of EBM and SDM is not commonplace [16].

Population-based research has transformed our knowledge of disease and treatment options and resulted in population medicine. Population medicine works fine for population-based infectious diseases but is less effective in chronic diseases (see Box 1.1). A key item for conducting proper EBM in chronic decease is the ability to personalize the best available evidence, originating from population-based research, for the individual patient. However, the individual patient most likely differs from the patients enrolled in the studies and has unique preferences and priorities that require consideration [17]. The health care professional should provide each individual patient useful evidence-based estimates of the benefits and harms to his or her specific situation facilitating shared decision making (SDM) [18], although the majority of patients with musculoskeletal issues do not want to be involved with all the surgery-related decisions [19]. A tool to enhance SDM during the EBM process could be P4Medicine. Figure 1.1 provides a graphic representation, inspired by Hoffman et al. [16], of the combination of EBM and SDM with the addition of $\mathrm{P} 4$ medicine. 
BOX 1.1.

Infectious diseases

If you want to stop an infectious disease like the measles from spreading, a population-based vaccination of $95 \%$ is advised by the WHO [47]. This works well for diseases with only one factor that can be easily addressed.

\section{Chronic disease}

In most chronic disease there are many factors involved that are not easily addressed with a cheap and cost efficient treatment. For example, with cancer, we do know certain factors could contribute to the development of cancer, but not in all people. Thereby, some of those factors are not or not easily modifiable, like genetic predisposition, which makes it hard to ban cancer from humanity with population-based medicine.

FIGURE 1.1. Modified model of the interdependence of Evidence-Based Medicine, Shared Decision Making and P4medicine as part of optimal patient care.

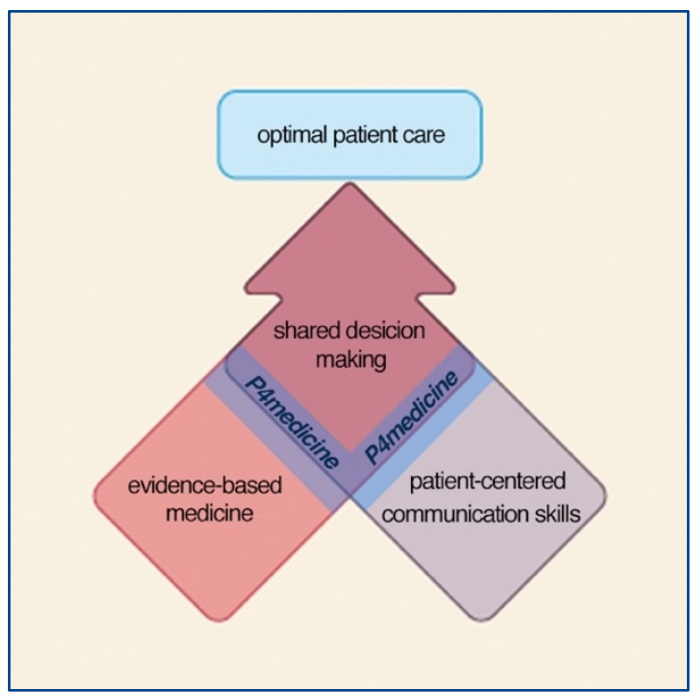




\section{P4 Medicine}

L. Hood first mentioned P4 medicine in the literature in 2008 as an addition to modern medicine. P4 medicine consists of predictive, preventive, personalized, and participatory medicine which, is and was in many ways different from the current practice of medicine. P4 medicine is proactive and focused on the individual patient, especially regarding diagnostics tools and treatment options [20].

The potential of the P4 medicine approach looks promising, explicitly focusing on the individual patient within a proactive state of mind. Considering the fact that P4 medicine is adopted by the scientific community and policymakers, we should incorporate the four domains, predictive, preventive, personalized, and participatory, more in the SDM process and day-to-day practice. However, which questions should we answer with patients to help them make a deliberate considered which treatment fits their needs the best?

\section{Predictive}

What is the predicted outcome for me in terms of recovery of activities over time?

\section{Preventive}

What should I do to enhance my recovery?

\section{Personalized}

Do the outcomes fulfill my needs and goals considering my specific context?

Can I fulfill the therapy regime within my current context?

\section{PARTICIPATORY}

Do I have the knowledge, motivation, and competences to access, understand, appraise, and apply health information to make judgments and decisions to improve my health/fulfill the treatment regime?

What information (test results/technology) do I need to make a judgment and make decisions during the treatment regime?

Do I need support from healthcare professionals during the therapy regime? 


\section{RECENT CHANGES IN CLINICAL PATHWAYS}

Healthcare for patients with hip osteoarthritis is constantly optimized by adopting new treatment protocols to enhance healthcare started with "joint care" [21], [22], which was a time-based regime with special attention to preoperative education and group dynamics. This was later followed by "fast track" [23]-[25], which focuses on the reduction of adverse effects/events after major joint replacement surgery. Key elements are 1) patient education to reduce fear, set realistic goals, and stimulate self-efficacy; 2) optimizing fluid management (fasting) to minimize postoperative nausea and reduce inflammation after surgery; 3) multimodal pain medication to reduce the side effects like nausea and enable early mobilization; 4) early mobilization within four hours after surgery to reduce functional decline and cognitive dysfunction. Those perioperative protocols are mainly a population-based approach and are therefore suitable for the majority of the patients. However, it is plausible that the effect of the standard intervention might lose its potential for specific patient groups. An additional treatment regime mentioned in the literature is function tailored care [26], were fast track elements are combined with the focus on the individual values of the patient related to his or her recovery of functions (activities). In other words: Which activities does the patient need to fulfill on his or her own within his or her living environment? This is a shift from a more population-based treatment regime to more personalized care.

The newest in THA is outpatient surgery, which is becoming more popular these days. The results in terms of adverse events and readmission are similar to "regular" treatment protocols with a length of stay of 1-5 days [27], [28]. However, outpatients tend to be younger ( $<50$ years), less likely to be (morbid) obese, more fit for surgery (American Society of Anesthesiologist class 1 or 2), and had less preoperative comorbidity [29], [30]. In conclusion, outpatient surgery is a safe treatment option, but only for a selecthealthy population [28], [30]-[32], but not for frail patients. The next step is the transition from hospitals to ambulatory surgery centers for total joint arthroplasty. Therefore, preparation of patients and surgeons is crucial. Adequate protocols must be developed and surgeons must cope with the reduced capabilities and options after surgery, and patients must be prepared to go home within hours after surgery [33].

\section{Clinical pathways in the NetherLands [2010-2015]}

Fasttrack protocols were becoming more and more popular. Several Dutch hospitals used clinical pathways that were (re)designed like or influenced by fast-track protocols. 


\section{Preoperative}

Patients with end-stage osteoarthritis were initially treated by their general practitioners, ideally with a stepped care strategy as reported by Smink et al. [34]. The first step starts with the assessment of functions/activities, mutual goal setting, education, lifestyle advice, and prescription of Acetaminophen/Paracetamol. When this approach fails, the next step concerns radiologic assessment of the affected joint, evaluation of coping styles and goals, exercise therapy, weight loss (only for overweight patients), and prescription of nonsteroidal antiinflammatory drugs (NSAIDs). In case those interventions fail as well, the last step consists of further adjusting the patient's goals, setting up multidisciplinary care, starting transcutaneous electrical nerve stimulation (TENS), and intraarticular injections. When "all" conservative treatment options reveal no adequate response to the patient's complaints, a total joint replacement should be considered.

After the indication for a THA, an anesthesiologist and nurse (in a few hospitals also a physical therapist) assessed the "surgical risk" and preoperative functional status of each patient [35], [36]. When this preoperative assessment was completed, the patient was placed on a waiting list.

\section{Postoperative}

During hospital admission patients were treated in specific orthopedic wards where the orthopedic surgeon was responsible for the medical treatment, and the nurse for the daily care. The hospital culture and facilities induced that patients were mostly inactive (lying in bed) during this inpatient period. The physical therapist treated patients on a daily basis; the goal was to optimize functions and regain functional independence to function independently indoors without 24/7 assistance. The use of a measurement instrument to assess functional recovery was not common in those days. After discharge patients went mainly to their own living environment and a subsample of approximately 30\% went to skilled nursing facilities [26]. Postoperative physical therapy was routinely prescribed to treat/coach most of the patients during the first months after surgery. 


\section{WHAT DO WE NEED TO CHANGE?}

To optimize health care, we should place the individual (patient) in the center of his or her care process; corresponding with EBM and the P4 medicine approach. In order to make a thoughtout decision, a patient needs relevant information about his or her treatment options with the related outcomes and consequences. To enhance this SDM process the P4Medicine components predictive, preventive, personalized, and participatorycan help the patient to decide which treatment option fits his or her preferences and priorities the best. During the SDM process, the health care professional together with the patient should focus on the ability to adapt to the consequences during each step in the treatment process and the possibilities of preventive options to enhance the adaptation.

Figure 1.2 shows such a tailor made clinical pathway model, which assesses the potential of the patient to recover from surgery during the two preoperative (indication and admission) and two postoperative (surgery and discharge) phases.

Figure 1.2. Continuum of care [37]

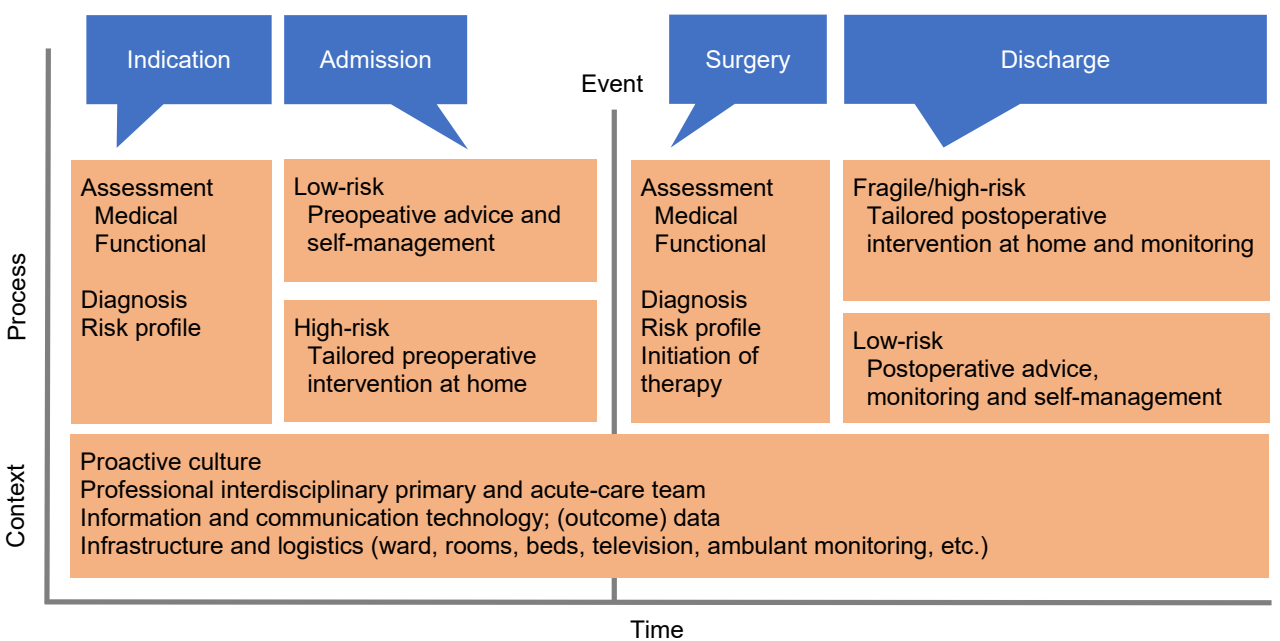




\section{Preoperative}

This phase is characterized by the possibility to predict (and perhaps improve) the functional status to enhance recovery.

\section{INDICATION}

During the indication phase, both patient and healthcare professionals should determine if all non-surgical treatments were considered or proven insufficient to cope with the effect of endstage osteoarthritis of the hip, as described in the BART-strategy [38]. As a shared decision, both patients and healthcare professionals should decide whether THA is the best treatment option at that moment. For healthcare professionals, it would be helpful to identify which phenotype the patient belongs to. This could alter the specific treatment options or add-on therapies for the individual patient [39].

\section{ADMISSION}

During the (pre)admission phase there is time to evaluate the functional status of the patient and predict postoperative recovery. This enables healthcare professionals to identify patients who are at risk and may benefit from preoperative preventive interventions to optimize their preoperative condition [40], ideally in their own home environment [41]. We used the modified model of Topp et al. to visualize the response of a patient on surgery and a period of preoperative exercise (see Figure 1.3) [42]. The majority of the patient's response is adequate to address the functional decline caused by surgery (Figure 1.3a). However, 7-34\% of patients have difficulty recovering and may never reach their preoperative levels again. [43], [44] (Figure 1.3b). This specific group may benefit the most from preoperative interventions such as weight reduction, lifestyle changes, preoperative exercise, etc. (Figure 1.3c).

\section{POSTOPERATIVE}

This phase is characterized by the titration of interventions to adapting the consequences after surgery.

\section{HOSPITAL}

During this phase, patients recover from surgery in a safe and controlled environment. To be discharged the patient must be medically sound and functionally independent next to all logistical 
able to independently conduct transfers, walk, and climb stairs (if necessary) [23], [45]. Healthcare professionals and patients should assess these medical and functional items to determine if the patient is ready to be discharged.

Figure 1.3. Courses of the functional status of patients before and after THA surgery. A) recovery of a patient with an adequate response to surgery; B) frail patient with an inadequate response to surgery; C) frail patient which followed a preoperative intervention to increase functional status resulting in an adequate response to surgery.

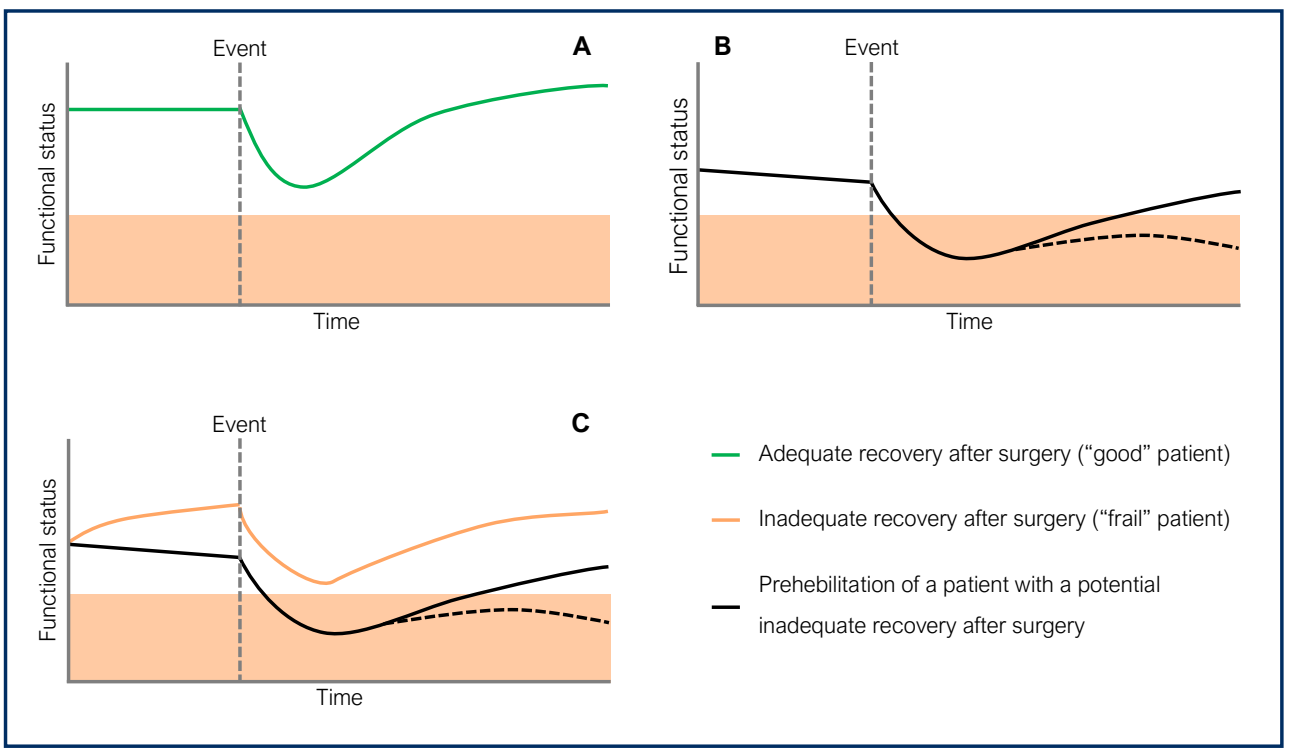

\section{DISCHARGE}

After discharge, the process of assessment continues by evaluating if the individual patient can cope with its new health situation and to achieve his or her goals. To acquire this kind of information, high frequency monitoring [46] of the patient's ability is needed, especially for frail or patients at risk for prolonged recovery of activities. With this information, the healthcare professional and patient can titrate the intervention, resulting in a more efficient outcome and use of healthcare utilization. 


\section{WHAT ADDS THIS THESIS TO THE CURRENT EVIDENCE}

As described above, we need to individualize the clinical pathway for every individual patient. To do so, we need evidence and tools to assess what is best for each individual. Looking at the new continuum of care there are some critical time points: (A) directly after indication for THA surgery: what type of patient profiles are presented and what are their specific differences and needs (Chapter 3: patient profiles); (B) preoperative phase: what is the risk of prolonged length of stay or recovery of activities (Chapter 4: risk assessment tool); (C) postoperative inpatient phase: measurement of the recovery of activities for each individual patient to assess if it is safe to be discharged based on his or her functional performance (Chapter 5: MILAS); (D) postoperative outpatient phase: assessment and evaluation of the recovery of functions, activities, and participation. These decisions are ideally based on comparing individual-level observations to evidence-based reference charts to determine whether to adjust the intervention (e.g. intensity, frequency, and/or form) to achieve the goals of the patient (Chapter 6: growth curves).

The Aim and outline of the thesis will describe the contributions to increase the evidence on the differences within the heterogeneous group of patients awaiting THA and the addition of new tools to predict and assess their recovery.

\section{AIM AND OUTLINE OF THE THESIS}

To enable personalized care, we have to assess patients on a more individual level instead of looking at the group as a whole. Therefore, in chapters 2-6, we investigate the following research questions:

To further improve the care process and outcomes for individual patients choosing total hip arthroplasty (THA) through the development of clinical tools that aid patients and healthcare providers in their decision making and expectations.

- Can we distinguish different groups of patients based on preoperative patient-related factors? CHAPTERS 2-4

- How to assess patient's recovery of activities during hospital stay? CHAPTER 5

- $\quad$ Can we develop a reference chart for monitoring postoperative recovery? CHAPTER 6 
Chapter 2 describes a retrospective study that investigates if there are different phenotypes present within a group of patients choosing THA. The following chapter (chapter 3 ) reviews the predicted value of patient-related factors on the length of stay or recovery of activities after a THA. With the results from chapter 3, a prospective cohort study (chapter 4) describes the development of a risk assessment tool to predict prolonged length of stay for patients choosing a total hip replacement.

Chapter 5 reports the modification of the lowa Levels of Assistance Scale (mILAS) by adding the essential transfer sit - supine to make a thorough assessment whether a patient is ready to be discharged. When the patient is discharged from the hospital, the recovery of functions/activities continues and should be monitored to titrate therapy regimes. Reference charts are a useful tool to compare the actual recovery of the patient with the recovery of other patients after THA surgery. Chapter 6 describes the methodology of the development for a reference chart to evaluate the postoperative recovery of functions/activities.

Chapter 7 is a general discussion, in which the aims of the thesis are summarized and critically appraised with the current literature. The thesis ends with recommendations for clinical practice and suggestions for future research.

Chapter 8 describes the valorization of the outcome of chapters 2-6 to clinical practice. 


\section{REFERENCES}

1. M. Sloan, A. Premkumar, and N. P. Sheth, "Projected Volume of Primary Total Joint Arthroplasty in the U.S., 2014 to 2030," J. Bone Jt. Surg., vol. 100, no. 17, pp. 14551460, Sep. 2018.

2. LROI, "hip-numbers-procedures-2010-2017," hip-numbers-procedures-2010-2017, 2019. [Online]. Available: http://www.Iroirapportage.nl/hip-numbers-procedures-20102017. [Accessed: 30-Sep-2019].

3. D. J. Berry, W. S. Harmsen, M. E. Cabanela, and B. F. Morrey, "Twenty-five-year survivorship of two thousand consecutive primary Charnley total hip replacements: factors affecting survivorship of acetabular and femoral components.," J. Bone Joint Surg. Am., vol. 84-A, no. 2, pp. 171-7, Feb. 2002.

4. C. A. Jones, D. C. Voaklander, D. W. Johnston, and M. E. Suarez-Almazor, "Health related quality of life outcomes after total hip and knee arthroplasties in a community based population.," J. Rheumatol., vol. 27, no. 7, pp. 1745-52, Jul. 2000.

5. S. T. Skou et al., "A Randomized, Controlled Trial of Total Knee Replacement," N. Engl. J. Med., vol. 373, no. 17, pp. 1597-1606, Oct. 2015.

6. S. A. Traven, R. A. Reeves, M. G. Sekar, H. S. Slone, and Z. J. Walton, "New 5-Factor Modified Frailty Index Predicts Morbidity and Mortality in Primary Hip and Knee Arthroplasty," J. Arthroplasty, vol. 34, no. 1, pp. 140-144, Jan. 2019.

7. G. A. Hawker et al., "Which Patients Are Most Likely to Benefit From Total Joint Arthroplasty?," Arthritis Rheum., vol. 65, no. 5, pp. 1243-1252, May 2013.

8. tweedekamer, "Van verzorgingsstaat naar participatiesamenleving [from welfare society to participatory society]," 2014. [Online]. Available: https://www.tweedekamer.nl/kamerstukken/pl enaire_verslagen/kamer_in_het_kort/verzorgin gsstaat. [Accessed: 30-Sep-2019].

9. Rijksoverheid, "Rijksoverheid- Wet langdurige zorg (Wlz)," 2018. [Online]. Available: https://www.rijksoverheid.nl/onderwerpen/verp leeghuizen-en-zorginstellingen/wet-langdurigezorg-wlz.
10. $\mathrm{WHO}$, "Preamble to the Constitution of $\mathrm{WHO}$ as adopted by the International Health Conference, New York, 19 June - 22 July 1946; signed on 22 July 1946 by the representatives of 61 States (Official Records of WHO, no. 2, p. 100) and entered into force on 7 April ," 1948.

11. M. Roser, “'Life Expectancy,'” 2018. [Online] Available: https://ourworldindata.org/lifeexpectancy.

12. C. D. Mathers, G. A. Stevens, T. Boerma, R. A. White, and M. I. Tobias, "Causes of international increases in older age life expectancy," Lancet, vol. 385, no. 9967, pp. 540-548, Feb. 2015.

13. M. Huber et al., "How should we define health?," BMJ, vol. 343, p. d4163, Jul. 2011.

14. T. J. VanderWeele, E. McNeely, and H. K. Koh, "Reimagining Health-Flourishing," JAMA, vol. 321, no. 17, p. 1667, May 2019.

15. D. L. Sackett, W. M. Rosenberg, J. A. Gray, R. B. Haynes, and W. S. Richardson, "Evidence based medicine: what it is and what it isn't.," BMJ, vol. 312, no. 7023, pp. 71-2, Jan. 1996.

16. T. C. Hoffmann, V. M. Montori, and C. Del Mar, "The connection between evidencebased medicine and shared decision making," JAMA - Journal of the American Medical Association. 2014

17. T. Agoritsas et al., "Decision aids that really promote shared decision making: the pace quickens.," BMJ, vol. 350, no. feb10 14, p. g7624, Feb. 2015

18. J. McCormack and G. Elwyn, "Shared decision is the only outcome that matters when it comes to evaluating evidence-based practice.," BMJ evidence-based Med., vol. 23, no. 4, pp. 137-139, Aug. 2018.

19. S. E. Lindsay et al., "Patient Preferences for Shared Decision Making," J. Am. Acad. Orthop. Surg., p. 1, Sep. 2019.

20. L. Hood, "A Personal Journey of Discovery: Developing Technology and Changing Biology," Annu. Rev. Anal. Chem., vol. 1, no. 1, pp. 1-43, Jul. 2008. 
21. P. Pilot, R. Bogie, W. F. Draijer, A. D. Verburg, J. J. van Os, and H. Kuipers, "Experience in the first four years of Rapid Recovery; is it safe?," Injury, vol. 37, pp. S37-S40, Dec. 2006.

22. Y. M. den Hartog, N. M. Mathijssen, and S. B. Vehmeijer, "Reduced length of hospital stay after the introduction of a rapid recovery protocol for primary THA procedures," Acta Orthop., vol. 84, no. 5, pp. 444-447, Oct. 2013.

23. H. Husted, T. H. Lunn, A. Troelsen, L. GaarnLarsen, B. B. Kristensen, and H. Kehlet, "Why still in hospital after fast-track hip and knee arthroplasty?," Acta Orthop., vol. 82, no. 6, pp. 679-684, Dec. 2011.

24. C. Wilches, J. D. Sulbarán, J. E. Fernández, J. M. Gisbert, J. M. Bausili, and X. Pelfort, "Técnica de recuperación acelerada (fasttrack) aplicada a cirugía protésica primaria de rodilla y cadera. Análisis de costos y complicaciones," Rev. Esp. Cir. Ortop. Traumatol., Jan. 2017.

25. K. Specht, P. Kjaersgaard-Andersen, $\mathrm{H}$. Kehlet, N. Wedderkopp, and B. D. Pedersen, "High patient satisfaction in 445 patients who underwent fast-track hip or knee replacement," Acta Orthop., vol. 86, no. 6, pp. 702-707, Nov. 2015.

26. G. van der Sluis et al., "What augmented physical activity and empowerment can bring to patients receiving total knee replacement: content, implementation, and comparative effectiveness of a new function-tailored care pathway in a routine care setting.," Biomed Res. Int., vol. 2015, p. 745864, 2015.

27. S. J. Nelson, M. L. Webb, A. M. Lukasiewicz, A. G. Varthi, A. M. Samuel, and J. N. Grauer, "Is Outpatient Total Hip Arthroplasty Safe?," J. Arthroplasty, Dec. 2016.

28. G. R. Klein, J. M. Posner, H. B. Levine, and M. A. Hartzband, "Same Day Total Hip Arthroplasty Performed at an Ambulatory Surgical Center: 90-Day Complication Rate on 549 Patients," J. Arthroplasty, Oct. 2016.

29. A. Sher, A. Keswani, D. Yao, M. Anderson, K. Koenig, and C. S. Moucha, "Predictors of Same-Day Discharge in Primary Total Joint Arthroplasty Patients and Risk Factors for Post-Discharge Complications," J. Arthroplasty, Dec. 2016.
30. M. R. Greenky, W. Wang, D. Y. Ponzio, and P. M. Courtney, "Total Hip Arthroplasty and the Medicare Inpatient-Only List: An Analysis of Complications in Medicare-Aged Patients Undergoing Outpatient Surgery," J. Arthroplasty, vol. 34, no. 6, pp. 1250-1254, Jun. 2019.

31. P. M. Courtney, A. J. Boniello, and R. A. Berger, "Complications Following Outpatient Total Joint Arthroplasty: An Analysis of a National Database," J. Arthroplasty, Dec. 2016.

32. J.-N. A. Argenson, H. Husted, A. Lombardi, R. E. Booth, and E. Thienpont, "Global Forum," J. Bone Jt. Surg., vol. 98, no. 13, p. e55, Jul. 2016.

33. C. A. DeCook, "Outpatient Joint Arthroplasty: Transitioning to the Ambulatory Surgery Center," J. Arthroplasty, vol. 34, no. 7, pp. S48-S50, Jul. 2019.

34. A. J. Smink et al., "Health Care Use of Patients With Osteoarthritis of the Hip or Knee After Implementation of a Stepped-Care Strategy: An Observational Study," Arthritis Care Res. (Hoboken)., vol. 66, no. 6, pp. 817-827, Jun. 2014.

35. G. Van Der Sluis et al., "Pre-operative functional mobility as an independent determinant of inpatient functional recovery after total knee arthroplasty during three periods that coincided with changes in clinical pathways," Bone Jt. J., vol. 99-B, no. 2, 2017.

36. J. Elings et al., "Development of a Risk Stratification Model for Delayed Inpatient Recovery of Physical Activities in Patients Undergoing Total Hip Replacement.," J. Orthop. Sports Phys. Ther., vol. 46, no. 3, pp. 135-43, Mar. 2016.

37. E. H. J. Hulzebos and N. L. U. van Meeteren, "Making the elderly fit for surgery," $\mathrm{Br}$. J. Surg., vol. 103, no. 4, pp. 463-463, Mar. 2016.

38. S. N. Hofstede, T. P. M. Vliet Vlieland, C. H. M. van den Ende, P. J. Marang-van de Mheen, R. G. H. H. Nelissen, and L. van Bodegom-Vos, "Designing a strategy to implement optimal conservative treatments in patients with knee or hip osteoarthritis in orthopedic practice: a study protocol of the BART-OP study.," Implement. Sci., vol. 9, p. 22, Feb. 2014. 
39. C. Gay, A. Chabaud, E. Guilley, and E. Coudeyre, "Educating patients about the benefits of physical activity and exercise for their hip and knee osteoarthritis. Systematic literature review," Ann. Phys. Rehabil. Med., vol. 59, no. 3, pp. 174-183, Jun. 2016.

40. R. Moyer, K. Ikert, K. Long, and J. Marsh, "The Value of Preoperative Exercise and Education for Patients Undergoing Total Hip and Knee Arthroplasty," JBJS Rev., vol. 5, no. 12, p. e2, Dec. 2017.

41. E. Oosting et al., "Preoperative home-based physical therapy versus usual care to improve functional health of frail older adults scheduled for elective total hip arthroplasty: a pilot randomized controlled trial.," Arch. Phys. Med. Rehabil., vol. 93, no. 4, pp. 610-616, Apr. 2012.

42. R. Topp, M. Ditmyer, K. King, K. Doherty, and J. Hornyak, "The effect of bed rest and potential of prehabilitation on patients in the intensive care unit.," AACN Clin. Issues, vol. 13, no. 2, pp. 263-76, May 2002.
43. A. D. Beswick, V. Wylde, R. Gooberman-Hill, A. Blom, and P. Dieppe, "What proportion of patients report long-term pain after total hip or knee replacement for osteoarthritis? A systematic review of prospective studies in unselected patients," BMJ Open, vol. 2, no. 1, p. e000435, Feb. 2012.

44. J. B. Arnold, J. L. Walters, and K. E. Ferrar, "Does Physical Activity Increase After Total Hip or Knee Arthroplasty for Osteoarthritis? A Systematic Review," J. Orthop. Sport. Phys. Ther., vol. 46, no. 6, pp. 431-442, Jun. 2016.

45. A. A. Guccione, T. L. Fagerson, and J. J. Anderson, "Regaining functional independence in the acute care setting following hip fracture.," Phys. Ther., vol. 76, no. 8, pp. 818-826, Aug. 1996.

46. P. Glasziou, L. Irwig, and D. Mant, "Monitoring in chronic disease: a rational approach.," $B M J$, vol. 330, no. 7492, pp. 644-8, Mar. 2005.

47. WHO, "Global measles and rubella strategic plan: 2012-2020," 2012. 


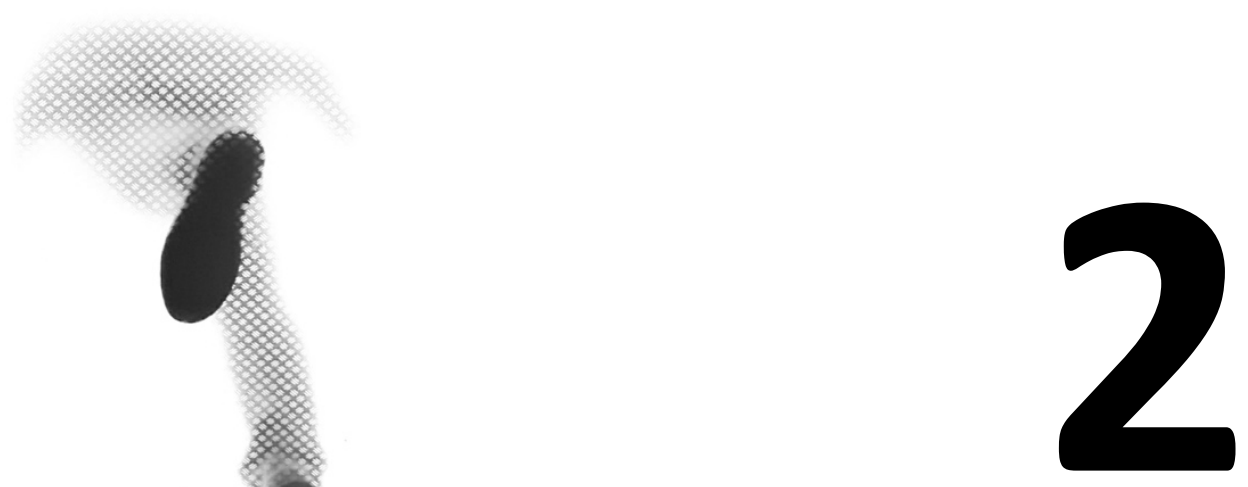

WHAT PREOPERATIVE PATIENT-RELATED FACTORS PREDICT INPATIENT RECOVERY OF PHYSICAL FUNCTIONING AND LENGTH OF STAY AFTER TOTAL HIP ARTHROPLASTY? A SYSTEMATIC REVIEW.

J. Elings | G.A.M. Lappenschaar | G. van der Sluis | S.M. Van Gaalen | R. Nijhuis | N.L.U. van Meeteren | T.J. Hoogeboom 


\section{ABSTRACT}

Objective: To identify the preoperative patient-related characteristics predicting inpatient recovery of functioning and/or length of hospital stay after elective primary total hip arthroplasty.

Design: A search was conducted of the electronic databases MEDLINE, EMBASE and CINAHL from inception through April 2014. Observational studies were selected for systematic review if they identified clinically relevant preoperative prognostic factors and reported an association between inpatient recovery of physical functioning and/or length of hospital stay. Study participants were adults undergoing an elective primary total hip arthroplasty.

Results: Fourteen studies were included, a total of 199,410 individual total hip arthroplasty procedures. Two studies investigated inpatient recovery of physical functioning, no strong level of evidence was found for a relationship between functional recovery and any of the preoperative predictors. Twelve studies investigated the length of hospital stay and reported 19 preoperative prognostic factors. A strong level of evidence suggested that higher scores on the American Society of Anaesthesiologists assessment (OR 3.34 to $6.22,+0.20$ days), increased number of comorbidities (RR of $1.10,+0.59$ to 1.61 days), presence of heart disease, (RR of $1.59,+0.26$ days), and presence of lung disease (RR of $1.30,+0.34$ days) were associated with longer lengths of hospital stay following total hip arthroplasty.

Conclusion: For the prediction of inpatient recovery of physical functioning no factors with a strong level of evidence were found. For length of stay there was a strong level of evidence for the American Society of Anaesthesiologists score, number of comorbidities, and presence of heart or lung disease. 


\section{INTRODUCTION}

Heterogeneity is the rule rather than the exception in health care [1]. Patients often possess identical medical diagnoses and undergo standardized clinical treatment pathways, but variations in individual characteristics contribute to health outcomes that seem inconsistent and unpredictable. This may be especially true for patients undergoing total hip arthroplasty surgery [2]. Previous studies have demonstrated great diversity among patients awaiting total hip arthroplasty, in factors such as age, primary diagnosis, number of comorbidities, functional capacity, and cognitive status [3].

Although several prognostic studies have been performed, identifying potential predictors of postoperative recovery, heterogeneity in study quality and methodology has thus far precluded any definitive conclusions on the factors most important to the early postoperative period. A systematic review of the literature may lead to a better understanding of the preoperative factors that demonstrate merit in predicting important postoperative outcomes, such as inpatient recovery of functioning and length of hospital stay [4].

To date, several systematic reviews have assessed the predictive value of preoperative factors on outpatient (long-term) functional recovery [2,5]. However, inpatient recovery of functioning remains a variable and unpredictable process that is yet to be assessed via systematic review. This is remarkable, as inpatient recovery of functioning is indicative of functional recovery in the long run $[6,7]$, is related to length of hospital stay [8], and, when appropriate, could be an important determinant of discharge destination following hospital stay [9]. Therefore, the aim of this systematic review is to investigate the relationship between preoperative patient characteristics and inpatient recovery of functioning and/or length of stay after elective primary total hip arthroplasty surgery.

\section{METHODS}

The online databases MEDLINE (1966 up to 28 April 2014), EMBASE (1980 up to 28 April 2014) and CINAHL (1982 up to 28 April 2014) were searched for all available articles. CINAHL was added to reduce the chance of missing eligible studies regarding inpatient functional recovery; typically the domain of the nurse and/or physical therapist [10]. Search terms regarding total hip arthroplasty, predictors and observational studies were combined using Boolean logic (supplementary material Appendix 2.1). Furthermore, to retrieve relevant articles that the search 
strings might have missed, the reference lists of each eligible article were examined by a single researcher (JE), as were other publications of the first and last authors of all eligible articles. Using pre-specified eligibility criteria, two researchers (JE and TH) screened all electronic citations independently to select reports for full-text review. Consequently, JE and TH assessed each fulltext article for inclusion; undecided cases were reviewed in plenary sessions. Reasons for exclusion of ineligible studies are depicted in Figure 2.1. The study is reported in accordance with the PRISMA guideline $[11,12]$.

A study was eligible for inclusion in the review if it: 1) investigated preoperative patient-related factors; 2) measured length of stay and/or inpatient recovery of functioning (process of reestablishing the ability to move between postures (for example sit to stand), maintain an upright posture, and to ambulate with increasing levels of complexity (speed, changes of direction, dual and multi-tasking)) [13]; 3) comprised a study population of patients (>18 years) undergoing elective primary total hip arthroplasty; 4) provided point estimates and measures of variability for associations between preoperative predictors and measures of inpatient recovery of functioning or length of stay; and 5) provided clinically interpretable analysis techniques, such as bivariate or multivariate regression coefficients or measures of relative risk (RR), odds ratio $(O R)$, or hazard ratio (HR). Thus, studies that reported only p-values for significant associations, but did not report parameter estimates were not included. Studies in languages other than Dutch or English were also excluded, because no language translators were available.

Potential sources of bias of the studies were independently quantified by JE and TH using the modified Risk of Bias tool [14]. This tool distinguishes six sources of bias in prognostic studies (i.e., study participants, study attrition, prognostic factor measurement, outcome measurements, confounding measurement and statistical adjustment, and reporting, analysis of adjustments and conclusions). To make the tool more suitable for our research question, the items $\mathrm{E}, \mathrm{I}, \mathrm{M}$, and $\mathrm{N}$ were slightly modified (supplementary material Appendix 2.2). The maximum score for the tool is 20 points; studies scoring $\geqslant 12$ items $(\geqslant 60 \%$ ) with 'yes' were regarded as methodologically sound [14]. The inter-rater reliability between scores of JE and TH was examined with Cohen's Kappa [15]. Discussion was used to reach consensus on any scoring disagreement.

The following study characteristics were extracted from all eligible papers by JE: authors, year of publication, study design, setting, methods of data collection, timing of preoperative measurements, inclusion and exclusion criteria, sample size, sex, age, preoperative prognostic patient related factors, assessment of the preoperative prognostic factors, outcome measures, discharge criteria, data analysis, validation and conclusions. These data were extracted using a 

modified criteria described by Hoogeboom et al. [17] (supplementary material Appendix 2.3).

As the included studies were heterogeneous regarding the study population and potential preoperative factors associated with the outcome, two sensitivity analyses were performed to examine the robustness of the results: 1) analyses were repeated with the cut-off for low risk of bias set at $80 \%$ (as opposed to 60\%), and; 2) another analysis was performed that did not make a distinction between studies with a short ( $\leqslant 4$ days) and long ( $>4$ days) lengths of stay to cope with the differences in clinical pathways [18].

Figure 2.1. Flow of information through the different phases of a systematic review.

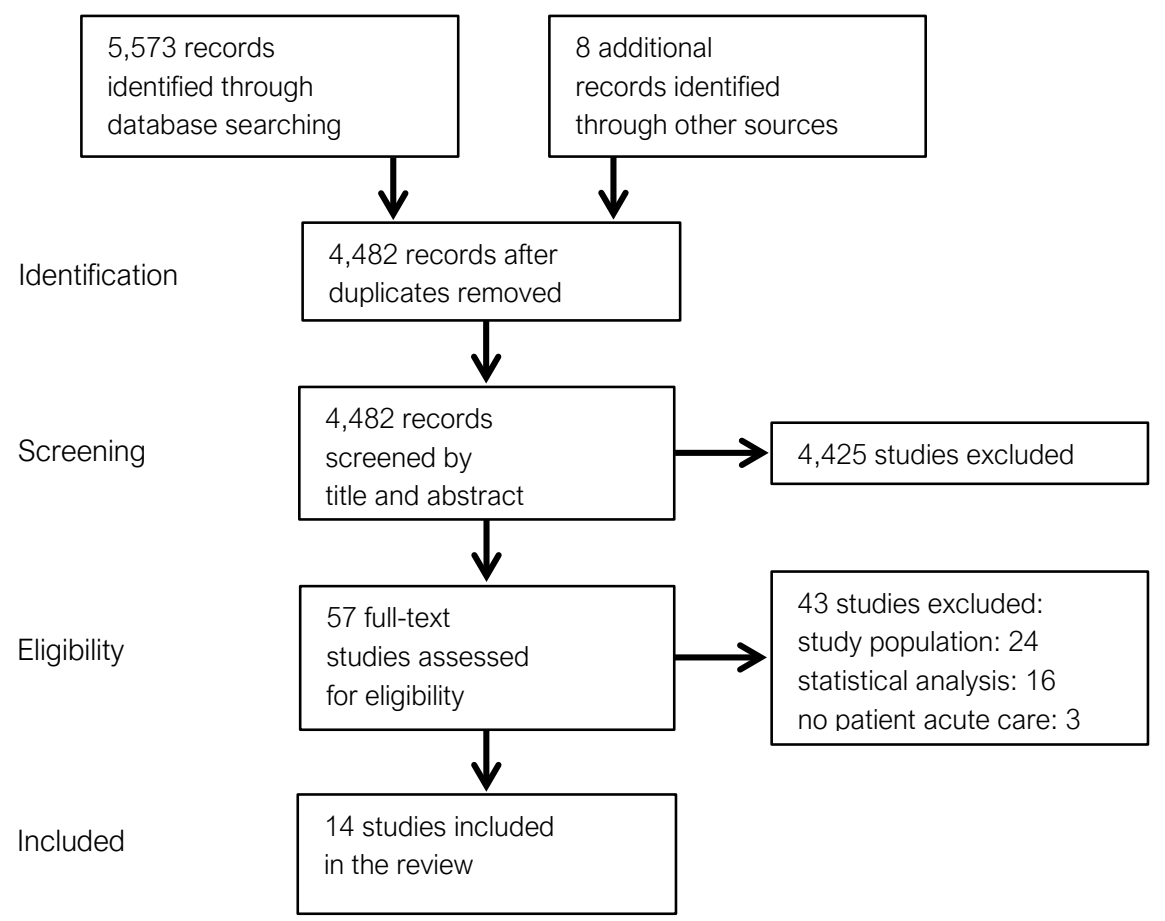


30 | Chapter 2

Table 2.1. Study characteristics.

\begin{tabular}{|c|c|c|c|c|}
\hline \multirow{3}{*}{$\begin{array}{l}\text { Study } \\
\text { Publication year } \\
\text { [data collection] }\end{array}$} & \multirow{3}{*}{$\begin{array}{l}\text { Eligibility } \\
\text { criteria }\end{array}$} & \multirow{3}{*}{$\begin{array}{l}\text { Setting } \\
\text { country }\end{array}$} & \multicolumn{2}{|c|}{ Patients } \\
\hline & & & $\mathrm{N}$ & Age \\
\hline & & & & Mean [range] \\
\hline Design & & & 우\% & Subgroup: $\mathrm{n}$ \\
\hline Abbas [22] & Unilateral THA & Unclear & 199 & $\leq 45: 88$ \\
\hline 2011 & No revision arthroplasty & Pakistan & & 46-65: 68 \\
\hline$[00-10]$ & Not initially treated & & 49 & $>65: 43$ \\
\hline Retrospective & elsewhere & & & \\
\hline Foote [26] & Primary THA & 1 & 675 & $<60: 169$ \\
\hline 2009 & & hospital & & 60-70: 202 \\
\hline$[\mathrm{NM}]$ & & UK & 63 & 70-80: 203 \\
\hline Prospective & & & & >80: 101 \\
\hline Higuera [24] & Primary THA & Unclear & 198 & $74[65-94]$ \\
\hline 2011 & $>65$ years & USA & & \\
\hline [08] & & & 62 & \\
\hline \multicolumn{5}{|l|}{ Retrospective } \\
\hline Huang [31] & Unilateral THA & 232 & 9335 & $56.62 \pm 14.61$ \\
\hline 2011 & No comorbidities effecting & hospitals & & to \\
\hline [05-06] & physical testing & Taiwan & 44 & $57.61 \pm 15.95$ \\
\hline \multicolumn{5}{|l|}{ Retrospective } \\
\hline John-Baptiste [25] & Elective THA & 3 & 1176 & \\
\hline 2004 & & hospitals & & \\
\hline [93-99] & & Canada & - & \\
\hline Retrospective & & & & \\
\hline
\end{tabular}




\begin{tabular}{|c|c|c|c|}
\hline $\begin{array}{l}\text { Prognostic } \\
\text { variables } \\
\text { (Independend) }\end{array}$ & $\begin{array}{l}\text { Outcome } \\
\text { measures } \\
\text { (Dependend) }\end{array}$ & $\begin{array}{l}\text { LoS } \\
\text { Mean } \\
\text { [SD/range] } \\
\text { (Days) }\end{array}$ & $\begin{array}{l}\text { Description } \\
\text { of } \\
\text { clinical } \\
\text { pathway }\end{array}$ \\
\hline Age & LoS (cut-off 12 days) & $11.8[4-45]$ & NM \\
\hline \multicolumn{4}{|l|}{ Sex } \\
\hline Body mass index & LoS: day of admission & & \\
\hline Comorbidities & until day of discharge & & \\
\hline \multicolumn{4}{|l|}{ Physical status } \\
\hline Age & LoS $<14$ or $>14$ days & 11.4 [2-198] & PoR \\
\hline Sex & & & PoPT \\
\hline Body mass index & LoS: day of admission & & PoD \\
\hline Medical comorbidities & until day of discharge & & \\
\hline \multicolumn{4}{|l|}{ Social deprivation } \\
\hline Age & LoS & NM & PeA \\
\hline Sex & & & PeS \\
\hline Body mass index & LoS not specified & & PoPM \\
\hline Preoperative comorbidities & & & PoM \\
\hline Preoperative diagnosis & & & PoPT \\
\hline Provider volumes & LoS & $7.32 \pm 3.18$ & NM \\
\hline Age & & to & \\
\hline Sex & LoS not specified & $9.18 \pm 4.50$ & \\
\hline \multicolumn{4}{|l|}{ Arthritis diagnosis } \\
\hline \multicolumn{4}{|l|}{ Comorbidities } \\
\hline English proficient & LoS & English & NM \\
\hline Age & & proficient & \\
\hline Sex & LoS not specified & Yes: 9.2 & \\
\hline Fiscal year & & No: 11.3 & \\
\hline \multicolumn{4}{|l|}{ Marital status } \\
\hline \multicolumn{4}{|l|}{ Comorbidity } \\
\hline \multicolumn{4}{|l|}{ Number of comorbidities } \\
\hline Income & & & \\
\hline
\end{tabular}


32 | Chapter 2

Table 2.1. (Continued)

\begin{tabular}{|c|c|c|c|c|}
\hline \multirow{2}{*}{$\begin{array}{l}\text { Study } \\
\text { Publication year }\end{array}$} & \multirow{2}{*}{$\begin{array}{l}\text { Eligibility } \\
\text { criteria }\end{array}$} & \multirow{2}{*}{$\begin{array}{l}\text { Setting } \\
\text { country }\end{array}$} & \multicolumn{2}{|c|}{ Patients } \\
\hline & & & $\mathrm{N}$ & Age \\
\hline [Data collection] & & & & Mean [Range] \\
\hline Design & & & 우 \% & Subgroup: $\mathrm{n}$ \\
\hline Kremers [32] & Primary THA & 1 hospital & 6410 & $64.5 \pm 14.6$ \\
\hline 2014 & & USA & & \\
\hline [00-08] & & & 51 & \\
\hline \multicolumn{5}{|l|}{ Retrospective } \\
\hline Laveria [28] & Primary THA & 1 hospital & 218 & Non drinkers \\
\hline 2013 & No conversion hip & USA & & 68 (NM) \\
\hline \multirow[t]{2}{*}{ [NM] } & surgery & & 59 & \\
\hline & & & & Occasional drinkers \\
\hline \multirow[t]{3}{*}{ Prospective } & & & & 67 (NM) \\
\hline & & & & Moderate drinkers \\
\hline & & & & 57 (NM) \\
\hline O'Malley [30] & Primary THA & $>100$ & 4281 & $64,8 \pm 12,7$ \\
\hline 2012 & No emergency & hospitals & & \\
\hline \multirow[t]{2}{*}{ [NM] } & procedures & USA & 54 & \\
\hline & No malignancy & & & \\
\hline Retrospective & (hip region) & & & \\
\hline Rajgopal [23] & Primary THA & 1 & 108 & Normal weight \\
\hline 2013 & & hospital & & $53.1(29-72)$ \\
\hline [98-09] & & UK & 83 & Class 1 obese \\
\hline \multirow[t]{3}{*}{ Retrospective } & & & & $52.6(30-72)$ \\
\hline & & & & Super obese \\
\hline & & & & $53.0(31-72)$ \\
\hline
\end{tabular}




\begin{tabular}{|c|c|c|c|}
\hline $\begin{array}{l}\text { Prognostic } \\
\text { variables }\end{array}$ & $\begin{array}{l}\text { Outcome } \\
\text { measures } \\
\text { (Dependend) }\end{array}$ & $\begin{array}{l}\text { LoS } \\
\text { Mean } \\
\text { [Range/SD] } \\
\text { (Days) }\end{array}$ & $\begin{array}{l}\text { Description } \\
\text { of } \\
\text { clinical } \\
\text { pathway }\end{array}$ \\
\hline Age & LoS & $4.6 \pm 2.3$ & NM \\
\hline \multicolumn{4}{|l|}{ Sex } \\
\hline Body mass index & LoS not specified & & \\
\hline Age & LoS & NM & PeS \\
\hline \multicolumn{4}{|l|}{ Sex } \\
\hline Race & LoS not specified & Mostly 3-4 days & \\
\hline \multicolumn{4}{|l|}{ Ethnicity } \\
\hline \multicolumn{4}{|l|}{ Body mass index } \\
\hline \multicolumn{4}{|l|}{ Comorbidities } \\
\hline \multicolumn{4}{|l|}{ Frequency of alcohol } \\
\hline \multicolumn{4}{|l|}{ consumption } \\
\hline Age & Complications & $3.7 \pm 2.3$ & NM \\
\hline Sex & LoS & & \\
\hline \multicolumn{4}{|l|}{ Obesity } \\
\hline History of weight loss & LoS not specified & & \\
\hline \multicolumn{4}{|l|}{ Steroid use } \\
\hline \multicolumn{4}{|l|}{ Redential status } \\
\hline \multicolumn{4}{|l|}{ Functional status } \\
\hline \multicolumn{4}{|l|}{ Comorbidities } \\
\hline \multicolumn{4}{|l|}{ Physical status } \\
\hline \multicolumn{4}{|l|}{ Anaemia } \\
\hline \multicolumn{4}{|l|}{ Hypoalbuminemia } \\
\hline \multirow[t]{6}{*}{ Weight class } & LoS & Normal weight & PeS \\
\hline & & $5.2[2-14]$ & \\
\hline & LoS not specified & Class 1 obese & \\
\hline & & $4.9[3-10]$ & \\
\hline & & Super obese & \\
\hline & & $7.0[3-28]$ & \\
\hline
\end{tabular}


34 | Chapter 2

Table 2.1. (Continued)

\begin{tabular}{|c|c|c|c|c|}
\hline \multirow{2}{*}{$\begin{array}{l}\text { Study } \\
\text { Publication year }\end{array}$} & \multirow{3}{*}{$\begin{array}{l}\text { Eligibility } \\
\text { criteria }\end{array}$} & \multirow{4}{*}{$\begin{array}{l}\text { Setting } \\
\text { country }\end{array}$} & \multicolumn{2}{|l|}{ Patients } \\
\hline & & & $\mathrm{N}$ & Age \\
\hline [Data collection] & & & & Mean [Range] \\
\hline Design & & & 우\% & Subgroup: $\mathrm{n}$ \\
\hline Rissanen [29] & Hip arthritis & National register & 10288 & \\
\hline 1996 & No (rheumatoid) arthritis & Finland & & \\
\hline [88-92] & No infrequent indications & & 60 hip & $66.9[23-91]$ \\
\hline \multirow[t]{2}{*}{ Retrospective } & No bilateral joint & & 79 knee & $69.3[29-91]$ \\
\hline & replacement & & & \\
\hline Sadr Azodi [21] & Primary THA & National register & 3309 & $65.6[33-89]$ \\
\hline 2006 & No women & Sweden & & \\
\hline [69-02] & No previous THA & & 0 & \\
\hline \multirow[t]{8}{*}{ Retrospective } & No emergency THA & & & \\
\hline & No rheumatoid arthritis & & & \\
\hline & No secondary & & & \\
\hline & osteoarthritis & & & \\
\hline & No lower extremity & & & \\
\hline & fractures & & & \\
\hline & No previous orthopaedic & & & \\
\hline & surgeries & & & \\
\hline Stundner [20] & Primary THA & \pm 400 hospitals USA & 157.775 & 63.9 \\
\hline 2013 & & & & $95 \% \mathrm{Cl}$ \\
\hline [06-10] & & & $56-75$ & $(63.54-64.34)$ \\
\hline \multicolumn{5}{|l|}{ Retrospective } \\
\hline & & & & 65.6 \\
\hline & & & & $95 \% \mathrm{Cl}$ \\
\hline & & & & $(65.57-65.71)$ \\
\hline
\end{tabular}




\begin{tabular}{|c|c|c|c|}
\hline $\begin{array}{l}\text { Prognostic } \\
\text { variables } \\
\text { (Independend) }\end{array}$ & $\begin{array}{l}\text { Outcome } \\
\text { measures } \\
\text { (Dependend) }\end{array}$ & $\begin{array}{l}\text { LoS } \\
\text { Mean } \\
\text { [Range/SD] } \\
\text { (Days) }\end{array}$ & $\begin{array}{l}\text { Description } \\
\text { of } \\
\text { clinical } \\
\text { pathway }\end{array}$ \\
\hline Age & LoS & $12.0(6.16)$ & NM \\
\hline \multicolumn{4}{|l|}{ Sex } \\
\hline Charge category & LoS not specified & & \\
\hline Body mass index & LoS & NM & NM \\
\hline Smoking & & Median of 9 & \\
\hline Tobacco preference & LoS not specified & & \\
\hline Age & LoS & $3.86(\mathrm{RA})$ & NM \\
\hline Sex & & $95 \% \mathrm{Cl}$ & \\
\hline Rheumatoid arthritis & LoS not specified & $(3.77-3.94)$ & \\
\hline \multicolumn{4}{|l|}{ Osteoarthritis } \\
\hline \multirow[t]{3}{*}{ Hospital } & & $3.51(\mathrm{OA})$ & \\
\hline & & $95 \% \mathrm{Cl}$ & \\
\hline & & $(3.50-3.52)$ & \\
\hline
\end{tabular}


36 | Chapter 2

Table 2.1. (Continued)

\begin{tabular}{|c|c|c|c|c|}
\hline Study & Eligibility & Setting & Patients & \\
\hline Publication year & criteria & country & $\mathrm{N}$ & Age \\
\hline [Data collection] & & & & Mean [Range] \\
\hline Design & & & 우 \% & Subgroup: $\mathrm{n}$ \\
\hline Unnanuntana [27] & Primary unilateral THA & 1 hospital & 200 & $66.5[35-91]$ \\
\hline 2012 & No complex surgical & USA & & \\
\hline [06-09] & procedure & & 56 & \\
\hline \multirow[t]{4}{*}{ Retrospective } & No serious cardio- & & & \\
\hline & pulmonary disease & & & \\
\hline & No immediately & & & \\
\hline & postoperative revision & & & \\
\hline Wang [19] & Primary THA & & & \\
\hline 1998 & No previous infection of & & & \\
\hline$[\mathrm{NM}]$ & the hip & & & \\
\hline \multirow[t]{2}{*}{ Porspective } & No malignancy in the & & & \\
\hline & hip region & & & \\
\hline
\end{tabular}

Abbreviations: THA: total hip arthroplasty; NM not mentioned; PT: physical therapy; ADL: activities of interval; PrE: preoperative education; PeA: peri-operative anesthetic technique; PeS: peri-operatieve postoperative daily assessement of recovery; PoM: postoperative mobilization protocol; PoD: postoperative 


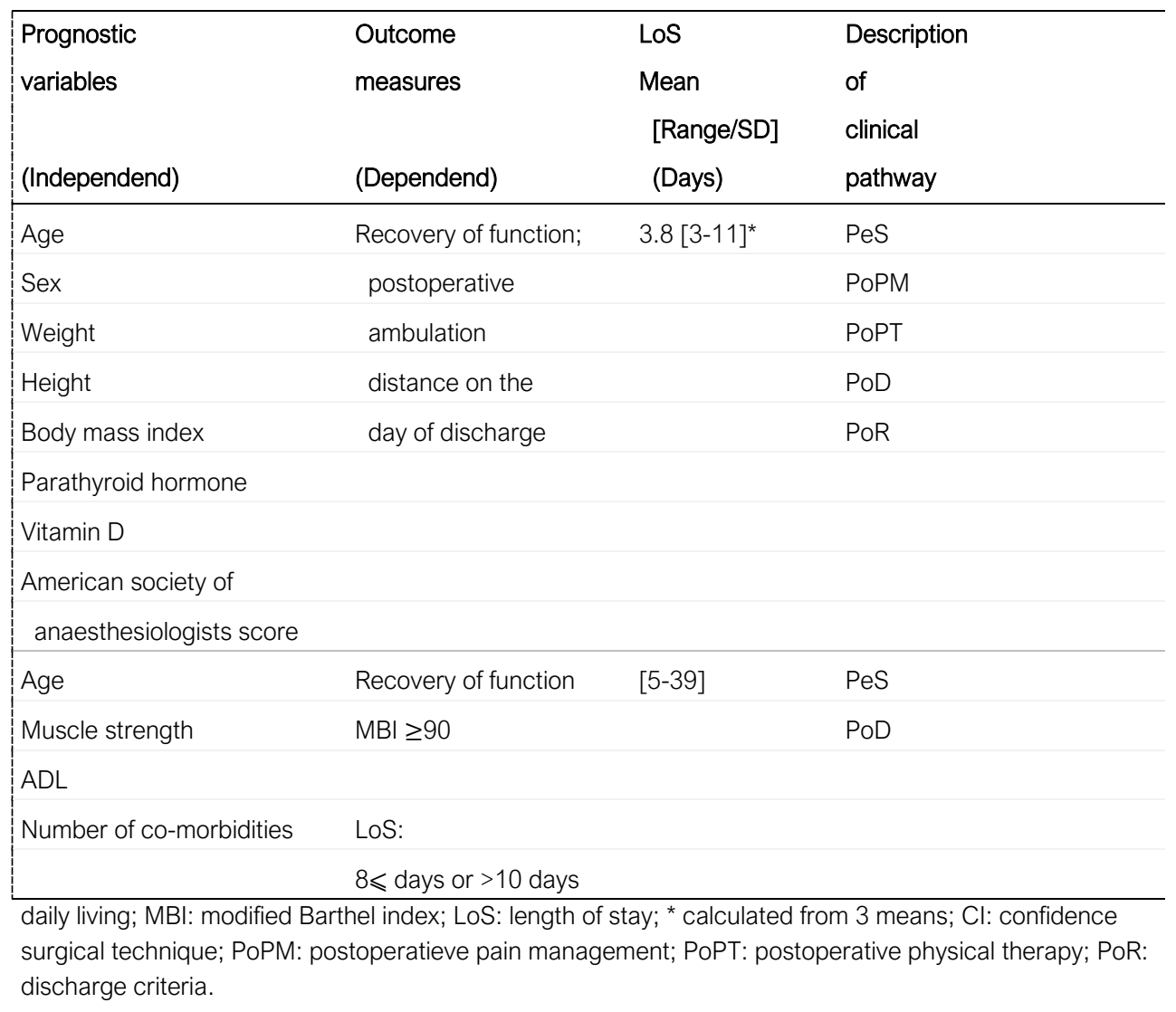


Table 2.2. Assessment of bias for individual studies conform Chapple et al. (13) (see appendix 2)

\begin{tabular}{|c|c|c|c|c|c|c|c|c|c|c|c|c|c|c|c|c|c|c|c|c|c|}
\hline \multirow[t]{2}{*}{ Study } & \multicolumn{4}{|c|}{ Study Participation } & \multicolumn{3}{|c|}{ Study Attrition } & \multicolumn{8}{|c|}{ Measurement and data presentation } & \multicolumn{5}{|c|}{$\begin{array}{l}\text { Analysis and presentation } \\
\text { of results }\end{array}$} & \multirow[t]{2}{*}{$\begin{array}{l}\text { Total } \\
\text { score }\end{array}$} \\
\hline & A & B & $\mathrm{C}$ & D & $E$ & $\mathrm{~F}$ & G & $\mathrm{H}$ & I & $\mathrm{J}$ & K & $\mathrm{L}$ & M & $\mathrm{N}$ & $\mathrm{O}$ & $P$ & $Q$ & $R$ & $\mathrm{~S}$ & T & \\
\hline Unnanuntana 2012 & & & & & & $\mathrm{NA}$ & $\mathrm{NA}$ & & & & & & & & & & & & & & 18 \\
\hline Abbas 2011 & & & & & & NA & NA & & & & & & & & & & & & & & 16 \\
\hline Foote 2009 & & & & & & NA & NA & & & & & & & & & & & & & & 16 \\
\hline O'Malley 2012 & & & & & & NA & NA & & & & & & & & & & & & & & 16 \\
\hline Sadre Azodi 2006 & & & & & & NA & NA & & & & & & & & & & & & & & 16 \\
\hline Hiquera 2011 & & & & & & NA & NA & & & & & & & & & & & & & & 15 \\
\hline Huang 2011 & & & & & & NA & NA & & & & & & & & & & & & & & 15 \\
\hline Kremers 2014 & & & & & & NA & NA & & & & & & & & & & & & & & 15 \\
\hline Rissanen 1996 & & & & & & NA & NA & & & & & & & & & & & & & & 15 \\
\hline Stundler 2013 & & & & & & NA & NA & & & & & & & & & & & & & & 15 \\
\hline Raigopal 2013 & & & & & & NA & NA & & & & & & & & & & & & & & 14 \\
\hline Wang 1998 & & & & & & NA & NA & & & & & & & & & & & & & & 14 \\
\hline John-Baptist 2004 & & & & & & NA & NA & & & & & & & & & & & & & & 13 \\
\hline Lavernia 2013 & & & & & & NA & NA & & & & & & & & & & & & & & 10 \\
\hline
\end{tabular}

Abbreviations: NA: not applicable

Shaded box: met criteria; blank box: did not met criteria 


\section{RESULTS}

The search retrieved 4,482 articles, of which 14 articles fulfilled the eligibility criteria (Figure 2.1). These studies examined a total of 24 preoperative patient-related prognostic factors. The study characteristics are presented in Table 2.1.

Fourteen studies, taking into account a total of 199,410 operations, were included for review. The sample sizes of these studies ranged from 65 participants [19] to 157,775 participants [20]. Data collection was retrospective in 11 out of 14 studies and ranged in time-frame from 19692002 [21] to 2000- 2010 [22] (see Table 2.1). The mean age of the populations under study ranged from 53 [23] to 74 years of age [24]. One study recruited only male participants [21], while the remaining studies reported sex distributions of 39\% [25] to 83\% [23] female participants. Pre-, peri- and/or postoperative treatment regimens were described in six of the 14 studies (e.g. surgical techniques, pain management, and postoperative mobilization protocols) $[19,23,24,26-28]$.

Twelve studies investigated the predictive value of preoperative factors on the length of hospital stay, and two studies investigated the predictive value of preoperative factors on inpatient recovery of functioning. Recovery of functioning was assessed with the Modified Barthel Index (MBI) (an observational scale) [19] and with the patients' performance of ambulation distance [27]. Table 2.2 shows the individual assessment of bias of all studies. Two reviewers (JE, TH) independently scored all studies, representing 216 bias criteria. Agreement was reached on 94\% of the cases, resulting in an excellent inter-rater reliability of 0.812 (Cohen's Kappa). After assessment of bias 13 out of 14 studies were classified as low risk [19-27] [29-32].

\section{PREDICTORS FOR LENGTH OF STAY}

Twelve studies [20-26] [28-32] investigated 19 preoperative patient-related factors and their relationship to length of stay; their associations are presented in Table 2.3. In terms of ICF domains, one factor was related to activity limitation, 16 factors were related personal health features, two factors were related environmental features, and no factors assessed body function/structure or social participation.

There was strong level of evidence that the number of comorbidities, American Society of Anaesthesiologists score $>2$, and presence of heart or lung disease were associated with length of stay. A higher number of comorbidities (OR 1.10; +0.59 to +1.61 days) [24,31], an American Society of Anaesthesiologists score of $>2$ (OR 3.34 to $6.22 ;+0.20$ days) [22,26], presence of 
Table 2.3. Preoperative patient-related prognostic factors for length of stay

\begin{tabular}{|c|c|c|c|c|}
\hline $\begin{array}{l}\text { Preoperative } \\
\text { baseline variables }\end{array}$ & ICF & $\begin{array}{l}\text { Number } \\
\text { of } \\
\text { studies }\end{array}$ & $\begin{array}{l}\text { Combined } \\
\text { sample } \\
\text { size }\end{array}$ & $\begin{array}{l}\text { Study } \\
\text { sample } \\
\text { size }\end{array}$ \\
\hline \multicolumn{5}{|l|}{ STRONG LEVEL OF EVIDENCE } \\
\hline \multirow[t]{2}{*}{ Higher number of comorbidities } & $P$ & 2 & 9.533 & 9.335 \\
\hline & & & & 198 \\
\hline \multirow[t]{2}{*}{ Presence of heart disease } & $\mathrm{P}$ & 2 & 4.479 & 4.281 \\
\hline & & & & 198 \\
\hline \multirow[t]{2}{*}{ Presence of lung disease } & $\mathrm{P}$ & 2 & 4.479 & 4281 \\
\hline & & & & 198 \\
\hline \multirow[t]{3}{*}{ American society of anaesthesiologists score $>2$} & $P$ & 3 & 5.155 & 4.281 \\
\hline & & & & 675 \\
\hline & & & & 199 \\
\hline \multicolumn{5}{|l|}{ MODERATE LEVEL OF EVIDENCE } \\
\hline Functional status (dependent vs independent) & A & 1 & 4281 & 4281 \\
\hline \multicolumn{5}{|l|}{ independent) } \\
\hline Diagnosis; avascular necrosis (reference) & $\mathrm{P}$ & & & \\
\hline vs osteoarthritis & & 1 & 9.335 & 9.335 \\
\hline vs rheumatoid arthritis & & 1 & 9.335 & 9.335 \\
\hline vs other & & 1 & 9.335 & 9.335 \\
\hline Rheumatoid arthritis vs osteoarthritis & $\mathrm{P}$ & 1 & 157.775 & 157.775 \\
\hline Presence of diabetes & $P$ & 1 & 4.281 & 4.281 \\
\hline Presence of renal disease & $P$ & 1 & 4.281 & 4.281 \\
\hline Presence of hepatic disease & $P$ & 1 & 4.281 & 4.281 \\
\hline Presence of bleeding disorder & $P$ & 1 & 4.281 & 4.281 \\
\hline Smoking & $P$ & 1 & 3.309 & 3.309 \\
\hline Low literacy & $P$ & 1 & 1.176 & 1.176 \\
\hline Private insurance & E & 1 & 10.288 & 10.288 \\
\hline Living in an institution & $\mathrm{E}$ & 1 & 10.288 & 10.288 \\
\hline \multicolumn{5}{|l|}{ LIMITED LEVEL OF EVIDENCE } \\
\hline Greater alcohol intake & $P$ & 1 & 125 & 125 \\
\hline
\end{tabular}




\begin{tabular}{|c|c|c|c|c|c|}
\hline $\begin{array}{l}\text { Association with LoS } \\
(95 \% \mathrm{Cl})\end{array}$ & $\begin{array}{l}\text { Anaylis } \\
\text { result }\end{array}$ & ref & $\begin{array}{l}\text { Mean } \\
\text { LoS } \\
\leq 4 \text { days }\end{array}$ & $\begin{array}{l}\text { Risk } \\
\text { of } \\
\text { bias }\end{array}$ & $\begin{array}{l}\text { Direction } \\
\text { of } \\
\text { effect }\end{array}$ \\
\hline+0.59 days ( 0.39 to 0.80 ) to & univariate & 31 & no & low & $\uparrow$ \\
\hline \multicolumn{6}{|l|}{+1.61 days (0.98 to 2.24 ) } \\
\hline RR 1.10 (1.05 to 1.56$)$ & multivariate & 24 & $?$ & low & $\uparrow$ \\
\hline+0.26 days $( \pm 0.11)$ & multivariate & 30 & yes & low & $\uparrow$ \\
\hline RR 1.59 (1.22 to 2.08) & multivariate & 24 & $?$ & low & $\uparrow$ \\
\hline+0.34 days $( \pm 0.16)$ & multivariate & 30 & yes & low & $\uparrow$ \\
\hline RR 1.30 (1.03 to 1.64$)$ & multivariate & 24 & $?$ & low & $\uparrow$ \\
\hline+0.20 days $( \pm 0.07)$ & multivariate & 30 & yes & low & $\uparrow$ \\
\hline OR 3.34 (2.05 to 5.43 ) & multivariate & 26 & no & low & $\uparrow$ \\
\hline OR 6.22 (2.96 to 13) & multivariate & 22 & no & low & $\uparrow$ \\
\hline+0.46 days $( \pm 0.13)$ & multivariate & 30 & yes & low & $\uparrow$ \\
\hline+0.04 days $(-0.14$ to 0.22$)$ & univariate & 31 & no & low & $=$ \\
\hline-0.17 days $(-0.64$ to 0.31$)$ & univariate & 31 & no & low & $=$ \\
\hline+0.68 days ( 0.12 to 1.24$)$ & univariate & 31 & no & low & $\uparrow$ \\
\hline OR 1.16 (1.08-1.23) & univariate & 20 & yes & low & $\uparrow$ \\
\hline+0.28 days $( \pm 0.10)$ & multivariate & 30 & yes & low & $\uparrow$ \\
\hline+1.26 days $( \pm 0.51)$ & multivariate & 30 & yes & low & $\uparrow$ \\
\hline+3.47 days $( \pm 1.48)$ & multivariate & 30 & yes & low & $\uparrow$ \\
\hline \multirow[t]{2}{*}{+0.49 days $( \pm 0.2)$} & multivariate & 30 & yes & low & $\uparrow$ \\
\hline & multivariate & 21 & no & low & $=$ \\
\hline RR 1.13 (1.03 to 1.23 ) & univariate & 25 & no & low & $\uparrow$ \\
\hline-1.0 days (?) & multivariate & 29 & no & low & $\downarrow$ \\
\hline \multirow[t]{2}{*}{-0.5 days (?) } & multivariate & 29 & no & low & $\downarrow$ \\
\hline & univariate & 28 & $?$ & high & $=$ \\
\hline
\end{tabular}


42 | Chapter 2

Table 2.3. (Continued)

\begin{tabular}{|c|c|c|c|c|}
\hline $\begin{array}{l}\text { Preoperative } \\
\text { baseline variables }\end{array}$ & ICF & $\begin{array}{l}\text { Number } \\
\text { of } \\
\text { studies }\end{array}$ & $\begin{array}{l}\text { Combined } \\
\text { sample } \\
\text { size }\end{array}$ & $\begin{array}{l}\text { Study } \\
\text { sample } \\
\text { size }\end{array}$ \\
\hline \multicolumn{5}{|c|}{ CONFLICTING LEVEL OF EVIDENCE } \\
\hline \multirow[t]{6}{*}{ Higher age } & $P$ & 6 & 20.695 & 10.288 \\
\hline & & & & 9.335 \\
\hline & & & & 4281 \\
\hline & & & & 675 \\
\hline & & & & 199 \\
\hline & & & & 198 \\
\hline \multirow[t]{5}{*}{ Female } & $\mathrm{P}$ & 5 & 11.360 & 10.288 \\
\hline & & & & 4.281 \\
\hline & & & & 675 \\
\hline & & & & 199 \\
\hline & & & & 198 \\
\hline \multirow[t]{4}{*}{ Higher body mass index } & $P$ & 5 & 4.381 & 3.309 \\
\hline & & & & 675 \\
\hline & & & & 199 \\
\hline & & & & 198 \\
\hline Per 5 units increase in body & $\mathrm{P}$ & & & 6410 \\
\hline \multicolumn{5}{|l|}{ mass index $>30 \mathrm{~kg} / \mathrm{m}^{2}$} \\
\hline Obese (30-34.9) vs normal & & & & 108 \\
\hline Super obese (>50) vs normal & & & & 108 \\
\hline
\end{tabular}




\begin{tabular}{|c|c|c|c|c|c|}
\hline $\begin{array}{l}\text { Association with LoS } \\
(95 \% \mathrm{Cl})\end{array}$ & $\begin{array}{l}\text { Anaylis } \\
\text { result }\end{array}$ & ref & $\begin{array}{l}\text { Mean } \\
\text { LoS } \\
\leq 4 \text { days }\end{array}$ & $\begin{array}{l}\text { Risk } \\
\text { of } \\
\text { bias }\end{array}$ & $\begin{array}{l}\text { Direction } \\
\text { of } \\
\text { effect }\end{array}$ \\
\hline+1.2 days to +2.5 days & multivariate & 29 & no & low & $\uparrow$ \\
\hline+0.02 days per year $(0.01$ to 0.02$)$ & univariate & 31 & no & low & $\uparrow$ \\
\hline+0.01 days per year $( \pm 0.003)$ & multivariate & 30 & yes & low & $\uparrow$ \\
\hline OR 2.86 (1.75 to 4.67$)$ to & multivariate & 26 & no & low & $\uparrow$ \\
\hline \multicolumn{6}{|l|}{ OR 6.27 (3.57 to 11.02 ) } \\
\hline OR 2.15 (1 to 4.6 ) to & multivariate & 22 & no & low & $\uparrow$ \\
\hline \multicolumn{6}{|l|}{ OR 3.78 (1.58 to 9.04$)$} \\
\hline & univariate $^{\wedge}$ & 24 & $?$ & low & $=$ \\
\hline +0.9 days & multivariate & 29 & no & low & $\uparrow$ \\
\hline \multirow[t]{2}{*}{+0.24 days } & multivariate & 30 & yes & low & $\uparrow$ \\
\hline & univariate * & 26 & no & low & $\mathrm{nm}$ \\
\hline \multirow[t]{2}{*}{ OR 1.91 (0.98 to 3.7) } & multivariate & 22 & no & low & $=$ \\
\hline & univariate $^{\wedge}$ & 24 & $?$ & low & $=$ \\
\hline$+4.7 \%(2.0$ to 7.5$)$ to & multivariate & 21 & no & low & $\uparrow$ \\
\hline \multicolumn{6}{|l|}{$+7.0 \%(2.9$ to 11.1$)$} \\
\hline & univariate * & 26 & no & low & $\uparrow$ \\
\hline & univariate & 22 & no & low & $=$ \\
\hline & univariate $^{\wedge}$ & 24 & $?$ & low & $=$ \\
\hline Increase LoS 0.16 days (?) & Univariate & 32 & No & Low & $\uparrow$ \\
\hline-0.3 days (?) & univariate & 23 & no & low & $\downarrow$ \\
\hline +1.8 days (?) & univariate & 23 & no & low & $\uparrow$ \\
\hline
\end{tabular}

E: environmental factor; P: personal factor; $\mathrm{Cl}$ : confidence interval; RR: relative risk; OR odds ratio; most significant variables associated to length of stay in the multivariate regression; ref: reference;

$=$ : no significant 
Table 2.4. Preoperative patient-related prognostic factors for recovery of functioning.

\begin{tabular}{|c|c|c|c|c|}
\hline $\begin{array}{l}\text { Preoperative } \\
\text { baseline variables }\end{array}$ & ICF & $\begin{array}{l}\text { Number } \\
\text { of } \\
\text { studies }\end{array}$ & $\begin{array}{l}\text { Combined } \\
\text { sample } \\
\text { size }\end{array}$ & $\begin{array}{l}\text { Study } \\
\text { sample } \\
\text { size }\end{array}$ \\
\hline \multicolumn{5}{|l|}{ STRONG LEVEL OF EVIDENCE } \\
\hline \multicolumn{5}{|l|}{ no factors found } \\
\hline \multicolumn{5}{|l|}{ MODERATE LEVEL OF EVIDENCE } \\
\hline low ADL level (MBI $\leq 90)$ & A & 1 & 65 & 65 \\
\hline female sex & $P$ & 1 & 200 & 200 \\
\hline lower body mass index & $\mathrm{P}$ & 1 & 200 & 200 \\
\hline muscle strength & $\mathrm{F} / \mathrm{S}$ & 1 & 65 & 65 \\
\hline number of comorbidities & $P$ & 1 & 65 & 65 \\
\hline parathyroid hormone & $P$ & 1 & 200 & 200 \\
\hline serum vitamin $D$ & $P$ & 1 & 200 & 200 \\
\hline $\begin{array}{l}\text { American society of anaesthesiologists score } \\
\text { anaesthesiologists score }\end{array}$ & $\mathrm{P}$ & 1 & 200 & 200 \\
\hline \multicolumn{5}{|l|}{ CONFLICTING LEVEL OF EVIDENCE } \\
\hline \multirow[t]{2}{*}{ higher age } & $P$ & 2 & 265 & 200 \\
\hline & & & & 65 \\
\hline
\end{tabular}

Abbreviations: ICF: international classification of functioning, disability and health; A: activity;

?: not (clearly) reported; ^ only RR of multivariate presented in article; * not described as one of the 5

$=:$ no significant relation; $\uparrow$ : longer length of stay; $\downarrow$ : shorter length of stay

heart disease (RR 1.59; +0.26 days) [24,30], and presence of lung disease (RR 1.30; +0.34 days) $[24,30]$, resulted in longer length of stay. Moderate level of evidence was found for the association between length of stay and dependent functional status (+0.49 days) [30], primary diagnosis other than avascular necrosis, osteoarthritis or rheumatoid arthritis (+0.68 days) [31], rheumatoid arthritis versus osteoarthritis (OR 1.16) [20], comorbid diabetes (+0.28 days) [30], renal disease (+1.23 days) [30], hepatic disease ( +3.47 days) [30], bleeding disorder (+0.49 days) [30], or demographic factors such as low literacy (RR 1.13) [25], type of health insurance (private -1.0 days) [29], and residence (institution -0.5 days) [29].

A moderate level of evidence was found for no association between length of stay and smoking [21], as well as for no association between length of stay and a primary diagnosis other than osteoarthritis or rheumatoid arthritis [31]. A limited level of evidence was found for no association between length of stay and alcohol consumption [28]. 


\begin{tabular}{|c|c|c|c|c|c|}
\hline $\begin{array}{l}\text { Association with LoS } \\
(95 \% \mathrm{Cl})\end{array}$ & $\begin{array}{l}\text { Anaylis } \\
\text { result }\end{array}$ & ref & $\begin{array}{l}\text { Mean } \\
\text { LoS } \\
\leq 4 \text { days }\end{array}$ & $\begin{array}{l}\text { Risk } \\
\text { of } \\
\text { bias }\end{array}$ & $\begin{array}{l}\text { Direction } \\
\text { of } \\
\text { effect }\end{array}$ \\
\hline OR 6.00 (1.30 to 28.3 ) & multivariate & 19 & no & low & $\downarrow$ \\
\hline$\beta-34.45$ (-65.70 to -3.20$)$ & multivariate & 27 & yes & low & $\downarrow$ \\
\hline$\beta-2.61$ (-5.18 to -.03$)$ & multivariate & 27 & yes & low & $\uparrow$ \\
\hline OR 4.00 (0.97 to 16.1$)$ & multivariate & 19 & no & low & $=$ \\
\hline OR 2.00 (0.5 to 7.4$)$ & multivariate & 19 & no & low & $=$ \\
\hline$\beta-.74(-1.53$ to .055$)$ & multivariate & 27 & yes & low & $=$ \\
\hline$\beta-.08$ (?) & multivariate & 27 & yes & low & $=$ \\
\hline$\beta-24.11$ (-52.37 to 4.15$)$ & multivariate & 27 & yes & low & $=$ \\
\hline$\beta-1.95(-3.41$ to -.49$)$ & multivariate & 27 & yes & low & $\downarrow$ \\
\hline OR 3.93 (0.55 to 27.8 ) & multivariate & 19 & no & low & $=$ \\
\hline
\end{tabular}

E: environmental factor; P: personal factor; Cl: confidence interval; RR: relative risk; OR odds ratio; most significant variables associated to length of stay in the multivariate regression; ref: reference;

We found conflicting evidence for the influence of personal factors; age, sex, and BMI. Four studies reported that higher age was related to longer length of stay (OR 2.15 [22] to 6.27 [26] or +0.013 days per year [30] to 2.5 days) [29], while one study did not find this relationship [24]. Two studies suggested that female sex was associated with longer length of stay $(+0.24$ [30] to +0.9 days) [29] and two studies reported no relationship between female sex and length of stay $[22,24]$. Three studies suggested that higher BMI (>25 to $>35$ respectively) was associated with prolonged the length of stay $(+4.7$ to $7.0 \%))[21,26,32]$ although one study [23] suggested that obese patients (BMI 30.0 - 34.9) tended to have shorter hospital stays (-0.3 days), while only superobese patients $(\mathrm{BMI}>50)$ had longer (+1.8 days) hospital stays than people with normal weight (BMI 18.5-24.9). Two other studies did not find a statistically significant relationship between BMl and length of stay [22,24]. 


\section{PREDICTORS FOR INPATIENT RECOVERY OF FUNCTIONING}

Two studies investigated nine preoperative factors related to inpatient recovery of functioning (Table 2.4; total of 265 patients). In terms of ICF domains, one factor was related to body function/structure, one factor was related to activity limitation, and seven personal contextual factors were examined. No participation or environmental factors were examined.

Moderate level of evidence was found for the association between inpatient recovery of functioning and preoperative ADL level (OR 6.00) [19], female sex ( $\beta$-34.45) [27], and BMI ( $\beta$ 2.61) [27]. Conflicting level of evidence was found for the association between inpatient recovery of functioning and age $[19,27]$.

Moderate level of evidence was found for no association between inpatient recovery of functioning and muscle strength [19], number of comorbidities [19], American Society of Anaesthesiologists score [27], parathyroid hormone [27], and serum vitamin D [27]. There was conflicting evidence for the influence of age in predicting inpatient functional recovery. One study reported that higher age was related to slower inpatient recovery of functioning as measured by ambulation distance [27] while the other study, which utilized the modified Barthel index to assess functioning, did not find a significant association [19].

\section{SENSITIVITY ANALYSIS}

For the first sensitivity analysis, the cut-off point for low risk of bias was increased from $60 \%$ to $80 \%$. This yielded five (36\%) studies with a low risk of bias instead of the initial 13 (93\%) studies. Increasing the cut-off did not produce any difference in the level of evidence for predictors with a strong level of evidence. For the second sensitivity analysis we made a distinction between studies with a short ( $\leqslant 4$ days) and long ( $>4$ days) length of stay. This made no substantial difference for studies reporting patient related factors associated with length of stay. For studies assessing the recovery of functioning we found one substantial difference, namely "conflicting level of evidence" instead of "moderate level of evidence" for the influence of age. 


\section{DISCUSSION}

In summary, this systematic review identified 14 observational studies that studied the association between 24 preoperative patient-related prognostic factors and length of stay or inpatient recovery of functioning. For the association between preoperative factors and length of stay, we found a strong level of evidence that American Society of Anaesthesiologists score (>2), greater number of comorbidity, and presence of heart or lung disease were associated with an increased length of stay. We found no strong evidence for preoperative factors predicting postoperative inpatient functional recovery.

To our knowledge, this study is the first attempt to systematically review the association between preoperative patient-related factors and inpatient recovery of functioning or length of stay in patients after total hip arthroplasty. Previous systematic reviews have focused either on predictors of postoperative complications [2] or on more intermediate or long-term outcomes in physical function [2,5], prosthesis survival [2,5], and pain [2]. Although our review examines some different outcomes, over a different time-frame than previous studies, the results appear to yield similar themes [2,5], namely that patients of higher age, with greater BMI, with comorbidities, and compromised preoperative functional status are at risk for delayed and/or disappointing recovery after total hip arthroplasty.

Our study has a number of strengths and weaknesses. Strengths of our review comprise: 1) the low risk for errors in methods of this systematic review as study selection, data extraction and bias scoring were all done by two independent researchers, and 2) our sensitivity analyses confirm the findings of the main analysis (suggesting that these are robust). Limitations were also present in our review. First, our decision to include only studies with "appropriate analysis techniques" resulted in clear and interpretable data, but it also resulted in the exclusion of two studies [33,34], These two studies did investigate factors within the ICF domains "functions/structures", "activities", and "participation" in the length of stay studies and concluded that being functional independent [34] and experiencing higher function and activity scores (measured with the Harris Hip Score, a perception self-rating measurement tool) [33] were associated with a shorter length of stay. Second, most of the data collection occurred over the course of previous decades (1960's [21]; 1980's [29]; 1990's [19,25]; 2000'-05's [22,23,31]; and 2006'-10's $[24,27,30])$, prior to the rise of the "fast-track" protocols that emphasize shorter length of stay [35] and the shifted thresholds for surgery in patients with (end stage) osteoarthritis of the hip [36]. Therefore, only two studies [27,30], with average lengths of stay $\leqslant 4$ days are likely to offer comparisons to current clinical pathways that emphasize fast-track protocols for 
inpatient stay following total hip arthroplasty surgery. Third, we did not contact the authors of the included studies for additional information about the lack of detail in the described protocols used in the studies. Perhaps this would have facilitated the comparison between the studies. Fourth and final, we excluded studies written in a language other than English or Dutch; perhaps our data our particularly relevant to English speaking countries.

The majority of studies were classified as having low risk of bias [14], however there was great overlap in the items that scored negatively. In particular, the validity of the outcome measurement (Item N) was inadequately described in six out of 12 studies. In 10 studies, no adequate description of the methods for assessment of length of stay was provided. This could mean that in some studies the length of stay was actually one day longer (i.e. including the day of surgery) than in other studies, perhaps jeopardizing comparison across settings. Furthermore, and perhaps of most concern, was the insufficient description provided of the clinical pathway experienced by the study cohorts (Item I). In 12 out of the 14 studies, descriptions of treatment exposure, including surgical protocols, postoperative pain management and physical therapy protocols were not provided. Only two studies [24,27] provided sufficient description of this treatment exposure (Item I). This makes comparing individual studies difficult because the postoperative therapy protocols may impact the length of stay and/or the speed of the inpatient recovery of functioning [37].

Most studies used length of stay as their primary outcome. Length of stay consists of logistical and clinical features (e.g. functional discharge criteria and inpatient recovery of functioning) [38], whereas inpatient recovery of functioning depends only on the patient and perioperative factors guiding their recovery. Thus, we hypothesized that there would be a difference between the factors predictive of inpatient recovery of functioning and the factors predictive of length of stay. This was partly confirmed by the difference in level of evidence between number of comorbidities and American Society of Anaesthesiologists score; strong for their association with length of stay and moderate for no association with inpatient recovery of functioning.

Our study demonstrates a number of hiatuses in the current literature. We used the ICF to classify the 24 factors derived from the included studies. Only one factor was related to body functions/structure (namely strength), only two factors were related to activity limitations (namely functional status (ADL level) and no factors were related to the ICF domain participation. The latter suggest that the THA literature is mainly studied from a biomedical perspective on health and function [16]. We might need to study factors related to functioning and participation, as their predictive value show promise [39-41]. Based on current recommendations $[39,40]$ functional 

management/anaesthesia, postoperative protocols) to allow pooling of factors.

In conclusion, the results of this systematic review suggest that little innovation has occurred in the last five decades of research regarding preoperative factors that influence early prognosis following total hip arthroplasty. Most are still personal factors according to the WHO's ICF (e.g. anthropometric, demographic, and medical related). Future studies should consider adding factors of relevance across International Classification of Function, Disability and Health domains (function/ structure, activity, participation, personal, and environmental factors) preferably measured with a combination of patients' objective performance and perception (self-report). This may result in better predictive models, enhancing person-centered care and optimizing outcomes for patients undergoing total hip arthroplasty surgery.

\section{CLINICAL MESSAGES}

1) For patients who underwent total hip arthroplasty surgery, there is strong evidence that the number of comorbidities, American Society of Anaesthesiologists score, and presence of heart or lung disease are associated with length of hospital stay.

2) For patients who underwent total hip arthroplasty surgery, there is moderate evidence that ADL level, sex, body mass index, muscle strength, number of comorbidities, parathyroid hormone, vitamin D, and American Society of Anaesthesiologists score are associated with the inpatient recovery of functioning.

\section{ACKNOWLEDGEMENTS}

We like to acknowledge Andrew Kittelson for his suggestions regarding the English grammar and wording. 


\section{REFERENCES}

1. Deeks JJ. Systematic reviews in health care: Systematic reviews of evaluations of diagnostic and screening tests. BMJ 2001;323:157-62.

2. Santaguida PL, Hawker GA, Hudak PL, Glazier $\mathrm{R}$, Mahomed NN, Kreder HJ, et al. Patient characteristics affecting the prognosis of total hip and knee joint arthroplasty: a systematic review. Can J Surg 2008;51:428-36.

3. Thorstensson CA, Gooberman-Hill R, Adamson J, Williams S, Dieppe P. Helpseeking behaviour among people living with chronic hip or knee pain in the community. BMC Musculoskelet Disord 2009;10:153.

4. McGinn TG, Guyatt GH, Wyer PC, Naylor CD, Stiell IG, Richardson WS. Users' guides to the medical literature: XXII: how to use articles about clinical decision rules. Evidence-Based Medicine Working Group. JAMA 2000;284:79-84.

5. Young NL, Cheah D, Waddell JP, Wright JG. Patient characteristics that affect the outcome of total hip arthroplasty: a review. Can J Surg 1998;41:188-95.

6. Kennedy DM, Stratford PW, Hanna SE, Wessel J, Gollish JD. Modeling early recovery of physical function following hip and knee arthroplasty. BMC Musculoskelet Disord 2006; 7:100.

7. Bade MJ, Wolfe P, Zeni JA, Stevens-Lapsley JE, Snyder-Mackler L. Predicting poor physical performance after total knee arthroplasty. J Orthop Res 2012.

8. Husted H. Fast-track hip and knee arthroplasty: clinical and organizational aspects. Acta Orthop 2012;83:1-39.

9. Mallinson TR, Bateman J, Tseng HY, Manheim $\mathrm{L}$, Almagor O, Deutsch A, et al. A comparison of discharge functional status after rehabilitation in skilled nursing, home health, and medical rehabilitation settings for patients after lower-extremity joint replacement surgery. Arch Phys Med Rehabil 2011.

10. Beckles Z, Glover S, Ashe J, Stockton S, Boynton J, Lai R, et al. Searching CINAHL did not add value to clinical questions posed in NICE guidelines. J Clin Epidemiol 2013.
11. Liberati A, Altman DG, Tetzlaff J, Mulrow C, Gøtzsche PC, loannidis JPA, et al. The PRISMA statement for reporting systematic reviews and meta-analyses of studies that evaluate healthcare interventions: explanation and elaboration. BMJ 2009.

12. Moher D, Liberati A, Tetzlaff J, Altman DG. Preferred reporting items for systematic reviews and meta-analyses: the PRISMA statement. Int J Surg 2010;8:336-41.

13. Centre $\mathrm{N}$. The management of hip fracture in adults. London: National Clinical Guideline Centre, 2011. Available at: http://www.ncgc.ac.uk (accessed April 2014). 2011.

14. Chapple CM, Nicholson H, Baxter GD, Abbott $\mathrm{JH}$. Patient characteristics that predict progression of knee osteoarthritis: A systematic review of prognostic studies. Arthritis Care Res 2011.

15. Landis JR, Koch GG. The measurement of observer agreement for categorical data. Biometrics 1977;33:159-74.

16. WHO. ICF 2001.

17. Hoogeboom TJ, van den Ende CHM, van der Sluis G, Elings J, Dronkers JJ, Aiken AB, et al. The impact of waiting for total joint replacement on pain and functional status: a systematic review. Osteoarthritis Cartilage 2009;17:1420-7.

18. Jørgensen CC, Kehlet $\mathrm{H}$. Role of patient characteristics for fast-track hip and knee arthroplasty. Br J Anaesth 2013.

19. Wang A, Ackland T, Hall S, Gilbey H, Parsons R. Funtional recovery and timing of hospital discharge after primary total hip arthroplasty. ANZ J Surg 1998;68:580-3.

20. Stundner O, Chiu Y-L, Sun X, Goodman SM, Russell LA, Calloway JJ, et al. Perioperative outcomes in patients with rheumatoid versus osteoarthritis for total hip arthroplasty: a population-based study. Clin Exp Rheumatol 2013;31:889-95.

21. Sadr Azodi O, Bellocco R, Eriksson K, Adami $J$. The impact of tobacco use and body mass index on the length of stay in hospital and the risk of post-operative complications among patients undergoing total hip replacement. J Bone Jt Surg - Ser B 2006. 
22. Abbas K, Umer M, Qadir I, Zaheer J, ur Rashid $H$. Predictors of length of hospital stay after total hip replacement. J Orthop Surg (Hong Kong) 2011;19:284-7.

23. Rajgopal R, Martin R, Howard JL, Somerville L, MacDonald SJ, Bourne R. Outcomes and complications of total hip replacement in super-obese patients. Bone Joint J 2013;95B:758-63.

24. Higuera CA, Elsharkawy K, Klika AK, Brocone M, Barsoum WK. 2010 Mid-America orthopaedic association physician in training award: Predictors of early adverse outcomes after knee and hip arthroplasty in geriatric patients. Clin Orthop Relat Res 2011.

25. John-Baptiste A, Naglie G, Tomlinson G, Alibhai SMH, Etchells E, Cheung A, et al. The effect of english language proficiency on length of stay and in-hospital mortality. J Gen Intern Med 2004.

26. Foote J, Panchoo K, Blair P, Bannister G. Length of stay following primary total hip replacement. Ann R Coll Surg Engl 2009.

27. Unnanuntana A, Rebolledo BJ, Gladnick BP, Nguyen JT, Sculco TP, Cornell CN, et al. Does Vitamin D Status Affect the Attainment of InHospital Functional Milestones After Total Hip Arthroplasty? J Arthroplasty 2012.

28. Lavernia CJ, Villa JM, Contreras JS. Alcohol use in elective total hip arthroplasty: risk or benefit? Clin Orthop Relat Res 2013;471:5049.

29. Rissanen P, Aro S, Paavolainen P. Hospitaland patient-related characteristics determining length of hospital stay for hip and knee replacements. Int J Technol Assess Health Care 1996;12:325-35.

30. O’Malley NT, Fleming FJ, Gunzler DD, Messing SP, Kates SL. Factors independently associated with complications and length of stay after hip arthroplasty: analysis of the National Surgical Quality Improvement Program. J Arthroplasty 2012;27:1832-7.

31. Huang CS, Cheu YD, Ying J, Wei MH. Association between provider volume and comorbidity on hospital utilization and outcomes of total hip arthroplasty among national health insurance enrollees. J Formos Med Assoc 2011.
32. Maradit Kremers H, Visscher SL, Kremers WK, Naessens JM, Lewallen DG. Obesity increases length of stay and direct medical costs in total hip arthroplasty. Clin Orthop Relat Res 2014;472:1232-9.

33. Dall GF, Ohly NE, Ballantyne JA, Brenkel IJ. The influence of pre-operative factors on the length of in-patient stay following primary total hip replacement for osteoarthritis: A multivariate analysis of 2302 patients. J Bone Jt Surg - Ser B 2009.

34. Weaver F, Hynes D, Hopkinson W, Wixson R, Khuri S, Daley J, et al. Preoperative risks and outcomes of hip and knee arthroplasty in the veterans health administration. J Arthroplasty 2003.

35. Kehlet H, Wilmore DW. Evidence-based surgical care and the evolution of fast-track surgery. Ann Surg 2008.

36. Birrell F, Johnell O, Silman A. Projecting the need for hip replacement over the next three decades: Influence of changing demography and threshold for surgery. Ann Rheum Dis 1999.

37. Husted H, Jensen CM, Solgaard S, Kehlet H. Reduced length of stay following hip and knee arthroplasty in Denmark 2000-2009: from research to implementation. Arch Orthop Trauma Surg 2012;132:101-4.

38. Husted H, Hansen HC, Holm G, Bach-Dal C, Rud K, Andersen KL, et al. What determines length of stay after total hip and knee arthroplasty? A nationwide study in Denmark. Arch Orthop Trauma Surg 2010

39. Gandhi R, Tsvetkov D, Davey JR, Syed KA, Mahomed NN. Relationship between selfreported and performance-based tests in a hip and knee joint replacement population. Clin Rheumatol 2009;28:253-7.

40. Malani PN. Functional Status Assessment in the Preoperative Evaluation of Older Adults. JAMA 2009;302:1582.

41. Vissers MM, Bussmann JB, Verhaar JAN, Busschbach JJV, Bierma-Zeinstra SMA, Reijman M. Psychological factors affecting the outcome of total hip and knee arthroplasty: A systematic review. Semin Arthritis Rheum 2012. 
52 | Chapter 2

APPENDIX 2.1. SEARCH STRATEGY FOR MEDLINE (2014-04-28)

\begin{tabular}{|c|c|c|}
\hline Search & Queries & Hits \\
\hline \#1 & $\begin{array}{l}\text { Search ((arthroplasty OR joint prosthesis OR arthroplasty, replacement, hip } \\
\text { OR hip prosthesis[MeSH Terms] OR arthroplasty[Text Word] OR total } \\
\text { joint*[Text Word] OR total hip*[Text Word])) }\end{array}$ & 74607 \\
\hline \#2 & $\begin{array}{l}\text { Search (((prospective studies[MeSH] OR longitudinal studies[MeSH] OR } \\
\text { cohort studies[MeSH] OR follow-up studies[MeSH] OR observational studies } \\
\text { OR predic* OR prognos* OR prognostic factor* OR course OR determinant* } \\
\text { OR Predictive Value of Tests[MeSH] OR Risk Factors[MeSH] OR Risk[MeSH] } \\
\text { OR Precipitating Factors[MeSH] })))\end{array}$ & 3390730 \\
\hline \#3 & $\begin{array}{l}\text { Search }(((\text { hospitalization[MeSH] OR Length of Stay[MeSH] OR Patient } \\
\text { Discharge[MeSH] OR discharge OR recovery of function[MeSH] OR Activities } \\
\text { of daily living[MeSH] OR Rehabilitation[MeSH] OR functional status })))\end{array}$ & 451985 \\
\hline \#4 & Search ((\#1) AND \#2) AND \#3 & 3901 \\
\hline \#5 & Search ((\#1) AND \#2) AND \#3 Filters: Adult: 19+ years & 3378 \\
\hline
\end{tabular}


APPENDIX 2.2. MODIFIED RISK OF BIAS TOOL.

\begin{tabular}{|c|c|}
\hline \multicolumn{2}{|c|}{ Study Participation } \\
\hline A & $\begin{array}{l}\text { Inception cohort (early/uniform point of disease) - positive if similar for whole cohort or if } \\
\text { cohort grouped according to similar stage of disease (accounted for in analysis). }\end{array}$ \\
\hline B & $\begin{array}{l}\text { Description of study population - positive if can determine that cohort is representative of } \\
\text { source population (positive if age and sex are described) }\end{array}$ \\
\hline $\mathrm{C}$ & $\begin{array}{l}\text { Description inclusion/exclusion criteria- positive if criteria addressed age, diagnostic } \\
\text { criteria, and relevant co morbidities }\end{array}$ \\
\hline D & $\begin{array}{l}\text { Response } \geq 75 \% \text { for cohorts and controls - at least } 75 \% \text { of people eligible participated in } \\
\text { trial/were included in study }\end{array}$ \\
\hline \multicolumn{2}{|c|}{ Study Attrition } \\
\hline $\mathrm{E}$ & Follow-up of entire length of stay \\
\hline $\mathrm{F}$ & Dropouts/Loss to follow-up $\leq 20 \%$ \\
\hline G & $\begin{array}{l}\text { Information completers vs. loss to follow-up - reasons for withdrawal, any differences in key } \\
\text { characteristics or outcomes between dropouts and completers }\end{array}$ \\
\hline \multicolumn{2}{|r|}{ Measurement and data presentation } \\
\hline $\mathrm{H}$ & $\begin{array}{l}\text { Prospective data collection - also positive in historical cohort if prognostic factors assessed } \\
\text { before outcome determined }\end{array}$ \\
\hline I & $\begin{array}{l}\text { Treatments/exposure of cohort fully described and standardised - positive if operative and } \\
\text { postoperative treatment protocols are described }\end{array}$ \\
\hline J & $\begin{array}{l}\text { Clinically relevant prognostic factors - may include physical, psychosocial, pre-existing } \\
\text { conditions, socio-demographic and medication factors }\end{array}$ \\
\hline K & $\begin{array}{l}\text { Standardised or valid measures of prognostic factors - positive if prognostic factors clearly } \\
\text { defined and reliably measured (limited reliance on recall, measurement method described) }\end{array}$ \\
\hline L & $\begin{array}{l}\text { Data presentation of the most important prognostic factors - positive if estimates and } \\
\text { precision are reported (e.g. frequency, percentage, mean, median, SD, Cl). Sufficient data } \\
\text { to assess adequacy of analysis. }\end{array}$ \\
\hline M & $\begin{array}{l}\text { Clinically relevant outcome measures - positive if outcome measures assessed length of } \\
\text { stay or inpatient recovery of functioning }\end{array}$ \\
\hline N & $\begin{array}{l}\text { Standardized or valid outcome measures - positive if the study presented the assessment } \\
\text { of the length of stay (begin and endpoints) or the use of clinical measurement instruments } \\
\text { to determine the inpatient recovery of functioning }\end{array}$ \\
\hline O & $\begin{array}{l}\text { Data presentation of the most important outcome measures - positive if estimates and } \\
\text { precision are reported (e.g. frequency, percentage, mean, median, SD, CI), sufficient data } \\
\text { to assess adequacy of analysis. }\end{array}$ \\
\hline \multicolumn{2}{|r|}{ Analysis and presentation of results } \\
\hline$P$ & $\begin{array}{l}\text { Appropriate analysis techniques (provision of } \mathrm{OR}, \mathrm{RR}, \mathrm{HR} \text { ) - positive if univariate estimates } \\
\text { (RR, OR, HR) were provided for association of prognostic factor with outcome. Negative if } \\
\text { only p values reported or no tests performed }\end{array}$ \\
\hline Q & $\begin{array}{l}\text { Prognostic model is presented (multivariate techniques) - positive if attempt is made to } \\
\text { determine set of prognostic factors with highest prognostic value using multivariate } \\
\text { techniques (e.g. logistic regression, linear regression). Negative if no multivariate } \\
\text { techniques. }\end{array}$ \\
\hline $\mathrm{R}$ & $\begin{array}{l}\text { Sufficient numbers ( } 10 \text { subjects per variable) - positive if sample size has } 10 \text { subjects per } \\
\text { prognostic variable }\end{array}$ \\
\hline
\end{tabular}


54 | Chapter 2

APPENDIX 2.2. (CONTINUED)

Confounding - positive if possible confounders (at least age and sex) were identified and accounted for in:

S The study design (matching for key variables, stratification, initial assembly of comparable groups, exposure to interventions)

The analysis (multivariate analysis, appropriate adjustment)

$\mathrm{T}$ Conclusions drawn accurately from results - positive if limitations of study discussed and conclusions supported by results 
APPENDIX 2.3. LEVEL OF EVIDENCE DESCRIBED BY HOOGEBOOM ET AL. [1]

\begin{tabular}{ll}
\hline Levels of evidence that were applied in the best-evidence synthesis \\
\hline Strong & Consistent findings among multiple high quality descriptive studies \\
\hline Moderate & $\begin{array}{l}\text { Consistent findings among multiple low quality descriptive studies and/or one } \\
\text { high quality descriptive studies }\end{array}$ \\
\hline Limited & One low quality descriptive study \\
\hline Conflicting & Inconsistent findings among multiple descriptive studies \\
\hline No evidence & No (high) descriptive studies could be found \\
\hline
\end{tabular}

\section{REFERENCE}

1. Hoogeboom TJ, van den Ende CHM, van der Sluis G, Elings J, Dronkers JJ, Aiken AB, et al. The impact of waiting for total joint replacement on pain and functional status: a systematic review. Osteoarthritis Cartilage 2009;17:1420-7. 
56 | Chapter 2 


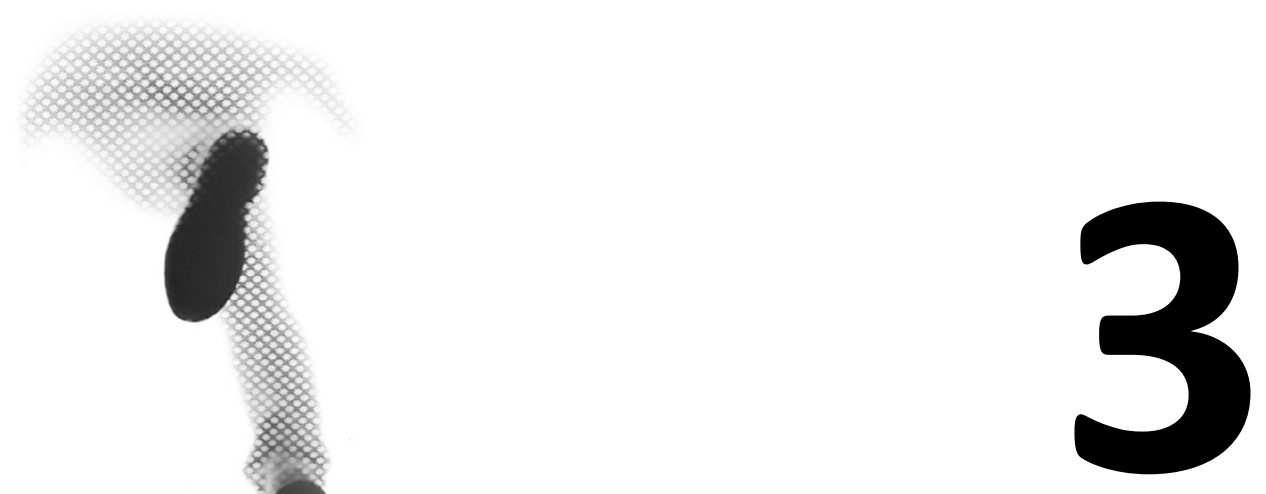

EXPLORATION AND CONFORMATION OF CLINICALLY RELEVANT PATIENT PROFILES OF INDIVIDUALS AWAITING TOTAL HIP ARTHROPLASTY

J. Elings | G.A.M. Lappenschaar | G. van der Sluis | S.M. Van Gaalen | R. Nijhuis | N.L.U. van Meeteren | T.J. Hoogeboom 


\section{ABSTRACT}

Background: Surgical interventions are no guarantees for optimal outcomes and not without risks. Results reported by people who undergo THA differ in achieving clinically relevant improvement in pain and functional ability. Insight into the factors influencing the expected course of recovery of functioning and outcomes is the first step to guide patients and healthcare professionals during further development of personalized care.

Objectives: 1) To identify and verify patient profiles based on preoperative patient characteristics present in a population of people awaiting total hip arthroplasty (THA); and 2) to determine if patient profiles differ in inpatient recovery of activities and/or length of stay (LoS).

Methods: Retrospective cross-sectional observational study of 1852 patients awaiting unilateral THA. Functional mobility, walking capacity, pain, BMI, medical fitness, and comorbidity scores were collected during clinical practice in two general hospitals in the Netherlands. Patient profiles were identified using latent class analysis and analyzed for differences in inpatient recovery of activities and/or LoS using multiple group comparison.

Results: Four patient profiles were identified and verified within our datasets. The Frailprofile were all women with a high BMI and low functional status; the Comorbid profile had the highest age, pain levels, and ASA scores; the Pain profile had high pain levels and moderate functional status, and the Fit profile had the lowest BMI and ASA-scores and highest functional status. The Fit profile had the lowest LoS (median 4 days (IQR 3-4)) and the fasted recovery of activities (4 days (IQR 3-4). The Frail patient profile showed the slowest recovery of activities (5 days (IQR 4.55.5)). Internal and external validation of the patient profiles confirmed quite similar results.

Conclusions: Patients awaiting THA can be divided into four patient profiles, each with its specific preoperative characteristics and postoperative outcomes. The patient profiles seem stable, valid, and clinically relevant in LoS and inpatient recovery of activities. 


\section{INTRODUCTION}

Total hip arthroplasty (THA) is one of the most common inpatient elective surgeries worldwide

[1] to improve hip pain and functioning of people with hip osteoarthritis [2,3]. Nevertheless, surgical interventions are no guarantees for optimal outcomes and not without risks. Hawker et al. (2013) suggest that only half of the people who undergo THA achieve clinically relevant improvement in pain and functional ability [4]. Insight in the factors influencing the expected course of recovery of functioning and outcomes is the first step to guide patients and healthcare professionals during their shared-decision making process [5].

It is well established that preoperative demographics, socioeconomics, and clinical factors of individual patients relate to the - functional - outcome of their THA surgery [6-10]. This relationship between preoperative factors and the postoperative outcome is, besides for the patient, also clinically relevant for the healthcare system (in terms of logistics, planning, organization, and economics), given that the population of people with hip osteoarthritis is heterogeneous in terms of disease progression, level of pain and functioning, and comorbidity $[4,11]$. To cope with this heterogeneity, we might need to inform and discuss with individual patients what their most likely patient profile is with the predicted recovery.

Therefore, the aim of this study is twofold: 1) to identify and verify patient profiles out of group data and based on preoperative patient characteristics present in a population of people awaiting THA and 2) to determine if individual people with different profiles differ in inpatient recovery of physical activities and/or length of hospital stay. Answering these questions may provide the groundwork for further development of personalized care.

\section{METHODS}

For this cross-sectional observational study, we used two datasets that have been collected during daily clinical practice in two general hospitals in the Netherlands between 2009 and 2015. According to a standardized protocol, all patients undergoing THA in both these hospitals were preoperatively screened by trained physical therapists [12]. The median time between data collection and surgery was 54 days. All procedures complied with a non-human subject research designation and were approved by the local Ethical Committee of the Diakonessenhuis Hospital in Utrecht and Nij Smellinghe Hospital in Drachten, as was the publication of the results of the study (reference number: JT/ds/160418 and 16-107/JS/AB, resp). 


\section{Preoperative Patient VARIABles}

For the pre-determination of the patient profiles, six different patient characteristics were chosen based on a combination of scientific evidence [13-15] and consensus among three highly experienced physical therapists in treating patients that opt for THA (MV, JE, GS), namely: functional mobility measured with the Timed Up and Go test (TUG), walking capacity measured with the 6-minute walking test (6MWT), pain measured with the visual analog scale, BMI, medical fitness assessed with the American Society of Anesthesiologists classification (ASA), and comorbidity assessed with the Charnley score. Additional information of the preoperative patient variables is available in Appendix 3.1. Based on those six patient characteristics, we hypothesize that four patient profiles (Frail, Comorbid, Pain, and Fit) are likely present in the THA population based on their preoperative baseline characteristics. In Box 3.1, the hypothesized patient profiles are presented with the expected relative values for each patient characteristics, classified as 'high', 'moderate' or 'low'. The four hypothesized patient profiles were verified by a Dutch physical therapy expert group ( $n=24)$ within the field of total hip and knee arthroplasty. Multiple imputation was used to compensate for missing data points of crucial patient characteristics.

\section{CLINICAL OUTCOMES}

Inpatient recovery of activities was measured as the number of consecutive nights a person needed to achieve a score of 0 on the MILAS [16]. With the help of the MILAS the physical therapist assesses during observation, patients' capability to safely perform 5 activities of daily life (supine-to-sit, sit-to-supine, sit-to-stand, walking, and stair climbing). Stair climbing was not a standard assessment for all patients, but only for those required to climb stairs at their discharge destination. Therefore, we excluded stair climbing from our outcome measure.

To assess the clinical outcome, inpatient recovery of activities and LoS was used. The LoS was measured as the number of consecutive nights a person was admitted from the day of surgery until discharge. The LoS was included as an outcome variable because it is: 1) the most frequently reported outcome measure in studies reporting relations between preoperative patient-related factors and recovery after THA [15]; and 2) a combination of recovery of activities, medical recovery, and logistics [12]. 
Box 3.1. Characteristics of the hypothesized patient profiles*

\begin{tabular}{|lllllll|}
\hline & TUG & 6MWT & Pain & BMI & ASA & Charnley \\
Pain profile & Low & High & High & Moderate & Moderate & Moderate \\
Comorbid profile & Moderate & Moderate & Moderate & Moderate & High & High \\
Fit profile & Low & High & Moderate & Low & Low & Low \\
Frail profile & High & Low & Moderate & High & High & High \\
\hline
\end{tabular}

* TUG: Timed Up-and-Go test; 6MWT: 6 Minute Walking Test; Pain24: pain in the last 24 hours; BMI: Body Mass Index; ASA score: American Society of Anesthesiologists physical status classification system; Charnley: effect of comorbidity on physical functioning.

\section{DATA ANALYSIS}

We used two datasets in this study: Utrecht data (collection between 2010 and 2015), randomly converted in two datasets: (dataset 1a) initial dataset for identifying patient profiles $(n=926)$; (dataset 1b) internal validation dataset ( $n=926)$; and Drachten data (collection between 2009 and 2010): (dataset 2) external validation dataset $(n=271)$.

Missing values were imputed using the multiple imputation (MI) method in Mplus, thereby averaging over 10 imputed datasets. Values were imputed using the observed variables, i.e., TUG, 6MWT, Pain, BMI, ASA, and Charnley, as predictors themselves. The TUG and 6MWT had a high negative correlation of -0.77 .

The data analysis was divided into three phases:

1. Exploration of patient profiles (dataset 1a)

2. Confirmation of the patient profiles (dataset $1 \mathrm{~b}$ and 2 )

3. Evaluation of clinical relevance of the patient profiles on the clinical outcomes (all datasets)

\section{PHASE 1: EXPLORATIVE ANALYSIS OF PATIENT PROFILES}

For this study, we based our analysis on the statistics used in similar research performed by Kittelson et al. [14] and Nylund et al. [17]. The variables of interest were first tested for co-linearity with the spearman's rho, a value of $<0.7$ was classified as a high correlation [18]. A Latent Class 
Analysis (LCA) was performed to explore patient profiles in dataset 1a, on the clustering variables mentioned above, using Mplus version 6.1 (Muthen \& Muthen). Analysis started with a two-class model analysis using all six preoperative variables, followed by an increasing number of classes to a maximum of six.

Outcomes of different fit-statistics were combined to decide the best model fit for our study population. The Bayesian Information Criterion (BIC), the sample size adjusted BIC, and the Akaike Information Criterion (AIC) were compared to the models with a difference in the number of classes. Furthermore, a Lo-Mendell-Rubin likelihood ratio test was used to compare a model's fit with $n$ classes with a model with $n-1$ classes if necessary. The number of patients of each class in a solution should ideally be at least equal to the number of parameters to be estimated. All LCAs were performed using 100 different starting values to avoid solutions based on local maxima.

After assessing the patient profiles in dataset $1 a$, all participants were assigned to a profile based on their most likely latent class membership. To assess whether patient profiles differed among themselves, we performed a multiple group comparison. An analysis of variance (ANOVA) was performed to compare the patient profiles variables across the different classes, followed by Tukey's Honestly Significant Difference (HSD) post hoc test. If the ANOVA's assumptions were violated, the Kruskal-Wallis test would be used, followed by Dunn's post hoc test, and the ChiSquare test for the categorical variables. A p-value lower than 0.05 was considered statistically significant.

\section{Phase 2: Confirmative ANAlysis Patient Profiles (INTERNAL AND EXternal Verification)}

The second part of the analysis consisted of verifying the patient profiles found in dataset 1a by performing a confirmative LCA on dataset $1 b$ and dataset 2 with constraints based on the patient profiles characteristics found in dataset 1 [19]. For this LCA, fixed value constraints were used, which are ratios for one or more patient profiles within one profile variable, to confirm or reject if the patient profiles found in dataset $1 \mathrm{a}$ are also present in dataset $1 \mathrm{~b}$. For example, a constraint for the mean age of patient profiles could be that the mean age was at least 1.25 times the other patient profiles' age. Constraints will be based on the characteristics of the patient profiles found in dataset 1a. The LCA was performed with and without constraints, and the entropy-values of both models were compared. The entropy-value is a measure of classification certainty, with an entropy of 1 being perfect classification certainty. The model with the highest entropy-value was 
The characteristics of the patient profiles found in dataset 1a will be compared with the patient profiles in dataset $1 b$ and dataset 2 and will be considered comparable if:

1. The differences between the patient profiles in one dataset are not significantly or clinically relevant differences between datasets $1 a, 1 b$ and 2, and,

2. The sizes of the patient profiles compared to the total population are to some extent comparable between datasets $1 a, 1 b$ and 2 .

\section{Phase 3: Patient PROFile Related to LoS or INPATIENT ReCovery OF ACtIVItIES}

To determine if the verified patient profiles differed in LoS or inpatient recovery of activities, we used an ANOVA combined with Tukey's HSD post hoc test or the Kruskal-Wallis test combined with Dunn's post hoc test if the assumptions for the ANOVA were not met.

All comparative analyses were performed using $\mathrm{R}$ version 3.3.1.

\section{RESULTS}

A total of 2,123 patients were analyzed in this study. The patient characteristics of the three datasets are shown in Table 3.1. There was no significant or clinically relevant difference in any patient characteristic between data subset $1 \mathrm{a}$ and data subset $1 \mathrm{~b}$. Data subset 1a and data subset $1 b$ were not significantly or clinically different on any patient characteristic. However, dataset 2 was significantly and clinically different from datasets $1 a$ and $1 b$ on all patient characteristics except for age and gender. In general, the patients in dataset 2 had a higher BMI, were slower on the TUG, walked more meters on the 6MWT, reported higher pain levels, had more bilateral complaints, and better ASA scores.

\section{Phase 1: Explorative identification Of PATIENT PROfiles (TABle 3.3)}

LCAs were conducted for models ranging from 2 to 6 classes to determine the best fitting model for the number of classes (patient profiles). We found improving AIC and BIC measures when comparing four classes with three classes (AIC 37177 vs. 37471 and BIC 37428 vs. 37664 , respectively), indicating a better fit for the model with four classes. When we compared a model 
consisting of five classes with a model of four classes, the AIC (37074) and BIC (37383) marginally improved, the entropy level worsened from 0.815 to 0.795 , and another small class $(n=55,6 \%)$ appeared.

Based on the fact that: 1) the AIC and BIC improves in the four-class model related to the threeclass model; 2 ) the smallest class $(n=9)$ is also adopted in the three-class model; 3 ) our focus group a-priori hypothesized four classes; and 4) a five-class model marginally improves fitstatistics and adds another small class, we selected the four-class model from dataset 1a. After determining our model's structure, all participants were assigned to a patient profile based on their most likely latent class membership adopted from our LCA on database 1a. Patient profile 1 and 4 matches our a-priory Frail and Fit profile on all items. Patient profile 2equals the Comorbid profile except for a worse than predicted outcome on the 6MWT distance and higher pain levels, and Patient profile 3 matches the Pain profile except for a better than predicted TUG time and lower than predicted 6MWT distance (see Table 3.3).

\section{PHASE 2: INTERNAL AND EXTERNAL CONFIRMATION OF PATIENT PROFILES}

After identifying the patient profiles present in database $1 \mathrm{a}$, we used the data from database $1 \mathrm{a}$ to determine the constraints by which the confirmation in databases $1 \mathrm{~b}$ (internal) and 2 (external) would be led. The constraints we used were relative, i.e., we only used restrictions of the type $p_{i}>p_{j}$ (with $p_{i}$ and $p_{j}$ represent the predicted value of a specific variable $p$ for class $i$ and $j$ ). In this way, we made sure that the average values of the TUG and 6MWT of the different classes are in the same order as in database 1a. No further restrictions on these or other variables were made.

\section{INTERNAL CONFIRMATION}

The internal validation revealed similar results compared to the initial identification of patient profiles, except that (1) the proportions between patient profiles Frail and Fit differed in size (45\% vs. $46 \%$ compared to $35 \%$ vs. $57 \%$, respectively); and that (2) patients in the Frail profile had better ASA, Charnley, and TUG scores compared to dataset 1a, although still with the worst preoperative status of all patient profiles. The descriptive data of internal confirmation are presented in Appendix 3.2. 
Table 3.1. Characteristics of the study population. Data are mean (1st - 3rd quartile) unless otherwise indicated.

\begin{tabular}{|c|c|c|c|c|c|c|c|c|}
\hline \multirow[b]{3}{*}{ Women, \% } & \multicolumn{2}{|c|}{$\begin{array}{l}\text { Database 1a } \\
(n=926)\end{array}$} & \multicolumn{2}{|c|}{$\begin{array}{l}\text { Database 1b } \\
(n=926)\end{array}$} & \multicolumn{2}{|c|}{$\begin{array}{l}\text { Database } 2 \\
(n=271)\end{array}$} & \multirow[t]{2}{*}{$\begin{array}{l}\text { Kruskal-Wallis } \\
X(2)\end{array}$} & \multirow[t]{2}{*}{$\begin{array}{l}\text { sign different } \\
\text { datasets }\end{array}$} \\
\hline & $n$ & $\begin{array}{l}\text { Mean } \\
\left(1^{\text {st }} Q-3^{\text {rd }} Q\right)\end{array}$ & $n$ & $\begin{array}{l}\text { Mean } \\
\left(1^{\text {st }} Q-3^{\text {rd }} Q\right)\end{array}$ & $n$ & $\begin{array}{l}\text { Mean } \\
\left(1^{\text {st }} Q-3^{\text {rd }} Q\right)\end{array}$ & & \\
\hline & 644 & 69.5 & 666 & 71.9 & 186 & 68.6 & $1.76^{\ddagger}$ & \\
\hline Age $(y)$ & 926 & $\begin{array}{l}71.8 \\
(64.7-78.2)\end{array}$ & 926 & $\begin{array}{l}70.8 \\
(63.8-78.7)\end{array}$ & 271 & $\begin{array}{l}71.0 \\
(65.0-77.5)\end{array}$ & $0.77^{\ddagger}$ & \\
\hline BMI $\left(\mathrm{kg} / \mathrm{m}^{2}\right)$ & 717 & $\begin{array}{l}26.3 \\
(23.9-29.4)\end{array}$ & 745 & $\begin{array}{l}26.3 \\
(23.9-29.7)\end{array}$ & 268 & $\begin{array}{l}27.4 \\
(24.9-30.1)\end{array}$ & $10.61^{\dagger}$ & $1-3 ; 2-3$ \\
\hline Obesity $\left(\geq 30 \mathrm{~kg} / \mathrm{m}^{2}\right), \%$ & 155 & 21.6 & 173 & 22.3 & 69 & 25.7 & & \\
\hline TUG (s) & 740 & $\begin{array}{l}9.06 \\
(7.0-12.5)\end{array}$ & 743 & $\begin{array}{l}9.00 \\
(7.0-12.4)\end{array}$ & 259 & $\begin{array}{l}10.03 \\
(7.8-14.0)\end{array}$ & $16.47^{\dagger}$ & $1-3 ; 2-3$ \\
\hline 6-MWT (m) & 750 & $\begin{array}{l}335 \\
(260-404)\end{array}$ & 738 & $\begin{array}{l}340 \\
(259-400)\end{array}$ & 259 & $\begin{array}{l}350 \\
(270-420)\end{array}$ & $6.15^{\dagger}$ & $1-3 ; 2-3$ \\
\hline Pain24-score & 849 & $\begin{array}{l}60 \\
(50-70)\end{array}$ & 855 & $\begin{array}{l}60 \\
(50-70)\end{array}$ & 259 & $\begin{array}{l}67 \\
(49-80)\end{array}$ & $16.18^{\dagger}$ & $1-3 ; 2-3$ \\
\hline ASA score, $\%$ & & & & & & & $34.86^{\dagger}$ & $1-3 ; 2-3$ \\
\hline ASA score 1 & 174 & 19.8 & 187 & 21.5 & 42 & 18.0 & & \\
\hline ASA score 2 & 564 & 64.2 & 540 & 62.1 & 168 & 72.1 & & \\
\hline ASA score 3 & 137 & 15.6 & 137 & 15.8 & 23 & 9.9 & & \\
\hline ASA score 4 & 3 & 0.4 & 5 & 0.6 & 0 & 0 & & \\
\hline Charnley score, \% & & & & & & & $259.2^{\dagger}$ & $1-3 ; 2-3$ \\
\hline Charnley score A & 476 & 64.6 & 501 & 65.8 & 144 & 53.7 & & \\
\hline Charnley score B & 118 & 16.0 & 123 & 16.1 & 70 & 26.1 & & \\
\hline Charnley score C & 143 & 19.4 & 138 & 18.1 & 54 & 20.2 & & \\
\hline
\end{tabular}

BMI: Body Mass Index; n= number of unique cases; TUG: Timed Up-and-Go test; 6-MWT: 6 Minute Walking Test; ASA: American Society of

Anesthesiologists, ${ }^{\dagger}$ : sign level $<0.01$; ${ }^{\ddagger}$ : sign level $>0.0$ 
Table 3.2. Descriptives of preoperative patient profiles on cluster variables dataset 1a (identification). Data are mean (1st - 3rd quartile) unless otherwise indicated.

\begin{tabular}{|c|c|c|c|c|c|c|}
\hline & $\begin{array}{l}\text { Profile 1 } \\
\text { Frail } \\
(n=11 ; 1 \%)\end{array}$ & $\begin{array}{l}\text { Profile 2 } \\
\text { Comorbid } \\
(n=73 ; 8 \%)\end{array}$ & $\begin{array}{l}\text { Profile } 3 \\
\text { Pain } \\
(n=417 ; 45 \%)\end{array}$ & $\begin{array}{l}\text { Profile } 4 \\
\text { Fit } \\
(n=425 ; 46 \%)\end{array}$ & $\begin{array}{l}\text { Kruskal- } \\
\text { Wallis } \\
X(2)\end{array}$ & $\begin{array}{l}\text { sign different } \\
\text { classes }\end{array}$ \\
\hline & $\begin{array}{l}\text { Mean } \\
\left(1^{\text {st }} Q-3^{\text {rd }} Q\right)\end{array}$ & $\begin{array}{l}\text { Mean } \\
\left(1^{\text {st }} Q-3^{\text {rd }} Q\right)\end{array}$ & $\begin{array}{l}\text { Mean } \\
\left(1^{\text {st }} Q-3^{\text {rd }} Q\right)\end{array}$ & $\begin{array}{l}\text { Mean } \\
\left(1^{\text {st }} Q-3^{\text {rd }} Q\right)\end{array}$ & & \\
\hline Age (y) & $\begin{array}{l}79 \\
(68-86)\end{array}$ & $\begin{array}{l}81 \\
(75-84)\end{array}$ & $\begin{array}{l}75 \\
(69-81)\end{array}$ & $\begin{array}{l}67 \\
(60-73)\end{array}$ & $194.21^{\dagger}$ & $1-2 ; 1-3 ; 1-4 ; 3-4$ \\
\hline Female, \% & $11(100)$ & $56(77)$ & $339(81)$ & $238(56)$ & $70.51^{\dagger}$ & $1-2 ; 1-3 ; 1-4$ \\
\hline BMI $\left(\mathrm{kg} / \mathrm{m}^{2}\right)$ & $\begin{array}{l}30.8 \\
(28.5-31.9)\end{array}$ & $\begin{array}{l}26.33 \\
(24.5-30.6)\end{array}$ & $\begin{array}{l}27.3 \\
(24.6-30.5)\end{array}$ & $\begin{array}{l}25.2 \\
(23.2-27.9)\end{array}$ & $42.68^{\dagger}$ & $1-2 ; 1-3 ; 1-4$ \\
\hline TUG (s) & $\begin{array}{l}>60 \\
(50->60)\end{array}$ & $\begin{array}{l}22.51 \\
(20.0-27.4)\end{array}$ & $\begin{array}{l}11.1 \\
(9.4-13.7)\end{array}$ & $\begin{array}{l}7 \\
(5.9-8.0)\end{array}$ & $488.87^{\dagger}$ & $1-2 ; 1-3 ; 1-4 ; 2-4 ; 3-4$ \\
\hline 6-MWT (m) & $\begin{array}{l}170 \\
(139-233)\end{array}$ & $\begin{array}{l}148 \\
(102-191)\end{array}$ & $\begin{array}{l}276 \\
(227-310)\end{array}$ & $\begin{array}{l}405( \\
368-450)\end{array}$ & $496.2^{\dagger}$ & $1-2 ; 1-3 ; 1-4 ; 3-4$ \\
\hline Pain24-score & $\begin{array}{l}50 \\
(15-60)\end{array}$ & $\begin{array}{l}70 \\
(60-80)\end{array}$ & $\begin{array}{l}70 \\
(50-80)\end{array}$ & $\begin{array}{l}58 \\
(40-70)\end{array}$ & $73.82^{\dagger}$ & $1-3 ; 1-4 ; 2-3 ; 2-4 ; 3-4$ \\
\hline ASA score, $\%$ & & & & & $203.46^{\dagger}$ & $1-2 ; 1-3 ; 1-4 ; 3-4$ \\
\hline ASA score 1 & $0(0)$ & $0(0)$ & $23(6)$ & $151(38)$ & & \\
\hline ASA score 2 & $6(55)$ & $40(57)$ & $281(71)$ & 237 (59) & & \\
\hline ASA score 3 & $5(45)$ & $28(40)$ & $90(23)$ & $14(3)$ & & \\
\hline ASA score 4 & $0(0)$ & $2(3)$ & $1(0)$ & $0(0)$ & & \\
\hline Charnley, \% & & & & & $109.74^{\dagger}$ & $1-2 ; 1-3 ; 1-4 ; 2-4 ; 3-4$ \\
\hline Charnley score A & $2(22)$ & $24(38)$ & $166(53)$ & $284(81)$ & & \\
\hline Charnley score B & $0(0)$ & $10(16)$ & $52(17)$ & $56(16)$ & & \\
\hline Charnley score C & $7(78)$ & $29(46)$ & $95(30)$ & $12(3)$ & & \\
\hline
\end{tabular}

Abbreviations: $\mathrm{n}=$ number of cases; BMI: Body Mass Index; TUG: Timed Up-and-Go test; 6-MWT: 6 Minute Walking Test; ASA: American Society of Anesthesiologists; $†$ : sign level $<0.01$ 
Table 3.3. Difference in recovery of activities and length of stay between datasets. Data are mean (1st - 3rd quartile) unless otherwise indicated.

\begin{tabular}{|c|c|c|c|c|c|c|c|c|c|c|}
\hline \multirow[t]{2}{*}{$\begin{array}{l}\text { data } \\
\text { set }\end{array}$} & \multicolumn{2}{|c|}{$\begin{array}{l}\text { Profile } 1 \\
\text { Frail }\end{array}$} & \multicolumn{2}{|c|}{$\begin{array}{l}\text { Profile } 2 \\
\text { Comorbid }\end{array}$} & \multicolumn{2}{|c|}{$\begin{array}{l}\text { Profile } 3 \\
\text { Pain }\end{array}$} & \multicolumn{2}{|c|}{$\begin{array}{l}\text { Profile } 4 \\
\text { Fit }\end{array}$} & \multirow[t]{2}{*}{$\begin{array}{l}\text { Kruskal- } \\
\text { Wallis } \\
X(2) \\
\end{array}$} & \multirow[t]{2}{*}{$\begin{array}{l}\text { sign different } \\
\text { classes }\end{array}$} \\
\hline & $\mathrm{n}$ & $\begin{array}{l}\text { median } \\
\text { (IQR) }\end{array}$ & $\mathrm{n}$ & $\begin{array}{l}\text { median } \\
\text { (IQR) }\end{array}$ & $\mathrm{n}$ & $\begin{array}{l}\text { median } \\
(\mathrm{IQR})\end{array}$ & $\mathrm{n}$ & $\begin{array}{l}\text { median } \\
(\mathrm{IQR})\end{array}$ & & \\
\hline & mlL & & & & & & & & & \\
\hline \multirow[t]{2}{*}{2} & 9 & $5.0(4.5-5.5)$ & 91 & $4.0(4.0-5.0)$ & 126 & $4.0(4.0-4.0)$ & 45 & $3.5(3.0-4.0)$ & $31.516^{\dagger}$ & $1-2 ; 1-3 ; 1-4 ; 2-3 ; 3-4$ \\
\hline & Len & th of stay & & & & & & & & \\
\hline $1 a$ & 11 & $5(3.5-8.5)$ & 73 & $5(4.0-7.0)$ & 417 & $4(3.0-5.0)$ & 425 & $4(3.0-4.0)$ & $117.33^{\dagger}$ & $1-2 ; 1-3 ; 1-4 ; 3-4$ \\
\hline $1 b$ & 14 & $5.5(4.0-7.0)$ & 56 & $5(4.0-7.0)$ & 322 & $4(4.0-6.0)$ & 534 & $4(3.0-4.0)$ & $122.59^{\dagger}$ & $1-2 ; 1-3 ; 1-4 ; 2-3$ \\
\hline 2 & 9 & $4(4.0-7.0)$ & 91 & $5(4.0-6.0)$ & 126 & $4(4.0-5.0)$ & 45 & $4(4.0-4.0)$ & $23.525^{\dagger}$ & $1-2 ; 1-3 ; 1-4 ; 2-3$ \\
\hline
\end{tabular}

Abbreviations: $n=$ number of cases; IQR: inter quartile range; mILAS: Modified Level of Assistance Scale; ${ }^{\dagger}$ : sign level $<0.01$ 


\section{EXTERNAL CONFIRMATION}

The external validation revealed similar results compared to the initial identification and internal validation of patient profiles, except that (1) the proportions between patient profiles Comorbid and Fit differed in size ( $\pm 7 \%$ vs. $34 \%$ compared to $\pm 50 \%$ vs. $17 \%$, respectively) and that (2) the pain levels in the Frail profile were higher than predicted. The descriptive data of external confirmation are presented in Appendix 3.3.

\section{Phase 3: PAtient PROFiles Related to LoS or inPatient ReCovery of Activities}

The Fit patient profile had the lowest LoS (4 days (IQR 3.0 - 4.0)) and fastest recovery of activities (MILAS score of 4 (IQR 3.0 - 4.0) and days until walking unassisted of 3.5 (IQR 3.0 - 4.0)) of all patient profiles within all three datasets (Table 3.3). The Frail patient profile showed the slowest recovery of activities on the MILAS (5 days (IQR 4.5-5.5)) of all patient profiles. The Pain patient profile was very similar to the Fit patient profile in terms of LoS and recovery of activities (LoS of 4 days (IQR 3.0 - 5.0 and MILAS score of 4 (IQR $4.0-4.3)$ ).

\section{DISCUSSION}

This retrospective cross-sectional observational study aimed to explore and confirm patient profiles based on preoperative patient-related characteristics present in a population of people awaiting THA and to determine if the different patient profiles differ in inpatient recovery of activities and/or length of hospital stay. The four a-priori patient profiles matched the identified patient profiles in our analysis and seemed to be verifiable, valid, and relevant within our study populations. Patients who are classified as Frail were likely to have a prolonged LoS (mean 5 days) and inpatient recovery of activities (mean 5 days), patients in the Fit profile tend to have the shortest LoS (mean 4 days) and inpatient recovery of activities (mean 4 days). Internal and external validation of the patient profiles confirmed quite similar results. To our knowledge, this is the first study to describe patient profiles related to the short-term outcomes LoS and recovery of activities in patients after THA. These patient profiles provide highly relevant information for patients and healthcare professionals to transform the clinical pathways to a yet more personalized approach, resulting in more efficient use of resources and faster recovery rates.

No patient profiles or phenotypes, described in the current literature for patients after THA, focused on early recovery as inpatient recovery of activities or LoS. Phenotypes or patient profiles 
reported in the literature describe the group differences during the conservative phase. Those patient profiles or phenotypes consists of the ICF category functions (radiographic, bone tissue, hormones, muscle strength) and personal factors (age, BMI) $[1,8,15,17,18,20]$ even though patients performance (ICF activities) is a significant predictor of functional recovery in patients after THA [4]. The inclusion of patient performance may result in patient profiles, which can better differentiate between short and long-term outcomes.

Although the TUG and the 6MWT had a high negative correlation of -0.77 , we decided that both functional tests were relevant within the patient profiles. The TUG gives the patient and healthcare professional a quick insight into functional abilities transfers, walking, and turning reflecting the more indoor-related functional capabilities. In contrast, the 6MWT measures the walking capacity, which reflects the more outdoor functional capabilities.

In all three datasets is a small, consistent group of Frail patients (1-3\%) with high comorbidity and low preoperative functional performance levels. The LoS differs between the two hospitals (dataset $1 a-b$ vs. dataset 2) from 5.5 to 4 days, whereas the recovery of activities is equally distributed, most likely due to the small sample size of dataset $2(n=271)$. Based on the small proportion of patients, one can argue if we should combine the patient profiles Frail and Comorbid to form a group of patients at risk for prolonged recovery. We opt to keep the Frail patient profile because of its consistency in the LCA and its deviant postoperative recovery. Additionally, based on these two profile-checks, characteristics, and consequent results of our statistics, these two "types of patient-profiles" might be better off with different types of (clinical) patient-professional insights and, consequently, other schedules of interventions.

Patient groups with the same medical diagnosis and surgical intervention are heterogeneous in baseline characteristics and functional performance patterns. The ability to assign patients to different patient profiles, with their unique preoperative characteristics and postoperative outcome, provides the healthcare professionals evidence to optimize their personalization in the care pathways to the different patient profiles [3]. Patients within the Fit patient profile recover faster after surgery and might not need the same perioperative health-related resources as Frail patients. This could lead to a shift in individually targeted physical therapy involvement for patients classified as Fit and those classified as Frail. For the former, a more general inpatient approach of activation by specific organization of the (orthopedic) wards infrastructure and culture might be sufficient, as advocated by Hulzebos and Van Meeteren in 2016 [13]. Whereas superimposed targeted supervised exercise training, preferably in the ward's context, seems necessary for the latter patients. Likewise, information regarding patient profiles could also be used during the 
shared decision-making process for the possibility of a preoperative intervention to increase physical functioning for patients with low physical performance.

The study results have implications for future research. First, it would be interesting and even plausible if patient profiles change over time, for instance, postoperative, during hospital stay, and afterward in a profile specific or personalized manner. Second, this study focused on patients awaiting THA, it would be of interest if (the same) patient profiles could be identified for other joint replacement surgeries such as total knee replacement. Third, additional characteristics affecting recovery (e.g. cognitive function, mental health [e.g., anxiety and depression], coping styles, social support, and patient expectations) could give a more realistic description of individual patient profiles with differences between qualitative and quantitative indicators of recovery of (physical) function.

This study has some limitations: (1) the data used for the external validation originated from 20092010; (2) both postoperative clinical care pathways were before the introduction of FastTrack [16] where patients were mobilized on the day of surgery. The absence of FastTrack principles within the clinical care pathways could influence the outcomes and should be kept in mind; (3) only a subgroup of Dutch physical therapy experts within the field of total hip and knee arthroplasty were consulted to from the a-priori patient profiles, which might have influenced our results; and (4) it is evident that only a limited number of variables were included in the build of these patient profiles, and, as always, many other candidate variables remain. Nevertheless, the six variables explored here can still distinguish preoperative and postoperative clinical relevant differences and may help further personalize physical therapy strategies for recovery of functioning of these patients. The strengths of the study are: (1) the data originated from regular care; (2) the dataset covers a broad timeline (2010-2015) with multiple changes in care pathways (e.g., changes in pain medication, introduction of the MILAS for assessing the recovery of activities) which might have positively influenced the robustness of the results; (3) the a-priori patient profiles were formed by consensus among three highly experienced physical therapists from three different hospitals. The consensus of three physical therapists working in different hospitals reduced bias during the draft of the different patient profiles triggered by working in the same environment, with the same care pathways, and within the same culture.

In conclusion, groups of patients awaiting THA can be divided into four patient profiles (Frail, Comorbid, Pain, and Fit), each with its specific preoperative characteristics and postoperative outcomes. The patient profiles seem stable, valid, and clinically relevant in LoS and inpatient recovery of activities. 


\section{REFERENCES}

1. Kurtz SM, Ong KL, Lau E, Bozic KJ. Impact of the economic downturn on total joint replacement demand in the United States: Updated projections to 2021. J Bone Jt Surg Am Vol 2014.

2. Berry DJ, Harmsen WS, Cabanela ME, Morrey BF. Twenty-five-year survivorship of two thousand consecutive primary Charnley total hip replacements: factors affecting survivorship of acetabular and femoral components. J Bone Joint Surg Am 2002;84A:171-7.

3. Jones CA, Voaklander DC, Johnston DW, Suarez-Almazor ME. Health related quality of life outcomes after total hip and knee arthroplasties in a community based population. J Rheumatol 2000;27:1745-52.

4. Hawker GA, Badley EM, Borkhoff CM, Croxford R, Davis AM, Dunn S, et al. Which Patients Are Most Likely to Benefit From Total Joint Arthroplasty? Arthritis Rheum 2013;65:1243-52.

5. van der Sluis G, Jager J, Punt IM, Goldbohm RA, Faber M, Bimmel R, et al. Challenges for development of shared decision making before and after total knee replacement surgery: a scoping review. Submitted n.d.

6. Lungu E, Maftoon S, Vendittoli P-A, Desmeules F. A systematic review of preoperative determinants of patient-reported pain and physical function up to 2 years following primary unilateral total hip arthroplasty. Orthop Traumatol Surg Res 2016;102:397-403.

7. Elings J, Van Der Sluis G, Goldbohm RA, Garre FG, De Gast A, Hoogeboom T, et al. Development of a risk stratification model for delayed inpatient recovery of physical activities in patients undergoing total hip replacement. J Orthop Sports Phys Ther 2016;46.

8. Heiberg KE, Ekeland A, Bruun-Olsen V, Mengshoel AM. Recovery and prediction of physical functioning outcomes during the first year after total hip arthroplasty. Arch Phys Med Rehabil 2013;94:1352-9.
9. Hofstede SN, Gademan MGJ, Vliet Vlieland TPM, Nelissen RGHH, Marang-van de Mheen PJ. Preoperative predictors for outcomes after total hip replacement in patients with osteoarthritis: a systematic review. BMC Musculoskelet Disord 2016;17:212.

10. Santaguida PL, Hawker GA, Hudak PL, Glazier R, Mahomed NN, Kreder HJ, et al. Patient characteristics affecting the prognosis of total hip and knee joint arthroplasty: a systematic review. Can J Surg 2008;51:428-36.

11. Thorstensson CA, Gooberman-Hill R, Adamson J, Williams S, Dieppe P. Helpseeking behaviour among people living with chronic hip or knee pain in the community. BMC Musculoskelet Disord 2009;10:153.

12. Elings J, van der Sluis G, Goldbohm R, Galindo Garre F, de Gast A, Hoogeboom T, et al. Development of a risk stratification model for delayed inpatient recovery of physical activities in patients undergoing total hip replacement. J Othopedic Sport Phys Ther 2015.

13. Knoop J, van der Leeden $\mathrm{M}$, Thorstensson CA, Roorda LD, Lems WF, Knol DL, et al. Identification of phenotypes with different clinical outcomes in knee osteoarthritis: data from the Osteoarthritis Initiative. Arthritis Care Res (Hoboken) 2011;63:1535-42.

14. Kittelson AJ, Stevens-Lapsley JE, Schmiege SJ. Determination of Pain Phenotypes in Knee Osteoarthritis: A Latent Class Analysis Using Data From the Osteoarthritis Initiative. Arthritis Care Res (Hoboken) 2016;68:612-20.

15. Elings J, Hoogeboom TJ, Van Der Sluis G, Van Meeteren N. What preoperative patient-related factors predict inpatient recovery of physical functioning and length of stay after total hip arthroplasty? A systematic review. Clin Rehabil 2015;29.

16. Elings J, Zoethout S, ten Klooster PM, van der Sluis G, van Gaalen SM, van Meeteren NLU, et al. Advocacy for use of the modified lowa Level of Assistance Scale for clinical use in patients after hip replacement: an observational study. Physiotherapy 2018. 
17. Nylund KL, Asparouhov T, Muthén BO. Deciding on the Number of Classes in Latent Class Analysis and Growth Mixture Modeling: A Monte Carlo Simulation Study. Struct Equ Model 2007;14:535-69.

18. Mukaka MM. Statistics corner: A guide to appropriate use of correlation coefficient in medical research. Malawi Med J 2012;24:6971.
19. Holmes Finch W, Cotton Bronk K. Structural Equation Modeling: A Multidisciplinary Journal Conducting Confirmatory Latent Class Analysis Using Mplus Conducting Confirmatory Latent Class Analysis Using Mplus. Struct Equ Model A Multidiscip J Struct Equ Model 2011;18. 


\section{APPENDIX 3.1. ADDITIONAL INFORMATION OF THE PREOPERATIVE PATIENT VARIABLES.}

Functional mobility was assessed with the Timed Up-and-Go test (TUG). The test measures the time (seconds) needed to rise from an armchair, walk $3 \mathrm{~m}$, turn, walk back, and sit down on the chair again. A low score on the TUG-test indicates a high functional mobility. This test has been found reliable and valid for quantifying functional mobility in frail older people [1]. Besides, patients were twice as likely to stay in hospital beyond 48 hours for every five second increase in TUG times $(\mathrm{OR}=2.02,95 \%$ confidence interval $[\mathrm{Cl}] 1.02-4.01, P=0.043)$ [2].

Walking capacity was measured using the 6 Minute Walking Test (6MWT), for which each individual had to walk as far as they could in a time period of 6 minutes, without running or jogging [3]. At the end of the test, the distance walked is defined in meters. This standardized test was executed over a trajectory of 10 meters. A higher distance on the 6MWT indicates a better physical status. The 6MWT is a reliable measurement tool $(R=0.94$, SEM 26.29, and $\left.\mathrm{MDC}_{90}=61.34\right)$ to measure functional walking capacity for patients before and after total hip- or knee arthroplasty [4].

Pain was assessed by scoring the participant's pain perceptions in the last 24 hours. This score was measured on a 0-100 VAS scale (reliability is good (ICC 0.97)[5]). Research by Halawi et al. found a significant relation between the preoperative level of pain and the LoS [6] in which higher pain levels correlated with a longer LoS.

BMI was calculated by dividing a person's weight in kilograms by the square of its length in meters $\left(\mathrm{kg} / \mathrm{m}^{2}\right)$. Research showed that every five-unit increase in BMI greater than $30 \mathrm{~kg} / \mathrm{m}^{2}$ was associated with an average of 0.16 more days in the hospital for people undergoing a primary THA procedure [7].

Medical status was assessed using the American Society of Anesthesiologists classification by the anesthesiologist. This classification consists of six different statuses. For this research only ASA I to ASA IV were used because participants classified as ASA V or ASA VI are not eligible for THA at the Diakonessenhuis Hospital. ASA I is a healthy person, ASA II is a person with mild systemic disease, ASA III is a person with severe systemic disease and ASA IV is a person with severe systemic disease that is a constant threat to life [8]. A higher ASA score is associated with a longer LoS (OR 3.34) [9], [10].

Comorbidity was assessed using the Charnley classification by the physical therapist. This classification provides information on the influence of comorbidity on physical functioning. The 
subject can be classified into three classes: "A" unilateral hip involvement and no other condition interferes with walking; "B" bilateral hip involvement and no other condition interferes with walking; and "C" uni- or bilateral hip involvement with some additions factors contributing to failure to achieve normal locomotion [11]. The Charnley score was found to be the highest contributing factor in a risk stratification model for predicting LoS after THA [12].

\section{REFERENCES}

1. D. Podsiadlo and S. Richardson, "The timed \&quot;Up \&amp; Go\&quot;: a test of basic functional mobility for frail elderly persons.," J. Am. Geriatr. Soc., vol. 39, no. 2, pp. 142-8, Feb. 1991.

2. S. M. Petis, J. L. Howard, B. A. Lanting, L. E. Somerville, and E. M. Vasarhelyi,

"Perioperative Predictors of Length of Stay After Total Hip Arthroplasty," J. Arthroplasty, vol. 31, no. 7, pp. 1427-1430, 2016.

3. J. Hassan, J. Van Der Net, P. J. M. Helders, B. J. Prakken, and T. Takken, "Six-minute walk test in children with chronic conditions," Br. J. Sports Med., vol. 44, no. 4, pp. 270-274, Mar. 2010.

4. D. M. Kennedy, P. W. Stratford, J. Wessel, J. D. Gollish, and D. Penney, "Assessing stability and change of four performance measures: a longitudinal study evaluating outcome following total hip and knee arthroplasty.," BMC Musculoskelet. Disord., vol. 6, p. 3, Jan. 2005.

5. E. J. Gallagher, P. E. Bijur, C. Latimer, and W. Silver, "Reliability and validity of a visual analog scale for acute abdominal pain in the ED," $\mathrm{Am}$. J. Emerg. Med., vol. 20, no. 4, pp. 287-290, 2002.

6. M. J. Halawi, T. J. Vovos, C. L. Green, S. S. Wellman, D. E. Attarian, and M. P. Bolognesi, "Preoperative pain level and patient expectation predict hospital length of stay after total hip arthroplasty.," J. Arthroplasty, vol. 30, no. 4, pp. 555-8, Apr. 2015.
7. H. Maradit Kremers, S. L. Visscher, W. K. Kremers, J. M. Naessens, and D. G. Lewallen, "Obesity increases length of stay and direct medical costs in total hip arthroplasty.," Clin. Orthop. Relat. Res., vol. 472, no. 4, pp. 12329, Apr. 2014.

8. A. S. of Anesthesiologists, "ASA Physical Status Classification System," October 15, 2014, 2014. .

9. J. Foote, K. Panchoo, P. Blair, and G. Bannister, "Length of stay following primary total hip replacement.," Ann. R. Coll. Surg. Engl., vol. 91, no. 6, pp. 500-4, Sep. 2009.

10. J. Elings, T. J. Hoogeboom, G. Van Der Sluis, and N. Van Meeteren, "What preoperative patient-related factors predict inpatient recovery of physical functioning and length of stay after total hip arthroplasty? A systematic review," Clin. Rehabil., vol. 29, no. 5, 2015.

11. J. Charnley, "The long-term results of lowfriction arthroplasty of the hip performed as a primary intervention.," J. Bone Joint Surg. Br., vol. 54, no. 1, pp. 61-76, Feb. 1972.

12. J. Elings et al., "Development of a risk stratification model for delayed inpatient recovery of physical activities in patients undergoing total hip replacement.," J. Othopedic Sport. Phys. Ther., 2015. 
Appendix 3.2. Descriptives of patient profiles on cluster variables dataset $1 \mathrm{~b}$ (internal validation). Data are mean ( $1^{\text {st }}$ quartile $-3^{\text {rd }}$ quartile) unless otherwise indicated.

\begin{tabular}{|c|c|c|c|c|c|c|}
\hline & $\begin{array}{l}\text { Profile } 1 \\
\text { Frail } \\
(n=14 ; 2 \%)\end{array}$ & $\begin{array}{l}\text { Profile } 2 \\
\text { Comorbid } \\
(n=56 ; 6 \%)\end{array}$ & $\begin{array}{l}\text { Profile } 3 \\
\text { Pain } \\
(n=322 ; 35 \%)\end{array}$ & $\begin{array}{l}\text { Profile } 4 \\
\text { Fit } \\
(n=534 ; 57 \%)\end{array}$ & $\begin{array}{l}\text { Kruskal-Wallis } \\
X(2)\end{array}$ & $\begin{array}{l}\text { sign different } \\
\text { classes }\end{array}$ \\
\hline Age $(y)$ & $79(69-82)$ & $82(78-86)$ & $77(71-81)$ & $67(61-74)$ & $218.07^{\dagger}$ & $1-2 ; 1-3 ; 1-4 ; 2-3 ; 3-4$ \\
\hline Female, \% & $11(79)$ & $45(80)$ & $279(87)$ & $331(62)$ & $62.891^{\dagger}$ & $1-2 ; 1-3$ \\
\hline BMI $\left(\mathrm{kg} / \mathrm{m}^{2}\right)$ & $\begin{array}{l}28.6 \\
(24.8-31.6)\end{array}$ & $\begin{array}{l}27.0 \\
(23.7-29.2)\end{array}$ & $\begin{array}{l}27.5 \\
(24.5-31.2)\end{array}$ & $\begin{array}{l}25.6 \\
(23.7-28.4)\end{array}$ & $24.121^{\dagger}$ & $1-2 ; 1-4$ \\
\hline TUG (s) & $\begin{array}{l}47.1 \\
(42.7-60)\end{array}$ & $\begin{array}{l}23.7( \\
22.0-28.8)\end{array}$ & $\begin{array}{l}12.3 \\
(10.5-15.0)\end{array}$ & $\begin{array}{l}7.4 \\
(6.2-8.9)\end{array}$ & $478.51^{\dagger}$ & $1-2 ; 1-3 ; 1-4 ; 2-3 ; 2-4$ \\
\hline 6-MWT (m) & $\begin{array}{l}97 \\
(74-285)\end{array}$ & $\begin{array}{l}151 \\
(120-170)\end{array}$ & $\begin{array}{l}250 \\
(205-292)\end{array}$ & $\begin{array}{l}383 \\
(345-435)\end{array}$ & $441.94^{\dagger}$ & $1-2 ; 1-3 ; 1-4 ; 2-3$ \\
\hline $\begin{array}{l}\text { Pain24- } \\
\text { score }\end{array}$ & $\begin{array}{l}60 \\
(50-80)\end{array}$ & $\begin{array}{l}60 \\
(45-80)\end{array}$ & $\begin{array}{l}70 \\
(50-80)\end{array}$ & $\begin{array}{l}60 \\
(40-70)\end{array}$ & $51.639^{\dagger}$ & $1-2 ; 2-3$ \\
\hline $\begin{array}{l}\text { ASA score, } \\
\%\end{array}$ & & & & & $186.66^{\dagger}$ & $1-2 ; 1-3 ; 1-4$ \\
\hline score 1 & $0(0)$ & $4(8)$ & $11(4)$ & $172(34)$ & & \\
\hline score 2 & $10(71)$ & $27(53)$ & $199(65)$ & 304 (61) & & \\
\hline score 3 & $4(29)$ & $20(39)$ & $89(29)$ & $24(5)$ & & \\
\hline score 4 & $0(0)$ & $0(0)$ & $5(2)$ & $0(0)$ & & \\
\hline Charnley, \% & & & & & $114.03^{\dagger}$ & $1-2 ; 1-3 ; 1-4 ; 2-3$ \\
\hline score A & $5(38)$ & $15(28)$ & $139(52)$ & $344(79)$ & & \\
\hline score B & $3(24)$ & $5(11)$ & $46(18)$ & $69(16)$ & & \\
\hline score C & $5(38)$ & $29(61)$ & $80(30)$ & $24(5)$ & & \\
\hline
\end{tabular}

Abbreviations: $\mathrm{n}=$ number of cases; BMl: Body Mass Index; TUG: Timed Up-and-Go test; 6-MWT: 6 Minute Walking Test; ASA: American Society of Anesthesiologists; ${ }^{\dagger}$ : sign level $<0.0$ 
Appendix 3.3. Descriptives of patient profiles on cluster variables dataset 2 (external validation). Data are mean ( $1^{\text {st }}$ quartile $-3^{\text {rd }}$ quartile) unless otherwise indicated.

\begin{tabular}{|c|c|c|c|c|c|c|}
\hline & $\begin{array}{l}\text { Profile 1 } \\
\text { Frail } \\
(n=9 ; 3 \%)\end{array}$ & $\begin{array}{l}\text { Profile } 2 \\
\text { Comorbid } \\
(n=91 ; 34 \%)\end{array}$ & $\begin{array}{l}\text { Profile 3 } \\
\text { Pain } \\
(n=126 ; 46 \%)\end{array}$ & $\begin{array}{l}\text { Profile 4 } \\
\text { Fit } \\
(n=45 ; 17 \%)\end{array}$ & $\begin{array}{l}\text { Kruskal- } \\
\text { Wallis } \\
X(2)\end{array}$ & $\begin{array}{l}\text { Significant } \\
\text { different } \\
\text { classes }\end{array}$ \\
\hline Age (y) & $84(80-86)$ & $76(71-79)$ & $71(66-76)$ & $59(55-65)$ & $94.32^{\dagger}$ & $1-2 ; 1-3 ; 1-4 ; 2-3 ; 2-4 ; 3-4$ \\
\hline Female, \% & $7(78)$ & $69(76)$ & $83(66)$ & $27(60)$ & 4.5226 & \\
\hline BMI $\left(\mathrm{kg} / \mathrm{m}^{2}\right)$ & $\begin{array}{l}30.1 \\
(26.4-33.2)\end{array}$ & $\begin{array}{l}28.3 \\
(25.9-30.9)\end{array}$ & $\begin{array}{l}27.3 \\
(24.9-29.5)\end{array}$ & $\begin{array}{l}25.7 \\
(23.2-27.4)\end{array}$ & $18.153^{\dagger}$ & $1-2 ; 1-3 ; 1-4 ; 2-3$ \\
\hline TUG (s) & $\begin{array}{l}34.6 \\
(28.8-38.0)\end{array}$ & $\begin{array}{l}15.11 \\
(13.0-17.8)\end{array}$ & $\begin{array}{l}9.3 \\
(7.8-10.5)\end{array}$ & $\begin{array}{l}6.7( \\
5.6-7.8)\end{array}$ & $169.77^{\dagger}$ & $1-2 ; 1-3 ; 1-4 ; 2-3 ; 2-4 ; 3-4$ \\
\hline 6-MWT (m) & $60(50-120)$ & $240(125-300)$ & $375(334-425)$ & $\begin{array}{l}460( \\
420-525)\end{array}$ & $162.11^{\dagger}$ & $1-2 ; 1-3 ; 1-4 ; 2-3 ; 2-4 ; 3-4$ \\
\hline Pain24-score & $\begin{array}{l}71 \\
(56-78)\end{array}$ & $\begin{array}{l}75 \\
(60-84)\end{array}$ & $\begin{array}{l}58 \\
(48-74)\end{array}$ & $\begin{array}{l}56 \\
(38-71)\end{array}$ & $25.173^{\dagger}$ & $1-2 ; 1-4 ; 2-3$ \\
\hline ASA score, $\%$ & & & & & $139.86^{\dagger}$ & $1-2 ; 1-3 ; 1-4 ; 2-3 ; 3-4$ \\
\hline score 1 & $0(0)$ & $4(5)$ & $0(0)$ & $38(90)$ & & \\
\hline score 2 & $5(56)$ & $58(73)$ & $101(98)$ & $4(10)$ & & \\
\hline score 3 & $4(44)$ & $17(22)$ & $2(2)$ & $0(0)$ & & \\
\hline score 4 & $0(0)$ & $0(0)$ & $0(0)$ & $0(0)$ & & \\
\hline Charnley, \% & & & & & $23.525^{\dagger}$ & $1-2 ; 1-3 ; 1-4 ; 2-3$ \\
\hline score A & $0(0)$ & $6(8)$ & $98(78)$ & $40(89)$ & & \\
\hline score B & $3(33)$ & $41(46)$ & $22(17)$ & $4(9)$ & & \\
\hline score C & $6(67)$ & $41(46)$ & 6 (5) & $1(2)$ & & \\
\hline
\end{tabular}

Abbreviations: $n=$ number of cases; BMI: Body Mass Index; TUG: Timed Up-and-Go test; 6-MWT: 6 Minute Walking Test; ASA: American Society of Anesthesiologists; ${ }^{\dagger}$ : sign level $<0.01$ 

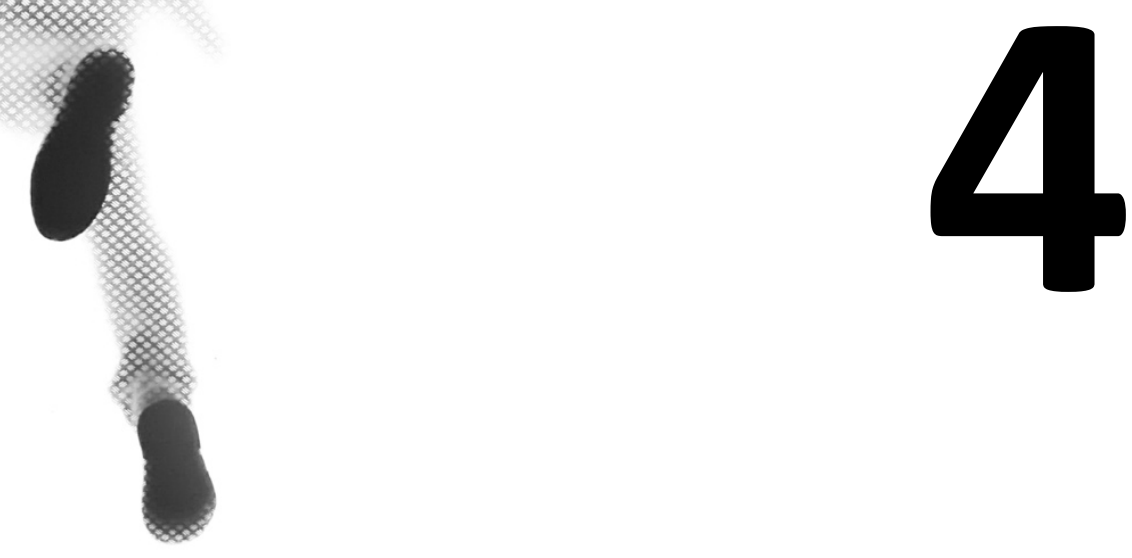

DEVELOPMENT OF A RISK STRATIFICATION MODEL FOR DELAYED INPATIENT RECOVERY OF PHYSICAL ACTIVITIES IN PATIENTS UNDERGOING TOTAL HIP REPLACEMENT.

J. Elings | G. van der Sluis | R.A. Goldbohm | F. Garlindo Garre |

A. de Gast | T.H. Hoogeboom | N.L. van Meeteren 


\section{ABSTRACT}

Study design: Prospective cohort design using data derived from usual care. Background: It is important that patients are able to function independently as soon as possible after total hip replacement. However, the speed of regaining activities differs significantly.

Objecives: To develop a risk stratification model (RSM) to predict delayed inpatient recovery of physical activities in people who underwent total hip replacement surgery.

Methodes: This study was performed in 2 routine orthopaedic settings: Diakonessenhuis Hospital (setting A) and Nij Smellinghe Hospital (setting B). Preoperative screening was performed for all consecutive patients. In-hospital recovery of activities was assessed with the Modified lowa Level of Assistance Scale. Delayed inpatient recovery of activities was defined as greater than 5 days. The RSM, developed using logistic regression analysis and bootstrapping, was based on data from setting $A(n=154)$. External validation was performed on the data set from setting $B(n=$ 271).

Results: Twenty-one percent of the patients in setting A had a delayed recovery of activities during their hospital stay. Multivariable logistic regression modeling yielded a preliminary RSM that included the following factors: male sex (odds ratio $[\mathrm{OR}]=0.8 ; 95 \%$ confidence interval $[\mathrm{Cl}]$ : $0.2,2.6), 70$ or more years of age ( $\mathrm{OR}=1.2 ; 95 \% \mathrm{Cl}: 0.4,3.4)$, body mass index of $25 \mathrm{~kg} / \mathrm{m}^{2}$ or greater $(\mathrm{OR}=2.2 ; 95 \% \mathrm{Cl}: 0.7,7.4)$, an American Society of Anesthesiologists score of $3(\mathrm{OR}=$ 1.2; $95 \% \mathrm{Cl}: 0.3,4.4)$, a Charnley score of $\mathrm{B}$ or $\mathrm{C}(\mathrm{OR}=6.1 ; 95 \% \mathrm{Cl}: 2.2,17.4)$, and a timed up-and-go score of 12.5 seconds or greater $(\mathrm{OR}=3.1 ; 95 \% \mathrm{Cl}: 1.1,9.0)$. The area under the receiver operating characteristic (ROC) curve was $0.82(95 \% \mathrm{Cl}: 0.74,0.90)$ and the HosmerLemeshow test score was 3.57 (P>.05). External validation yielded an area under the ROC curve of 0.71 (95\% Cl: $0.61,0.81)$. CONCLUSION: We demonstrated that the risk for delayed recovery of activities during the hospital stay can be predicted by using preoperative data. 


\section{INTRODUCTION}

In the next 2 decades, the number of total hip replacements (THRs) will rise considerably [1]. Efficient use of resources is key to coping with this rise. A straightforward way to save costs is to reduce the length of hospital stay and increase the number of people discharged home after THR. To do so, it is important that people can function independently as soon as possible, as the inability to do so is associated with prolonged length of hospital stay and an increased rate of discharge to chronic care facilities [2].

Through preoperative identification of patients at risk for delayed inpatient recovery of activities, health care professionals may be able to adjust and optimize functional recovery and discharge planning for these vulnerable individuals. To our knowledge, there is no available preoperative screening instrument to predict delayed inpatient recovery of activities after THR. The current literature mainly comprises studies that assess the predictive value of individual variables in the International Classification of Functioning, Disability and Health (ICF) domain "personal factors."[3] Ideally, one would combine these individual predictors into a single model, augmented with relevant self-reported and performance-based variables from each ICF domain [2-4], to serve as a risk stratification model (RSM) [5].

Therefore, the aim of our study was to develop a clinically feasible RSM that identifies people with a low or high risk for delayed inpatient recovery of activities after THR [3] by combining literature based variables with relevant indices from each domain of the ICF.

\section{METHODS}

This prospective, observational study consisted of 2 parts: (1) development of a preliminary RSM with data from Diakonessenhuis Hospital in Utrecht, the Netherlands (data set A), and (2) external validation of the RSM with data from Nij Smellinghe Hospital in Drachten, the Netherlands (data set B). Data collection at both sites was performed in the routine care setting for people undergoing THR. An anesthesiologist, a physical therapist, and a nurse assessed the surgical risk and preoperative functional status of each patient placed on the waiting list for a primary THR. During their hospital stays, we monitored recovery of activities, length of hospital stay, and complications. 
We only used data from regular patient files. According to Dutch law, research with anonymized regular care data does not require approval from a medical ethical committee (confirmed by the local ethical committee, reference 131211) and is subject to a general opt-out procedure by the hospital. This study is reported in accordance with the STROBE statement [6].

\section{OUTCOME VARIABLE}

The duration (days) of inpatient recovery of activities was assessed with the Modified lowa Level of Assistance Scale (MILAS). The MILAS assesses the assistance necessary to safely perform 5 activities of daily living (ie, supine-to-sit, sit-to-supine, sit-to-stand, walking, and stair climbing). Each of these activities was scored daily on an ordinal scale ranging from 0 to 6 with the following response categories: 0 (independent; 1, standby/supervision; 2, 1 point of contact; 3, 2 points of contact; 4,3 or more points of contact; 5 , failed with maximal assistance; 6 , not tested due to medical reasons or for reasons of safety) [7].

Stair climbing was not a standard assessment for all patients, but only for those who were required to climb stairs at their discharge destination. To avoid loss of statistical power due to separating groups of stair climbers and non-stair climbers, we excluded stair climbing from our outcome measure.

This exclusion resulted in a sum score range for the MILAS of 0 to 24 points. A sum score of 1 or less on the MILAS suggests that a patient may be able to function safely at home. We recorded the number of postoperative days necessary to achieve this sum score, then divided the patients into 2 groups: patients who reached functional independence within 5 days (timely recovery) and those who reached functional independence in more than 5 days (delayed recovery). Five days was chosen as the cutoff because it is the typical period for clinical pathways like "rapid recovery."[8]

All physical therapists $(n=11)$ had relevant work experience in a hospital setting. They had worked in this setting for 2 to 33 years (median, 10 years) and, prior to the introduction of functional screening into the care pathway, were trained to assess the MILAS in a standardized and uniform way. Further details about the MILAS can be found in the Appendix 4.1.

\section{PReDictor VARIABLES}

We collected the following preoperative predictor variables: age (less than 70 years or 70 years or greater) [9]; body mass index (BMI) (less than $25 \mathrm{~kg} / \mathrm{m}^{2}, 25-30 \mathrm{~kg} / \mathrm{m}^{2}$, or $30 \mathrm{~kg} / \mathrm{m}^{2}$ or greater); 
American Society of Anesthesiologists (ASA) score (1 to 2 or 3 and higher, with a higher score indicating less fitness for surgery) [10]; Charnley score (a score of $A$ or $B$ or $C$ to indicate the function of the hip with regard to the ability to walk, with $A$ being more favorable than $C$ ) [11]; the Western Ontario and McMaster Universities Osteoarthritis Index (WOMAC) score (to assess pain, stiffness, and activities of daily living, with ranges of $0-20,0-6$, and $0-68$, respectively, a higher score indicating more perceived discomfort or dysfunction) [12]; the numeric rating scale for pain (0 to 10, with a higher score indicating more pain) [13]; and estimated walking capacity (minutes) [14].

We also collected performance-based functional activities. These included the six-minute walk test ([distance in meters] to assesses walking capacity, with a higher score indicating a better walking capacity) [15], chair-rise time ([in seconds] to assess functional lower-leg power, with a lower score indicating better muscle power) [16], a handheld dynamometer ([in Newton-meters] to assess quadriceps muscle strength, with a higher score indicating better muscle strength) [17], and the timed up-and-go (TUG) test ([in seconds] to assess functional mobility, with a lower score indicating better functional mobility) [18]. Further details about these measurements can be found in the Appendix 4.1.

\section{Clinical Care Pathway}

The surgical approach was similar for all patients (straight lateral or posterolateral). In the majority of cases, hip replacement surgery was performed without the use of cement; however, the postoperative clinical pathway was identical regardless of the procedure.

Physical therapy started 1 day after surgery. The patients received one 20 to 30-minute therapy session per day that consisted of (1) bed exercises to regain muscle power and strength, avoid inactivity, and prevent deep vein thrombosis; (2) muscle exercises in sitting and standing positions to regain muscle power and strength; and (3) practicing transfers (into and out of bed, walking indoors) to achieve functional independence [19]. Patients were discharged from the hospital when (1) there was no further need for medical treatment, (2) their MILAS score was 1 or less, and (3) necessary care was arranged at the discharge destination.

\section{StATISTical AnAlysis}

We used data set A to develop the RSM. We first tested all individual variables for multicollinearity (variance inflation factor, less than 10) [20]. Consequently, we used receiver operating 
characteristic (ROC) curves to dichotomize each of the performance-based variables at the visually optimal sensitivity and specificity cutoffs related to inpatient recovery of activities [21].

Logistic regression modeling was used to compose the preliminary prediction model. First, we included age, sex, BMI, and ASA score in the logistic regression analysis (enter method), as these variables were established predictors based on the literature [3]. We then used backward deletion (stepwise multivariable backward method) of the remaining variables in 2 blocks, under the premise that their univariate correlation with inpatient recovery of activities was $\rho<0.20$. Block 1 consisted of conventional medical indices and block 2 consisted of performance-based measures. The final model, therefore, consisted of the base model plus (conventional indices plus performance tests).

The remaining, independent predictors were then weighted by their regression coefficients relative to the weakest predictor. The cutoff point for the RSM was set at a point where both sensitivity and specificity were relatively high. Moreover, we determined the area under the ROC curve (AUC) and the HosmerLemeshow statistic. The AUC represents the sensitivity and specificity of the test, with higher values representing more sensitivity and specificity on each part of the RSM.

Finally, we used bootstrap validation to account for possible data overfitting produced by generating and testing a logistic regression model with the same data set. Five hundred bootstrap samples generated through replacement were used to estimate the model performance if the selected model was applied to a different sample from the same data set.

When the AUC of the RSM was high (greater than 0.80 [22]), we conducted an external validation, using the data collected at the Nij Smellinghe Hospital (setting B) to fit the original RSM. We recalculated the AUC statistic for these data to determine the predictive value of the RSM. All statistics were performed using Stata Version 12 (StataCorp LP, College Station, TX).

\section{RESULTS}

\section{Development of the Prediction Rule (Data Set A)}

The medical files of 224 consecutive patients were included in the study. Each patient attended a preoperative assessment by the physical therapist. Of the 224 patients, 70 were lost to followup, as their medical files could not be retrieved due to the transition from a paper-based to a 
digital filing system. In general, the patients lost to follow-up were not clinically different from those included in the study (Table 4.1).

Data from 154 patients were analyzed. The majority of patients were female (70\%), with a mean $\pm \mathrm{SD}$ age of $70.8 \pm 9.2$ years and $\mathrm{BMI}$ of $27.1 \pm 4.4 \mathrm{~kg} / \mathrm{m}^{2}$. More detailed information about the study population is presented in Table 4.1. Seventeen postoperative complications that might have affected the inpatient recovery of activities were reported, fissure of the femur $(n=6,3.9 \%)$ being the most commonly reported (Table 4.2).

Univariate association with delayed inpatient recovery of activities demonstrated that the WOMAC stiffness score, Charnley score, chair-rise time, handheld dynamometer, TUG, and sixminute walk test were all associated with delayed functional recovery. Variables such as hip flexion, estimated walking time, pain, WOMAC pain score, and WOMAC physical function score were not related to delayed inpatient recovery of activities $(\rho>0.20)$.

Multivariable logistic regression with the forced literature-based variables (ie, sex, age, BMI, and ASA score) yielded a base model with an AUC of $0.68(95 \% \mathrm{Cl}: 0.58,0.78)$. Adding the dichotomized TUG and the Charnley score to the base model increased the AUC to 0.82 (95\% Cl: $0.74,0.90)$ (Table 4.3), with a HosmerLemeshow goodness-of-fit test score of $3.57(P=.89)$.

The final prediction model consisted of 6 dichotomous variables: sex (odds ratio $[O R]=0.8 ; 95 \%$ confidence interval $[\mathrm{Cl}]: 0.2,2.6)$, age $(\mathrm{OR}=1.2 ; 95 \% \mathrm{Cl}: 0.4,3.4)$, $\mathrm{BMI}(\mathrm{OR}=2.2 ; 95 \% \mathrm{Cl}$ : 0.7 , 7.4), ASA score (OR = 1.2; 95\% Cl: 0.3, 4.4), Charnley score (OR $=6.1 ; 95 \% \mathrm{Cl}: 2.2,17.4)$, and TUG (OR $=3.1 ; 95 \% \mathrm{Cl}: 1.1,9.0)$. The bootstrap yielded an adjusted AUC that was 0.04 lower than the original $\mathrm{AUC}(0.78 ; 95 \% \mathrm{Cl}: 0.67,0.88$ and $0.82 ; 95 \% \mathrm{Cl}: 0.74,0.90$, respectively).

To create a simple scoring system, points were assigned to the high-risk category of each predictor and summed (Table 4.4). The curve based on the sum scores of the 6 predictors completely overlapped the curve based on the original regression coefficients. We chose a sum score of 14.5 , with $68 \%$ sensitivity and $81 \%$ specificity, as the optimal cutoff for distinguishing patients at high risk for delayed inpatient recovery of activities from those with normal recovery (Figure 4.1).

Nineteen of the 40 patients (48\%) with a predicted high risk of delayed inpatient recovery of activities experienced a postoperative inpatient recovery-of-activities time of more than 5 days, in contrast to 9 of 99 patients (9\%) with a predicted normal inpatient recovery-of-activities time (Table 4.5). 
84 | Chapter 4

Table 4.1. Characteristics of patients with total hip replacement at intake before surgery.

\begin{tabular}{|c|c|c|c|c|c|c|}
\hline \multirow[b]{2}{*}{ Characteristic } & \multicolumn{2}{|c|}{$\begin{array}{l}\text { Diakonessenhuis } \\
\text { Hospital }(n=154)\end{array}$} & \multicolumn{2}{|c|}{$\begin{array}{c}\text { Nij Smellinghe } \\
(n=271)\end{array}$} & \multicolumn{2}{|c|}{$\begin{array}{c}\text { lost to follow-up } \\
(n=70)\end{array}$} \\
\hline & $\mathrm{n}$ & value $^{*}$ & $\mathrm{n}$ & value $^{*}$ & $\mathrm{n}$ & value $^{*}$ \\
\hline Age, y & 154 & $70.8 \pm 9.2$ & 271 & $70.4 \pm 8.9$ & 70 & $72.6 \pm 8.9$ \\
\hline \multicolumn{7}{|l|}{$\operatorname{Sex}^{\dagger}$} \\
\hline Male & 46 & 29.9 & 85 & 31.4 & 19 & 28.0 \\
\hline Female & 108 & 70.1 & 186 & 68.6 & 49 & 72.0 \\
\hline BMI, $\mathrm{kg} / \mathrm{m} 2$ & 151 & $27.1 \pm 4.4$ & 268 & $27.7 \pm 4.3$ & 55 & $26.9 \pm 4.6$ \\
\hline Hip flexion, deg & 136 & $85.6 \pm 22.9$ & & & 45 & $84.3 \pm 17.7$ \\
\hline Pain (0-100) & 147 & $51.7 \pm 20.4$ & & & 70 & $45.1 \pm 20.8$ \\
\hline Walking time, min & 147 & $18.7 \pm 16.6$ & & & 70 & $21.2 \pm 21.2$ \\
\hline MILAS (0-30) & 136 & $0.9 \pm 2.1$ & & & 70 & $0.4 \pm 1.6$ \\
\hline WOMAC pain (0-20) & 95 & $12.8 \pm 4.4$ & 255 & $11.9 \pm 4.3$ & 43 & $12.1 \pm 4.0$ \\
\hline WOMAC stiffness (0-8) & 95 & $4.9 \pm 1.6$ & 254 & $4.3 \pm 1.7$ & 43 & $4.2 \pm 1.7$ \\
\hline WOMAC PF (0-68) & 94 & $48.6 \pm 14.2$ & 246 & $42.9 \pm 13.4$ & 43 & $46.1 \pm 13.7$ \\
\hline Chair-rise time, s & 137 & $40.4 \pm 33.7$ & 239 & $38.2 \pm 18.2$ & 67 & $31.8 \pm 15.9$ \\
\hline Quadriceps strength, Nm & 126 & $185.0 \pm 73.2$ & & & 66 & $188.9 \pm 67.3$ \\
\hline Timed up-and-go test, s & 143 & $12.1 \pm 8.2$ & 259 & $11.7 \pm 6.3$ & 70 & $11.8 \pm 9.2$ \\
\hline Six-minute walk test, $\mathrm{m}$ & 140 & $\begin{array}{l}315.8 \\
\pm 116.6\end{array}$ & 259 & $\begin{array}{l}336.0 \\
\pm 129.0\end{array}$ & 70 & $302.0 \pm 128.6$ \\
\hline \multicolumn{7}{|l|}{ ASA score $^{\dagger}$} \\
\hline 1 & 30 & 19.7 & 42 & 18.0 & 38 & 62.3 \\
\hline 2 & 101 & 66.5 & 168 & 72.1 & 8 & 13.1 \\
\hline 3 & 21 & 13.8 & 23 & 9.9 & 15 & 24.6 \\
\hline \multicolumn{7}{|l|}{ Bilateral problems ${ }^{\dagger}$} \\
\hline Yes & 38 & 24.7 & 141 & 52.6 & 15 & 50.0 \\
\hline No & 116 & 75.3 & 127 & 47.4 & 15 & 50.0 \\
\hline \multicolumn{7}{|l|}{ Charnley score $^{\dagger}$} \\
\hline A & 96 & 62.3 & 144 & 53.7 & 14 & 25.9 \\
\hline B & 30 & 19.5 & 70 & 26.1 & 36 & 66.7 \\
\hline C & 28 & 18.2 & 54 & 20.2 & 4 & 7.4 \\
\hline \multicolumn{7}{|l|}{ Use of preoperative care ${ }^{\dagger}$} \\
\hline Yes & 51 & 33.1 & & & 23 & 32.9 \\
\hline No & 103 & 66.9 & & & 47 & 67.1 \\
\hline
\end{tabular}


Table 4.1. (Continued)

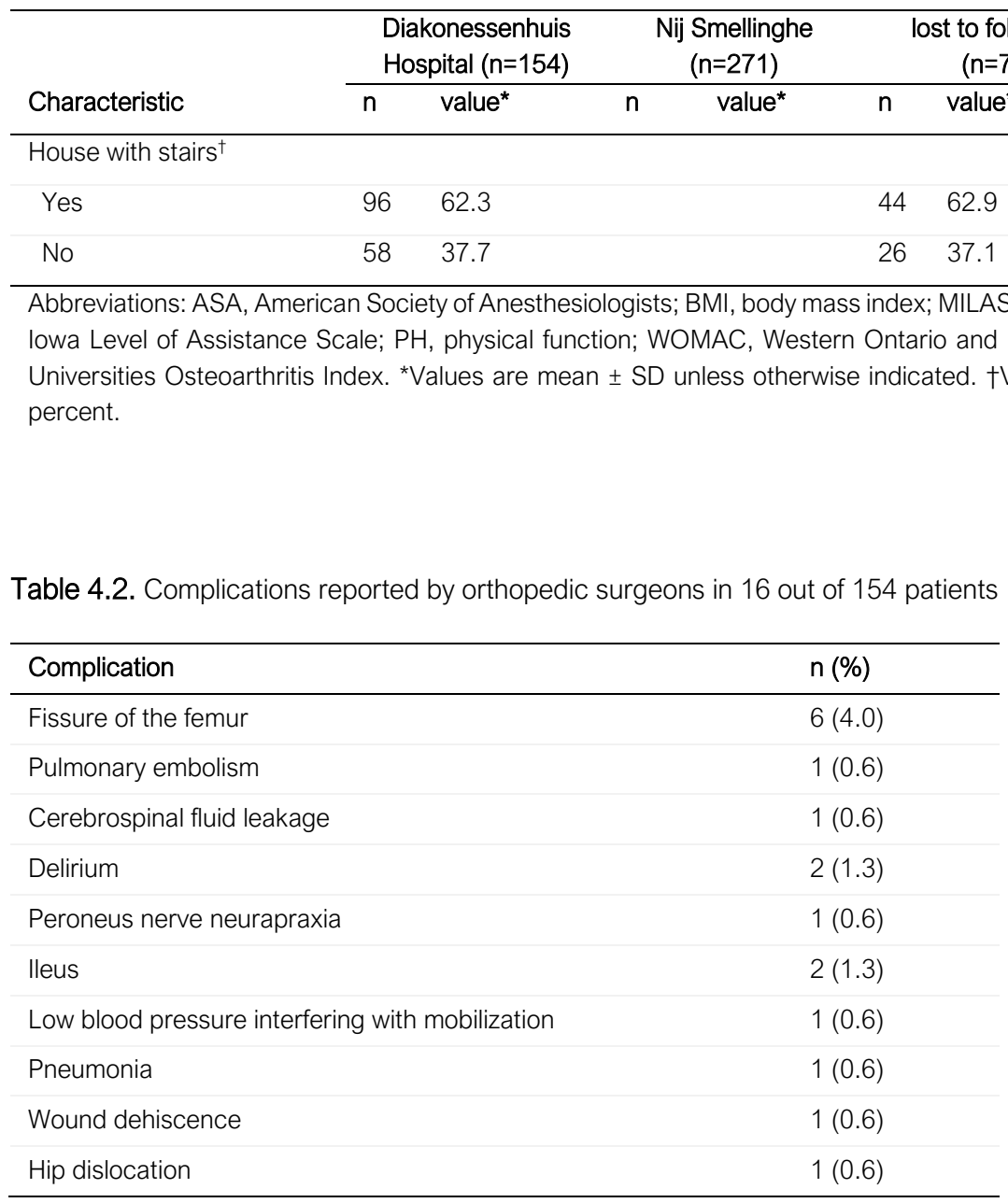


Table 4.3. Predictors of delayed functional recovery ( $>5$ days) after total hip replacement (logistic regression)*

\begin{tabular}{|c|c|c|c|c|}
\hline Independent variables & $\mathrm{n}$ & Odds ratio $^{\dagger}$ & AUC & $\begin{array}{r}\text { AUC change } \\
\text { from base } \\
\text { model }\end{array}$ \\
\hline Base model & 150 & & .68 & \\
\hline Sex (female vs. male) & & $0.61(0.21-1.74)$ & & \\
\hline Age ( $\geq 70$ vs. $<70$ years) & & $1.74(0.71-4.27)$ & & \\
\hline BMI $\left(\geq 25 \mathrm{~kg} / \mathrm{m}^{2} \mathrm{vs} .<25 \mathrm{~kg} / \mathrm{m}^{2}\right)$ & & $2.56(0.88-7.45)$ & & \\
\hline ASA (1/2 vs. 3) & & $2.71(0.96-7.69)$ & & \\
\hline Base model plus & 140 & & .82 & $.15^{\ddagger}$ \\
\hline Charnley score $(B \text { or } C \text { versus } A)^{\S}$ & & $6.12(2.15-17.4)$ & & \\
\hline Timed up and go $(\geq 12.5 \text { versus }<12.5 \mathrm{~s})^{\S}$ & & $\begin{array}{l}3.15(1.10- \\
8.96)\end{array}$ & & \\
\hline \multicolumn{5}{|c|}{$\begin{array}{l}\text { Abbreviations: ASA, American Society of Anesthesiologists; AUC, area under the curve; BMI, body } \\
\text { mass index. } \\
\text { *Patients were dropped from the analyses if no data were present for the item included in the } \\
\text { regression analyses, }{ }^{\vee} \text { Values in parentheses are } 95 \% \text { confidence interval, }{ }^{\ddagger} \mathrm{P}<.05,{ }^{\text {SEach individual }} \\
\text { functional test was added together with the Charnley score to the base model, with listwise deletion } \\
\text { of subjects with missing tests. }\end{array}$} \\
\hline
\end{tabular}

Table 4.4. Factor point distribution for the final model for prediction of clinical postoperative recovery.

\begin{tabular}{|c|c|}
\hline Risk factor & Points* \\
\hline Sex (male) & 1.0 \\
\hline Age ( $\geq 70$ y) & 1.0 \\
\hline $\mathrm{BMI}(\geq 25 \mathrm{~kg} / \mathrm{m} 2)$ & 4.5 \\
\hline ASA score (3) & 1.0 \\
\hline Charnley score (B or C) & 10.0 \\
\hline Timed up-and-go test ( $\geq 12.5 \mathrm{~s}$ ) & 6.5 \\
\hline
\end{tabular}


Table 4.5. Classification of predicted functional recovery time by actual recovery time*

\begin{tabular}{llcl}
\hline \multirow{2}{*}{ Predicted by CPR } & \multicolumn{2}{c}{ Actual } & \\
\cline { 2 - 3 } & $>5$ days & \multicolumn{2}{c}{ Total } \\
\hline$>5$ days & 19 & 21 & 40 \\
$\leq 5$ days & 9 & 90 & 99 \\
Total & 28 & 111 & 139 \\
\hline
\end{tabular}

Abbreviations: $\mathrm{Cl}$, confidence interval; CPR, clinical prediction rule.

${ }^{*}$ Sensitivity, 68\% (95\% Cl: 47.6\%, 84.1\%). Specificity, 81\% (95\% Cl: 72.5\%, 87.9\%). Positive predictive value, $48 \%$ (95\% Cl: 31.5\%, 63.9\%). Negative predictive value, 91\% (95\% Cl: $83.4 \%$, $95.8 \%)$. Positive likelihood ratio $=3.6(95 \% \mathrm{Cl}: 2.26,5.69)$. Negative likelihood ratio $=0.4(95 \% \mathrm{Cl}$ : $0.23,0.68)$.

Table 4.6. Classification of predicted functional recovery time by actual recovery time (external validation data set)*

\begin{tabular}{|c|c|c|c|}
\hline \multirow[b]{2}{*}{ Predicted by CPR } & \multicolumn{2}{|c|}{ Actual } & \multirow[b]{2}{*}{ Total } \\
\hline & $>4$ days & $\leq 4$ days & \\
\hline$>4$ days & 23 & 48 & 71 \\
\hline$\leq 4$ days & 13 & 101 & 114 \\
\hline Total & 36 & 149 & 185 \\
\hline
\end{tabular}

Abbreviations: $\mathrm{Cl}$, confidence interval; CPR, clinical prediction rule.

*Sensitivity, 64\% (95\% Cl: 46.2\%, 79.2\%). Specificity, 68\% (95\% Cl: 59.6\%, 75.2\%). Positive predictive value, $32 \%$ (95\% Cl: $21.8 \%, 44.5 \%)$. Negative predictive value, $89 \%$ (95\% Cl: $81.3 \%$, 93.8\%). Positive likelihood ratio $=2.0(95 \% \mathrm{Cl}: 1.41,2.78)$. Negative likelihood ratio $=0.5(95 \% \mathrm{Cl}$ : $0.34,0.83)$. 
Figure 4.1. Receiver operating characteristic curve of the final model. Area under the curve was 0.82 .

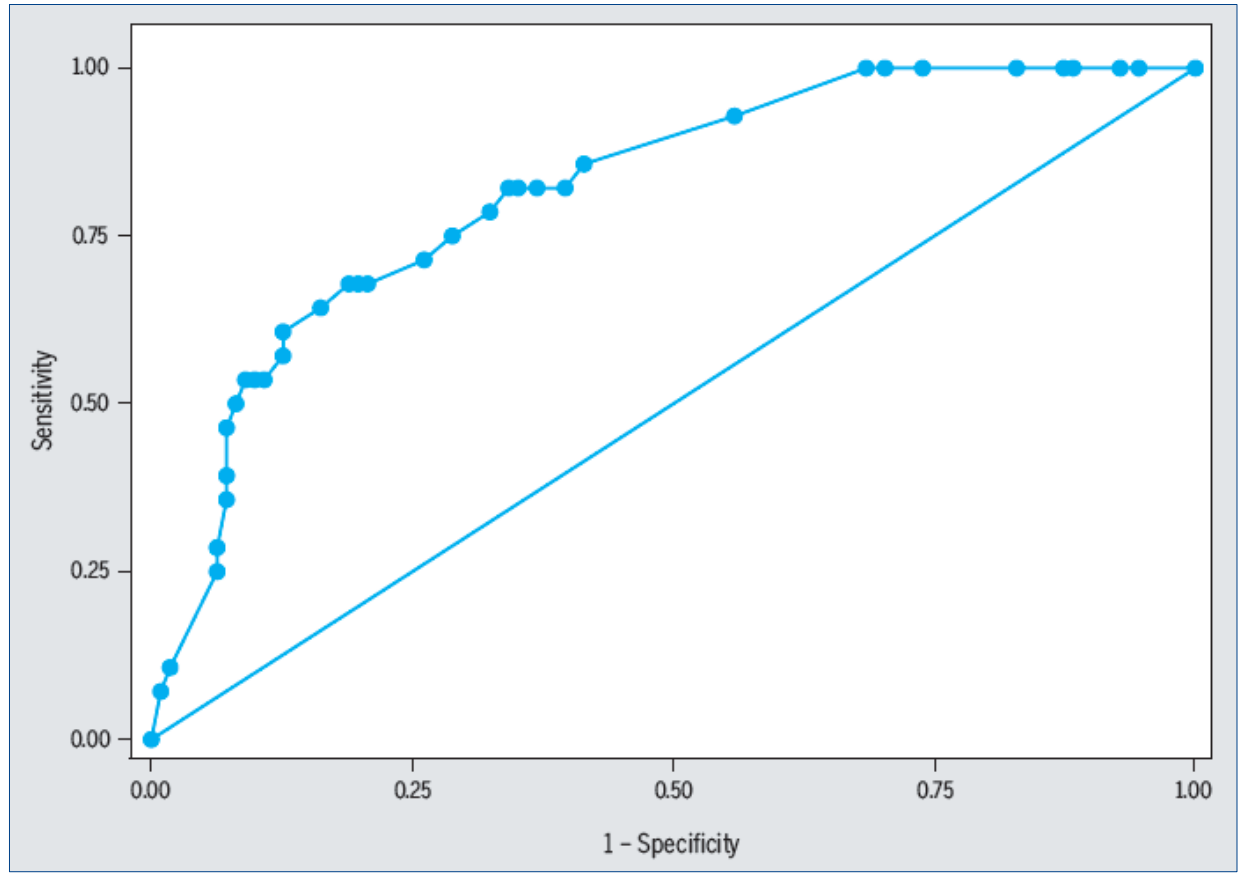

\section{External Validation of Prediction Rule (Data Set B)}

In the second part of the study, the study population used to validate the prediction rule (data set B) was comparable to that of the initial study population (data set A) in terms of age and BMI, but was slightly faster on the chair-rise time and TUG, and walked a little farther on the six minute walk test (Table 4.1). Twenty-three of 71 patients (32\%) with a predicted high risk of delayed inpatient recovery of activities experienced a postoperative inpatient recovery-of-activities time of more than 4 days, compared to less than or equal to 4 days in 13 of 114 patients (11\%) with a predicted normal inpatient recovery-of-activities time (Table 4.6). For the 7 patients who could not perform the TUG, the TUG was classified as 12.5 seconds or longer. A ROC curve was assessed with the scores derived from the prediction model developed in the index data. The AUC of the prediction rule applied to the external data set was 0.71 (95\% Cl: 0.61, 0.81). Exclusion of patients with a missing TUG (as applied in the index set) did not change the AUC. 


\section{POSt Hoc ANALYSIS}

In contrast to the model for predicting prolonged inpatient recovery of activities, the same procedure was conducted to investigate which patients needed 3 days or fewer after THR to reach a MILAS score of 1 or less. Those patients were more often younger men (less than 70 years old) with normal BMI (less than $25 \mathrm{~kg} / \mathrm{m}^{2}$ ), low ASA scores (less than 3), and high walking capacities (greater than $337 \mathrm{~m}$ on the six-minute walk test). The AUC of this model was 0.81 (95\% Cl: 0.72, 0.90).

\section{DISCUSSION}

In this study, we developed an RSM for inpatient recovery of activities by combining literaturebased indices with additional variables (mostly performance tests) within all ICF domains except participation. The literature-based indices represent an AUC of 0.68 (95\% Cl: 0.58, 0.78); when they were combined with 2 additional variables, the AUC increased to 0.82 (95\% Cl: 0.74, 0.90). The best prediction model (with a sensitivity of $68 \%$ and specificity of $81 \%$ ) for identifying patients at high risk for delayed inpatient recovery of activities combined the 4 literature-based indices (sex, age, BMI, and ASA score) with the Charnley score and the TUG test. Because the replication of our findings in the validation study was acceptable, the RSM was not altered.

The length of hospital stay is the most frequently studied main outcome variable in studies evaluating the association between preoperative patient-related factors and the recovery of patients undergoing THR [3], despite the fact that length of hospital stay depends on more than functional recovery alone. Other contributing factors are (1) medical (preoperative and postoperative protocols, etc) and (2) discharge variables (availability of nursing home beds, etc). Therefore, this study identified risk factors for delayed inpatient recovery of activities measured with MILAS instead of length of hospital stay. Wang et al [23] used a clinical instrument to assess inpatient recovery of activities (modified Barthel index) instead of length of hospital stay. The modified Barthel index overlaps with the MILAS, as they both measure transfers, walking, and stair climbing. Two of the 3 factors reported by Wang et al [23] (age and comorbidity) were also included in our RSM. Charnley score is the most predictive variable in our RSM. This confirms the conclusions of Röder et al. [14], who reported that patients with a preoperative Charnley score of $\mathrm{B}$ or $\mathrm{C}$ were less likely to functionally recover and experience pain relief than were patients with a Charnley score of $A$. 
There are some considerations about 2 of the performance tests in this study. First, muscle strength was measured with the handheld dynamometer, but most patients were forced to give up due to pain before reaching their maximum muscle strength. This could explain why muscle strength did not increase the AUC in the logistic regression. Second, the refinement of the lowa Level of Assistance Scale into the MILAS by adding a fifth activity (transfer from sit to supine), which in our clinical experience is crucial for the functional independence of a THR patient, could have affected its clinimetric properties.

The strengths of the study are its pragmatic design (all data collected from regular care) and the acceptable generalizability of the RSM after validation. However, there are also some limitations. First, the analyses for the RSM were conducted with a relatively small sample size, which might have erroneously eliminated slightly weaker predictors from the model. However, the results of our validation show that the RSM outcome may be considered relatively robust. Second, patients in the validation study were mobilized on the day of surgery. Therefore, the cutoff for delayed inpatient recovery of activities was set at 4 days for the validation data set instead of 5 days in the index data set. This should be kept in mind when interpreting the external validation analysis. Third, the data in this study were collected between 2007 and 2009. The reader should consider that the clinical pathway in use at that time is different from the currently accepted fast-track regime [24]. Fourth, the mean age of the study population was 70 years, whereas the current mean age for patients undergoing THR is around 65 years [3]. This might impact the generalizability of the model.

The RSM provides a preoperative prediction of the postoperative inpatient recovery of activities of individual patients. For instance, patients at high risk for delayed inpatient recovery of activities may benefit from a preoperative physical program [25]. There is some evidence that a preoperative, individualized, high intensity physical exercise program may increase preoperative function ${ }^{20}$ and decrease inpatient recovery-of-activities time $[25,26]$ in high-risk individuals.

The study results have implications for future research. First, future studies should include performance-based measurements to properly identify patients at risk for delayed inpatient recovery of activities [27]. Patient-reported measures, like the WOMAC score, are more influenced by patients' experience and confidence in their own abilities $[4,28]$. Furthermore, the inpatient recovery of activities measures the postoperative basic mobility of patients (eg, transfers and walking), whereas the WOMAC items reflect more complex activities (eg, shopping, putting on socks, and domestic duties). Second, this study was focused on literature based classical patient-related variables and preoperative physical function as risk factors for postoperative 
inpatient recovery of activities; however, the RSM explained only $22 \%$ of the variance in recovery. It would be interesting to assess whether other characteristics (eg, cognitive function [29], mental health [eg, anxiety and depression] [30], coping styles [31], social support [10], and patient expectations [32]) also contribute to the prediction of delayed inpatient recovery of activities.

\section{CONCLUSION}

This RSM can determine the risk of delayed inpatient recovery of activities in people undergoing THR. Interestingly, physical performance is a strong predictor of risk for delayed inpatient recovery of activities. Considering that these data are easily acquired, health care professionals should augment their classical preoperative risk evaluation with performance-based indices for predicting the short-term outcome of THR.

\section{KEY POINTS}

FINDINGS: Twenty percent to $30 \%$ of the patients demonstrated delayed inpatient recovery of physical activities after a THR. Preoperative performance-based tests are strong predictors for delayed inpatient recovery of physical activities.

IMPLICATIONS: Health care professionals should augment their classical preoperative risk evaluation with performance-based indices for predicting the short-term outcome of THR.

CAUTION: The RSM was developed in a specific clinical care setting without fast-track or rapid-recovery interventions (eg, mobilizing 4 hours postoperatively and avoiding the use of opiates). 


\section{REFERENCE}

1. Kurtz S, Ong K, Lau E, Mowat F, Halpern M. Projections of Primary and Revision Hip and Knee Arthroplasty in the United States from 2005 to 2030. J Bone Jt Surg 2007;89:780.

2. Malani PN. Functional Status Assessment in the Preoperative Evaluation of Older Adults. JAMA 2009;302:1582.

3. Elings J, Hoogeboom TJ, Van Der Sluis G, Van Meeteren N. What preoperative patient-related factors predict inpatient recovery of physical functioning and length of stay after total hip arthroplasty? A systematic review. Clin Rehabil 2015;29.

4. Gandhi R, Tsvetkov D, Davey JR, Syed KA, Mahomed NN. Relationship between selfreported and performance-based tests in a hip and knee joint replacement population. Clin Rheumatol 2009;28:253-7.

5. McGinn TG, Guyatt GH, Wyer PC, Naylor CD, Stiell IG, Richardson WS. Users' guides to the medical literature: XXII: how to use articles about clinical decision rules. Evidence-Based Medicine Working Group. JAMA 2000;284:79-84.

6. von Elm E, Altman DG, Egger M, Pocock SJ, Gøtzsche PC, Vandenbroucke JP. The strengthening the reporting of observational studies in epidemiology (STROBE) statement: Guidelines for reporting observational studies. Int J Surg 2014.

7. Jesudason C, Stiller K. Are bed exercises necessary following hip arthroplasty? Aust J Physiother 2002;48:73-81.

8. Brunenberg DE, Van Steyn MJ, Sluimer JC, Bekebrede LL, Bulstra SK, Joore MA. Joint recovery programme versus usual care: An economic evaluation of a clinical pathway for joint replacement surgery. Med Care 2005.

9. Hardy SE, Concato J, Gill TM. Stressful life events among community-living older persons. J Gen Intern Med Off J Soc Res Educ Prim Care Intern Med 2002.

10. Owens WD, Felts JA, Spitznagel EL. ASA physical status classifications: A study of consistency of ratings. Anesthesiology 1978;49:239-43.
11. Charnley J. The long-term results of lowfriction arthroplasty of the hip performed as a primary intervention. J Bone Joint Surg Br 1972;54:61-76.

12. Roorda LD, Jones CA, Waltz M, Lankhorst GJ, Bouter LM, Van Der Eijken JW, et al.

Satisfactory cross cultural equivalence of the Dutch WOMAC in patients with hip osteoarthritis waiting for arthroplasty. Ann Rheum Dis 2004.

13. Gallagher EJ, Bijur PE, Latimer C, Silver W. Reliability and validity of a visual analog scale for acute abdominal pain in the ED. Am J Emerg Med 2002;20:287-90.

14. Röder C, Staub LP, Eggli S, Dietrich D, Busato A, Müller U. Influence of preoperative functional status on outcome after total hip arthroplasty. J Bone Jt Surg - Ser A 2007.

15. Kennedy DM, Stratford PW, Wessel J, Gollish JD, Penney D. Assessing stability and change of four performance measures: a longitudinal study evaluating outcome following total hip and knee arthroplasty. BMC Musculoskelet Disord 2005;6:3.

16. Suzuki T, Bean JF, Fielding RA. Muscle power of the ankle flexors predicts functional performance in community-dwelling older women. J Am Geriatr Soc 2001.

17. Roy MAG, Doherty TJ. Reliability of hand-held dynamometry in assessment of knee extensor strength after hip fracture. Am J Phys Med Rehabil 2004.

18. Shumway-Cook A, Brauer S, Woollacott M. Predicting the probability for falls in community-dwelling older adults using the Timed Up \& Go Test. Phys Ther 2000;80:896903.

19. Guccione AA, Fagerson TL, Anderson JJ. Regaining functional independence in the acute care setting following hip fracture. Phys Ther 1996;76:818-26.

20. Steyerberg E. Clinical Prediction Models: A Practical Approach to Development, Validation, and Updating. New York: NY: Springer; 2009. 
21. Hanley JA, McNeil BJ. The meaning and use of the area under a receiver operating characteristic (ROC) curve. Radiology 1982.

22. El Khouli RH, Macura KJ, Barker PB, Habba MR, Jacobs MA, Bluemke DA. Relationship of temporal resolution to diagnostic performance for dynamic contrast enhanced MRI of the breast. J Magn Reson Imaging 2009.

23. Wang A, Hall S, Gilbey H, Ackland T. Patient variability and the design of clinical pathways after primary total hip replacement surgery. J Qual Clin Pract 1997;17:123-9.

24. Jans, Bundgaard-Nielsen M, Solgaard S, Johansson PI, Kehlet H. Orthostatic intolerance during early mobilization after fasttrack hip arthroplasty. Br J Anaesth 2012.

25. Topp R, Ditmyer M, King K, Doherty K, Hornyak J. The effect of bed rest and potential of prehabilitation on patients in the intensive care unit. AACN Clin Issues 2002;13:263-76.

26. Villadsen A, Overgaard S, Holsgaard-Larsen A, Christensen R, Roos EM. Postoperative effects of neuromuscular exercise prior to hip or knee arthroplasty: a randomised controlled trial. Ann Rheum Dis 2014;73:1130-7.

27. Hoogeboom TJ, van den Ende CHM, van der Sluis G, Elings J, Dronkers JJ, Aiken AB, et al. The impact of waiting for total joint replacement on pain and functional status: a systematic review. Osteoarthritis Cartilage 2009;17:1420-7.
28. Stevens-Lapsley JE, Schenkman ML, Dayton MR. Comparison of Self-Reported Knee Injury and Osteoarthritis Outcome Score to Performance Measures in Patients After Total Knee Arthroplasty. PM R 2011.

29. Söderqvist A, Miedel R, Ponzer S, Tidermark J. The influence of cognitive function on outcome after a hip fracture. J Bone Jt Surg - Ser A 2006.

30. Singh JA, O'Byrne MM, Colligan RC, Lewallen DG. Pessimistic explanatory style: A psychological risk factor for poor pain and functional outcomes two years after knee replacement. J Bone Jt Surg - Ser B 2010.

31. Greenglass ER, Marques S, DeRidder M, Behl S. Positive coping and mastery in a rehabilitation setting. Int J Rehabil Res 2005.

32. Gonzalez Saenz De Tejada M, Escobar A, Bilbao A, Herrera-Espiñeira C, García-Perez L, Aizpuru $F$, et al. A prospective study of the association of patient expectations with changes in health-related quality of life outcomes, following total joint replacement. BMC Musculoskelet Disord 2014. 


\section{APPENDIX 4.1. DETAILED DESCRIPTIONS OF THE INCLUDED TESTS}

\section{Minute Walking Test (6MWT)}

The patient was instructed to cover as much distance's walking within 6 minutes with a possibility to take a break if necessary [1]. This standardized test was executed over a trajectory of $10 \mathrm{~m}$. The result of the standardized test is the walking distance $(m)$ after 6 minutes.

\section{Chair RISe TIME TESt (CRT)}

This test assesses the time (s) needed to stand up and sit down 10 times on a chair with armrests. While performing the test, the patient was instructed not to use the armrests, unless the patient was unable to stand up without using the arms [2].

\section{HAND HeLd DyNAMOMETER (HHD) FOR THE M. QUADRICEPS}

The patient was asked in a sitting position to fully extend the knee and try to keep it extended. The patients were allowed to fixate their hands during the test and were verbally encouraged to keep the knee actively extended. Pressure was exercised at the ankle trying to flex the knee. To familiarize with the test it was first performed twice with the contralateral side and subsequently twice with the affected side. The highest score in newton meters ( $\mathrm{Nm})$ of the affected side was taken [3].

\section{TIMED UP AND GO TEST (TUG)}

The time (s) needed to rise from a armchair, walk $3 \mathrm{~m}$, turn, walk back and sit down on the chair again. This test has been found reliable and valid for quantifying functional mobility in frail older people [4].

\section{THE WESTERN ONTARIO AND MCMASTER UNIVERSITIES (WOMAC) OSTEOARTHRITIS INDEX}

A disease-specific questionnaire for patients with osteoarthritis consisting of three dimensions: pain, stiffness and physical functioning. Responses are based on a 5-point Likert scale, from worst to best [5].

\section{Visual Analog SCALE (VAS)}

The VAS was used to measure the pain perception: 
Patients defined their pain perception on a $100 \mathrm{~mm}$ line with "no pain" at left $(0 \mathrm{~mm})$ and "worst pain ever" at right $(100 \mathrm{~mm})$. Patients have to pinpoint their pain perception over the past 24 hours on the line between these two extremes. The reliability of this test is good (ICC 0.97) [6].

\section{THE AMERICAN SOCIETY OF ANESTHESIOLOGISTS (ASA) SCORE}

Measures the fitness of patients for surgery. It discriminates 6 classes, but for elective THR surgery only classes 1-3 are relevant: (1) healthy; (2) mild systemic disease; and (3) severe systemic disease [7].

\section{THE ChARNLEY-sCoRe}

Indicating the function of the hip with regard to the ability to walk and categorizes patients into three groups: (A) unilateral hip involvement with no other condition that interferes with walking; (B) bilateral hip involvement with no other condition that interferes with walking; (C) uni- or bilateral hip involvement with other conditions interfering normal locomotion, such as hemiplegia, or respiratory disability [8]. A contralateral THR without complaints was considered as a healed hip joint.

\section{Modified IOWA LeVels of Assistance SCALE (MILAS)}

The inter-rater reliability of the total ILAS score is good (Inter Class Correlation (ICC) 0.98) [9]. The ILAS assesses the capability of patients to perform safely four activities of daily life (supine to sit, sit to stand, walking, and stair climbing) and rates the amount of assistance necessary. For this study the ILAS was modified into the M(odified)ILAS by adding a fifth activity, namely the transfer from sitting to supine since clinical experience has found that transfer to be difficult for patients after THR. Each activity of the mILAS was scored daily on an ordinal scale ranging from 0 (independent); 1 (standby/supervision); 2 (one point of contact); 3 (two points of contact); 4 (three or more points of contact); 5 (failed with maximal assistance); 6 (not tested due to medical reasons or for reasons of safety) [9]. Inpatient recovery of activities of the patient was defined as 7 or less points on the mILAS, indicating that, except stair climbing, the patient could safely perform the transfers and walk independently and perform maximally one item under supervision. Stair climbing was excluded because many patients were already discharged before they were able to climb stairs. 


\section{REFERENCES}

1. Enrichi PL, Sherrill DL. Reference equations for the six-minute walk in healthy adults. Am J Respir Crit Care Med 1998.

2. Suzuki T, Bean JF, Fielding RA. Muscle power of the ankle flexors predicts functional performance in community-dwelling older women. J Am Geriatr Soc 2001.

3. Roy MAG, Doherty TJ. Reliability of hand-held dynamometry in assessment of knee extensor strength after hip fracture. Am J Phys Med Rehabil 2004.

4. Podsiadlo D, Richardson S. The timed \&quot;Up \&amp; Go\&quot;: a test of basic functional mobility for frail elderly persons. J Am Geriatr Soc 1991;39:142-8.

5. Roorda LD, Jones CA, Waltz M, Lankhorst GJ, Bouter LM, Van Der Eijken JW, et al.

Satisfactory cross cultural equivalence of the Dutch WOMAC in patients with hip osteoarthritis waiting for arthroplasty. Ann Rheum Dis 2004.
6. Gallagher EJ, Bijur PE, Latimer C, Silver W. Reliability and validity of a visual analog scale for acute abdominal pain in the ED. Am J Emerg Med 2002;20:287-90.

7. [Owens WD, Felts JA, Spitznagel EL. ASA physical status classifications: A study of consistency of ratings. Anesthesiology 1978;49:239-43.

8. Charnley J. The long-term results of lowfriction arthroplasty of the hip performed as a primary intervention. J Bone Joint Surg $\mathrm{Br}$ 1972;54:61-76.

9. Jesudason C, Stiller K. Are bed exercises necessary following hip arthroplasty? Aust J Physiother 2002;48:73-81. 

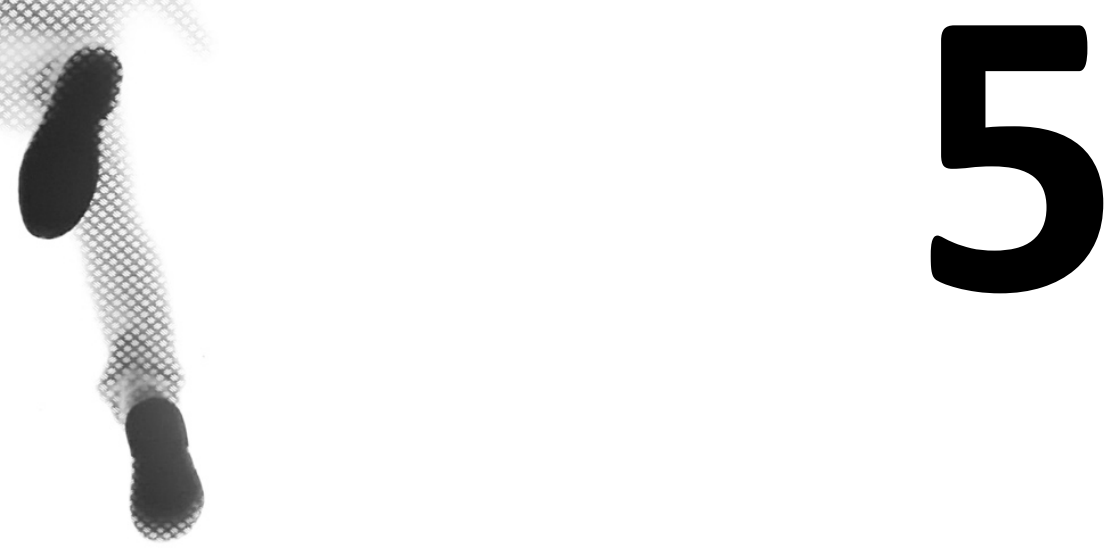

\title{
ADVOCACY FOR USE OF THE MODIFIED IOWA LEVEL OF ASSISTANCE SCALE FOR CLINICAL USE IN PATIENTS AFTER HIP REPLACEMENT: AN OBSERVATIONAL STUDY
}

\author{
J. Elings | S. Zoethout | P.M. ten Klooster | G. van der Sluis | \\ S.M. van Gaalen | N.L.U. van Meeteren | T.J. Hoogeboom
}




\section{ABSTRACT}

Objectives. To test the internal consistency and item difficulty of the modified lowa Level of Assistance Scale (mILAS).

Design. Retrospective observational study.

Setting. Two orthopaedic wards of two general hospitals.

Participants. Following elective primary unilateral total hip replacement surgery, all participants performed mILAS activities that were scored daily to assess their recovery of activities during hospitalisation.

Main outcome measures. The internal consistency and the level of assistance needed by the patient (item difficulty) of the mILAS were calculated using data from Deventer Hospital, Deventer, the Netherlands $(n=255)$. A cross-validation was performed using data from $\mathrm{Nij}$ Smellinghe Hospital, Drachten, the Netherlands $(n=224)$.

Results. The internal consistency of the mILAS was acceptable on all three postoperative days ( $\alpha=0.84$ to 0.97 ). Cronbach's $\alpha$ and Rasch analysis revealed a misfit of stair climbing with the other items of the mILAS. The item difficulty of the mILAS items changed over the first wo postoperative days. During the first three postoperative days, the sit to supine transfer was generally the most difficult item to achieve, and the sit to stand transfer was the least difficult item to achieve as rated by physiotherapists. The cross-validation analysis revealed similar results.

Conclusions. The mILAS is a clinically sound measurement tool to assess the ability of patients to perform five functional tasks safely during hospitalisation. Stair climbing appears to be the easiest item to complete, and the sit to supine transfer is generally the most difficult after surgery. 


\section{INTRODUCTION}

The lowa Level of Assistance Scale (ILAS) was developed as a tool to monitor functional recovery for hospitalized patients, including patients immediately following total hip replacement (THR) surgery [1]. The original ILAS assessed patients' independence with five functional tasks, but since its development in 1995, several scoring changes have been proposed and certain functional tasks have been added or removed from the scale [2-6]. The modified ILAS (mILAS)is now commonly used in many hospital settings, and offers potential advantages for monitoring patients following THR as it incorporates a sit to supine transfer. This particular task is often difficult for patients to perform in the early postoperative period, especially considering the movement restrictions(limited hip flexion and rotation) often imposed after THR. However, the mILAS has yet to be examined for its ecological validity or psychometric properties in patients following THR.

The aim of this study was to formally assess the performance of the mILAS as a tool for monitoring early recovery following THR by: (1) examining construct validity via internal consistency analysis of the mILAS items across two different large-scale data sources; and (2) determining the level of assistance needed by the patient (item difficulty)of mILAS items over the course of hospitalisation. This approach was designed such that mILAS performance was established using one data source, and confirmation was sought by validating the results against a different data source. A secondary aim of this study was to describe mILAS scores for patients following THR to provide patients and health-care professionals with essential information regarding early recovery of functional mobility.

\section{METHODS}

\section{PATIENT CHARACTERISTICS AND DEMOGRAPHICS}

This retrospective study was performed using data from two large general hospitals in a routine care setting for people undergoing THR. All data for this study were extracted by SZ/GvdS by electronic interprofessional medical record review. At the time of care, patient characteristics were documented by various healthcare professionals: before surgery, an anaesthetist, a physiotherapist and a nurse assessed the surgical risk and functional status of all patients undergoing primary THR [5]. The documented date of birth was used to calculate patient age. Similarly, body mass index $(\mathrm{kg} / \mathrm{m} 2)$ was calculated from the documented height and weight. The 
Society of Anesthesiologists score, assessed by the anaesthetist, was extracted as a proxy of the patients' fitness for surgery [7]. The Charnley score (A/B/C) [8] and the timed up and go test [9], typically assessed by the physiotherapist, were recorded as measures of patient functioning. Explorative analyses were performed on consecutive data $(n=225)$ from Deventer Hospital, Deventer, the Netherlands (April 2014 to February 2015; of the 287 consecutive patients, seven did not undergo surgery and 55 had no postoperative mILAS data),and confirmative analyses were performed using consecutive data $(n=224)$ from Nij Smellinghe Hospital, Drachten, the Netherlands (March 2009 to December 2010; of the 271 consecutive patients, 47 had no postoperative mILAS data).Patients that gave informed consent were included if they were aged $\geq 18$ years and had undergone unilateral primary THR surgery. No exclusion criteria were used. Data from regular patient files built up during routine day-to-day care in both clinical settings were used. According to 'Dutch' law, the study did not fall within the remit of the medical ethics committee. However, both hospital policies demanded local ethical review of all scientific studies (JT/ds/16.0635 and 16-107/JS/AB). The study was performed in accordance with the Declaration of Helsinki.

\section{MILAS DATA COLLECTION}

During hospitalisation, the mILAS was used daily to assess the capability of patients to perform five functional milestones safely (supine to sit, sit to supine, sit to stand, walking and stair climbing). These milestones are necessary for an individual to function independently at home. The amount of assistance required and the type of assistive devices used were recorded by physiotherapists. All mILAS items were scored from zero to six for the amount of assistance required (see Appendix 5.1 for scoring details). The total score reflects the sum of all five functional milestones, and ranges from zero to 30 points. Higher scores indicate that a person needs more assistance. The sequence of performing the individual mILAS items was not standardised; the position and/or location of the patient at the start of the therapy session was the decisive factor. For example, if the patient was sitting on a chair, the first item to assess was the sit to stand transfer. All participating physiotherapists at both hospitals were trained in executing and scoring the mILAS uniformly in a formal training session before they implemented use of the mILAS as part of usual care (see Appendix 5.2 for additional information regarding clinical care pathway and experience of the physiotherapists). Stair climbing was only assessed and scored for patients who needed to be able to climb stairs at their preferred discharge destination. For patients who did not have to climb stairs, this item was not tested and was therefore rated with a score of six points. 


\section{STATISTICAL ANALYSES}

Descriptive statistics (frequencies, proportions, means, standard deviations and percentages) were calculated as appropriate for all patient characteristics. Complementary to the descriptive statistics of the mILAS scores, the recovery curves of all individual patients over the first three days were visualised by individual trajectory plots. For internal consistency analysis, the data sources were divided into exploratory and confirmatory datasets.

\section{EXPLORATORY ANALYSIS}

Data collected consecutively from Deventer Hospital, Deventer, the Netherlands were used for initial examination of internal consistency of mILAS scores. These data were collected for 225 patients undergoing THR between April 2014 and February 2015. Cronbach's $\alpha$ and the change in this statistic upon deletion of a single mILAS item were calculated to assess the internal consistency of the mILAS, and to explore the contribution of each mILAS item to the total internal consistency. Cronbach's $\alpha$ values between 0.70 and 0.95 are considered to be acceptable [10].

To assess the level of difficulty of the individual mILAS items, the Rasch partial credit model was used for ordered categorical data. Using this approach, each mILAS item was allowed to have its own unique rating scale structure [11]. Prior to the item response theory analysis, the authors checked if all rating categories ( 0 to 6 ) of the mILAS were being used effectively and consistently according to the criteria of Linacre [12]. If a rating category failed to meet these criteria, merging with neighboring categories was considered. After possible rating scale optimisation, the fit of individual items to the latent trait was analysed by the infit and out-fit mean-square statistics. Values between 0.5 and 1.7 were considered to be indicative of acceptable fit [13]. Thereafter, Wright person-item maps were used to examine the distribution of item difficulty levels against the patients' levels of functioning during the first three days of hospitalisation.

\section{CONFIRMATORY ANALYSIS}

A cross-validation of internal consistency and Rasch item difficulty levels was conducted to confirm the findings of the exploratory analysis. A separate data source (Nij Smellinghe Hospital, Drachten, the Netherlands) was used for this analysis, including 224 patients undergoing THR surgery between March 2009 and December 2010. All statistics were performed using R Version 3.3.1 or Winsteps Version 3.65.0. 


\section{RESULTS}

\section{EXPLORATORY ANALYSIS}

The patient characteristics of the two hospitals are shown in Table 5.1. Analysis of the scoring options revealed that Options 2, 3, 4 and 5 were not compliant with the preset criteria (at least 10 observations per category), and were recoded to maximize statistical performance and clinical meaningfulness of the mILAS (Table 5.2). Therefore, the response options were reduced from 7 to 3, merging Options 2 (minimal), 3(moderate), 4 (maximal) and 5 (failed), and recoding Option 6 (not tested) to missing (recoded scoring: 0, 1, 2, 2, 2, 2, missing). The response options used for statistical analysis were 0 (independent), 1 (supervision) and 2 (with help).

For the purpose of visualizing the recovery curves of them ILAS (Appendix 5.3), one can argue to adopt a score of 3 instead of a missing value with the original scoring options.

Table 5.1. Patient characteristic of the exploratory and confirmatory datasets.

\begin{tabular}{|c|c|c|c|c|c|c|c|}
\hline & & \multicolumn{3}{|c|}{ Deventer hospital $(n=225)$} & \multicolumn{3}{|c|}{ Nij Smellinghe hospital $(n=224)$} \\
\hline & & $\mathrm{n}$ & $\begin{array}{l}\text { Mean } \\
\text { (median) }\end{array}$ & SD (range) & $\mathrm{n}$ & $\begin{array}{l}\text { Mean } \\
\text { (median) }\end{array}$ & $\begin{array}{l}\text { SD } \\
\text { (range) }\end{array}$ \\
\hline \multicolumn{2}{|l|}{ Age } & 225 & 71.2 & 9.9 & 224 & 69.0 & 8.9 \\
\hline \multicolumn{2}{|l|}{ TUG (s) } & 213 & 14.27 & 10.17 & 215 & 10.8 & 4.9 \\
\hline \multirow{2}{*}{\multicolumn{2}{|c|}{ Length of stay (d) }} & 225 & (3) & $(2-20)$ & 224 & $(4)$ & $(3-14)$ \\
\hline & & $\mathrm{n}$ & $\%$ & & $\mathrm{n}$ & $\%$ & \\
\hline \multirow{2}{*}{ Sex } & Male & 81 & 36 & & 75 & 34 & \\
\hline & Female & 144 & 74 & & 149 & 67 & \\
\hline \multirow{2}{*}{ BMI } & $<25$ & 82 & 37 & & 60 & 27 & \\
\hline & $\geq 25$ & 142 & 63 & & 164 & 73 & \\
\hline \multirow{4}{*}{ ASA-score } & 1 & 34 & 15 & & 42 & 23 & \\
\hline & 2 & 152 & 68 & & 136 & 73 & \\
\hline & 3 & 38 & 17 & & 9 & 5 & \\
\hline & 4 & 1 & 0 & & 0 & 0 & \\
\hline \multirow{2}{*}{ Charnley-score } & A & 187 & 84 & & 128 & 58 & \\
\hline & $B / C$ & 37 & 17 & & 93 & 42 & \\
\hline
\end{tabular}

Abbreviations: ASA, American Society of Anesthesiologists; BMl: body mass index; SD, standard deviation; TUG, timed up and go test. 
Rasch analysis demonstrated adequate fit over the first three days, except for the mILAS items 'walking' (Day 1) and 'stair climbing' (Day 3), which did not fit with the partial credit model based on their outfit statistics (Table 5.4).

Table 5.2. Percentage of patients within each rating category of the modified lowa Level of Assistance Scale (mILAS) items during the first three days after total hip replacement surgery.

\begin{tabular}{|c|c|c|c|c|c|c|c|c|c|c|}
\hline & \multicolumn{7}{|c|}{ Percentage of patients by mILAS score ${ }^{\mathbf{a}}$} & \multicolumn{3}{|c|}{ Overall score } \\
\hline & 0 & 1 & 2 & 3 & 4 & 5 & 6 & Mean & SD & Skew \\
\hline \multicolumn{11}{|l|}{ Day 1} \\
\hline Supine to sit & 24 & 21 & 37 & 5 & 2 & 0 & 11 & 1.82 & 1.74 & 1.26 \\
\hline Sit to supine & 23 & 20 & 34 & 5 & 1 & 0 & 17 & 2.10 & 1.98 & 1.01 \\
\hline Sit to stand & 27 & 36 & 24 & 3 & 1 & 1 & 8 & 1.47 & 1.62 & 1.70 \\
\hline Walking & 8 & 51 & 21 & 3 & 1 & 2 & 15 & 2.04 & 1.87 & 1.35 \\
\hline Stair climbing & 0 & 0 & 0 & 0 & 0 & 0 & 0 & 6.00 & 0.00 & - \\
\hline \multicolumn{11}{|l|}{ Day 2} \\
\hline Supine to sit & 68 & 12 & 18 & 2 & 0 & 0 & 1 & 0.57 & 0.94 & 1.85 \\
\hline Sit to supine & 62 & 12 & 23 & 2 & 0 & 0 & 2 & 0.74 & 1.17 & 2.14 \\
\hline Sit to stand & 75 & 15 & 7 & 2 & 1 & 0 & 1 & 0.42 & 0.93 & 3.20 \\
\hline Walking & 65 & 24 & 7 & 1 & 1 & 1 & 2 & 0.56 & 1.06 & 3.00 \\
\hline Stair climbing & 16 & 3 & 0 & 0 & 0 & 1 & 80 & 4.88 & 2.30 & $-1,57$ \\
\hline \multicolumn{11}{|l|}{ Day 3} \\
\hline Supine to sit & 78 & 10 & 11 & 0 & 0 & 0 & 2 & 0.42 & 1.02 & 3.49 \\
\hline Sit to supine & 72 & 11 & 15 & 0 & 0 & 0 & 2 & 0.53 & 1.07 & 2.89 \\
\hline Sit to stand & 86 & 11 & 3 & 0 & 0 & 0 & 1 & 0.22 & 0.72 & 5.44 \\
\hline Walking & 81 & 16 & 2 & 0 & 0 & 0 & 1 & 0.26 & 0.72 & 5.20 \\
\hline Stair climbing & 82 & 7 & 0 & 0 & 0 & 0 & 11 & 0.75 & 1.92 & 2.28 \\
\hline
\end{tabular}

a 0 , independent; 1 , standby; 2, minimal; 3, moderate; 4, maximal; 5, failed; 6, not tested. 
The level of difficulty of mILAS items is presented in Appendix 5.4 as a distribution of the functional ability of participants and item difficulty of the mILAS items, as rated by the physiotherapist, for Days 1 to 3 after THR surgery. The item difficulty changed between Days 1 and 3, whereby, in particular, the mILAS item 'walking' was increasingly less difficult on Days 2 and 3 compared with the other items. The sit to stand transfer was the least difficult item on all three postoperative days, and the sit to supine transfer was the most difficult item on Days 2 and 3.

Table 5.3. Internal consistency (Cronbach's alpha) of the modified lowa Level of Assis- tance Scale (mILAS) during the first three days after total hip replacement surgery.

\begin{tabular}{|c|c|c|c|}
\hline & Raw & Std & $\Delta \mathrm{Std}$ \\
\hline \multicolumn{4}{|l|}{ Day 1} \\
\hline mILAS & 0.94 & 0.94 & 0 \\
\hline mILAS without supine to sit & 0.92 & 0.92 & -0.02 \\
\hline mILAS without sit to supine & 0.93 & 0.93 & -0.01 \\
\hline mILAS without sit to stand & 0.91 & 0.91 & -0.03 \\
\hline mILAS without walking & 0.94 & 0.94 & 0 \\
\hline mILAS without stair climbing & 0.94 & 0.94 & 0 \\
\hline \multicolumn{4}{|l|}{ Day 2} \\
\hline mILAS & 0.91 & 0.88 & 0 \\
\hline mILAS without supine to sit & 0.84 & 0.81 & -0.07 \\
\hline mILAS without sit to supine & 0.86 & 0.82 & -0.06 \\
\hline mILAS without sit to stand & 0.85 & 0.81 & -0.07 \\
\hline mILAS without walking & 0.86 & 0.82 & -0.06 \\
\hline mILAS without stair climbing & 0.97 & 0.97 & 0.11 \\
\hline \multicolumn{4}{|l|}{ Day 3} \\
\hline mILAS & 0.96 & 0.95 & 0 \\
\hline mILAS without supine to sit & 0.93 & 0.93 & -0.02 \\
\hline mILAS without sit to supine & 0.93 & 0.93 & -0.02 \\
\hline mILAS without sit to stand & 0.93 & 0.93 & -0.02 \\
\hline mILAS without walking & 0.93 & 0.93 & -0.02 \\
\hline mILAS without stair climbing & 0.99 & 0.99 & 0.04 \\
\hline
\end{tabular}

Abbreviations: Raw, raw score; Std, standardised; $\Delta$ Std, difference in internal consistency of the mILAS without one item vs internal consistency score of the total mILAS score 
Table 5.4. Summary statistics of the item response theory (partial credit model) analysis.

\begin{tabular}{|c|c|c|c|c|}
\hline & Difficulty & SE & $\begin{array}{l}\text { infit Mnsq } \\
\text { (Z-std) }\end{array}$ & $\begin{array}{l}\text { Outfit Mnsq } \\
\text { (Z-std) }\end{array}$ \\
\hline \multicolumn{5}{|l|}{ Day 1} \\
\hline Sit to supine & -0.01 & 0.23 & $0.60(-3.0)$ & $0.66(-1.4)$ \\
\hline Supine to sit & 0.29 & 0.21 & $0.78(-1.5)$ & $0.66(-1.3)$ \\
\hline Sit to stand & 1.56 & 0.24 & $1.01(0.1)$ & $0.85(-0.4)$ \\
\hline Walking & -1.84 & 0.29 & $1.37(2.1)$ & $4.51(4.8)$ \\
\hline Stair climbing & - & - & - & - \\
\hline \multicolumn{5}{|l|}{ Day 2} \\
\hline Sit to supine & -1.25 & 0.21 & $1.01(0.1)$ & $1.22(0.8)$ \\
\hline Supine to sit & -0.42 & 0.20 & $0.50(-3.7)$ & $0.58(-2.0)$ \\
\hline Sit to stand & 1.31 & 0.24 & $0.70(-2.0)$ & $0.63(-2.1)$ \\
\hline Walking & 0.36 & 0.24 & $1.60(3.6)$ & $1.54(3.0)$ \\
\hline Stair climbing & - & - & - & - \\
\hline \multicolumn{5}{|l|}{ Day 3} \\
\hline Sit to supine & -0.85 & 0.30 & $1.07(0.4)$ & $1.10(0.4)$ \\
\hline Supine to sit & 0.10 & 0.28 & $0.69(-1.5)$ & $0.53(-1.4)$ \\
\hline Sit to stand & 1.86 & 0.36 & $0.70(-1.3)$ & $0.60(-1.2)$ \\
\hline Walking & 1.80 & 0.36 & $1.27(1.4)$ & $1.33(1.4)$ \\
\hline Stair climbing & -2.91 & 1.31 & $2.22(2.1)$ & $4.27(1.8)$ \\
\hline
\end{tabular}

Abbreviations: Mnsq, mean square; SE, standard error; std, standard.

\section{CONFIRMATIVE ANALYSIS}

External cross-validation revealed similar results for internal consistency (Cronbach's $\alpha 0.86$ to 1.0, except for stair climbing which could not be assessed based on the low frequencies reported in the confirmatory dataset on Days 1 to3) and item difficulty levels (sit to supine transfer was most difficult, sit to stand transfer was least difficult).

\section{DISCUSSION}

The aim of this retrospective observational study was to assess the internal consistency and item difficulty of the mILAS in routine clinical practice across two large hospitals. In the exploratory analysis, the internal consistency of the mILAS was acceptable on all three postoperative days. 
However, both Cronbach's $\alpha$ and Rasch analysis revealed that stair climbing may measure a different construct compared with the other mILAS items. The item difficulty of some mILAS items changed over the first two postoperative days. However, during the first three postoperative days, the sit to supine transfer was generally the most difficult item to achieve, and the sit to stand transfer was the least difficult item to achieve as rated by physiotherapists. The confirmatory analysis, conducted in a dataset from a different hospital, revealed similar results.

The internal consistency analysis revealed a misfit between stair climbing and the other items of the mILAS. This misfit may be caused by the variance in difficulty (assistance needed by the patient) of the independent mILAS items. The analysis revealed a skewed distribution of outcomes for stair climbing, which was the easiest item to complete for the majority of patients. During stair climbing, all patients used infrastructural assistance of a guardrail, and the timing of the measurement was at the end of the inpatient rehabilitation period. Based on these results, one might consider that stair climbing should be omitted from the mILAS because it is too easy to complete. However, it is an item that is highly relevant for patients who need to perform this activity from their first day at home. Therefore, it is suggested that stair climbing should not be omitted from the mILAS, but there is a need for awareness that its inclusion may be problematic from a purely psychometric point of view. Therefore, stairclimbing might not be so easy when measured in a different population of patients (e.g. patients after abdominal surgery or neurologic diseases).

The recorded measurement of an instrument is linked inextricably to the context in which the measurement is performed [14]. In this study, the mILAS was measured within the context of two hospitals, where patients likely tended to rely on assistance from caregivers. An important question is whether the mILAS score would be the same in a different environment, where assistance is less readily available. Although it is encouraging that the results were similar in two different hospitals, concerns over ecological validity should be borne in mind when interpreting the results of this study. It is suggested that healthcare professionals should keep this in mind during hospitalisation. Patients should be allowed to try their best before receiving help, and help should only be provided when necessary, rather than when it is expected by the patient.

For research and statistical purposes, the scoring rules of the mILAS could be altered as suggested by Benedetti et al. [15]. Based on the current findings, it is suggested that the six scoring options should be reduced to three scoring categories. However, this suggestion is based on the performance of mILAS scores when aggregated for statistical purposes. Use of the mILAS in a clinical setting could involve other considerations, where six scoring levels could prove 
relevant for the patient and (informal) caregiver. For example, the difference between minimal and maximal assistance could help individuals choose the proper help/assistance at home, although they are less meaningful for statistical purposes. Therefore, it is recommended that the scoring options of the mILAS should not be reduced in clinical practice.

These data for patients following THA surgery suggest that there is variability over time in internal consistency and item difficulty of the mILAS items. For example, internal consistency was lower on Day 2 compared with Days 1 and 3 (see Table 5.3), and the difficulty for walking item changed on Day 2 compared with Day 1 (see Appendix 5.4). This new information could be useful for patients to form expectations for their recovery of activities, and for healthcare professionals to optimise clinical care pathways to the needs of the patients.

Strengths of this study include the use of data from regular clinical care with multiple physiotherapists involved in mILAS data collection. Additionally, use of a confirmatory sample should increase confidence in the generalisability of the findings. However, this study also had some limitations. First, the inter-/intrareliability of the mILAS could not be assessed with these data. Additional work in this area could be valuable. This lack of inter-/intrarater reliability should be kept in mind when interpreting the results. Second, the dataset used for the confirmatory cross-validation originated from 2009 to 2010. Although this dataset is older, it revealed similar results, suggesting a stable outcome over time in spite of temporal or geographic differences. Third, during the study period, no fast-track regime was implemented, although this has recently increased in popularity for THR patients across many health systems [16]. Additionally, all patients in these datasets were mobilised on the day after surgery. This should be kept in mind when interpreting the results.

\section{CONCLUSION}

The mILAS is a clinically sound measurement tool to assess the ability of patients to perform five functional tasks safely during hospitalisation. Stair climbing seems to be the easiest item to complete, and sit to supine transfer is the most difficult item to complete on Days 2 and 3, indicating that the latter item adds to the practical measurement range of the scale. 
108 | Chapter 5

\section{ACKNOWLEDGEMENT}

The authors wish to thank Andrew Kittelson for his suggestions regarding English grammar and wording.

\section{ETHICAL APPROVAL:}

Local ethics committee (JT/ds/16.0635 \&16-107/JS/AB).

\section{CONFLICT OF INTEREST:}

None declared. 


\section{REFERENCES}

1. Shields RK, Enloe LJ, Evans RE, Smith KB, Steckel SD. Reliability, validity, and responsiveness of functional tests in patients with total joint replacement. Phys Ther 1995;75:169-76; discussion 176-9.

2. Oldmeadow LB, Edwards ER, Kimmel LA, Kipen E, Robertson VJ, Bailey MJ. No rest for the wounded: early ambulation after hip surgery accelerates recovery. ANZ J Surg 2006;76:607-11.

3. van der Sluis G, Goldbohm RA, Bimmel R, Garre FG, Elings J, Hoogeboom TJ, et al. What augmented physical activity and empowerment can bring to patients receiving total knee replacement: content, implementation, and comparative effectiveness of a new function-tailored care pathway in a routine care setting. Biomed Res Int 2015;2015:745864.

4. Hoogeboom TJ, Dronkers JJ, van den Ende CHM, Oosting E, van Meeteren NLU. Preoperative therapeutic exercise in frail elderly scheduled for total hip replacement: a randomized pilot trial. Clin Rehabil 2010;24:901-10.

5. Elings J, van der Sluis G, Goldbohm RA, Galindo Garre F, de Gast A, Hoogeboom T, et al. Development of a Risk Stratification Model for Delayed Inpatient Recovery of Physical Activities in Patients Undergoing Total Hip Replacement. J Orthop Sports Phys Ther 2016;46:135-43.

6. Oosting E, Jans MP, Dronkers JJ, Naber RH, Dronkers-Landman CM, Appelman-de Vries SM, et al. Preoperative home-based physical therapy versus usual care to improve functional health of frail older adults scheduled for elective total hip arthroplasty: a pilot randomized controlled trial. Arch Phys Med Rehabil 2012;93:610-6.
7. Owens WD, Felts JA, Spitznagel EL. ASA physical status classifications: A study of consistency of ratings. Anesthesiology 1978;49:239-43.

8. Charnley J. The long-term results of lowfriction arthroplasty of the hip performed as a primary intervention. J Bone Joint Surg Br 1972;54:61-76.

9. Shumway-Cook A, Brauer S, Woollacott M. Predicting the probability for falls in community-dwelling older adults using the Timed Up \& Go Test. Phys Ther 2000;80:896903.

10. Tavakol M, Dennick R. Making sense of Cronbach's alpha. Int J Med Educ 2011;2:535.

11. Masters GN. A rasch model for partial credit scoring. Psychometrika 1982;47:149-74.

12. Linacre JM. Optimizing rating scale category effectiveness. J Appl Meas 2002;3:85-106.

13. Bond T, Fox C. Applying the Rasch Model: Fundamental Measurement in the Human Sciences. Lawrence Erlbaum Associates Publishers; 2001.

14. Fridrich A, Jenny GJ, Bauer GF. The Context, Process, and Outcome Evaluation Model for Organisational Health Interventions. Biomed Res Int 2015;2015:414832.

15. Benedetti MG, Franchignoni F, Morri M, Franchini N, Natali E, Giordano A. Rasch analysis of the lowa Level of Assistance Scale in patients with total hip and knee arthroplasty. Int J Rehabil Res 2014;37:118-24.

16. Zhu S, Qian W, Jiang C, Ye C, Chen X. Enhanced recovery after surgery for hip and knee arthroplasty: A systematic review and meta-analysis. Postgrad Med J 2017;93:73642. 


\section{APPENDIX 5.1. Modified lowa Level of Assistance Scale and definitions for level of assistance score during functional activities (additional item to the original scale is printed in bold text).}

\begin{tabular}{|c|c|c|}
\hline Item & Score & Definition \\
\hline \multirow{4}{*}{$\begin{array}{l}1 \text { - supine to sit } \\
2 \text { - sit to supine } \\
3 \text { - sit to stand } \\
4 \text { - walking }(4.8 \mathrm{~m})\end{array}$} & 0 & $\begin{array}{l}\text { 'Independent' - no assistance or supervision is necessary to } \\
\text { perform the activity safely with or without assistive devices, aids } \\
\text { or modifications }\end{array}$ \\
\hline & 1 & $\begin{array}{l}\text { 'Standby' - nearby supervision is required for safe performance } \\
\text { of the activity; no contact is necessary }\end{array}$ \\
\hline & 2 & $\begin{array}{l}\text { 'Minimal' - one point of contact is necessary for safe performance } \\
\text { of the activity, including helping with application of the assistive } \\
\text { device (part of ambulation), getting leg(s) on or off the leg rest, } \\
\text { and stabilising an assistive device }\end{array}$ \\
\hline & 3 & $\begin{array}{l}\text { 'Moderate' - two points of contact are necessary (by one or two } \\
\text { individuals) for safe performance of the activity }\end{array}$ \\
\hline \multirow[t]{3}{*}{5 - stair climbing } & 4 & $\begin{array}{l}\text { 'Maximal' - significant support is necessary at a total of three or } \\
\text { more points of contact (by one or more people) for safe } \\
\text { performance of the activity }\end{array}$ \\
\hline & 5 & 'Failed' - attempted activity but failed with maximal assistance \\
\hline & 6 & $\begin{array}{l}\text { 'Not tested' - because of medical reasons or reasons concerning } \\
\text { safety, test was not attempted; the test was attempted and was } \\
\text { not completed at less than maximal assistance }\end{array}$ \\
\hline
\end{tabular}


APPENDIX 5.2. Additional information on clinical care pathway and therapists

\section{Clinical care pathway}

The surgical approach was similar for all patients (straight-lateral or posterolateral). In the majority of cases, total hip replacement surgery was performed under spinal anaesthesia and without the use of cement; however, the postoperative clinical pathway was identical regardless of the type of anaesthesia or procedure. Mobilisation started the day after surgery and patients were allowed full weight bearing. Patients had to follow hip precautions ( $<90$ degrees of flexion and no adduction or external rotation) and were routinely provided with a walking aid, generally starting with a walker followed by crutches. Stair climbing was only assessed and scored for those who needed to be able to climb stairs at their preferred discharge destination.

\section{THERAPISTS}

Prior to introduction of the modified lowa Level of Assistance Scale (mILAS), all physical therapists were trained to assess the mILAS with real patients in a standardised and uniform way. The table below shows additional details concerning sex, experience and age.

\begin{tabular}{lll}
\hline Sex & Experience (years) & Age (years) \\
\hline Female & 1 & 23 \\
Female & 1 & 23 \\
Female & 8 & 30 \\
Female & 10 & 32 \\
Male & 1 & 24 \\
Male & 3 & 24 \\
Male & 4 & 28 \\
Male & 20 & 48 \\
\hline
\end{tabular}


APPENDIX 5.3. Recovery curves of the modified lowa Level of Assistance Scale (mlLAS) during the first three days after total hip replacement surgery before recoding. (A) Deventer hospital dataset; and (B) Nij Smellinghe dataset

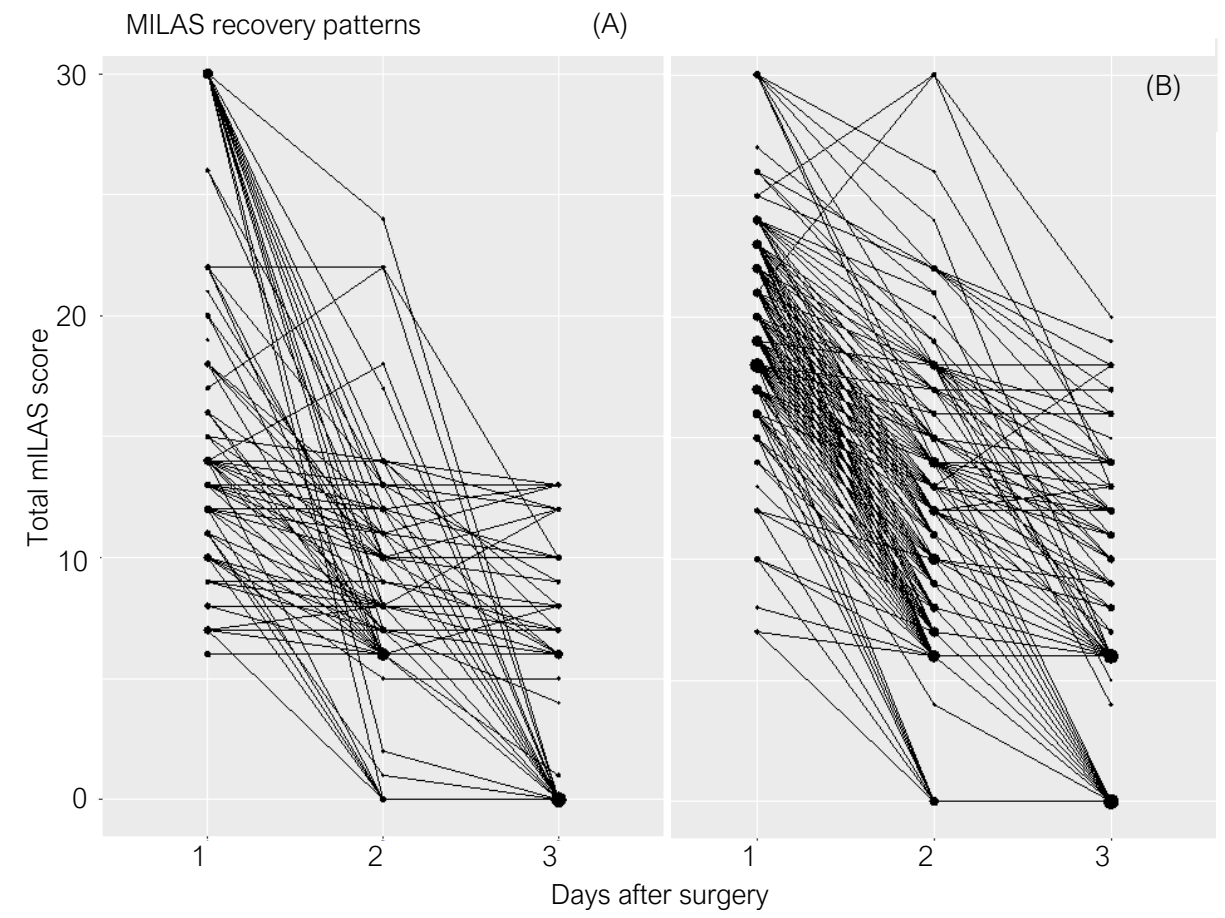



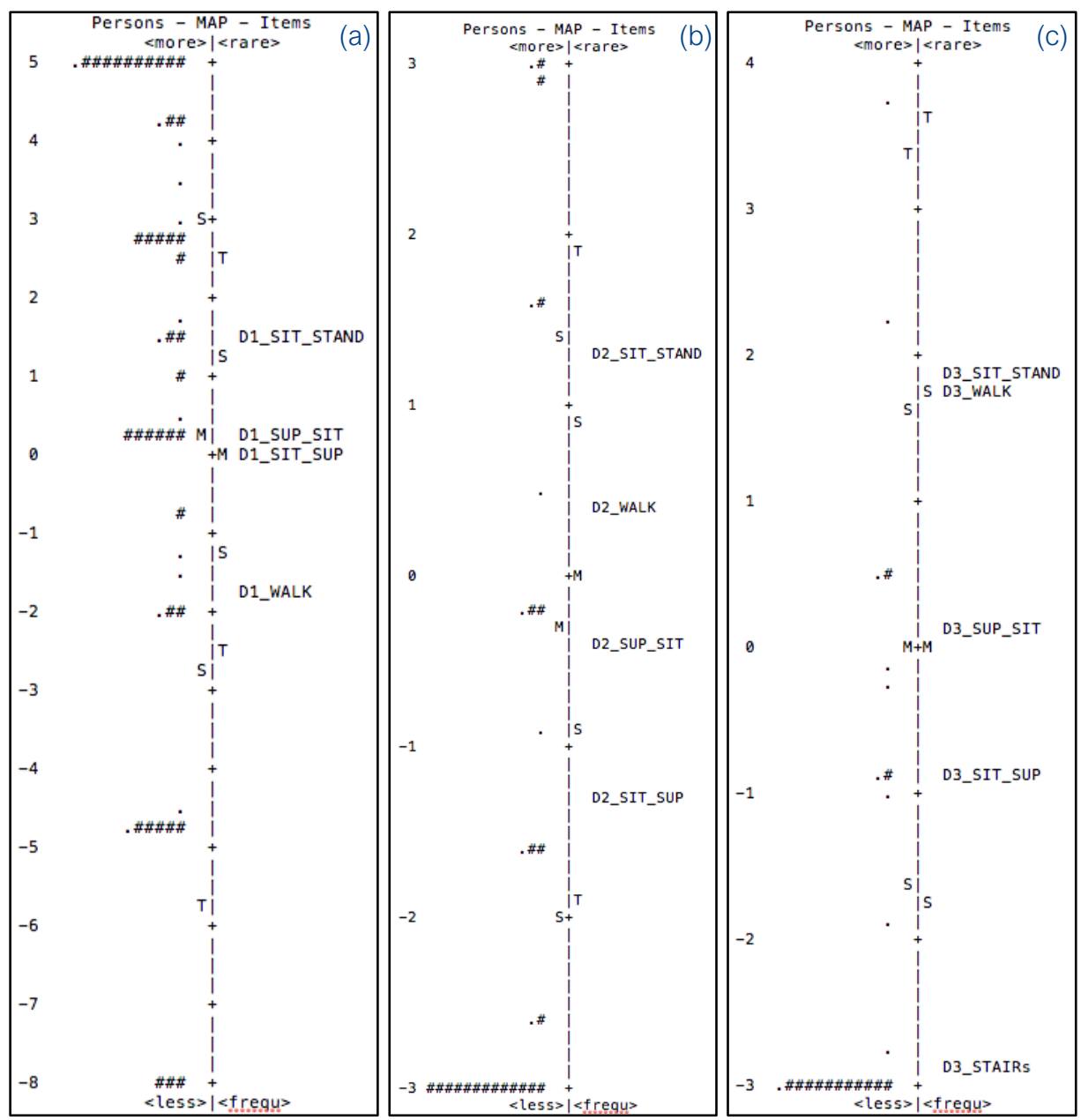

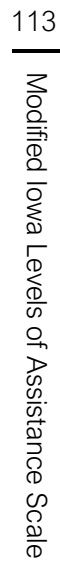

Map of patient ability (left-hand column; each \# represents a specific number of patients) and item difficulty (right-hand column) of the mILAS. The vertical axes represent the item difficulty, measured in linear logit units. By default, the average difficulty of all items is set at 0 logits. A more negative logit score indicates more difficult items and a better functioning patient. (a) Postoperative day 1; (b) Postoperative day 2; (c) Postoperative day 3. 
114 | Chapter 5 


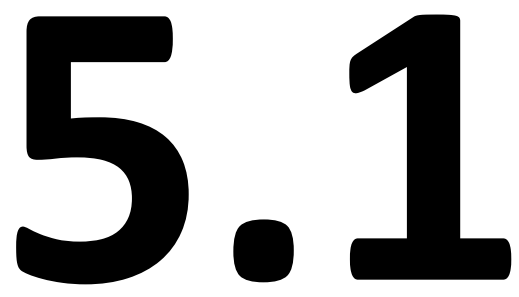

\section{LETTER TO THE EDITOR}

F. Franchignoni | M. Benedetti | A Giordano 


\section{LETTER TO THE EDITOR}

\section{ON ITEM DIFFICULTY IN THE MODIFIED IOWA LEVEL OF AsSistanCE SCALE}

\section{Dear Editor,}

We read with interest the paper by Elings et al. [1] investigating the modified lowa Level of Assistance Scale (mILAS) in patients after hip replacement. We are concerned, however, about their recoding and computing procedures, which could have introduced serious flaws in the results.

1. Treating 'not tested' answers (scoring option six) as missing responses (and then excluding these cases) produces mathematical problems and could lead to significantly biased item and person parameter estimates [2], particularly when high percentages are missing and/or there are so-called 'missing not at random' data [3]. Indeed, the missing values relate to two distinct categories: 1) patients not tested for reasons of safety (the highest level of dependence according to Shields et al. [4]); 2) patients who did not have to climb stairs at their preferred discharge destination, and thus were not assessed (see Ref. [1, Appendix B]). We do not know how many there were in this second category.

2. 'Stair climbing' was the item showing highest difficulty in both Table 5.2 and Table 5.4 (note "a more negative logit score indicates more difficult items" [1, Appendix D]). Please also refer to our Rasch map in Figure 5.1.1 (regarding 99 subjects who underwent total hip arthroplasty within the six previous days; (for Materials and Methods please see [5]), where the hierarchy of ILAS item difficulty shows that 'stair climbing' was one of the most difficult items (after 'walking speed'). Nonetheless, Elings et al. state that stair climbing "was the easiest item to complete for the majority of patients. ..". This statement is in harsh contrast with the literature on this topic [4-6].

3. We wonder if their operational definition of 'stair climbing' is comparable with that in the original ILAS [5]. During 'stair climbing' patients used 'infrastructural assistance of a guardrail', while in the original ILAS the item 'climbing-up and down three steps' can be performed with sticks, crutches, or frames: no mention of a handrail.

4. In order to reduce the early floor effect in the ILAS scale measuring the assistance needed during functional activities, the ILAS authors [5] added a complementary scale, related to the need for assistive devices, not used in the present study. For these reasons, we wonder whether Elings et al. could 
Figure 5.1.1. Map of person-ability (left-hand column; each "\#" indicates two patients) and itemdifficulty (right-hand column; each item is indicated by its number in the scale) for the ILAS. The vertical line represents the measure, in linear logit units (on the extreme left-hand side). By convention, the average difficulty of items in the test is set at 0 logits (and indicated with "M"). Accordingly, a candidate with average ability is indicated with M. "S" markers are placed one sample standard deviation away from the mean, and "T" markers are placed two sample standard deviations away from the mean.

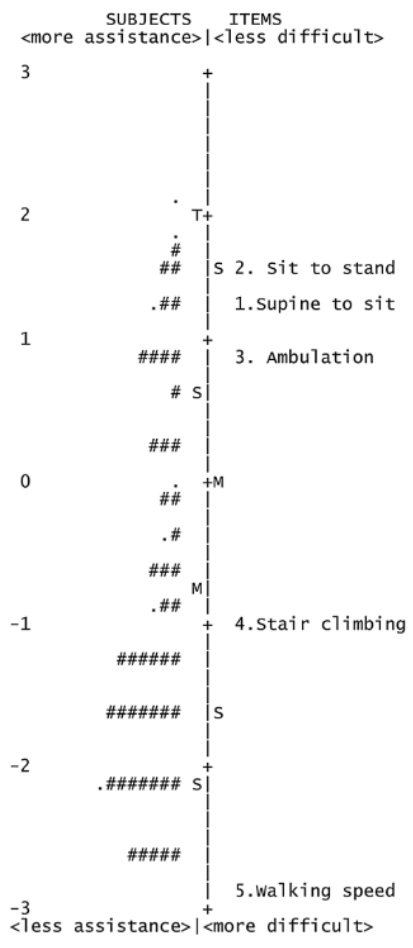

\section{ETHICAL APPROVAL}

Data presented in this Letter come from a study approved by the local ethical committee, and all patients gave their informed consent (same protocol as in Ref. [5]). 


\section{CONFLICT OF INTEREST}

None declared.

\section{REFERENCES}

1. Elings J, Zoethout S, ten Klooster PM, van der Sluis G, van Gaalen SM, van Meeteren NLU, et al. Advocacy for use of the modified lowa Level of Assistance Scale for clinical use in patients after hip replacement: an observational study. Physiotherapy 2018.

2. Holman R, Glas CAW. Modelling non-ignorable missing-data mechanisms with item response theory models. Br J Math Stat Psychol 2005.

3. Combrinck C, Scherman V, Maree D, Howie S. Multiple Imputation for Dichotomous MNAR Items Using Recursive Structural Equation Modeling With Rasch Measures as Predictors. SAGE Open 2018.
4. Shields RK, Enloe LJ, Evans RE, Smith KB, Steckel SD. Reliability, validity, and responsiveness of functional tests in patients with total joint replacement. Phys Ther 1995;75:169-76; discussion 176-9.

5. Benedetti MG, Franchignoni F, Morri M, Franchini N, Natali E, Giordano A. Rasch analysis of the lowa Level of Assistance Scale in patients with total hip and knee arthroplasty. Int J Rehabil Res 2014;37:118-24.

6. Jesudason C, Stiller K. Are bed exercises necessary following hip arthroplasty? Aust J Physiother 2002;48:73-81. 


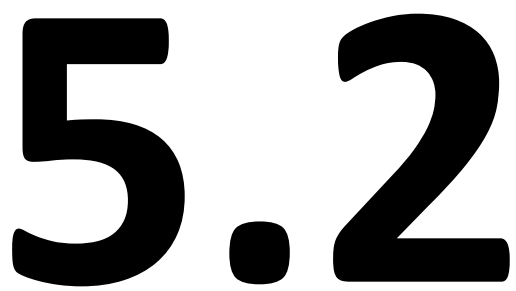

\title{
RESPONSE TO LETTER TO THE EDITOR
}

\author{
J. Elings
}

PHYSIOTHERAPY 106 (2020) 213-214 


\section{LETTER TO THE EDITOR}

\section{RESPONSE TO LETTER TO THE EDITOR ‘AdVOCACY FOR THE USE OF THE MODIFIEd IOWA LEVELS OF ASSISTANCE SCALE FOR CLINICAL USE IN PATIENTS AFTER HIP REPLACEMENT: AN OBSERVATIONAL STUDY'}

Dear Editor,

We want to thank Benedetti et al. for their time and effort to respond to our paper "Advocacy for use of the modified lowa Level of Assistance Scale (mILAS) for clinical use in patients after hip replacement: an observational study". With this reply, we will provide additional information to clarify the questions and issues raised. However, before we provide a detailed response, we believe it is important to point out that the mILAS data used in this work were primarily collected as part of day-to-day practice as formerly advised by van Genderen et al. [1]. This means that the mILAS data were actually used as part of clinical decision-making, and thus not purely for the sake of psychometric properties testing. From the perspective of ecological validity [2], it makes sense to test psychometric properties of outcome measures as part of their real-world setting, however, this typically does result in a number of (mainly statistical) challenges. Some of those challenges were raised by Benedetti et al. In order to properly use the ILAS in day-to-day care (e.g.,to assess the progress of functional recovery, to inform therapeutic management and to aid in discharge planning), we (in collaboration with the clinical staff, among which the physiotherapy team, and patients) felt the need to reduce and alter some of its original items, namely:

1. Remove the item "walking speed". Walking speed was not considered a relevant item to determine if a person could safely walk without assistance. Moreover, we believed the walking speed item would hamper the implementation of the mILAS in daily practice, as this would require additional, therapeutically-irrelevant actions by the participating physiotherapists;

2. Alter the item requirement "stair climbing". We changed the item stair climbing from 3 steps to a complete staircase with the use of a guardrail which better reflects a homesituation and therefore makes it a more suitable therapeutic goal;

3. Add the item "sit to supine". From a clinical perspective, therapists noted that a proportion of people needing assistance getting back in bed while in the hospital and they believed this was a relevant milestone to function independently at home; 
4. Remove the scoring option "walking aids". Although physiotherapists did score this item, we did not include it in the overall mILAS score, as we were solely interested whether a patient was able to independently perform those activities that he/she would need at their discharge destination.

Abovementioned changes have consequences for the analysis and interpretation of results compared to, for example, studies who particularly focus on the psychometric properties of the instrument, but not on the instrument in relation to its real-world context and use. In the first point raised by Benedetti et al., they ask us why we treated the score 6 as missing. During regular care the scoring option 6 [not tested] is useful, after all, items like stair climbing are not typically performed during the first sessions of therapy. However, and here we full-heartedly agree with Benedetti et al., from a statistical analysis point of view, the scoring option 6 is far from ideal. First of all, because it substantially reduces the variability in item responses necessary for psychometric analyses, such as internal consistency and Rasch analysis. Additionally, as Benedetti et al. rightly note, it may obscure different reasons for missingness on items. Both of which may explain some of the differences in the outcomes between our study and that of our colleagues Benedetti et al. [3].

In their second point, Benedetti et al. point out an eye catching difference between our study and the current evidence-base on the ILAS [3-5], namely the difference in item difficulty of "stair climbing". We believe that our choice of wording was inconvenient and led to misunderstanding, however, we agree with the comment that stair climbing is indeed the most difficult item of all mILAS items (see Table 5.4) looking at the Rasch statistics alone [6]. However, the exact item difficulty estimate was very unreliable, given the poor fit-statistics and large error (difficulty -2.91 , SE 1.31, infit 2.22 (Z-std 2.1) and outfit 4.27 (Z-std 1.8)). The statement that stair climbing was the easiest item, was based on the observation that the vast majority of the people could fulfill the item stair climbing without any assistance (see Table 5.2) [6]. As stated in our discussion, we considered to omit stair climbing from the mILAS because it seems to measure a different construct but concluded not to do so because it is a clinically relevant item to assess in order to evaluate if a person can be discharged based on their recovery of activities. The third point raises the question if the operational definition of stairclimbing was comparable to the original ILAS. As stated earlier, we altered the original operational definition to reflect a patient's living context (mostly home)-situation better and therefore make it a more suitable therapeutic goal. The final point regarded the scale that measures the assistive devices. As indicated earlier, we did score the assistive device the patient needed during the mILAS. However, we found it irrelevant in 
assessing if the patient was ready for discharge and did not adopt it to the sum score of the mILAS. We were solely interested if the patient could perform all mILAS items required at his discharge destination regardless of the assistive device needed. In conclusion, we all want a clinically useful tool that measures the mutual goal(s) of the patient and healthcare professional the best during hospitalization. In daily practice, this required us to adjust the ILAS measurement tool in order to properly fit the individual patient and his living context. We strongly believe that developing a clinical useful scale to properly inform day-to-day clinical practice with good psychometric properties should be advocated over creating a perfect standardized scale from the perspective of statistical uniformity with limited clinical usefulness. We therefore stand by our conclusion that the mILAS is a clinically sound measurement tool to assess the ability of patients to perform five functional tasks safely during hospitalization and at the same time monitor progress in order to anticipate and organize their discharge.

\section{REFERENCES}

1. Van Genderen FR, De Bie RA, Helders PJM, Van Meeteren NLU. Reliability Research: Towards a More Clinically Relevant Approach. Phys Ther Rev 2003;8:169-76.

2. Brewer M. Research Design and Issues of Validity. In Reis H and Judd C (eds) Handbook of Research Methods in Social and Personality Psychology. Cambrigde: Cambridge University Press.; 2000.

3. Benedetti MG, Franchignoni F, Morri M, Franchini N, Natali E, Giordano A. Rasch analysis of the lowa Level of Assistance Scale in patients with total hip and knee arthroplasty. Int J Rehabil Res 2014;37:118-24.
4. Jesudason C, Stiller K. Are bed exercises necessary following hip arthroplasty? Aust J Physiother 2002;48:73-81.

5. Shields RK, Enloe LJ, Evans RE, Smith KB, Steckel SD. Reliability, validity, and responsiveness of functional tests in patients with total joint replacement. Phys Ther 1995;75:169-76; discussion 176-9.

6. Elings J, Zoethout S, ten Klooster PM, van der Sluis G, van Gaalen SM, van Meeteren NLU, et al. Advocacy for use of the modified lowa Level of Assistance Scale for clinical use in patients after hip replacement: an observational study. Physiotherapy 2018. 


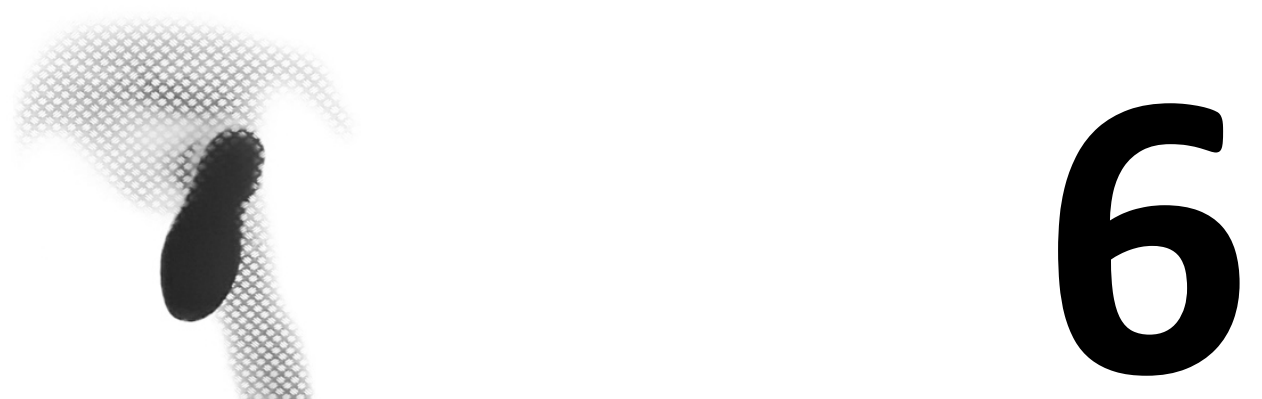

REFERENCE CHART FOR KNEE FLEXION FOLLOWING TOTAL KNEE ARTHROPLASTY: A NOVEL TOOL FOR MONITORING POSTOPERATIVE RECOVERY

\author{
A.J. Kittelson | J. Elings | K. Colborn | T.J. Hoogeboom | J.C. \\ Christensen | N.L.U. van Meeteren | S. van Buuren | J. Stevens-Lapsley
}




\section{ABSTRACT}

Background: Clinicians and patients lack an evidence-based framework by which to judge individual-level recovery following total knee arthroplasty (TKA) surgery, thus impeding personalized treatment approaches for this elective surgery. Our study aimed to develop and validate a reference chart for monitoring recovery of knee flexion following TKA surgery.

Methods: Retrospective analysis of data collected in routine rehabilitation practice for patients following TKA surgery. Reference charts were constructed using Generalized Additive Models for Location Scale and Shape. Various models were compared using the Schwarz Bayesian Criterion, Mean Squared Error in 5-fold cross validation, and centile coverage (i.e. the percent of observed data represented below specified centiles). The performance of the reference chart was then validated against a test set of patients with later surgical dates, by examining the centile coverage and average bias (i.e. difference between observed and predicted values) in the test dataset.

Results: A total of 1,173 observations from 327 patients were used to develop a reference chart for knee flexion over the first 120 days following TKA. The best fitting model utilized a non-linear time trend, with smoothing splines for median and variance parameters. Additionally, optimization of the number of knots in smoothing splines and power transformation of time improved model fit. The reference chart performed adequately in a test set of 171 patients (377 observations), with accurate centile coverage and minimal average bias ( $<3$ degrees).

Conclusion: A reference chart developed with clinically collected data offers a new approach to monitoring knee flexion following TKA. 
There are approximately 700,000 procedures performed per year in the United States, and surgical rates are comparable in many European countries (120-200 per 100,000 people) $[1,2]$. Despite the prevalence of TKA, there is little agreement in the clinical community regarding postoperative care and rehabilitation [3-5]. Rehabilitation practices vary widely by clinical site, and the content and goals of therapy are based largely on clinicians' experience and intuition [3]. Postoperative protocols typically indicate recovery milestones based on the expected clinical course for the average person, but surgical populations are heterogeneous [6-8]. Fundamentally, clinicians and patients lack an evidence-based framework by which to judge individual patients' recovery following TKA surgery, thus impeding efforts to advance personalized or patientcentered treatment approaches for this elective surgery.

Reference charts are commonly used in healthcare settings to assist in monitoring patients' progress and to inform clinical decisions at the level of the individual patient. The concept of monitoring the clinical course and adapting treatment decisions according to observations at the individual level has been promoted in psychotherapy [9,10], in patients with chronic disease [11], and more recently in research designs (one-person trials) [12]. In rehabilitation, reference charts have been proposed as a means of assessing patients' response to preoperative inspiratory muscle training [13]. The key concept in all cases is to base clinical decisions on the comparison of individual-level observations to an evidence-based reference [14].

The goal of this study was to develop and validate a reference chart with clinically collected data, to inform monitoring of knee flexion active range of motion (AROM) following TKA surgery. Knee flexion is frequently assessed following TKA and is widely cited in postoperative protocols as a marker of progress throughout recovery $[3,15]$. Additionally, we sought to describe a systematic approach to generating reference charts, including model fitting and selection procedures, so that future investigations could extend this methodology to other outcomes following TKA or to clinical trajectory data for other patient populations. Ultimately, this work could serve as a template for developing evidence-based references to aid in monitoring and decision-making for a variety of health conditions. 


\section{METHODS}

Data were collected in the context of routine clinical practice at three sites (ATI Physical Therapy, in partnership with Greenville Health Systems) in South Carolina.

As part of ongoing quality improvement efforts for patients undergoing knee arthroplasty, outcomes data were recorded on a semi-weekly basis throughout postoperative rehabilitation. Therapists were trained in the standardized application of outcomes assessments. The postoperative rehabilitation regime was also standardized across clinic locations and therapists. Outcomes data were compiled in a quality improvement (QI) database, housed at the University of Colorado Denver, using Research Electronic Data Capture (REDCap), a secure web-based software for database development. All analyses complied with a non-human subject research designation and were approved by the Colorado Multiple Institutional Review Board (COMIRB \#: 15-1797).

\section{PATIENTS}

For the purposes of this analysis, the QI database was queried for all available (de-identified) patient records. At the time of data extraction, a total of 897 patient records were available, with surgical dates between January 2013 and May 2016. However, 321 records could not be used because they lacked postoperative flexion AROM data. This was not unexpected, as patients commonly travel to the surgical center for preoperative consultation and surgery but subsequently undergo postoperative rehabilitation at a clinic closer to home. An additional 59 records were excluded because patients underwent a procedure other than primary unilateral TKA (17 patients underwent revision arthroplasty and 42 patients underwent unicompartmental arthroplasty). For the remaining records, postoperative flexion AROM data were available between 2 and 857 days (median 36 days) following surgery. We utilized the first 120 postoperative days for this project. We reasoned that rehabilitation typically occurs during this time window, and recovery plateaus between months 1 and 3 following surgery [16]. Thus, we felt a reference chart describing recovery over the first 120 days would adequately capture the relevant time frame. A total of 498 patient records (1,550 observations of flexion AROM) were used for this analysis. 


\section{Knee Flexion Active RANGe of Motion (AROM)}

Knee flexion AROM (in degrees) was measured in a supine position via long-arm goniometry (see supplementary material). Briefly, patients were allowed to practice bending their knee 5 times, with therapist-assist as needed, prior to the therapist making the final assessment. For the final assessment the knee was placed in extension, and the patient was instructed to flex the knee as far as possible using only muscle power, leaving the heel on the surface. The fulcrum of the goniometer was placed at the medial joint line, with the lateral malleolus of the fibula and greater trochanter of the femur as distal landmarks [17]. Physical Therapists were trained on a quarterly basis in this protocol, to standardize the collection of outcomes measures. Flexion AROM was measured on a semi-weekly basis throughout postoperative rehabilitation.

Table 6.1. Strategy for reference chart development

- Generate flexion by time curves using GAMLSS with a variety of candidate distributions (e.g. Normal, Gamma, Box-Cox)

- Determine whether the addition of smoothing splines to median, variance, skewness and kurtosis improve fit of the models, using the Schwarz Bayesian Criterion (SBC) as a numerical guide.

- $\quad$ Optimize the number of knots of smoothing splines and power transformation of time using the find.hyper function

- Compare model fit for different candidate distributions using SBC and Mean Squared Error (MSE) by 5 -fold cross validation. The best model minimizes these metrics.

- Examine reference charts for each of the candidate distributions to determine the percentage of data captured below each of the specified centiles. The best model accurately represents the observed data (e.g. $5 \%$ below the $5^{\text {th }}$ percentile, etc.).

- For similar models, a less-complex approach (fewer degrees of freedom) is preferred. 


\section{DATA ANALYSIS}

We divided the sample of patient records temporally (by surgical date) into a development set and test set. By this approach, the development set contained the earlier $75 \%$ of the knee flexion measurements and the test set contained the later $25 \%$ of the available knee flexion measurements. Model fit was adjudicated and a reference chart was constructed using the development set, and the performance of this chart was subsequently examined using the test set. The steps for generating and assessing reference curves were analogous to those used to develop reference charts for childhood growth, emphasizing procedures that would also yield a simple solution that limits the risk of overfitting the data (Table 6.1) [18-20].

\section{Reference Chart Development}

Using data from the development set, a series of statistical models were examined describing the variation of flexion AROM over the first 120 days following surgery. Generalized Additive Models for Location Scale and Shape (GAMLSS, version 4.4.0) [20] were used to obtain estimates of the median and other fitted centiles as smooth functions of the measurements in days. In GAMLSS, a variety of distributions can be used to fit the mean/median, variance, skewness, and kurtosis of the outcome. We selected 6 candidate distributions, of increasing complexity, for which to model knee flexion AROM. The Normal (NO) and Gamma (GA) distributions modeled 2 parameters (the median and variance) of the outcome. The t-family (TF) and Box-Cox Cole and Green (BCCG) distributions modeled the median, variance, and skewness of the outcome. The Box-Cox $t$ distribution (BCT) and Box-Cox Power Exponential (BCPE) distributions modeled the median, variance, skewness and kurtosis of the outcome $[21,22]$. Model fit was adjudicated numerically by the Schwarz Bayesian Criterion (SBC) [23]. To protect against over-fitting, we also calculated the Mean Square Error (MSE) via 5-fold cross validation of each model (i.e. by developing the model in $80 \%$ of the development set and testing the model in the left-out $20 \%$ ). Based on these metrics, we pursued model selection by the following approach:

First, we examined whether fitting cubic splines for each of the different parameters (i.e. median, variance, skewness, kurtosis) improved model fit. Next, we optimized: 1) the number of knots specified in splines for each parameter, and 2) the power-transformation of time, using the "find.hyper" function in GAMLSS. We then constructed reference charts and calculated the percentage of observed values captured below each of the specified centiles $\left(5^{\text {th }}, 10^{\text {th }}, 25^{\text {th }}, 50^{\text {th }}\right.$, $75^{\text {th }}, 90^{\text {th }}$, and $95^{\text {th }}$ centile). Of the candidate models, the best solution would minimize the SBC, demonstrate low MSE by within-sample cross validation, and accurately describe percentiles in 


\section{Preliminary Validation}

Reference chart performance was examined by applying the reference curves to a test set of patients with later surgical dates. This approach was designed to mimic the process for development and subsequent use of the reference chart in practice. The accuracy with which the reference curves fit the new data was examined by z-test for proportions, and the average bias (difference between predicted and observed values) was calculated. Ideal performance would be reflected by accurate representation of the test set data (e.g., $5 \%$ of the observed data captured below the $5^{\text {th }}$ percentile, $10 \%$ below the $10^{\text {th }}$ percentile, etc.), and zero bias.

\section{RESULTS}

Demographic and anthropometric characteristics did not differ significantly between the development and test datasets (Table 6.2). The development set included 327 patient, with surgical dates between January 2013 and August 2015, while the test set included 177 patients with surgical dates between August 2015 and May 2016.

Table 6.2. Demographic and anthropometric characteristics of patients used to develop the reference chart (development set) vs. patients used to examine the performance of the reference chart (test set). Values are presented as mean \pm standard deviation unless otherwise reported.

\begin{tabular}{llll}
\hline & Development Set & Test Set & t-test (CHI2) \\
\cline { 2 - 4 } & $\mathrm{n}=327(1173$ obs) & $\mathrm{n}=171$ (377 obs) & p-value \\
\hline Age (yrs) & $64.3 \pm 9.4$ & $64.9 \pm 13.5$ & 0.72 \\
BMl (kg/m2) & $32.9 \pm 6.6$ & $31.4 \pm 7.9$ & 0.23 \\
Female (\%) & 57.1 & 55.7 & $(0.8)$ \\
\hline
\end{tabular}

Abbreviations: BMI, Body Mass Index; obs, observations. 


\section{MOdel SELECTION}

For each of the 6 selected GAMLSS distributions (NO, GA, TF, BCCG, BCT, BCPE) we examined model fit under a variety of conditions. According to SBC, it was beneficial to model the location (mean/median) and variance parameters with cubic splines (Table 6.3). However, fitting splines to skewness and kurtosis parameters did not yield additional improvements in model fit (Table 6.3). Further improvements in SBC were achieved by optimizing the power transformation of time and the number of knots in smoothing splines (Table 6.4). Additionally, the process of optimization yielded simpler models with fewer overall degrees of freedom. The optimized models specified 2.2 knots for the median and 1.2 knots for variance, with a power transformation approximating the square root of time (0.56).

Overall, reference charts for the optimized models demonstrated similar fit statistics and withinsample performance (i.e. within the development set). The BCCG, BCT, and BCPE distributions performed marginally better than the NO, GA and TF distributions in representing percentiles of the development set data. For example, $45.7 \%$ of the observed data fell below the median for the reference chart built with a GA distribution, whereas $49.9 \%$ of the observed data fell below the median for the reference chart built with the BCCG distribution (Figure 6.1a). The BCCG distribution performed incrementally better than BCPE in centile fit, and incrementally better than BCT according to SBC and MSE. Additionally, the BCCG model was the simpler model, with fewer overall degrees of freedom. Based on these metrics we chose to build the final reference chart for flexion AROM using the BCCG distribution.

\section{Preliminary Validation}

The performance of the curves in the test set was slightly diminished relative to the performance in the development set. For example, $80 \%$ of the observations fell below the $75^{\text {th }}$ percentile ( $p=0.03$ for the difference between the observed and expected proportions). However, other observed proportions were similar to expected proportions, and the average bias remained minimal at -2.5 degrees of flexion AROM (Figure 6.1b).

\section{REFERENCE VALUES AND CHART}

Figure 6.2 shows the reference chart we developed for monitoring flexion AROM after TKA. It gives a sense of the general trajectory and variability in postoperative recovery of flexion AROM over the first 120 days following surgery. The typical recovery trajectory demonstrates flexion 
Table 6.3. Schwarz Bayesian Criterion (SBC) for models of increasing complexity (lower SBC values indicate a better solution), using data from the development set. Adding smoothing parameters for skewness and kurtosis parameters does not improve model fit.

\begin{tabular}{|c|c|c|c|c|}
\hline & \multicolumn{4}{|c|}{ Parameters with smoothing splines } \\
\hline & Median & $\begin{array}{l}\text { Median, } \\
\text { Variance }\end{array}$ & $\begin{array}{l}\text { Median, } \\
\text { Variance, } \\
\text { Skewness }\end{array}$ & $\begin{array}{l}\text { Median, } \\
\text { Variance, } \\
\text { Skewness, } \\
\text { Kurtosis }\end{array}$ \\
\hline \multicolumn{5}{|c|}{ GAMLSS Distribution } \\
\hline NO & 9343.77 & 9309.87 & - & - \\
\hline GA & 9503.95 & 9379.81 & - & - \\
\hline TF & 9333.56 & 9313.83 & 9312.84 & - \\
\hline BCCG & 9334.84 & 9281.30 & 9292.47 & - \\
\hline $\mathrm{BCT}$ & 9341.22 & 9288.37 & 9299.56 & 9306.63 \\
\hline $\mathrm{BCPE}$ & 9341.87 & 9285.50 & 9295.17 & 9301.96 \\
\hline
\end{tabular}

Abbreviations: NO, Normal; GA, Gamma; TF, t-Family; BCCG, Box Cox Cole and Green; BCT, Box Cox t-distribution; BCPE, Box Cox Power Exponential.

Table 6.4. Characteristics of GAMLSS models fit with smoothing splines for the median and variance, following optimization of smoothing spline knots and the power transformation of time. The best GAMLSS distribution for each metric is bolded. Results reflect within sample performance (i.e., within the development set).

\begin{tabular}{|c|c|c|c|c|c|c|c|c|}
\hline & \multirow{2}{*}{$\begin{array}{l}\text { Model Degrees } \\
\text { of Freedom }\end{array}$} & \multirow{2}{*}{ SBC } & \multirow{2}{*}{ MSE } & \multicolumn{5}{|c|}{$\begin{array}{l}\text { Percentage of observed values captured } \\
\text { below model centiles }\end{array}$} \\
\hline & & & & 5 th & 25th & 50th & 75th & 95th \\
\hline \multicolumn{9}{|c|}{ GAMLSS Distribution } \\
\hline NO & 7.45 & 9298.6 & 166.0 & 6.05 & 23.53 & 47.49 & 73.49 & 97.1 \\
\hline GA & 7.45 & 9364.7 & 165.6 & 6.05 & 22.59 & 45.69 & 73.83 & 98.04 \\
\hline TF & 8.45 & 9303.0 & 171.1 & 6.05 & 24.47 & 48.34 & 73.49 & 97.19 \\
\hline $\mathrm{BCCG}$ & 8.45 & 9266.5 & 166.4 & 5.12 & 25.15 & 49.87 & 74.51 & 95.14 \\
\hline $\mathrm{BCT}$ & 9.45 & 9273.5 & 167.4 & 5.12 & 25.15 & 49.87 & 74.51 & 95.14 \\
\hline BCPE & 9.45 & 9271.0 & 166.3 & 5.29 & 24.55 & 49.79 & 74.85 & 95.06 \\
\hline
\end{tabular}

Abbreviations: SBC, Schwarz Bayesian Criterion; MSE, Mean Squared Error; NO, Normal; GA, Gamma; TF, t-Family; BCCG, Box Cox Cole and Green; BCT, Box Cox t-distribution; BCPE, Box Cox Power Exponential. 
Figure 6.1. Knee flexion active range of motion (AROM) reference curves, applied to: a) the development set (from which the curves were derived), and b) the test set (a temporally distinct sample of patients). The worst fitting model (GA) and best fitting model (BCCG) according to Schwarz Bayesian Criterion are displayed (a). The BCCG model is applied to the test set (b), and the percent of observations captured below each of the specified centiles is provided. The p-value, according to general z-test, describes the probability of the observed percentage, given the expected percentage. The average bias describes the mean difference between observed values and values predicted from the GAMLSS model.

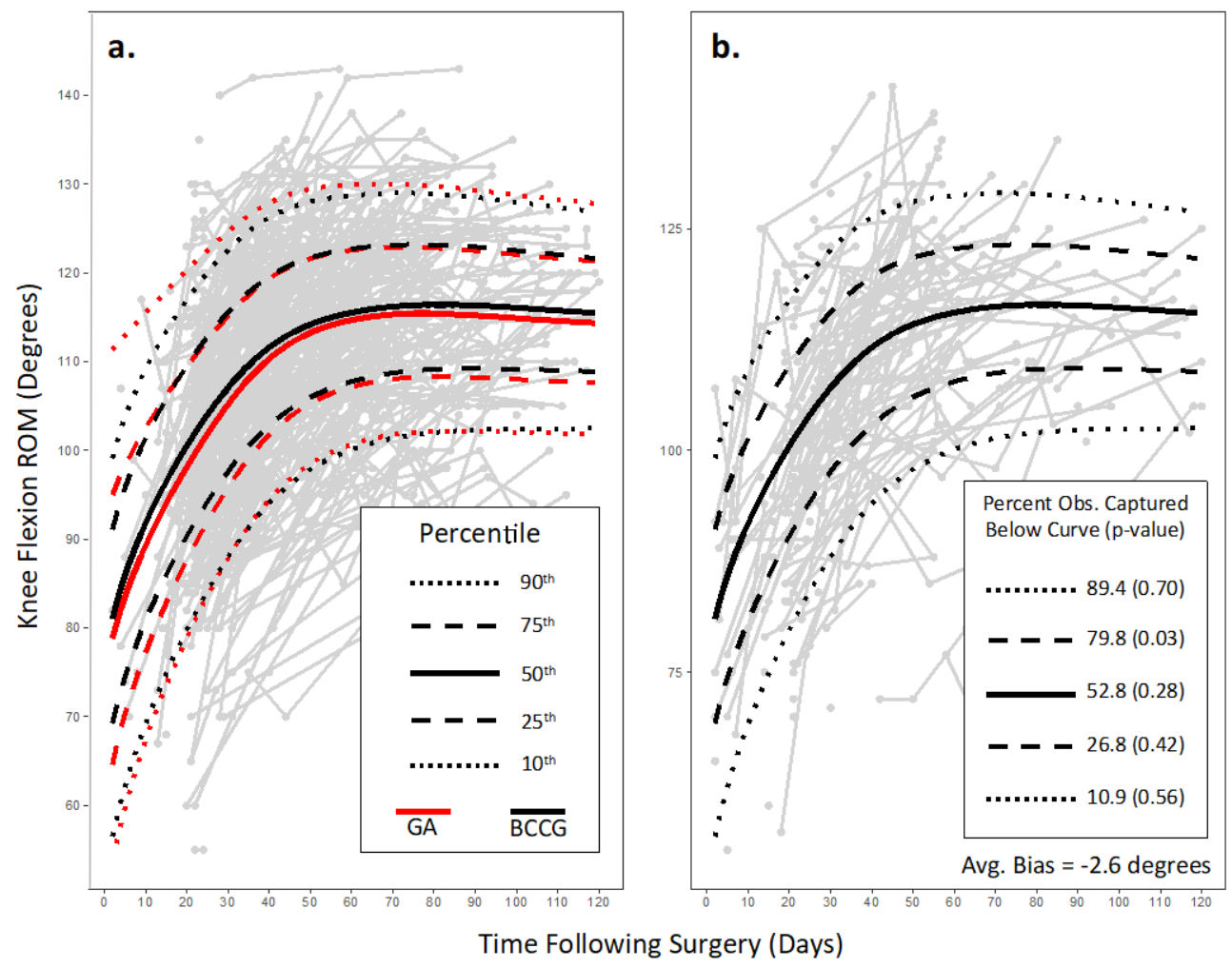




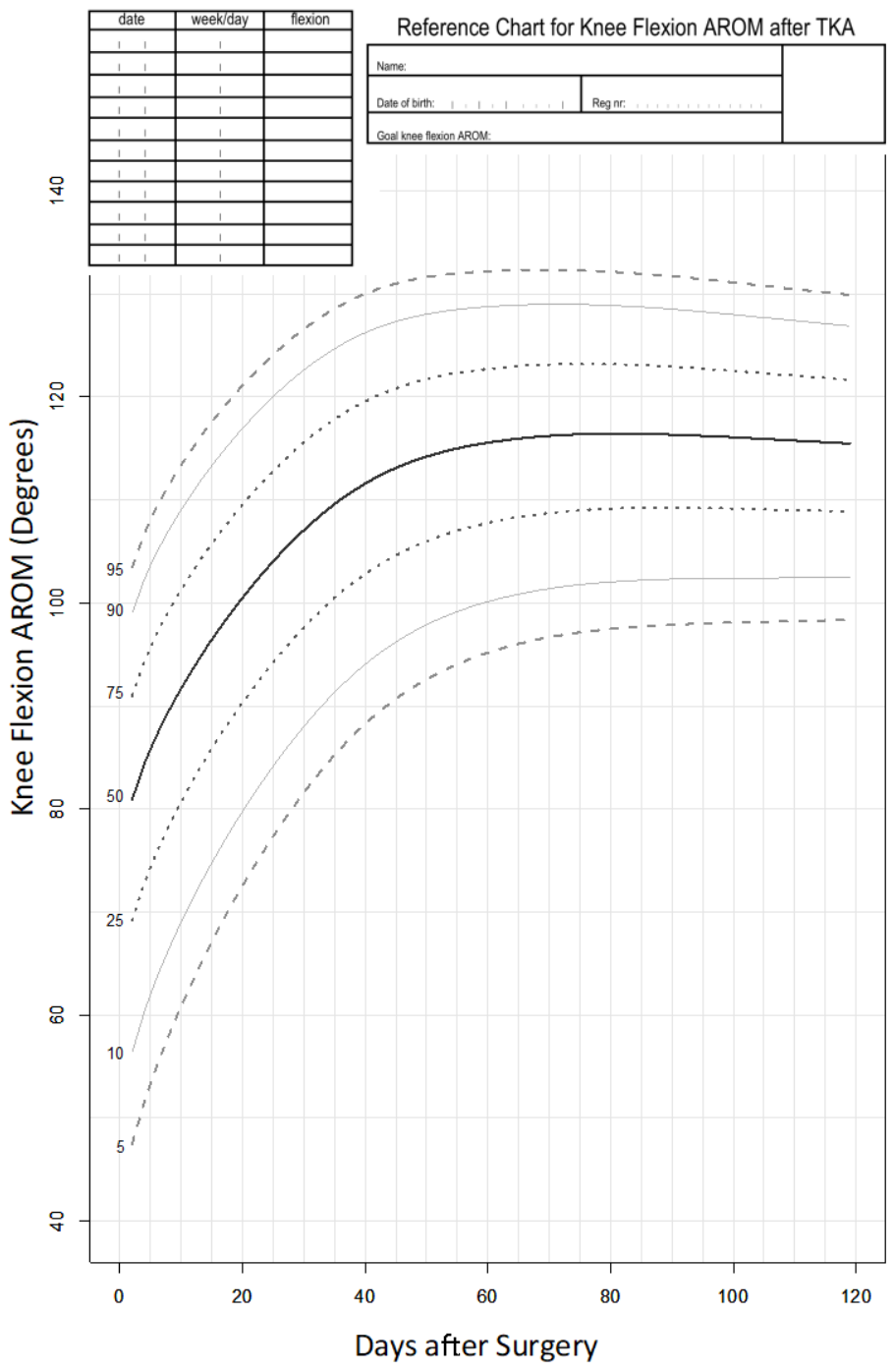

\section{DISCUSSION}

This reference chart illustrates how flexion AROM changes following surgery. In general, there is a period of rapid increase within the first 40 days, followed by a gradual plateau. The shape of the recovery trajectory differs depending on the centile of the reference chart. Higher centiles plateau more rapidly than lower centiles, with the lowest centiles continuing to demonstrate improvements up until 60-80 days following surgery. Moreover, there is substantial variability 
between individual patients in recovery of knee flexion. The interquartile range is between 13-22 degrees throughout the first 4 months of recovery. This variability illustrates the limitations of a one-size-fits-all approach to postoperative rehabilitation, as both the content of therapy and resource requirements are likely to differ between individuals with fast versus slow recovery of flexion. Tools such as this reference chart extend the work of previous studies (which have modeled the trajectory of recovery of the sample mean) $[16,24]$ to include an intuitive display of the variability in recovery, which may facilitate decisions at the level of the individual patient [25].

This flexion AROM reference chart represents a departure from one-size-fits-all protocols, which have traditionally been used to guide decisions following TKA surgery [15]. A typical TKA rehabilitation protocol might stipulate a postoperative flexion AROM goal of 110 degrees, as this is the amount of knee flexion required for many activities such as symmetrical stair gait or cycling [26]. However, at an individual level, patients may have more or less ambitious functional goals, and this reference chart provides an indication of the likelihood (as well as the timing) of whatever is best for the individual. Moreover, the variability in knee flexion AROM outcomes, readily apparent on the reference chart, further illustrates the problems in stipulating a single goal for all patients. According to the reference chart, a patient who demonstrates $>90$ degrees of flexion AROM early after surgery should ultimately achieve an outcome much greater than 110 degrees, whereas a patient who demonstrates $<60$ degrees of flexion AROM early after surgery has a high likelihood of not achieving 110 degrees. Thus, the reference chart provides a more nuanced picture of the clinical course, which could augment or replace protocol-based approaches to rehabilitation.

A strength of our study is the use of data collected in routine clinical practice, as the results are less likely to be influenced by volunteer bias or research eligibility criteria. This potentially enhances the future translation to rehabilitation clinical settings. The temporal validation used in this study is also a strength; it suggests the reference chart remains accurate over time. However, as our data were collected in a single clinic system (3 sites), the geographic generalizability is unknown. The references reported here could be compared to data collected at other sites in future work. Another potential limitation is the time frame selected for chart development. We limited our dataset to the first 4 postoperative months to cover the typical time frame of rehabilitation, but recovery may persist at a slower rate for many additional months [27]. Thus, there may be value in expanding our reference chart to cover a longer post-operative time frame. Finally, the reference chart presented here describes knee flexion, but multiple outcome measures are likely to be important to individuals and clinicians following TKA surgery [28,29]. 
Future work could focus on developing a menu of reference charts describing a range of clinical outcome measures (e.g. physical functioning, pain, quality of life) to support recovery monitoring [14].

\section{CONCLUSION}

We have developed and tested a reference chart for knee flexion AROM following TKA surgery. The final reference chart was accurate via both within-sample and out-of sample testing. It is designed to be easy to use in practice to track postoperative recovery of knee flexion AROM for individual patients, relative to others who have previously undergone TKA surgery.

\section{ETHICS APPROVAL AND CONSENT TO PARTICIPATE}

Ethics approval to conduct this study was obtained from the University of Colorado Denver Multiple Institutional Review Board (COMIRB \#: 15-1797).

\section{COMPETING INTERESTS}

The authors have no conflicts of interest to report.

\section{FUNDING}

This study is funded by the Agency for Healthcare Research and Quality (AHRQ R03 HS024316, AHRQ R01 HS025692) and the National Institutes of Health (NIH K12 HD055931). The funding body had no role in the study design, data collection, data analysis, and interpretation of data, nor any role in writing the manuscript. 


\section{REFERENCE}

1. Kurtz SM, Ong KL, Lau E, Widmer M, Maravic M, Gómez-Barrena E, et al. International survey of primary and revision total knee replacement. Int Orthop 2011;35:1783-9.

2. Healthcare Cost and Utilization Project. Facts and Figures 2009. 2010. http://www.hcupus.ahrq.gov/reports/factsandfigures/2009/exhi bit3_1.jsp. (accessed May 22, 2017).

3. Peter WF, Nelissen RGHH, Vlieland TPMV. Guideline recommendations for post-acute postoperative physiotherapy in total hip and knee arthroplasty: are they used in daily clinical practice? Musculoskeletal Care 2014;12:125-31.

4. NIH Consensus Statement on total knee replacement. NIH Consens State Sci Statements 2003;20:1-34.

5. Naylor JM, Hart A, Harris IA, Lewin AM. Variation in rehabilitation setting after uncomplicated total knee or hip arthroplasty: A call for evidence-based guidelines. BMC Musculoskelet Disord 2019.

6. Naylor JM, Harmer AR, Heard RC, Harris IA. Patterns of recovery following knee and hip replacement in an Australian cohort. Aust Health Rev 2009;33:124-35.

7. Weiss JM, Noble PC, Conditt MA, Kohl HW, Roberts S, Cook KF, et al. What functional activities are important to patients with knee replacements? Clin Orthop Relat Res 2002:172-88.

8. Lugano G, Gianola S, Castellini G, Banfi G, Seil R, Denti M, et al. Evidence-Based Medicine (EBM) is properly perceived but its application is still limited in the orthopedic clinical practice: an online survey among the European Society of Sports Traumatology, Knee Surgery and Arthroscopy (ESSKA) members. Knee Surgery, Sport Traumatol Arthrosc 2020.

9. Lutz W, Rafaeli E, Howard KI, Martinovich Z. Adaptive Modeling of Progress in Outpatient Psychotherapy. Psychother Res 2002;12:42743.

10. Lueger RJ, Howard KI, Martinovich Z, Lutz W, Anderson EE, Grissom G. Assessing treatment progress of individual patients using expected treatment response models. J Consult Clin Psychol 2001;69:150-8.
11. Glasziou P, Irwig L, Mant D. Monitoring in chronic disease: a rational approach. BMJ 2005;330:644-8.

12. Schork NJ. Personalized medicine: Time for one-person trials. Nature 2015;520:609-11.

13. van Buuren $S$, Hulzebos EHJ, Valkenet $K$, Lindeman E, van Meeteren NLU. Reference chart of inspiratory muscle strength: a new tool to monitor the effect of pre-operative training. Physiotherapy 2014;100:128-33.

14. Kittelson AJ, Hoogeboom TJ, Schenkman M, Stevens-Lapsley JE, van Meeteren NLU. Person-Centered Care and Physical Therapy: A "People-Like-Me" Approach. Phys Ther 2019.

15. Kisner C, Colby L. Therapeutic exercise : foundations and techniques. 6th ed. Philadelphia: F.A. Davis Company; 2012.

16. Kennedy DM, Stratford PW, Riddle DL, Hanna SE, Gollish JD. Assessing recovery and establishing prognosis following total knee arthroplasty. Phys Ther 2008;88:22-32.

17. Brosseau L, Balmer S, Tousignant M, O'Sullivan JP, Goudreault C, Goudreault M, et al. Intra- and intertester reliability and criterion validity of the parallelogram and universal goniometers for measuring maximum active knee flexion and extension of patients with knee restrictions. Arch Phys Med Rehabil 2001;82:396-402.

18. Hayes DJ, van Buuren S, ter Kuile FO, Stasinopoulos DM, Rigby RA, Terlouw DJ. Developing regional weight-for-age growth references for malaria-endemic countries to optimize age-based dosing of antimalarials. Bull World Health Organ 2015;93:74-83.

19. Flegal KM, Cole TJ. Construction of LMS parameters for the Centers for Disease Control and Prevention 2000 growth charts. Natl Health Stat Report 2013:1-3.

20. Stasinopoulos M, Rigby B, Akantziliotou C. Instructions on how to use the gamlss package in R Second Edition 2008.

21. Rigby RA, Stasinopoulos DM. Smooth centile curves for skew and kurtotic data modelled using the Box-Cox power exponential distribution. Stat Med 2004;23:3053-76. 
22. Rigby R, Stasinopoulos D. Using the Box-Coxt distribution in GAMLSS to model skewness and kurtosis. Stat Modelling 2006;6:209-29.

23. Cavanaugh JE, Neath AA. Generalizing the derivation of the schwarz information criterion. Commun Stat - Theory Methods 1999;28:4966.

24. Kennedy DM, Stratford PW, Hanna SE, Wessel J, Gollish JD. Modeling early recovery of physical function following hip and knee arthroplasty. BMC Musculoskelet Disord 2006;7:100.

25. Kraemer HC, Frank E, Kupfer DJ. Moderators of treatment outcomes: clinical, research, and policy importance. JAMA 2006;296:1286-9.

26. Rowe PJ, Myles CM, Walker C, Nutton R. Knee joint kinematics in gait and other functional activities measured using flexible electrogoniometry: how much knee motion is sufficient for normal daily life? Gait Posture 2000;12:143-55.
27. Bade MJ, Kittelson JM, Kohrt WM, StevensLapsley JE. Predicting functional performance and range of motion outcomes after total knee arthroplasty. Am J Phys Med Rehabil 2014;93:579-85.

28. Yoshida Y, Mizner RL, Ramsey DK, SnyderMackler L. Examining outcomes from total knee arthroplasty and the relationship between quadriceps strength and knee function over time. Clin Biomech 2008.

29. Mizner RL, Petterson SC, Clements KE, Zeni JAJ, Irrgang JJ, Snyder-Mackler L. Measuring functional improvement after total knee arthroplasty requires both performance-based and patient-report assessments: a longitudinal analysis of outcomes. J Arthroplasty 2011;26:728-37. 
138 | Chapter 6 


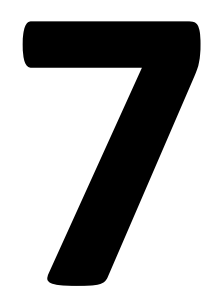

GENERAL DISCUSSION 
During my 20 years' employment as a Bachelor physical therapist in clinical acute care practice, I have built up experience in the screening and treatment of over 5,000 people awaiting for and recovering from a total hip arthroplasty (THA). What gradually became clear to me, was a wide range of inter-individual differences regarding perioperative pain, anxiety, and (recovery of) daily activities. However, were these differences real or just the result of my own cognitive biases as a clinician? And if these differences were real, what then was their impact on people's perioperative trajectory and recovery over time? These questions resulted in my decision to follow an academic Master of Sciences course and thereafter combine my clinical tasks with scientific tasks. By doing so, I became an embedded physical therapy scientist engaged with my clinical colleagues in the professional guiding and study of the perioperative trajectory, focused mainly on the functional outcomes of individual patients. With this thesis, an exciting and intriguing clinical and scientific journey comes to a closure. At the same time, this closure marks a new phase in my career, in which I hope to develop additional means to further optimize the perioperative trajectory. In parallel, I hope to implement the revenues of this thesis in the Diakonessenhuis hospital as well as elsewhere to benefit other patients beyond those at the Diakonessenhuis.

The studies included in this thesis were conducted in a time frame with ongoing changes in society at large and healthcare more specifically. These changes found their origin way back, namely in the late $19^{\text {th }}$ century intertwined processes of urbanization, education, and industrialization. From that time onwards, an almost continuous process of societal and technological change led to an unprecedented and rapid increase of prosperity and life expectancy, resulting in a demographic spin-off of a vastly aging population and an increased incidence of chronic medical conditions [1]. Aging and chronicity put societal and economic pressure on society as a whole and certainly on an important system as the healthcare system. This pressure demands specific attention from patients, caregivers, researchers, innovative industries, and governments to retain the systems' affordability and availability [2].

One of the options to retain the systems' affordability and accessibility was the reconceptualization of health combined with the reorganization and redesign of healthcare and its organization and infrastructure. And indeed, several experts have recently done so: 1) Machteld Huber reconceptualized health as "the ability to adapt and to self-manage" [3] instead of "a state of complete physical, mental and social well-being and not merely the absence of disease or infirmity," as was formerly conceptualized by the WHO [4]. In parallel, 2) Heerkens et al discussed an alternative for the prevailing WHO-framework out of which the International Classification of Functioning (ICF) was constructed [5]. Whereas, the original framework starts 
with "health condition and disorders," Heerkens and colleagues plead for the superposition of functioning. Both these initiatives reduced the dominance of the medical perspective and advocated a more broadened spectrum of what health would or even should be, close or even beyond the biopsychosocial perspective in the seventies of the former century advocated by amongst others Engel [6]. Within these reconceptualization efforts, health should no longer be seen as the ultimate goal by itself, but as an important resource: a resource to function in the ever-changing environment of the individual person.

Besides the reconceptualization of health, experts like Elroy Hood and Frank Miedema developed concepts to change the orientation of the healthcare system, itself, as well as the system of science, especially the part that is related to the healthcare system. Consequently constructs like P4-medicine [7] and Science in transition [8] were launched, with the goals of on the one hand shifting health and healthcare towards personalization, prediction, prevention, and participation, and reducing costs, whilst on the other hand reducing redundancy in research policy and execution.

For patients with end-stage hip osteoarthritis THA is the most common inpatient elective surgery worldwide [9], [10] to decrease hip pain and increase daily physical functioning [11]-[13]. It is in general expected that the numbers of THA procedures will double in the next decade [14], putting further operational and financial pressure on the healthcare system if no adjustments in policies and practice are made. With the aforementioned paradigm-shifts and this outlook in mind, the healthcare context for patients opting for THA changed quite radically the last ten years. For instance, concepts as rapid recovery / enhanced recovery after surgery (ERAS) were introduced. These concepts reduced the mean length of hospital stay to a bare minimum of 1-2 days compared to 6-12 days during the period between 2006 to 2010 [15]. Such concepts were able to lower the costs of a THA procedure by $10 \%-20 \%$ within various countries with different healthcare systems [16]. Nowadays, even forms of outpatient surgery are more and more considered a safe option for a selective proportion of patients undergoing joint arthroplasty [17]; an option where patients become ambulatory right after surgery and do not need to stay overnight in the hospital. Despite the evolution in surgical interventions and peri-operative procedures, there are no guarantees for optimal outcomes nor are these without risk. To decide with the patient if THA is the best option at a specific timepoint given his or her end-stage arthrosis complaints, professionals still need preoperative tools to predict the potential functional benefits (recovery of daily activities) as well as the risks of the entire procedure for individual patients. 
In the general introduction of the thesis (Chapter 1), we introduced the continuum of care model of Hulzebos and van Meeteren [18] (Figure 7.1). This model substantiates the need to personalize perioperative healthcare interventions. Figure 7.1 is an copy of this figure, in which the studies included in this thesis are plotted one by one in the model. Thereby, this thesis is divided into three parts: 1) prediction of inpatient recovery of physical functioning, activities or LoS; 2) instrument I: inpatient recovery of activities; and 3) instrument II: outpatient recovery. In the first part, a systematic review was presented regarding preoperative patient-related factors predicting inpatient recovery of activities or LoS (Chapter 2). Based on the SR-outcomes we prospectively studied the physical functional status of the patient as a predictor on top of to the more classical preoperative patient-related factors as age/sex/BMI and developed and internally and externally validated two preoperative prediction tools: I) exploration and conformation of clinically relevant patient profiles (Chapter 3) and II) risk stratification model for delayed inpatient recovery of activities (Chapter 4). In the second part of the thesis, measuring inpatient recovery of activities, we presented a clinical measurement tool to assess recovery of activities (Chapter 5). Finally, in part three we showed the feasibility of conducting recovery curves to predict post clinical shortterm recovery (Chapter 6).

As stated in the introduction, I noted through my work as a clinical PT that there was a large range of inter-individual differences regarding preoperative and postoperative pain, anxiety, and especially recovery of daily activities of patients after THA surgery. This observation was confirmed by our findings in this thesis. We found that the postoperative recovery of basic daily activities after THA is heterogeneous, yet staged in fairly stable subsequent steps and may consequently seem to be fairly predictable as well. A key factor for the prediction of the postoperative recovery of daily physical activities seems to be the preoperative physical performance of individual patients.

The discussion of this thesis is structured as follows: In section 7.1 we discuss the main outcomes of this thesis. Methodological considerations are provided in section 7.2. followed by section 7.3 where we discuss the implications of our findings for clinical practice. Finally, in section 7.4 we provide our recommendations for future research. 
Figure 7.1. Focus of the studies visualized in the continuum of care model of Hulzebos and van Meeteren [18].

Part I:

Prediction of inpatient recovery of physical functioning, activities or LoS Chapter Chapter Chapter

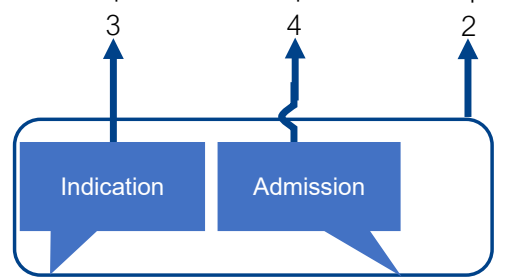

Assessment Medical

Functional

Diagnosis Risk profile

\section{Low-risk}

Preopeative advice and

self-management

\section{High-risk}

Tailored preoperative intervention at home
Part II:

Inpatient

recovery

Chapter

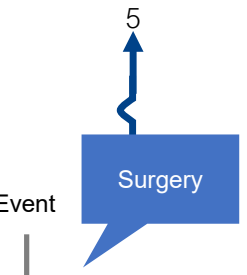

Assessment

Medical

Functional

Diagnosis

Risk profile

Initiation of

therapy
Part III:

Outpatient

recovery

Chapter

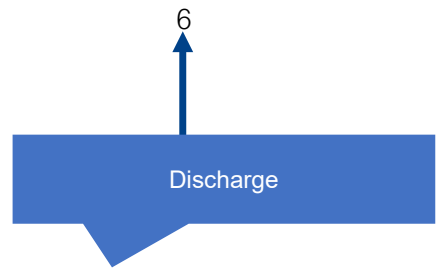

Fragile/high-risk

Tailored postoperative

intervention at home and monitoring

Low-risk

Postoperative advice,

monitoring and self-management

Proactive culture

Professional interdisciplinary primary and acute-care team

Information and communication technology; (outcome) data

Infrastructure and logistics (ward, rooms, beds, television, ambulant monitoring, etc.)

\section{MAIN OUTCOMES}

The main outcomes of this thesis will be discussed in an order that resembles each part of the continuum of care as presented in Figure 7.1. As an underlying construct for the discussion, we will use the P4-medicine domains Predictive, Preventive, Personalized, and Participatory. At the end of each paragraph, we will summarize our conclusions of the discussion within the relevant P4-medicine domains. 


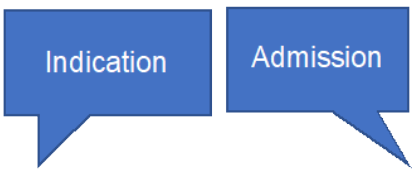

\section{PART I: PReOPERATIVE INPATIENT PREDICTION OF ACTIVITIES (ChAPTERS 2-4)}

To construct a clinically practical and relevant prediction instrument, we needed on the one hand to include the proper prognostic factor(s) and on the other hand a relevant outcome for the patient and/or healthcare professional at the appropriate moment in time.

To do so, our review of the literature (Chapter 3) demonstrated that previous studies aiming to predict LoS and inpatient recovery of activities of patients after THA were generally focused on preoperative factors within domains "personal factors" and "body functions and structures" of the ICF [19]. This rather limited focus of just two of the five domains of the ICF appeared to be a hiatus in the, up until then, current literature. In 2014, Hoogeboom et al. presented a physiologic model explaining the "normal" adaptive response of the patient after major surgery [20]. In this model, the patients' preoperative functional status plays a key role in the coping strategy with the physiological stress associated with major surgery (including surgical stress) to function at least on the same level or preferably better as before surgery. Therefore, patients with a vulnerable preoperative functional status, for instance as a result of a decline in the capacity of one or multiple organs, for instance muscles or the cardiopulmonary system, will more likely have trouble adapting to the postoperative situation, resulting in a slower and even poorer recovery than those patients who are in good and fit shape.

The abovementioned is supported by our findings presented in Chapter 2 (Patient Profiles), and Chapter 4 (Risk Stratification Model). In these two chapters, we demonstrated that patients with a more vulnerable functional status demonstrate a slower recovery than patients with a better preoperative status. This is in line with the systematic review of Buirs et al. [21] who reported that 16 out of the 17 included studies reported that the preoperative physical function had a significant correlation with the postoperative functional outcome with a mean follow-up of 16 months in patients after THA. Based on these findings they concluded that there is strong evidence between the preoperative physical function and the functional outcome after THA surgery. Moreover, this is in line with the literature in cardiac [22], abdominal [23], [24] and oncological populations [25][27]. 
comorbidities with regard to the ability to walk). The TUG and the body mass index (BMI) are to be seen as representatives of the only possible treatable traits in the risk stratification model (age, sex, BMI, American Society of Anesthesiologists physical status classification (ASA-score), Charnley score, TUG).

In conclusion, the preoperative functional status of the patient is a relevant prognostic factor for prediction of the recovery of physical functioning and ought to be taken into account for the planning and decoration of the clinical pathway with individual patients before and after THA. Moreover, functional recovery of physical activities after THA surgery provides essential additional information to personalize care interventions after THA than LoS alone.

\section{CONCLUSIONS BASED ON THE OUTCOMES OF THIS THESIS}

- Predictive: Quality and speed of recovery of activities and LoS are fairly predictable before surgery on the basis of 8 determinants: age, sex, BMI, pain, ASA-score, Charnley score, TUG, and 6 minutes walking test.

- Preventive: BMI, walking capacity, and functional mobility are treatable traits that can be targeted in the preoperative phase (chapters 2 and 4 , respectively).

- Participatory: Prediction of risks warrants active involvement of both patient and professional during the assessment of the patient profiles and risk stratification model

- Personalized: The four patient profiles and the risk stratification model developed in this thesis can be used by healthcare professionals with individual patients to potentially initiate personalized preoperative prophylactic interventions.

\section{Practical ReCOMmendations}

We recommend healthcare professional to use our model to predict the postoperative recovery of activities of patients after total hip replacement (predictive). Subsequently, we recommend that they discuss the outcomes together with the patient (participatory). In case a patient has a high risk for prolonged recovery of activities after surgery, we recommend healthcare professionals 
discuss the potential merit of preoperative prophylactic interventions (preventive), including prioritization, weight loss, prehabilitation, cognitive behavioral therapy, surgery postponement, and other conservative treatment. The preoperative interventions should preferably be organized with and within the patient's own physical and social environment [28], [29] (personalize).

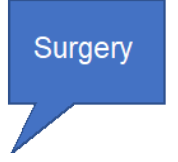

\section{PART II: INPATIENT RECOVERY OF ACTIVITIES (CHAPTER 5)}

An important element to address are the outcomes utilized during the inpatient recovery in our systematic review (Chapter 3$)$, namely the $\operatorname{LoS}(n=12)$ and recovery of activities $(n=2)$ [30]. These outcomes are related to the aim of the thesis to gain insight into patients' physical daily functioning trajectories throughout their perioperative THA journey. First, LoS is an essential outcome measure regarding hospital production and logistics and is reported in (almost) all studies. However, the LoS in itself hardly provides any essential information about the daily functioning of the patient. Recovery of activities data can distinguish different recovery patterns, which can be used to introduce a more progressive approach towards the restoration of the activities to personalize interventions for the individual patient. Patients with a predicted prolonged recovery of activities might benefit from a more intensive PT regime to regain basic activities such as transfers and walking. Therefore, in our opinion, to evaluate or improve healthcare by evaluating data originated from regular care, we need more than LoS data alone.

LoS is influenced by of at least 3 factors: (1) medical recovery; (2) recovery of activities; (3) organizational and logistical indices of the hospital regarding the discharge residence of the patient [31]. By measuring all three elements, the healthcare professionals gather relevant information which could be the input to further improve patients' recovery after surgery and the utilization of hospital care for the better. However, the possible reduction of LoS is of less interest to the patient; their perspective is more focused on the mid-term and long-term outcomes (e.g., self-supporting, walking without walking aid, working, vacation, etc.) after THA surgery. To decide if patients can be discharged, we need an adequate tool that measures the recovery of basic activities essential for individual patients in their specific living context, for instance at home (transfers, walking, and stair climbing) [32]. 
In-hospital clinical pathways for patients undergoing THA have changed over the years. From joint care [33] where all patients were treated within the same time contingent approach, to Fast Track [15] / Rapid recovery / Early Recovery After Surgery protocols with the main focus on process optimization and patient engagement, to even more individualized perioperative care concentrating on the ability and context of the patient [34]. The aforementioned alterations in clinical care pathways are one of the many factors that contributed to the reduction of hospital stay to 1-2 nights. Although there are still patients that need more time to recover, related to for instance high inflammatory responses and pain, which urge for developing/using additional rehabilitation strategies [35].

Through their premorbid status combined with the negative side-effects of surgery, a subgroup of patients (slow recovery) needs more time to recuperate regarding their recovery of activities than the more and more planned 1-2 nights. To identify slow recovering patients, it is crucial to gather detailed information on the postoperative recovery of basic activities such as transfers in and out of bed, transfer sit to stand, walking, and stair climbing. To do so, the modified Barthel Index (MBI) [36] and postoperative ambulation distance on the day of discharge [37] were reported in our SR (Chapter 3) as measurement tools to quantify the inpatient recovery of activities after THA. Neither the MBI nor the ambulation distance provided the preferred detailed information on the recovery of basic activities. On the contrary, the lowa Levels of Assistance Scale (ILAS) [38] that was already published by Shields et al. in 1995 and which measures the assistance needed during transfers, walking, and stair climbing was a more preferred option for our purpose. However, to fully fulfill our need for detailed information on the recovery of activities we modified the ILAS by adding the transfer sit-supine because this item appeared to be difficult for a specific subgroup of patients during the first days after THA surgery. This addition was especially needed considering the movement restrictions (limited hip flexion of more than 90 degrees, adduction, and internal rotation) imposed after a straight lateral or posterolateral THA surgical approach during the time of this thesis. The effectiveness of such movement restrictions are not supported in a systematic review from 2016 in which the unrestricted group had fewer dislocations after THA [39].

The next step in the care for patients opting for a THA is outpatient surgery. With outpatient surgery, there is more need for patient and informal caregivers-involvement, and multidisciplinary care coordination, standardized perioperative protocols, discharge planning, and careful patient selection are considered more and more essential [40]. Nowadays, at least $15 \%$ of all the patients awaiting THA can be treated within outpatient facilities [41]. This selected group of fit patients 
can be safely supplemented with other patients [42]. Close monitoring of the recovery of activities will become even more important during the short period the patient is admitted to ensure the patient can function within his own context/home. Alternatively, we may be able to instruct the patients themselves to monitor their functional gradual recovery of essential milestones with help of the easy mILAS.

In conclusion, the outcome of the mILAS provides essential information to the patient, his or her informal caregivers, and formal healthcare professionals regarding the ability of the patient to fulfill the basic activities needed to get back home based on their recovery of activities (transfers, walking, and, if necessary, stair climbing).

\section{CONCLUSIONS BASED ON THE OUTCOMES OF THIS THESIS}

- Predictive: The mILAS provides a more complete picture of patients' recovery of activities than the ILAS, as a result of additionally assessing the transfer sit-supine. Physical therapists should be aware that completing the sit-supine transfer is most challenging for patients on day 2 and 3 after THR surgery.

- Preventive: The use of the mILAS can assist to prevent a longer than necessary admission to the hospital by monitoring the mILAS on a daily basis and by observing whether patients are ready to be discharged based on their independence on functional milestones.

- Participatory: Patients were actively involved during the assessment of the mILAS in all relevant activities (transfers supine-sit, sit-supine, sit-stand, walking, and stair climbing). Assessing these activities is essential in order to determine whether a patient is sufficiently physically independent to be discharged home.

- Personalized: Discharge time and destination can be personalized on the basis of individual mILAS/recovery of physical activities patterns instead of hospital logistics and organization matters.

\section{Practical ReCOMmendations}

We recommend the mILAS as the primary outcome measure for the prediction and monitoring of inpatient recovery of activities after THA surgery (predictive). In addition, we recommend adding 
the DEMMI on the day of discharge, because of the ceiling effect of the mILAS. The DEMMI score can provide the patient and his/her therapist additional insight in the patient's physical recovery phase, which can be used to monitor throughout the continuum of care [43] (predictive). Furthermore, we recommend patients and healthcare professionals to frequently measure inpatient recovery of activities with the mILAS after THA surgery for two reasons (participatory). First, to provide patients insight in their recovery of activities related to their goals and/or discharge destination. This insight could result in an incentive for the patient to be more in the lead to train and test [44], possibly on their own, those activities/transfer which are difficult, nonetheless essential to reach the patient desired goals (participatory). And second, to provide insight in the recovery patterns of patients, possible lag of recovery of activities during the direct postoperative period, and to give reason for (immediate) intervening preventively or curatively (predictive and preventive). Patient-specific recovery patterns can help titrate the treatment with the individual patient; e.g., for patients with a slow recovery of activities more intense and/or frequent clinical physical therapy might be helpful, and for patients with a fast recovery of activities discharge might be pushed forward (personalize).

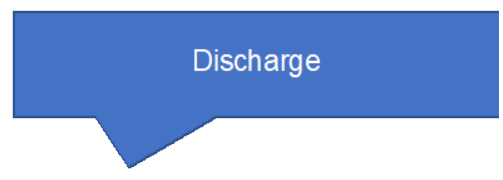

\section{PART III: SHORT-TERM OUTPATIENT PREDICTION (CHAPTER 6)}

To jointly decide if THA surgery is the best option for the patient, patients and their healthcare team may need predictions of the short-term and long-term outcomes of functions and activities. As stated in Part I, the patient is less interested in the direct postoperative recovery (LoS) and more focused on the short-term and long-term outcomes, like walking without walking aid, working, riding a bike, vacation, etc. Depending on indices like multiple troublesome joints, comorbidities, low mental wellbeing, and low physical function of the cohort under study, approximately $15 \%$ to $50 \%$ of the patients after THA are not satisfied after one year on parameters as pain and disability after THA [45], [46]. One of the reasons reported for dissatisfaction is the mismatch between the expectations' of the patient and the actual recovery of long term activities 3-6 years after total hip or knee replacement [47]. A personalized prediction of short-term/long-term recovery of activities after THA may help patients and health professional set more realistic expectations regarding the predicted recovery of activities. Those more realistic 
expectations may lead to a higher satisfaction rate of the patient with the outcome of the THA surgery.

In this thesis, we introduced recovery curves (see Figure 7.2), to visualize the predicted shortterm (first postoperative days) and long-term (until three months) outcomes for patients and healthcare professionals. These recovery curves provide an estimate of the predicted mean outcome on a group level with a 95\% uncertainty boundary. This uncertainty boundary depicts essential information to the patient and healthcare professionals regarding the best and worst achievable outcome after THA, helping them to make a more realistic, evidence-based decision to either move forward with surgery or not and consequently consider other therapeutic options. Evidence-based decision making in this respect may be defined as follows: a decision in which the patient's preoperative daily functioning, postoperative wishes, and expectations are properly taken into account and a decision where the clinician had sufficient knowledge on the predicted recovery to aid in his own clinical reasoning process.

Another benefit of these recovery curves, beside their predictive capacities, is that they can be informative for patients and their (in)formal caregivers for the use and interpretations of clinimetric instruments to evaluate their recovery process. Especially during the early postoperative treatment period, frequent measuring is essential to evaluate and, if necessary, to make guided decisions to titrate the treatment to optimize the investments in the recovery of the individual patient [48], [49]. Moreover, frequently monitoring recovery progression allows patients to become more involved or even "owners"/decisionmakers of the relevant treatment decisions that aid their recovery. Moreover, it may also help identify any deviations from the "natural/normal" curve at the right time and with greater precision (see for an example Figure 7.2 III).

Working with growth charts is, for many decades, standard care in pediatric healthcare. However, their application with patients during the THA-trajectory remained obscure, although some preliminary research has been performed by Kennedy and Stratford [49], [50]. Our data warrants further exploration of these recovery curves in daily practice. Yet, in a recently paper by Kittelson et al. [51], the authors showed that these recovery curves can be further optimized by tailoring them to each individual patient. The authors introduced a method called "people like me." In this methodology, recovery curves are built using only data from people with similar traits like the unique patient of interest. This method helps to further narrow the uncertainty bandwidth of the prediction, which may result in an even more realistic personalized prediction, which has to be validate in daily practice. 
flexion range of motion (active range of motion) following TKA surgery; III) Practical example using the recovery curve wherein Patient $A$ reflects almost maximal flexion at all times with measurements located at the upper part of the curves above the 95th percentile; Patient B starts with poor recovery of flexion located at the 5th percentile eventually settling around the 50th percentile; Patient $\mathrm{C}$ started with low flexion scores (10th percentile) and scores leveling of below the 5th percentile.
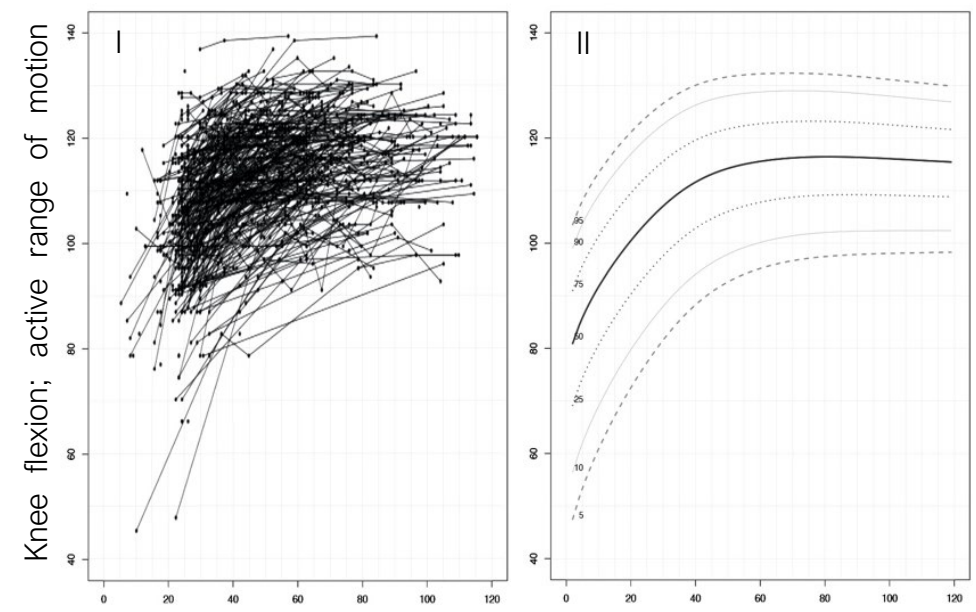

Days after surgery

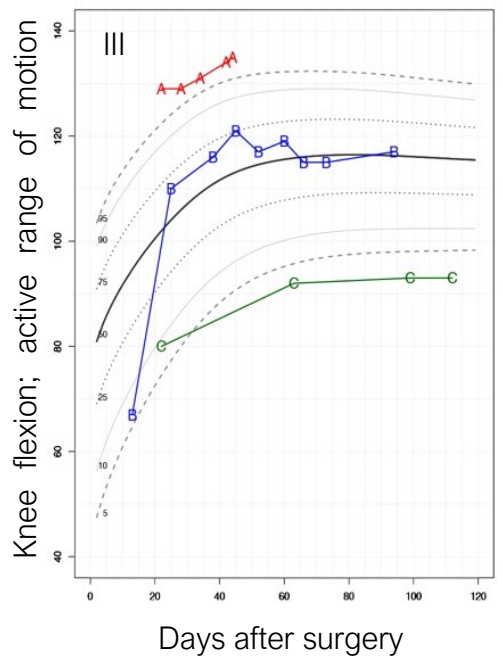


In conclusion, the prediction of short-term and/or long-term recovery of patients after THA is possible with recovery curves. Thereby, recovery curves can be used 1) to decide if the predicted outcomes of THA surgery meet the patients' expectations, and 2) to monitor and optimize the postoperative recovery trajectory.

\section{CONCLUSIONS BASED ON THE OUTCOMES OF THIS THESIS}

- $\quad$ Predictive: Recovery curves provide a visual depiction of the predicted mean recovery curve on a specific outcome measure over time.

- Preventive: Recovery curves can be used to assess the recovery of patients related to the predicted mean recovery curve on a specific outcome measure over time. Deviations from the predicted mean recovery curve can be detected early during the rehabilitation period if measured frequently.

- Participatory: To monitor the recovery of flexion mobility of the knee patients were actively involved during the knee mobility assessments during the first 120 days after surgery.

- Personalized: Recovery curves can be considered for use to compare the recovery of individual patients to the predicted mean recovery curve related to the preoperative baseline situation. Deviations, especially negative, from the mean curve should trigger the patient and his/her physical therapist to titrate therapy for the better and/or refer back to the orthopedic surgeon to rule out medical complications.

\section{Practical Recommendations}

We recommend to implement these recovery curves in daily physical therapy practice to determine if restrictions in knee mobility during the early postoperative period (first 120 days) give reason for immediate intervening curatively or preventively [48] (preventive). Simultaneously, we recommend to further optimize the mean recovery curves, through curve matching by developing recovery curves for the individual patient by only using data from near identical twins (based on preoperative patient characteristics) which results in "patient specific" curves which can result in more accurate predictions with less variability surrounding the estimates [51], [52] (personalize and predictive). These curves provide patients insight into their own recovery related to the predicted recovery and, if applicable, patients can measure themselves and thereby monitor their 
own recovery progression over time (participatory). Finally, we recommend to use recovery curves in a personalized way, meaning: use them to give patients insight in their predicted recovery over time and the consequences regarding return to, for the patient, relevant activities like cycling/sports/work/etcetera. This information might influence the patient in his/her decision about the choice for THA surgery and the consideration if that would be the best therapeutic option and, if indeed so, to plan the exact best moment of the surgery in time based on his/her condition, both physically as well as socially (personalize).

\section{METHODOLOGICAL CONSIDERATIONS}

As an embedded scientist and innovator working in a peripheral/local (non-academic) hospital, I wanted to resolve questions that originated from daily practice with data from daily care. To answer those questions, together with my team I used a participatory action research approach [53] wherein data from daily practice were used to further develop, optimize, and evaluate our clinical care pathway for the individual patient. In this section, we discuss the pros and cons of such an action research approach to the validity of our results in this thesis.

The studies reported in Chapters 4 and 5 (Risk Stratification Model and mILAS, respectively) were conducted through an action research approach, which is a simultaneous process of delivering daily care and doing scientific research. Planning, acting, observing, and reflection are the four key elements. We conclude that the action research approach fits the embedded scientist well. The free and existing data originated from daily practice can be used to develop new scientific evidence, although the outcomes of our action research approach were a compromise between the usability and the scientific value of the end-products/models. Essential decisions were made in favor of the usability over the best scientific methods, which should be considered interpreting the results.

The research studies (Chapters 2, 4-6) in this thesis originated from real-life daily practice using fully coded and anonymized data from three community hospitals in the Netherlands and an outpatient care center in the USA. We used two cross-sectional designs (Chapters 2 and 4) and two longitudinal designs (Chapters 5 and 6 ) in this thesis. The major limitation of the crosssectional design is that it provides an overview of a specific point in time [54]. We know that the impact of end-stage osteoarthritis and the negative side effects after surgery vary over time within patients [55], and clinical pathways will constantly be adapted by implementing new procedures 
and techniques due to changing rules and regulations and health-related developments [56]. Therefore, a longitudinal study design is the preferred method of evaluating the associations between variables, as these kind of approaches also allow for changes over time within patients and clinical pathways and their ingredients [57].

In all of our studies, no specific exclusion criteria were used during patient selection to avoid selection bias and improve the generalizability of our findings [58]. In addition, to evaluate the generalizability we used two datasets from different healthcare institutions to externally validate our findings (Chapters 2, 4, and 5). The fully coded and anonymized data used for the external validity originated from two community/general hospitals located in different parts of the Netherlands, namely North (Ny Smellinghe, Drachten) and East (Deventer hospital, Deventer), ranging from the fourth largest city in the Netherlands to a more rural area, and representing somewhat different cultures and patients' perspectives. This variety of patients may have reduced the external validity of our models. However, we perhaps must be careful of always wanting to extrapolate our findings to other hospitals and regions or countries with other cultures, perspectives, and healthcare systems [59]. If we want to further personalize our prediction models, we might need to start valuing internal over external predictions in some scenarios. In addition, we want to address the FAIR-data approach which "emphasise machine-actionability (i.e., the capacity of computational systems to Find, Access, Interoperate, and Reuse data with none or minimal human intervention) because humans increasingly rely on computational support to deal with data as a result of the increase in volume, complexity, and creation speed of data." [60]. By reusing the already available datasets of two other hospitals we facilitated the R in FAIR which stands for Reuse.

Using data from daily practice has some advantages in terms of low impact on patients (no extra efforts needed), high feasibility (no additional proceedings are needed), low costs (no additional equipment needed), and high generalizability (no specific exclusion criteria). However, besides the advantages, some disadvantages are also present. As an embedded scientists I am constantly in confrontation and debate with the scientist and the clinical practitioner in myself. Searching for the optimal decisions regarding the 1) scientific quality of the data and studies; 2) feasibility of conducting the studies; and 3) the methodological possibilities of the study in favor of the feasibility of the outcome product. A decision in favor of one has its consequences for the other(s). For example, if you want to assess the association of cardiovascular fitness related to the recovery of activities after THA, you would preferably use a maximum oxygen uptake test (VO2 max) such as the steep ramp test to quantify the physical fitness. Although this test is not 
commonly performed in patients awaiting THA, there are more common tests available such as the 6-minute walking test (6MWT), which has a fair to moderate [61] correlation with the VO2 max (0.51-0.76) [62] and which is less expensive and does not need expensive equipment. On the one hand, for the quality of the study the VO2 max test would be preferable because of its accuracy but is less feasible, and on the other hand the 6MWT more feasible but the outcome are less accurate. It is a continuous seesaw between applicability and validity. One needs to be aware of this and make informed decisions.

Finally, this thesis is conducted within a strong positivist approach using existing constructs and evidence. We forced classical factors like age, BMI and comorbidity-score in our prediction models (Chapters 2 and 4 ) and we used relatively new methods for conducting recovery curves (Chapter 6) after THA surgery. A more (social) constructivist approach would not be amiss and could lead to new concepts of healthcare delivery, as stated in recommendations of future research by applying $\mathrm{P} 4$-medicine principles within $\mathrm{N}$ of 1 studies and personalization of recovery curves. The ideas, constructs, and methodology of the different studies were shared and discussed within a community of practice that holds eight hospitals and joins forces for already 10 years in the field of improvement of perioperative care under the name "Better in - Better out" (total hip and knee arthroplasty, spinal fusion, and abdominal cancer surgery). The community of practice consisted of multiple PTs, embedded scientists, post-docs, and a professor in the field of physical therapy, and was complemented with two CEOs of a private party in implementing revenues of "Better in - Better out" in the Netherlands.

\section{IMPLICATIONS FOR FUTURE PRACTICE}

This thesis aimed to generate new knowledge to improve day-to-day healthcare. The findings of this thesis can be used to further individualize clinical care pathways by including preoperative prediction of the recovery of activities during the inpatient and short-term outpatient period and likewise probably plan additional or alternative interventions more adequately in the entire perioperative trajectory of patients with end-stage hip osteoarthritis awaiting THA.

\section{PREDICTIVE}

During the preoperative phase of THA surgery, we recommend assessing the functional status of patients in addition to the already common assessment of medical and personal factors as comorbidity, BMI, pain, and age. We found that the physical status is a robust prognostic factor 
for postoperative recovery of physical activities (Chapters 2 and 4). Whereby, the TUG and the 6-minute walking test showed a significant difference between the four different profiles in Chapter 2 and the TUG and 6-minute walking test had both high associations with the postoperative recovery of activities in Chapter 4; based on the practical issues we choose the TUG since it takes less time to administer. Thereby, functional status can be assessed with a lot of different measurement tools; most of them are easy to use with marginal costs, basic requirements, and little time consumption, and their outcomes are fairly easy to interpret in the context of the perioperative trajectory of an individual patient.

\section{PREVENTIVE}

The outcome of our preoperative prediction model (Chapter 4) can be the incentive for preventive actions to increase the functional status with the patient awaiting THA. On the one hand, with respect to patients with a low risk of prolonged recovery combined with a low functional status, the advice to be more active during the "waiting period" before surgery might already be sufficient. On the other hand, patients with a high risk of prolonged and low functional recovery might benefit from participating in a preventive preoperative exercise intervention to increase their functional status to withstand the negative effects of surgery. The effect of such preoperative interventions seems so far inconclusive when looking to the literature, especially the many systematic reviews published the last decade. However, most likely this could be triggered by selection bias through excluding the wrong patients and other study flaws as analyzed in a metaanalysis [63]. The high-risk patients for prolonged recovery of activities were mainly excluded based on their low expected ability to fulfill the exercise regime caused by personal factors affecting their functional status (cardio-pulmonary failure; age). If those high-risk patients became involved, the results look more promising [20]. Therefore we opt for a stringent inclusion of patients with a high-risk of prolonged recovery with a low functional status. To accomplish that all high-risk patients can participate in such preoperative interventions, therefore, an adjustment of health insurance reimbursements would be necessary. In the current situation in the Netherlands, the preoperative intervention before THA is not covered by the healthcare insurance companies, which implies that patients must pay for it themselves. From my personal experience, most of the patients with a high risk for prolonged recovery of activities were not intended to start preoperative supervised exercise therapy. After all they were not willing to pay for it, mostly because they could not afford it. 

recovery of activities/functions (Chapters 5,6 ) might give reason to adjust the up to now "standard" clinical pathway to the individual needs of the patient. As stated above, the preoperative status of the patient can be a reason for different preoperative actions. Correspondingly, postoperative mILAS measures can advocate for adjustment of normal care planning by adding extra interventions so that patients are able to master the necessary activities they need at home. Or deviations from the predicted recovery curves might trigger the patient and his healthcare professionals to titrate their interventions for the better as presented in Figure 7.2 III.

\section{PARTICIPATION}

Predicting, measuring, and evaluating recovery of activities before and after THA provides patients and healthcare professionals new and relevant additional information to form (1) adequate expectations of the speed of recovery, (2) initiate and titrate treatment, and (3) plan logistics (time to discharge, start home care, time to restart work and leisure, etc.).

The patient and his healthcare professionals have become more and more an integrated team nowadays. In former days, it was the healthcare professional who was in charge of healthcare as a whole, while it is nowadays a collaboration between the patient and his healthcare professionals. Currently, patients are more and more talented, willing, and sometimes forced by the system to take charge of their health and when necessary also for their care. Based on monitoring their recovery, patients have better insights and can make well-considered decisions about the specific needs during their peri-operative treatment. To cope which this change in responsibilities, the role of the healthcare professionals need to shift from an expert to a more consultant-based role in which shared decision making is a key element. The health care professionals support the patients during the preoperative phase by informing them about their predicted recovery of activities (Chapters 2, 4-6) after THA surgery. In addition to this, healthcare professionals can discuss the possible patient-specific options, if appropriate, to facilitate recovery, such as preoperative exercise to increase physical performance. This information can be used during the SDM process to evaluate if THA is the best option to fulfill the needs of the individual patient at this particular moment in time within the current context of the patient. Furthermore, the use of recovery curves (Chapter 6) can also expand the insight and awareness of the patient regarding his recovery progression in time. This might result in a higher involvement 
and compliance during the intervention period (e.g., home-based exercises) and could be used to decide when to end physical therapy. Next, the step of patients using the clinimetric instruments for the recovery of their daily activities themselves, coached by the therapist when and where needed, might be a paramount step. By doing so the P4-concept becomes more and more fully utilized, and patients get involved entirely. Evidence should be used to decide on the cost-effectiveness of such a remedy.

Besides the direct implications of our results in the field of providing medical care, we also want to address implications for future academic practice. The vast availability of free online courses, including world-class universities as Yale, Stanford, and leading companies like IBM and Google, urge for remodeling current curricula of universities [64]. The added value of universities should shift from a "solely" teaching organization to a combination of teaching and applying knowledge; whereby, the universities provide an environment where students can apply their gained knowledge in real-time practice, supervised by their teachers, by addressing relevant topics from the (medical) field. The teachers will be the connection between the provided knowledge and the skills of the students to apply their acquired knowledge to resolve these relevant questions. Those teachers are the equivalent of the embedded scientist: the embedded academic. In our opinion, the combination of both embedded scientists and embedded academics are essential and will gain the best results in terms of high quality (embedded academic), clinically relevant (embedded scientist)new knowledge with high potential of implementation (embedded scientist) in daily care. An example of such a collaboration of embedded academics and embedded scientists is the "Better in - Better out" community of practice in the Netherlands. This group of 25 people consists of regular PTs, bachelors, masters, PhD candidates and university teachers addressing questions regarding topics related to preoperative prediction of and interventions to improve the postoperative outcome of patients awaiting total hip or knee arthroplasty and major abdominal surgery. This community of practice exists for over 10 years and produced over 30 scientific peer-reviewed articles and $5 \mathrm{PhD}$ dissertations to date.

In conclusion, the outcome of this thesis provides patients and healthcare professionals practical tools to further individualize healthcare during the entire trajectory of THA surgery; from the SDM process deciding if THA is the best option until the SDM conclusion to end physical therapy. The tools need minimal requirements to administer, are easy to use, and are in line with the daily practice of physical therapists. Thereby, we suggest a closer collaboration of healthcare professionals, embedded scientists, and embedded academics to improve healthcare efficiently. 


\section{IMPLICATIONS FOR FUTURE RESEARCH}

Scientific research has evolved based on previously conducted scientific outcomes. We want to share our thoughts considering the future of research within the care for patients undergoing THA surgery.

It is well established to provide detailed descriptions of the study population (like gender, age, BMI, comorbidities, etc.) for comparison with other patient populations and generalization of the interpretations [65]. However, this is not the case with the content of the clinical care pathways reported in studies adopted in our systematic review [66]. Six out of the twelve studies reported some information regarding their clinical care pathways; of those six studies three described only the type of surgical technique used. However, detailed descriptions of clinical care pathways are essential for comparison between studies, since the care provided within the clinical care pathways may contribute to the outcome of interest. An example of such a lack of detail is the description of the postoperative mobilization protocol used during the treatment of patients after THA. If the outcome of interest is the recovery of activities measured in days after surgery, a difference might be observed between study $A$, where patients were allowed to start mobilizing on the day of surgery, compared to study $B$, where patients started mobilizing the second day after surgery. Therefore, we suggest that the clinical care pathways should be described in detail in future published studies.

The need to individualize clinical care pathways should also be implemented in clinical research to enable efficient use of healthcare utilization and facilitate faster / better functional outcomes for the individual patient. To do so, the Hypothesis-Oriented Algorithm for Clinicians II (HOAC II) could be the tool to use, as it provides a method for evaluation and treatment planning within a patient-centered framework [67]. The predicted short-term outcomes of recovery of activities can be used to facilitate the customization of health for the individual patient or patient-groups. A tool to facilitate the customization of health for the individual patient or patient-groups could be the predicted short-term outcomes of recovery of activities. Our studies regarding patient profile (Chapter 2) and the risk stratification model for prolonged recovery of activities (Chapter 4) demonstrated that there are different patient groups present in patients awaiting total hip arthroplasty. It would be of interest to study if I) a customized clinical care pathways enhances the recovery of activities of the four patient profiles reported in Chapter 2, and II) patients with a high risk of prolonged inpatient recovery of activities benefit from a preoperative intervention to enhance their postoperative functional recovery of activities. 
Thereby, we have to take into account that the temporary (state) and enduring (trait) characteristics of the patients can also influence the outcome or even the decision of the patient to participate in preoperative interventions [68]. Patient's "normal" trait characteristics can temporarily shift into a different state caused by the upcoming THA surgery. For example, a patient can shift from his enduring calm and cooperative nature into a temporary anxious and negative personality affecting his coping strategies resulting in a wait and see attitude. Naylor et al. [69] reported an association between the habitual activity pre-surgery and the post-surgery participation in physical activity, where patients tend to stick to their habitual physical activity patterns; whereby, approximately one-third of the patients did not engage in physical activity at least once a week after 1-3 years after THA surgery.

In addition, we opt for more personalized medicine and a holistic view of patient's healthcare in future research, not just examining the disease or direct medical implications of the disease but also looking at the patient from a much broader perspective. A patient is as good as he or she functions in his or her current context. Therefore, during daily healthcare, we opt for the assessment of the ability of the patient to function in his own context by measuring essential activities the patient needs within his context. Thereby, we opt for a shift to focus more on the inpatient and short-term recovery of activities rather than the LoS alone. However, we have to take into account that the LoS is the most frequently used outcome measure after surgery in scientific literature and associated with the hospital costs [70]. If we want to reduce the LoS without compromising the quality of care, it would be essential for future research to focus on the different factors that consist within the LoS: medical recovery, functional recovery, and logistics (see Figure 7.3). Nevertheless, for patients, the LoS is not the most important issue after surgery; however, their functional recovery is. Therefore, we recommend the development of recovery curves for several relevant activities such as walking without crutches, doing laundry, riding a bike, etc. for patients after THA.

Furthermore, as stated above, we opt for more personalized medicine and a holistic view on healthcare. Within this thesis, we adopted the P4-medicine concept as the operationalization for personalized medicine. However, we must be aware that within the literature personalized medicine and precision medicine are used interchangeably. Nonetheless, personalized medicine and precision medicine are two different fundamental concepts, which could be translated as "patient-specific" and "disease-specific," respectively [71]. Whereas patient-specific reflects a holistic view, based on the multifactorial interrelated characteristics of the patient within a specific context, and disease-specific reflects a reductionistic view because of the focus on the molecular 
characteristics of the disease of the patient. Regardless of the differences between personalized medicine and precision medicine, they are fused in the concept of P4-medicine [72]. Thereby, the evidence that fuel personalized-medicine and precision-medicine come from large cohort studies. The main assumption is that we treat average patients; suggesting that the evidence originated from large cohort studies applies to individual patients with their unique personal, contextual, and disease characteristics. However, average patients are not easy to find. To offer the best care for individual patients within their specific context based on the evidence available, the HOAC II can be helpful to make informed choices as shown in a recent case study of van Beijsterveld et al. [73]. Thereby, this hurdle of treating "average patients" can also be tackled with a relatively new research design; $N$ of 1 . In this research design, different therapy options (which could be originated from large cohort studies) can be tested within one patient with his specific characteristics and context, where the patient acts as his own control group. Through repeated measures, the patient and the healthcare professionals gather relevant data of the outcome of the specific treatment.

Additionally, one of the most challenging aspects of scientific research is the implementation of the results. It usually takes on average 17 years for a new intervention to be adopted in daily practice [74]. The Dutch Health Institute [75] presented several research projects (2016-2018) reporting their implementation hurdles. The lessons learned from those 7 projects can be divided into four domains: (1) communication (informing relevant other parties about your work); (2) conditions (providing essential conditions to facilitate implementation); (3) collaboration (interaction and involvement with other parties); and (4) process. (planning and understanding of the (potential) implementation hurdles). Personally, I experienced multiple hurdles within the aforementioned four domains during the process of conducting this thesis. The three most important factors for successful implementation within this thesis were 1) the integration of our results in the electronic patient records; 2) the early involvement of other healthcare professionals; 3 ) the financial structure for preoperative interventions for patients with a high risk for prolonged recovery of activities. However, the latter is still under construction in a nationwide initiative endorsed by the government. Working as an embedded scientist using action research made the implementation hurdles of the newly acquired evidence easier to conquer. By evaluating the workability and usability of the new work processes during daily practice throughout the study period, we were able to tackle the main hurdles early in the progress. Therefore, we suggest that in future research, implementation hurdles should be assessed and tackled early in the process to facilitate the implementation of results. 
Figure 7.3. Actual LoS versus LoS based on the mILAS of 147 patients after total hip replacement. The diagonal line represents the ideal situation in which there is an agreement between the actual LoS and the LoS based on the mILAS. The shaded area resembles the patients which have a longer LoS then necessary based on their recovery of activities measured with the mILAS. This reflects 291 additional days of hospital stay, approximately 2 days per patient at a total cost of $€ 1.200$ (one day of admission costs about $€ 600$ ).

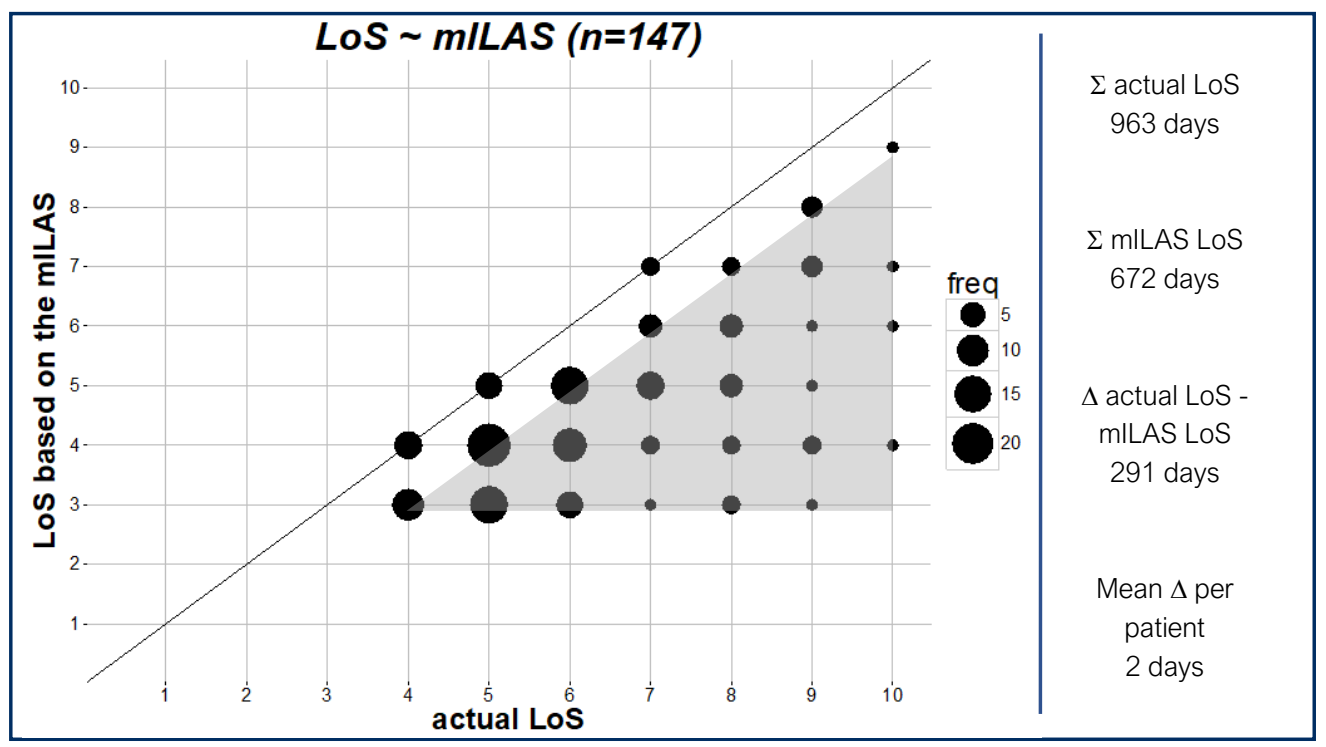

In conclusion, the studies conducted in this thesis emphasize the prediction of the short-term recovery of activities in patients scheduled for total hip arthroplasty in which preoperative physical performance is a key factor. We hope that patients and healthcare professionals will use the PREDICTED outcome to PERSONALIZE care through PREVENTIVE interventions and increase the PARTICIPATION of the patient during the entire treatment period to facilitate the optimal outcome in time and function and activities for the individual patient.

To accomplish this, we need scientific evidence, preferably originated from daily practice, which endorses the uniqueness of each individual patient. The good news is that physiotherapists (and all other healthcare professionals) are using intentionally or unintentionally a study design that could fuel the needed scientific evidence to make considered treatment decisions based on data. This study design, $\mathrm{N}$ of 1 , fits the healthcare professionals well because every patient has unique characteristics and requires personalized diagnostics and therapy. Thereby, the scientific use of the $\mathrm{N}$ of 1 study design becomes more and more feasible nowadays. One of the reasons is the availability of new methodology in which data from multiple $\mathrm{N}$ of 1 studies can be aggregated and 
statistically analyzed, and if the $\mathrm{N}$ adds up to a sufficiently high number, resulting in generalizable insight similar to clinical trials with larger cohorts [71]. Also, new data initiatives like FAIR DATA [60] facilitate data sharing, which makes it easier to use real-world data, e.g. multiple $\mathrm{N}$ of 1 studies, without the burden of retrieving data by finding the authors of the study and placing a request for the data. Summarizing, the $\mathrm{N}$ of 1 study design together with the new methodological possibilities and data sharing options connect the "scientific community" with the "treatment community" by facilitating healthcare professionals to make decisions regarding the treatment of individual patients based on real data instead of the experience of the healthcare professionals alone. The embedded scientist could be a key figure to facilitate the connection between the "scientific community" with the "treatment community."

\section{FINAL THOUGHTS}

The literature as well as what I have learned from patients, as both a PT and as an embedded scientist, was worth the effort of executing all the clinical and scientific efforts and, last but not least, writing this thesis. The knowledge acquired from the literature and the essential needs individual patients discussed during treatment were the bases for my research of the preoperative functional capacity of patients related to their recovery of activities after THA surgery. This combined clinical and scientific journey resulted in multiple studies that I conducted with a great team of PTs and scientists working together achieving five scientific articles. More importantly, we created patient profiles, a risk stratification model for prolonged inpatient recovery of activities, a modified measurement tool for objectively classifying inpatient recovery of activities, and a method for conducting reference curves predicting short-term recovery that patients and healthcare professionals can use during the perioperative treatment of THA surgery to further individualize healthcare for the better. Last but not least, l've learned so much from my relatively new team members ... the patients. And especially these team members might be the key to success in the next decades. 


\section{REFERENCES}

1. Health Holland, "GROZ Initiative," 2018. [Online]. Available: https://www.healthholland.com/partnerships/groz. [Accessed: 08-Apr-2020].

2. Health Holland, "Gezondheid \& Zorg; kennisen innovatieagenda 2020-2023," 2019. .

3. M. Huber et al., "How should we define health?," BMJ, vol. 343, p. d4163, Jul. 2011.

4. WHO, "Constitution of the World Health Organization.," 2006. [Online]. Available: https://www.who.int/governance/eb/who_cons titution_en.pdf.

5. Y. F. Heerkens et al., "Reconsideration of the scheme of the international classification of functioning, disability and health: incentives from the Netherlands for a global debate," Disabil. Rehabil., vol. 40, no. 5, pp. 603-611, 2018.

6. G. L. Engel, "The need for a new medical model: A challenge for biomedicine," Science (80-. )., 1977.

7. "P4medicine institute." [Online]. Available: https://www.p4mi.org. [Accessed: 18-Nov2019].

8. "Science in transition." [Online]. Available: https://www.scienceguide.nl/wpcontent/uploads/2019/02/POSITION-PAPER16-sep-2013.pdf. [Accessed: 18-Nov-2019].

9. S. M. Kurtz, K. L. Ong, E. Lau, and K. J. Bozic, "Impact of the Economic Downturn on Total Joint Replacement Demand in the United States," J. Bone Jt. Surgery-American Vol., vol. 96, no. 8, pp. 624-630, Apr. 2014.

10. A. Mealy and J. Sorensen, "Effects of an aging population on hospital costs related to elective hip replacements," Public Health, vol. 180, pp. 10-16, Mar. 2020.

11. D. J. Berry, W. S. Harmsen, M. E. Cabanela, and B. F. Morrey, "Twenty-five-year survivorship of two thousand consecutive primary Charnley total hip replacements: factors affecting survivorship of acetabular and femoral components.," J. Bone Joint Surg. Am., vol. 84-A, no. 2, pp. 171-7, Feb. 2002.
12. C. A. Jones, D. C. Voaklander, D. W. Johnston, and M. E. Suarez-Almazor, "Health related quality of life outcomes after total hip and knee arthroplasties in a community based population.," J. Rheumatol., vol. 27, no. 7, pp. 1745-52, Jul. 2000.

13. P. J. Van Der Wees et al., "Patient-reported health outcomes after total hip and knee surgery in a Dutch University Hospital Setting: Results of twenty years clinical registry," $B M C$ Musculoskelet. Disord., 2017.

14. M. Sloan, A. Premkumar, and N. P. Sheth, "Projected Volume of Primary Total Joint Arthroplasty in the U.S., 2014 to 2030," J. Bone Jt. Surg., vol. 100, no. 17, pp. 14551460, Sep. 2018.

15. H. Husted, T. H. Lunn, A. Troelsen, L. GaarnLarsen, B. B. Kristensen, and H. Kehlet, "Why still in hospital after fast-track hip and knee arthroplasty?," Acta Orthop., vol. 82, no. 6, pp. 679-684, Dec. 2011.

16. M. Büttner, A. M. Mayer, B. Büchler, U. Betz, P. Drees, and S. Susanne, "Economic analyses of fast-track total hip and knee arthroplasty: a systematic review," European Journal of Orthopaedic Surgery and Traumatology. 2019.

17. N. P. Kort, Y. F. L. Bemelmans, P. H. M. van der Kuy, J. Jansen, and M. G. M. Schotanus, "Patient selection criteria for outpatient joint arthroplasty," Knee Surgery, Sports Traumatology, Arthroscopy. 2017.

18. E. H. J. Hulzebos and N. L. U. van Meeteren, "Making the elderly fit for surgery," $\mathrm{Br}$. J. Surg., vol. 103, no. 4, pp. 463-463, Mar. 2016.

19. WHO, "Towards a Common Language for Functioning , Disability and Health ICF," Int. Classif., vol. 1149, pp. 1-22, 2002.

20. T. J. Hoogeboom, J. J. Dronkers, E. H. J. Hulzebos, and N. L. U. van Meeteren, "Merits of exercise therapy before and after major surgery," Curr. Opin. Anaesthesiol., vol. 27, no. 2, pp. 161-166, Apr. 2014. 
21. L. D. Buirs, L. W. A. H. Van Beers, V. A. B. Scholtes, T. Pastoors, S. Sprague, and R. W. Poolman, "Predictors of physical functioning after total hip arthroplasty: a systematic review," BMJ Open, vol. 6, no. 9, p. e010725, Sep. 2016.

22. H. P. Hulzebos EH, Van Meeteren NL, De Bie RA, Dagnelie PC, "Prediction of Postoperative Pulmonary Complications on the Basis of Preoperative Risk Factors in Patients Who Had Undergone Coronary Artery Bypass Graft Surgery," Phys. Ther., vol. 83, no. 1, pp. 8-16., 2003.

23. J. J. Dronkers, A. M. J. Chorus, N. L. U. Van Meeteren, and M. Hopman-Rock, "The association of pre-operative physical fitness and physical activity with outcome after scheduled major abdominal surgery," Anaesthesia, vol. 68, no. 1, pp. 67-73, 2013.

24. A. F. J. M. Heldens, B. C. Bongers, A. F. Lenssen, L. P. S. Stassen, W. F. Buhre, and N. L. U. van Meeteren, "The association between performance parameters of physical fitness and postoperative outcomes in patients undergoing colorectal surgery: An evaluation of care data.," Eur. J. Surg. Oncol., vol. 43, no. 11, pp. 2084-2092, Nov. 2017.

25. W. J. Evans, "Physical function in men and women with cancer. Effects of anemia and conditioning.," Oncology (Williston Park)., vol. 16, no. Suppl 10, pp. 109-15., 2002.

26. C. A. F. M. Van Beijsterveld, B. C. Bongers, M. Den Dulk, S. M. J. Van Kuijk, C. H. C. Dejong, and N. L. U. Van Meeteren, "Exploring the relation between preoperative physical functioning and the impact of major complications in patients following pancreatic resection.," HPB (Oxford)., Nov. 2019.

27. C. A. Van Beijsterveld, B. C. Bongers, M. Den Dulk, S. M. J. Van Kuijk, K. C. H. Dejong, and N. L. U. Van Meeteren, "The association between preoperative physical functioning and short-term postoperative outcomes: a cohort study of patients undergoing elective hepatic resection.," HPB (Oxford)., vol. 21, no. 10, pp. 1362-1370, Oct. 2019.

28. E. Carpenter-Song, "Putting meaning into medicine: Why context matters in psychiatry," Epidemiology and Psychiatric Sciences. 2015.
29. E. Oosting et al., "Preoperative home-based physical therapy versus usual care to improve functional health of frail older adults scheduled for elective total hip arthroplasty: a pilot randomized controlled trial.," Arch. Phys. Med. Rehabil., vol. 93, no. 4, pp. 610-616, Apr. 2012.

30. J. Elings, T. J. Hoogeboom, G. Van Der Sluis, and N. Van Meeteren, "What preoperative patient-related factors predict inpatient recovery of physical functioning and length of stay after total hip arthroplasty? A systematic review," Clin. Rehabil., vol. 29, no. 5, 2015.

31. J. Elings et al., "Development of a Risk Stratification Model for Delayed Inpatient Recovery of Physical Activities in Patients Undergoing Total Hip Replacement.," J. Orthop. Sports Phys. Ther., vol. 46, no. 3, pp. 135-43, Mar. 2016.

32. A. A. Guccione, T. L. Fagerson, and J. J. Anderson, "Regaining functional independence in the acute care setting following hip fracture.," Phys. Ther., vol. 76, no. 8, pp. 818-826, Aug. 1996.

33. P. P. Dreessen F, Engelen M, "Eerder naar huis.," Med Contact, vol. 55, no. 42, p. 1492 , 2000.

34. G. Van Der Sluis et al., "What augmented physical activity and empowerment can bring to patients receiving total knee replacement: Content, implementation, and comparative effectiveness of a new function-tailored care pathway in a routine care setting," Biomed Res. Int., vol. 2015, 2015.

35. T. W. Wainwright and H. Kehlet, "Fast-track hip and knee arthroplasty-have we reached the goal?," Acta Orthop., vol. 90, no. 1, pp. 35, 2019.

36. A. Wang, T. Ackland, S. Hall, H. Gilbey, and R. Parsons, "Funtional recovery and timing of hospital discharge after primary total hip arthroplasty," ANZ J. Surg., vol. 68, no. 8, pp. 580-583, Aug. 1998.

37. A. Unnanuntana et al., "Does Vitamin D Status Affect the Attainment of In-Hospital Functional Milestones After Total Hip Arthroplasty?," J. Arthroplasty, vol. 27, no. 3, pp. 482-489, Mar. 2012. 
38. R. K. Shields, L. J. Enloe, R. E. Evans, K. B. Smith, and S. D. Steckel, "Reliability, validity, and responsiveness of functional tests in patients with total joint replacement.," Phys. Ther., vol. 75, no. 3, p. 169, Mar. 1995.

39. W. van der Weegen, A. Kornuijt, and D. Das, "Do lifestyle restrictions and precautions prevent dislocation after total hip arthroplasty? A systematic review and meta-analysis of the literature.," Clin. Rehabil., vol. 30, no. 4, pp. 329-339, Apr. 2016.

40. R. M. Meneghini, "Outpatient Joint Replacement: Practical Guidelines for Your Program Based on Evidence, Success, and Failures, a Moderator Introduction," $\mathrm{J}$. Arthroplasty, vol. 34, no. 7, pp. S38-S39, 2019.

41. S. B. W. Vehmeijer, H. Husted, and H. Kehlet, "Outpatient total hip and knee arthroplasty: Facts and challenges," Acta Orthop., vol. 89, no. 2, pp. 141-144, 2018.

42. O. I. Feder, K. Lygrisse, L. Hultzer, R. Schwarzkopf, J. Bosco, and R. I. Davidovitch, "Outcomes of Same Day Discharge after Total Hip Arthroplasty in the Medicare Population," J. Arthroplasty, 2019.

43. P. W. New, G. D. Scroggie, and C. M. Williams, "The validity, reliability, responsiveness and minimal clinically important difference of the de Morton mobility index in rehabilitation," Disabil. Rehabil., 2017.

44. S. Robinson, M. Reed, T. Quevillon, and E. Hirvi, "Patient perceptions and interactions with their web portal-based laboratory results," BMJ Heal. Care Informatics, vol. 26, 2019.

45. C. Palazzo et al., "Determinants of satisfaction 1 year after total hip arthroplasty: The role of expectations fulfilment," BMC Musculoskelet. Disord., 2014.

46. G. A. Hawker et al., "Which Patients Are Most Likely to Benefit From Total Joint Arthroplasty?," Arthritis Rheum., vol. 65, no. 5, pp. 1243-1252, May 2013.

47. M. J. Halawi, W. Jongbloed, S. Baron, L. Savoy, V. J. Williams, and M. P. Cote, "Patient Dissatisfaction After Primary Total Joint Arthroplasty: The Patient Perspective," J. Arthroplasty, vol. 34, no. 6, pp. 1093-1096, 2019.

48. P. Glasziou, L. Irwig, and D. Mant, "Monitoring in chronic disease: a rational approach.," $B M J$, vol. 330, no. 7492, pp. 644-8, Mar. 2005.
49. D. M. Kennedy, P. W. Stratford, D. L. Riddle, S. E. Hanna, and J. D. Gollish, "Assessing recovery and establishing prognosis following total knee arthroplasty.," Phys. Ther., vol. 88, no. 1, pp. 22-32, Jan. 2008.

50. D. M. Kennedy, P. W. Stratford, S. E. Hanna, J. Wessel, and J. D. Gollish, "Modeling early recovery of physical function following hip and knee arthroplasty.," BMC Musculoskelet. Disord., vol. 7, p. 100, Dec. 2006.

51. A. J. Kittelson, T. J. Hoogeboom, M. Schenkman, J. E. Stevens-Lapsley, and N. L. U. van Meeteren, "Person-Centered Care and Physical Therapy: A 'People-Like-Me' Approach," Phys. Ther., Oct. 2019.

52. S. van Buuren, "Curve Matching: A DataDriven Technique to Improve Individual Prediction of Childhood Growth," Ann. Nutr. Metab., vol. 65, no. 2-3, pp. 227-233, 2014.

53. E. T. Stringer, Action research, Third edit. Los Angeles: Sage Publications, 2007.

54. D. S. Thelle and P. Laake, "Chapter 9 Epidemiology," P. Laake, H. B. Benestad, and B. R. B. T.-R. in M. and B. S. (Second E. Olsen, Eds. Amsterdam: Academic Press, 2015, pp. 275-320.

55. S. Glyn-Jones et al., "Osteoarthritis.," Lancet (London, England), vol. 386, no. 9991, pp. 376-387, Jul. 2015.

56. M. Szelągowski and J. Berniak-Woźny, "A Process-Centered Approach to the Description of Clinical Pathways-Forms and Determinants," Int. J. Environ. Res. Public Health, vol. 16, no. 15, p. 2638, Jul. 2019.

57. E. J. Caruana, M. Roman, J. HernándezSánchez, and P. Solli, "Longitudinal studies," J. Thorac. Dis., vol. 7, no. 11, pp. E537-E540, Nov. 2015.

58. T. Kennedy-Martin, S. Curtis, D. Faries, S. Robinson, and J. Johnston, "A literature review on the representativeness of randomized controlled trial samples and implications for the external validity of trial results.," Trials, vol. 16, p. 495, Nov. 2015.

59. T. Baetu, "The 'Big Picture': The Problem of Extrapolation in Basic Research," Br. J. Philos. Sci., vol. 67, Mar. 2015.

60. Go Fair Initiative, "Go FAIR," 2020. [Online]. Available: https://www.go-fair.org/fairprinciples/. [Accessed: 25-Apr-2020]. 
61. Y. H. Chan, "Biostatistics 104: correlational analysis," Singapore Med. J., vol. 44, no. 12, pp. 614-619, Dec. 2003.

62. T. Takken, "De 6-minutenwandeltest: bruikbaar meetinstrument," Stimulus, vol. 24, pp. 244-58, 2005.

63. T. J. Hoogeboom et al., "Therapeutic Validity and Effectiveness of Preoperative Exercise on Functional Recovery after Joint Replacement: A Systematic Review and Meta-Analysis," PLoS One, vol. 7, no. 5, p. e38031, May 2012,.

64. Claire Shaw, "The flipped academic: turning higher education on its head," Gardian, 11Dec-2012.

65. D. W. en L. W. L. D. M. ten H. Pauline Meurs; Daan Dohmen; Jan Kremer; Bas Leerink; José Manshanden; Liesbeth Noordegraaf-Eelens; Greet Prins, "No evidence without context; About the illusion of evidence-based practice in healthcare," Den Haag, 2017.

66. J. Elings, T. J. Hoogeboom, G. van der Sluis, and N. L. U. van Meeteren, "What preoperative patient-related factors predict inpatient recovery of physical functioning and length of stay after total hip arthroplasty? A systematic review.," Clin. Rehabil., vol. 29, no. 5, pp. 477-92, 2015.

67. J. M. Rothstein, J. L. Echternach, and D. L. Riddle, "The Hypothesis-Oriented Algorithm for Clinicians II (HOAC II): a guide for patient management.," Phys. Ther., vol. 83, no. 5, pp. 455-470, May 2003.

68. H. Schöller, K. Viol, W. Aichhorn, M.-T. Hütt, and G. Schiepek, "Personality development in psychotherapy: a synergetic model of statetrait dynamics," Cogn. Neurodyn., vol. 12, no. 5, pp. 441-459, Oct. 2018,.
69. J. M. Naylor, N. Pocovi, J. Descallar, and K. A. Mills, "Participation in Regular Physical Activity After Total Knee or Hip Arthroplasty for Osteoarthritis: Prevalence, Associated Factors, and Type," Arthritis Care Res., vol. 71, no. 2, pp. 207-217, 2019.

70. I. B. Molloy, B. I. Martin, W. E. Moschetti, and D. S. Jevsevar, "Effects of the length of stay on the cost of total knee and total hip arthroplasty from 2002 to 2013," J. Bone Jt. Surg. - Am. Vol., 2017.

71. S. Huang and L. Hood, "Personalized, Precision, and N-of-One Medicine: A Clarification of Terminology and Concepts," Perspect. Biol. Med., vol. 62, no. 4, pp. 617639, 2019.

72. C. Schmidt, "Leroy Hood looks forward to P4 medicine: predictive, personalized, preventive, and participatory," J. Natl. Cancer Inst., vol. 106, no. 12, p. dju416, Dec. 2014.

73. C. A. van Beijsterveld, B. C. Bongers, M. den Dulk, C. H. Dejong, and N. L. van Meeteren, "Personalized community-based prehabilitation for a high-risk surgical patient opting for pylorus-preserving pancreaticoduodenectomy: a case report.," Physiother. Theory Pract., pp. 1-13, Feb. 2020.

74. Z. S. Morris, S. Wooding, and J. Grant, "The answer is 17 years, what is the question: understanding time lags in translational research," J. R. Soc. Med., vol. 104, no. 12, pp. 510-520, Dec. 2011.

75. Zorg Instituut Nederland, "7 concrete lessen voor samen beslissen," 2019. [Online]. Available: https://7-concrete-lessen-voorsamen-beslissen.zorginstituutnederland.nl. [Accessed: 03-Mar-2020]. 
$168 \mid$ Chapter 7 


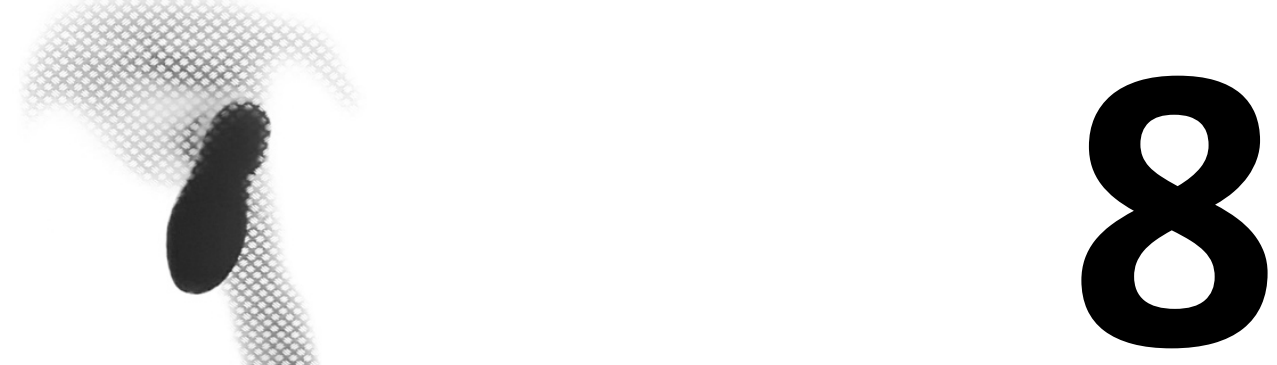

\section{VALORIZATION}


The predicted global life expectancy will increase another ten years, from 75 to 85 years, in the next century due to, among other things, medical treatments converting fatal diseases into chronic conditions [1]. Therefore, the definition of health has shifted from the absence of disease to adaption and managing the physical, mental, and social challenges throughout life [2]. To keep health and healthcare financially affordable for societies and their economy with steadily aging populations, these societies need to gradually accommodate their macro budgets on the one hand and their economy on the other hand. A clear focus on the forecasts of the increase of life expectancy of their total population is crucial. In line with these insights, the Dutch government has set out a national strategy for the coming 20 years. This strategy demands a clear cut change in society and the healthcare system for the coming ten years, with the perspective to create its optimal impact in 2040. An impact that should almost completely solve the immense economic and healthcare problems when the current care-demand and its parallel budget-rise will be left untouched. To do so, the Dutch government's central mission states that in 2040 all residents in the Netherlands live at least five years longer in good health and that health inequalities between the low and high socioeconomic groups will decrease by 30\%. Innovations are needed to improve citizens' lifestyle and the living context, healthcare should mitigate for at the least $50 \%$ towards home, and people with chronic disease(s) should be able to increase their participation in society by $25 \%$ in 2030 [3]. A common ingredient in these central and underlying missions is the P4medicine approach of Leroy Hood, in which health and healthcare need a personalized, preventive, predictive, and participatory approach to assist vital functioning citizens in the Netherlands. New knowledge, ideas, assumptions, processes, treatments, and products are needed, resulting in essential validated innovations. Alas, adoption and implementation are still seen as the missing links in the uptake of innovations in society. Consequently valorization is seen nowadays as pivotal in closing the gap between science/theory and healthcare practice and the collective strive for their societal and economic impact [4].

In general, universities have three main strategic tasks; education, research, and valorization of new knowledge in society and everyday practice [5], thereby assisting the economy to grow. This valorization chapter aims to discuss the social and economic relevance of the reported research and its outcomes, as presented in this thesis, to improve health and healthcare for people who opt for a total hip arthroplasty (THA). 
For people in general and patients in particular, optimal physical performance is essential to function independently and participate in society. However, during the preoperative period, patients with end-stage osteoarthritis awaiting THA experience an extra gradient decline in function and activities due to the effects of their decease and will challenge them even more. Their ability to function and participate will be further tested, during the direct postoperative period, due to the physical stress response related to hospitalization and surgery [6], [7]. If a patient cannot adapt to this stress response, they will likely have a prolonged recovery of activities, and a patient with a poor preoperative function might have a higher risk for such prolonged recovery.

Figure 8.1. The continuum of care for elective total hip arthroplasty [9].

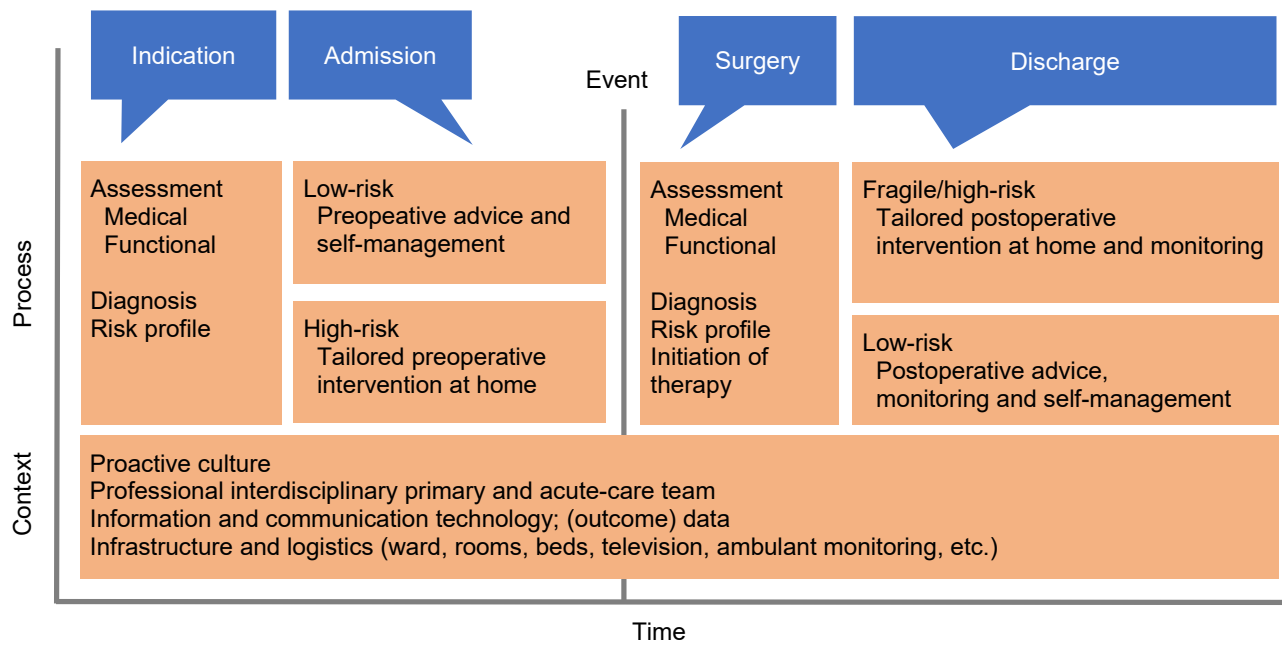

Clinical (allied) healthcare treatment, in general, is standardized using (local) guidelines according to theoretical recovery for standard patients. These guidelines are in place to reduce unwanted treatment variance. However, these protocols can also cause a reduction in wanted treatment variance [8]. Standardizations that are overly strict could be potentially harmful mentally, physically, and/or economically, especially for patients at both ends of the normal distribution of the "standard patient" [most fragile and very fit]. Both patients groups, fragile and fit, might not receive the optimal care they need based on the standardized recommendations; the fragile patient may need extra care to recuperate from surgery while the very fit patients get more care than need. In this thesis, we have strived to personalize these recommendations by 
introducing prediction models and clinical innovations (assessing and monitoring recovery) throughout the continuum of care (see Figure 8.1).

Insight into the predicted recovery of individual patients could help to allocate the available care resources better. So the patient receives the right amount of care they need, and the workload of healthcare professionals can allocate more efficiently, at best resulting in the most efficient patient mix per hospital ward and/or healthcare professional. This coordination of the demand for and availability of care is critical in the decreasing healthcare professionals' resources in the Netherlands.

\section{SHARING AND IMPLEMENTING KNOWLEDGE}

The products within this thesis are a co-creation between patients, healthcare professionals, and researchers, all intending to improve healthcare for patients after THA. A learning community grew gradually alongside the conception of this thesis; first on a micro-level (physical therapy department of the Diakonessenhuis), secondly on a meso-level (interdisciplinary teams within the Diakonessenhuis), and eventually on a macro-level (national community of practice (CoP)). For the local implementation, input from the micro and meso-levels were collected focusing on the usability of the newly developed tools combined with local communication and coordination to enhance efficiency and quality of care. The board of the Diakonessenhuis supported our innovation of care by awarding a grand of $€ 30 \mathrm{k}$ for the implementation of preoperative exercise (the "Better in - Better out" network) for outpatient physical therapists in the catchment area of the hospital. Committed inpatient and community physical therapists jointly developed a guideline for preoperative exercise for patients awaiting THA with a high risk for prolonged recovery of activities assessed with the risk assessment tool (Chapter 6). This guideline was developed by consensus to reduce the implementation burdens within the different working fields.

\section{LOCAL AND NATIONAL IMPLEMENTATION OF OUR RESULTS}

During the preoperative phase, patients are preferably treated according to a stepped-care approach [10], starting with life-style recommendations and drug treatment from their general practitioner. Some patients end with a THA surgery performed by an orthopedic surgeon. Ideally, throughout this stepped-care process the healthcare professionals, in co-creation with the patient, his family, and other (in)formal caregivers, discuss the available treatment options during 
the decision for THA is made and less invasive treatment options have been tried, then the innovations described in this thesis come into play to further facilitate the SDM process. All innovations in this thesis, comprising prediction models and assessment of the recovery of activities of patients undergoing THA surgery, have been sustainably integrated into the continuum of care during indication, admission, and postoperative outpatient periods for patients awaiting and recovering from THA at the Diakonessenhuis. Moreover, some innovations have been disseminated on a national level.

\section{INDICATION \& ADMISSION}

Although THA is widely accepted as an effective treatment for end-stage osteoarthritis of the hip, about $15-50 \%$ of the patients [11], [12] are not satisfied with the results after surgery. More accurate predictions of the functional outcome after THA, based on characteristics of the individual patient, can facilitate the SDM process in which the patient, together with his team, makes an informed decision whether THA is the best option at this specific point in time. Based on new knowledge regarding patient-related factors associated with the recovery of activities and/or length of hospital stay (LoS) (Chapter 2), patient profiles (Chapter 3), and the risk assessment tool (Chapter 4), the screening was optimized. These three studies showed that, next to the conventional patient-related factors (age, BMI, gender, ASA-score, and Charnley score), the functional status of the patient significantly contributes to the explained variance of the predicted inpatient functional recovery of activities resulting in the addition of the Timed up and Go (TUG) during the preoperative screening. Thereby, the outcome of the risk assessment tool - which includes the TUG - gives the patient and the physical therapist essential information about the predicted inpatient recovery of activities and if preoperative exercise might enhance the postoperative recovery of the patient. Nowadays, the preoperative physical therapy screening in the Diakonessenhuis has three pillars: 1) prediction of inpatient recovery of activities; 2) determine if the patient can be discharged home based on their predicted recovery of activities and; 3) determine and discuss if preoperative exercises (supervised or unsupervised) are beneficial for the individual patient to improve their functional status [7].

On a national level, this approach to prediction-based care has been integrated into the Royal Dutch Physical Therapy Association (KNGF) guideline. The KNGF guideline states that "preoperative exercise can indeed be considered in case a patient is at risk for delayed functional 
recovery after THA" [13]. Our risk assessment model (Chapter 4) has been presented as one of the instruments that clinicians can use to determine which high-risk patient for prolonged recovery of activities might benefit from such preoperative interventions.

\section{INPATIENT RECOVERY AFTER SURGERY}

Our research has shifted the perspective on how to objectify the inpatient recovery after THA surgery in the Diakonessenhuis. Initially, LoS was considered one of the critical process indicators. LoS comprises 1) medical recovery, 2) functional recovery, and 3) logistics. However, in theory, patients can be discharged if they meet items 1 and 2, in other words, if they are medically stable and capable of performing basic functional tasks (like making transfers, walking, and, if necessary, stairclimbing).

We showed that physical therapists could use the mILAS to monitor the functional recovery of patients after THA on a daily basis, using five functional activities - transfers in and out of bed, transfer sit to stand, walking, and if necessary stairclimbing - as part of the routine physical therapy care during hospital admission. For the mILAS to be useful in clinical practice, structural use by all colleagues is essential. Therefore, the mILAS was integrated into the hospital information system, and the scores were made accessible for all healthcare professionals.

After implementing the mILAS (Chapter 6) in the Diakonessenhuis, we gathered new information about the patients' functional recovery of activities after THA surgery. Evaluation of these postoperative data revealed a difference of two days between the theoretical LoS (items 1 and 2) and the actual LoS (items 1, 2, and 3); thus, hospital logistics delayed discharge substantially. To close this gap between the theoretical and actual LoS, the functional recovery of activities is the main topic nowadays during the multidisciplinary consultations of patients after THA. To date, in the Diakonessenhuis, objective day-to-day recovery of patients' activities provides healthcare professionals essential information to determine if and when the patient is ready to be discharged so logistical issues can be addressed on time, resulting in a lower actual LoS.

As the risk assessment tool, the use of the mILAS was recommended through the KNGF guideline 'Osteoarthritis of the hip and knee' [13]. 
All patients discharged from the Diakonessenhuis receive a transfer letter detailing their recovery after the THA surgery. Previously, this transfer letter included only medical items, like LoS, wound healing status, pain levels, etcetera. To date, the transfer letter also includes details about the functional recovery of patients, including the preoperative level of functioning and level of functioning at discharge. This information about the patient's functioning helps both the patient and the primary care physical therapist better estimate the potential speed and (maximum) level of recovery. For patients recovering from TKA, we now also include the recovery curve for active flexion after TKA (Chapter 7) in the transfer letter. The patient and physical therapist can use this curve as a reference tool to monitor the recovery of flexion. Besides, researchers in the US have developed a mobile application to enhance the daily use of such recovery curves (see Figure 8.2). With this application, both patients and healthcare professionals gain easy access and visual insight into the (expected) recovery speed. The app provides two curves: A) curve generated with data from patients similar to the index-patient [14] and; B) curve generated with data from all patients [15]. Attempts are made to translate and incorporate this app into the Dutch care setting.

Finally, this thesis's results were disseminated through guest lectures at applied universities, the professional master physical therapy, the Better In - Better Out community of practice meetings, and other hospitals.

\section{POTENTIAL VALORIZATION OF OUR RESULTS}

Besides the relevance of our work to the quality of care for patients awaiting and recovering from THA, our work might also have economic potential.

First, using preoperative prediction models. As stated before, by identifying patients with a high risk for prolonged recovery before surgery, preoperative interventions might be useful to enhance their functional status yielding a faster recovery of functions resulting in a lower LoS and fewer post clinical physical therapy sessions [13]. During the 8 weeks of "waiting time" before surgery, a preoperative exercise intervention with 2 supervised sessions of 30 minutes, at $€ 40$ per session, costs approximately $€ 640$. The potential reduction in hospital costs is $€ 600$ for each day the patient is discharged earlier than he or she was without the preoperative exercise intervention, 
Figure 8.2. Knee Recovery App in use.

\section{A. Patients like me}

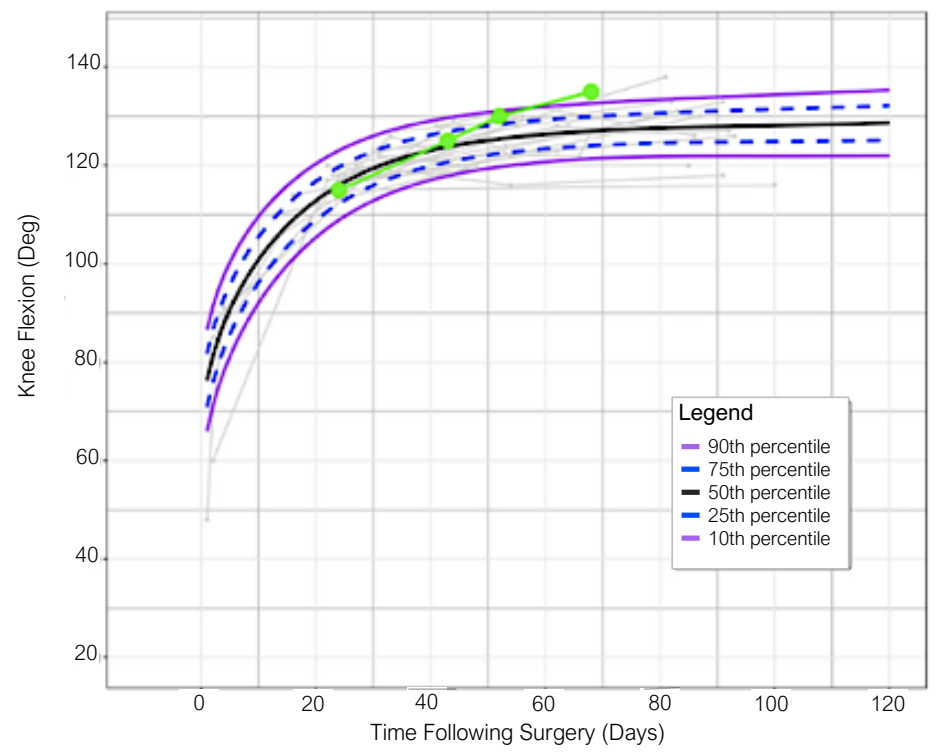

Knee tlexion RUM recovery is taster than expected; only 3 percent of similar patients have more flexion ROM at this time point.

\section{B. All patients}

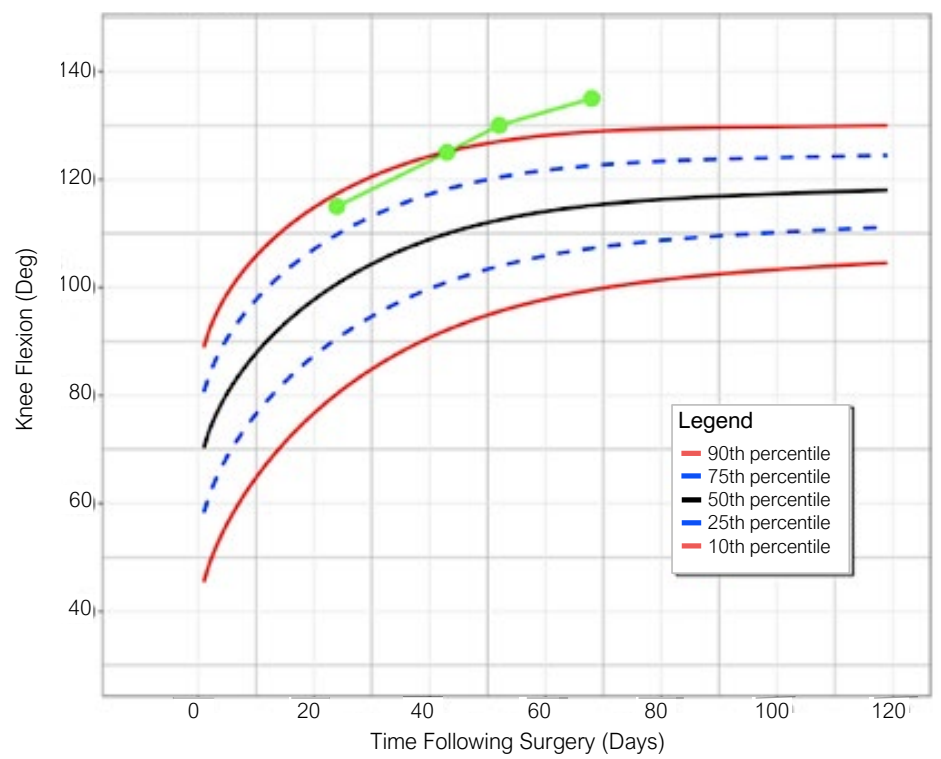

Of all patients with TKA, 97 percent have less flexion ROM and 3 percent have more flexion ROM at this time point. 
the better direct postoperative functions and level of activity. Moreover, if the postoperative functional status of a patient is sufficient to be discharged home, instead of a skilled nursing home, the potential cost reduction rises to $\sim € 7.5 \mathrm{k}$ per patient (€254 per day [16] with a mean total stay of 30 days [17]). Finally, some patients even reconsider THA surgery after a 6-week conservative treatment intervention to reduce symptoms and improve functioning [18], [19]. Each of the three scenarios mentioned above are cost-effective.

Second, using inpatient outcome monitoring of recovery. If the outcomes on the mILAS are actually in the lead to determine whether an individual patient can or cannot be discharged (assuming that the patient is medically stable after one night and logistical issues are addressed), the LoS could be lowered by 2 days according to our data of 2015. The reduction of the LoS by 2 days equals an estimated reduction of hospital costs of $€ 1.200$ per patient. Annually, 500 THA are performed at the Diakonessenhuis hospital; with the 2-day reduction, the total revenue would be $500 x € 1.200=€ 600 k$. Moreover, 1000 admission days (500 patients with 2-day lower admission days) are available for other patients.

Third and final, using recovery curves during rehabilitation. We believe that the use of recovery curves during the peri-operative period may reduce healthcare costs even further. Fifteen to fifty percent of the patients after THA are not completely satisfied with surgery outcomes [11], [12]. Recovery curves provide essential information about the predicted improvement of functions and activities overtime during the postoperative phase. Some patients' expectations might not likely to be achieved after THA surgery, despite that they are willing to undergo surgery and invest in (p)rehabilitation interventions. If patients, together with their support team, are provided with personalized predictions of their most likely outcome after THA, they can make a more informed decision regarding THA surgery. If their expectations are too high concerning the outcome provided by the recovery curves, they might reconsider THA surgery or accept the end result of their recovery sooner, resulting in earlier termination of their postoperative physical therapy treatment. 


\section{CONCLUSION AND AMBITION}

The population of patients awaiting THA surgery is heterogeneous in terms of preoperative function and level of activities and their postoperative recovery of activities and opts for more personalization of care. The P4-Medicine indices prediction, prevention, personalize, and participatory help optimize the perioperative quality of THA surgery further and might even have an economic benefit for society. Therefore, we recommend that proper identification, monitoring, and titration of care should be implemented in daily healthcare routines for THA surgery care pathways. 
1. S. E. Vollset et al., "Fertility, mortality, migration, and population scenarios for 195 countries and territories from 2017 to 2100: a forecasting analysis for the Global Burden of Disease Study," Lancet, Aug. 2020.

2. M. Huber et al., "How should we define health?," BMJ, vol. 343, p. d4163, Jul. 2011.

3. Health Holland, "Gezondheid \& Zorg; kennisen innovatieagenda 2020-2023," 2019.

4. P. Rangachari, P. Rissing, and K. Rethemeyer, "Awareness of evidence-based practices alone does not translate to implementation: Insights from implementation research," Qual. Manag. Health Care, 2013.

5. VSNU, "Een Raamwerk Valorisatieindicatoren," 2013.

6. E. M. Helander et al., "Metabolic and the Surgical Stress Response Considerations to Improve Postoperative Recovery.," Curr. Pain Headache Rep., vol. 23, no. 5, p. 33, Apr. 2019.

7. F. Carli and V. Ferreira, "Prehabilitation: a new area of integration between geriatricians, anesthesiologists, and exercise therapists.," Aging Clin. Exp. Res., vol. 30, no. 3, pp. 241244, Mar. 2018.

8. Raad voor volksgezondheid en samenleving.., "No evidence without context," 2017.

9. E. H. J. Hulzebos and N. L. U. van Meeteren, "Making the elderly fit for surgery," Br. J. Surg., vol. 103, no. 4, pp. 463-463, Mar. 2016.

10. A. J. Smink et al., "Agreement of general practitioners with the guideline-based stepped-care strategy for patients with osteoarthritis of the hip or knee: a crosssectional study.," BMC Fam. Pract., vol. 14, p. 33, Mar. 2013.
11. C. Palazzo et al., "Determinants of satisfaction 1 year after total hip arthroplasty: The role of expectations fulfilment," BMC Musculoskelet. Disord., 2014.

12. G. A. Hawker et al., "Which Patients Are Most Likely to Benefit From Total Joint Arthroplasty?," Arthritis Rheum., vol. 65, no. 5, pp. 1243-1252, May 2013.

13. KNGF, "kngf-richtlijn artrose heup-knie." p. 32, 2018.

14. A. J. Kittelson, T. J. Hoogeboom, M. Schenkman, J. E. Stevens-Lapsley, and N. L. U. Van Meeteren, "Person-Centered Care and Physical Therapy: A 'people-Like-Me' Approach,” Physical Therapy. 2020.

15. A. Kittelson, J. Elings, N. L. U. van Meeteren, K. Colborn, T. H. Hoogeboom, and J. StevensLapsley, "Reference chart for knee flexion following total knee arthroplasty: a novel tool for monitoring postoperative recovery."

16. Zorgverzekeraars. Nederland, "Inkoopgids GRZ 2014," 2013.

17. ACTIS, "Geriatrische Revalidatiezorg factsheet 2019," 2019. [Online]. Available: https://www.actiz.nl/stream/actiz-infographicgrz-2019.pdf/20191031142733.

18. A. Cronström, L. E. Dahlberg, H. Nero, and C. S. Hammarlund, "'I was considering surgery because I believed that was how it was treated': a qualitative study on willingness for joint surgery after completion of a digital management program for osteoarthritis," Osteoarthr. Cartil., vol. 27, no. 7, pp. 10261032, 2019

19. L. S. G. Teoh, J. P. Eyles, J. Makovey, M. Williams, C. K. Kwoh, and D. J. Hunter, "Observational study of the impact of an individualized multidisciplinary chronic care program for hip and knee osteoarthritis treatment on willingness for surgery.," Int. J. Rheum. Dis., vol. 20, no. 10, pp. 1383-1392, Oct. 2017. 
180 | Chapter 8 

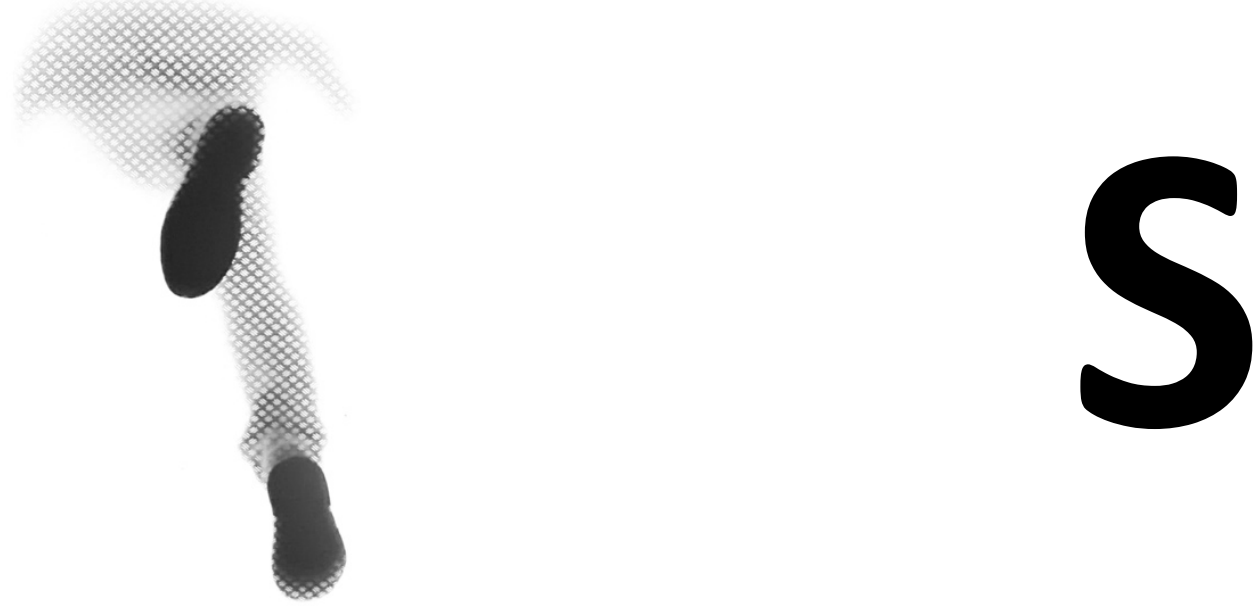

SUMMARY 
Due to, among other things, an aging population and increasingly broader surgical indications, from very fit to very fragile, joint replacement surgeries are one of the most performed elective surgeries worldwide and will continue to increase in number in the coming decades. A total hip arthroplasty (THA) is considered a safe and effective surgical procedure to reduce hip pain and improve physical function. However, such an operation is neither without risks nor a guarantee for a good result. Also, the context in which the health care system functions has changed in recent decades, which has resulted in a reorganization of health care. An example of such a reorganization of care is the centralization of (complex) surgeries, whereby a minimum number of procedures per doctor per year are required to be allowed to perform the surgery. Besides, the concept of "health" is being adjusted, among other things, by explaining the concept differently: from "a state of complete well-being" to "the ability to adapt and deal with challenges in life". Changes are also visible in society; society is transforming from a welfare state to a participatory society in which citizens are increasingly looking after themselves, together with their loved ones.

Embedded in the developments mentioned earlier, the clinical care pathways before and after a THA have also changed in recent decades. The time-contingent approach of Joint Care ${ }^{\circledR}$, introduced in 1997, has made way for the Fast-Track principles with Evidence-Based Medicine targeted interventions to reduce the negative consequences of surgery as much as possible. The latest treatment method is a combination of Fast-Track principles, in which patient-specific values and functional goals play a central role. In other words: which activities do patients want to perform independently in their living situation after surgery, and how can Fast-Track principles contribute to achieving this faster. Over the past 20 years or so, this evolution in healthcare shows a shift from a population-based approach to a more person-centered treatment, which generally seems appropriate given the changes in the healthcare system and society as described above. Also, the patient cannot be seen separately from his or her context; essential aspects in this are the presence of (committed) carers and the material (including financial) possibilities of the patient.

To be able to play a central role in the new organization of care, the patient (and his treatment team) needs relevant information about the expected outcomes and consequences of the available treatment options. In addition, the four pillars of "P4-Medicine" - Prediction, Prevention, Personalization, and Participation - can support the patient with his informal caregivers and the treatment team in making the most appropriate choice concerning treatment options, taking into account the preferences and priorities of the individual patient at a specific point in time. For the 
readability of the thesis, the care process that a patient follows before and after a THA is divided by the 4 phases of the "continuum of care" model (see Figure 1): indication, admission, operation, and discharge.

Figure 1. Continuum of care model.

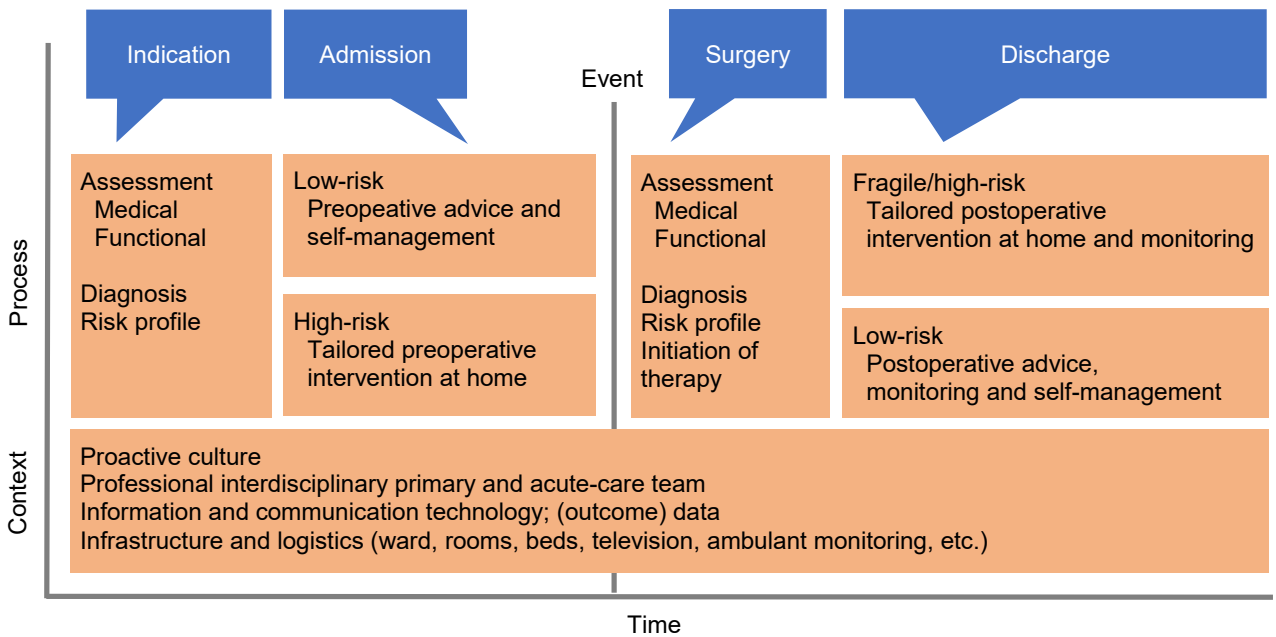

The studies underlying this thesis aimed to optimize the outcomes for individual patients opting for THA. Increasing insight into recovery and developing clinical (measuring) instruments play a central role. The acquired knowledge can support the patient and healthcare professionals in making healthcare-related decisions and monitoring recovery.

\section{INDICATION \& ADMISSION}

\section{WHICH GROUPS OF PATIENTS CAN WE DISTINGUISH PREOPERATIVELY AND WHICH FACTORS ARE PREDICTIVE FOR THEIR RECOVERY DURING HOSPITALIZATION (CH2-4)}

Disease-specific care pathways are, as a rule, developed from cohort studies and a logisticalorganizational perspective and are therefore basically aimed at the "average" patient. More and more, we discover that the average patient does not exist, which has led to the development of personalized medicine. Personalization of care is necessary in order to better tailor care to the individual patient. The first step in this is to investigate whether different specific and, above all, clinically relevant patient profiles can be distinguished from the multitude of patients. In preparation for this step, a systematic literature study is discussed in Chapter 2 with the question 
"Which preoperative patient-related factors are predictive for the length of stay (LoS) and the recovery of activities during hospitalization of patients after THA?". A striking conclusion of this review is that the focus was mainly on personal factors, environmental factors, and functions/structures in accordance with the International Classification of Functioning Disability and Health (ICF), with little or no attention to the activities and participation of the patient. This outcome suggests that within the included studies, the biomedical perspective prevails. Age, gender, and co-morbidity of the patient are the most studied factors in the included articles within this systematic review, with the ASA-score and the presence of lung or heart problems showing a strong association with the speed and quality of recovery. The recovery of the patient after a THA is typically objectified by LoS. LoS is influenced by, among other things: 1) medical recovery, 2) functional recovery, and 3) logistics. If only LoS is used as an outcome measure, it is no longer possible to determine where any treatment adjustments might contribute to the further optimization of care and recovery. After all, the information about the functional recovery and logistics is lacking. Therefore, a broader view of objectifying postoperative recovery is essential and is discussed further in the thesis in chapter 5 (Monitoring functional recovery in the clinical phase).

With the insights gained in Chapter 2, we investigated, using data from two hospitals' regular practice, whether different patient profiles can be distinguished preoperatively within the total population of patients who opt for a THA. Ultimately, four patient profiles - "Fit", "Pain", "Comorbidity", and "Fragile" - could be distinguished, each with their own specific pattern of functional recovery and LoS $(\mathrm{H} 3)$. The fit patients are younger and show the best preoperative functional status and recover fastest, in contrast to the frail elderly patients with low preoperative functional status and the slowest postoperative recovery. The acquired knowledge of the predictive value of the classical patient characteristics $\left(\mathrm{H}_{2}\right)$ and the predictive value of the preoperative functional status of the patient $(\mathrm{H} 3)$ form the prelude to Chapter 4 , which describes the development of a prediction model for delayed inpatient recovery of physical activities. Chapter 4 revealed that by adding a preoperative functional measure (Timed Up and Go (TUG)), in addition to the classical patient characteristics, the risk model performs significantly better. The final risk model consists of 6 factors - age, gender, BMI, ASA-score, Charnley score, and the TUG - with the TUG (see Figure 2) being the second-best predictive factor of the risk model, endorsing the importance of the patient's preoperative functional status. The knowledge that the patient's functional status partly predicts the speed of recovery provides an entry point to investigate whether the patient's functional status can be improved preoperatively during the "waiting list period" to influence postoperative recovery positively. 
Figure 2. Timed Up and Go

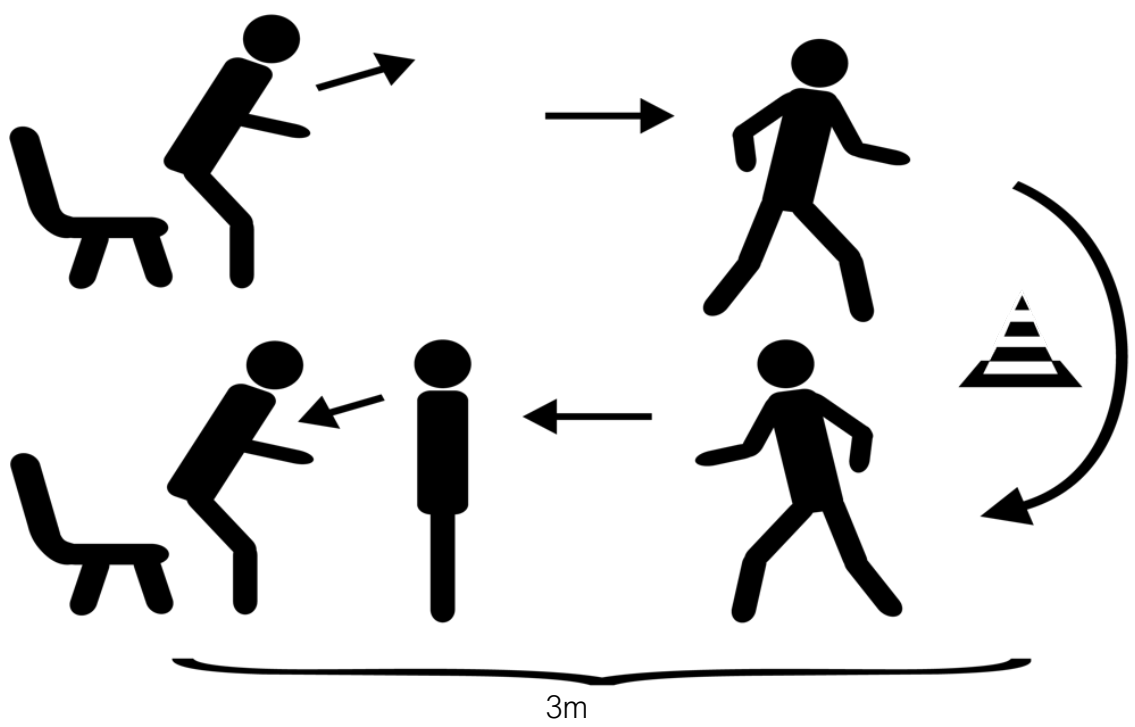

Get up from the chair, walk 3 meters; turn around the pawn, walk back and sit down again.

\section{SURGERY}

\section{MONITORING FUNCTIONAL RECOVERY IN THE CLINICAL PHASE (CH5)}

Chapter 2 showed a wide variation in LoS within and between the different studies. What induces these differences? As described earlier (under INDICATION \& ADMINISTRATION), the LoS is, among other things, influenced by medical recovery, functional recovery, and logistics. Chapter 5 describes how the functional recovery of the patient during hospitalization can be objectified. The degree of functional recovery - the ability to independently perform several essential basic activities - can be used by the healthcare professional in assessing whether the patient can function independently at home without 24-hour care. The measuring instrument "lowa Levels of Assistance Scale (ILAS)" was used as a basis for monitoring the postoperative functional recovery of patients. With the ILAS healthcare professionals, within this thesis the hospital physiotherapists, can assess the patient's independence during the transfers supine to sit, sit to stand, walking, and climbing stairs. However, several hospital physiotherapists from different hospitals in the Netherlands reported that the transfer sit to supine was a difficult activity for some patients that had to be added to the ILAS. The ILAS has been modified to the mILAS by adding the transfer sit to supine based on this clinical experience. Subsequently, it was examined 
whether the transfer's difficulty - sit to supine - differs from the other items of the mILAS. The analysis confirmed that the activity sit to supine was, on average, the most challenging item of the mILAS during the first days after surgery, which supports hospital physiotherapists' experiences mentioned earlier. When the patient can independently perform the 4 or 5 items of the mILAS (for some patients climbing stairs, the 5th item, is not necessarily in their home situation), the patient is functionally ready for discharge.

\section{DISCHARGE}

\section{EVALUATING THE RECOVERY USING REFERENCE DATA (CH 6)}

Patients and practitioners lack evidence-based reference data to assess the quality of the patient's postoperative physical recovery. This lack of data makes it challenging to detect delayed and/or insufficient recovery in time to adjust therapy or refer the patient back for additional diagnostics and/or interventions. Chapter 6 describes the process to develop such reference data. Using data from different physiotherapy practices in the United States, a reference curve has been developed that displays the recovery of flexion mobility (bending of the knee) over time for patients after total knee surgery, which could serve as a blueprint for monitoring patients after THA as well. Physiotherapists can use such reference curves to monitor recovery together with the patient and adjust therapy if necessary. Reference curves allow the physiotherapist and the patient to monitor the postoperative recovery of the individual patient more precisely by comparing the outcomes with the mean variation in the recovery of previously treated patients. The reference curves can also be used in the preoperative orientation phase to assess whether the patient's and the healthcare professional's expectations concerning functional recovery are realistic compared to previously treated (almost identical) patients. 
Chapter 7 contains the discussion and reflects on the results and methodology of the different chapters and examines the practical applicability of the outcomes presented in this thesis in both clinical practice and research. In this thesis, only data is used from three Dutch hospitals' daily practices and several American private physiotherapy practices. This dissertation shows that research with daily practice data is well possible and fits both the embedded scientist and the action research approach. By using the available data from daily practice, this approach has a limited impact on the patient, while regular care evaluates with the outcomes that appear to be generalizable. The 4p's of P4Medicine - Prediction, Prevention, Personalization, and Participation - play a central role in this thesis to further personalize the regular care around the patient who opts for a THA. Participation of the patient during the entire treatment process is essential to achieve a good result. Care will have to be tailored to the individual patient as much as possible, to achieve this, a committed patient is necessary. For example, prediction can contribute to developing realistic expectations of the patient and the healthcare professionals about the outcomes in the short (hospitalization) and long term (recovery of activities in the first months after surgery). It may also be useful for a select group of high-risk patients - to consider a preventive intervention to increase the functional status to withstand the operation's negative consequences better. Furthermore, monitoring recovery is essential to objectify the degree and speed of recovery, especially when reference curves are used with data from patients who have already been treated. Only if all treatment elements are well attuned to and with the individual patient (personalization), there is the greatest chance that the patient will make every effort to achieve a good result. This holistic and personal treatment approach can also be implemented in future research within THA and other patient populations.

\section{CONCLUSION}

Personalization of care is essential for an optimal result after THA surgery. After all, every patient is unique and requires a tailor-made treatment plan in which prediction, prevention, and participation are essential components to achieve the best possible result. This dissertation realizes that need. 
188 | Summary 


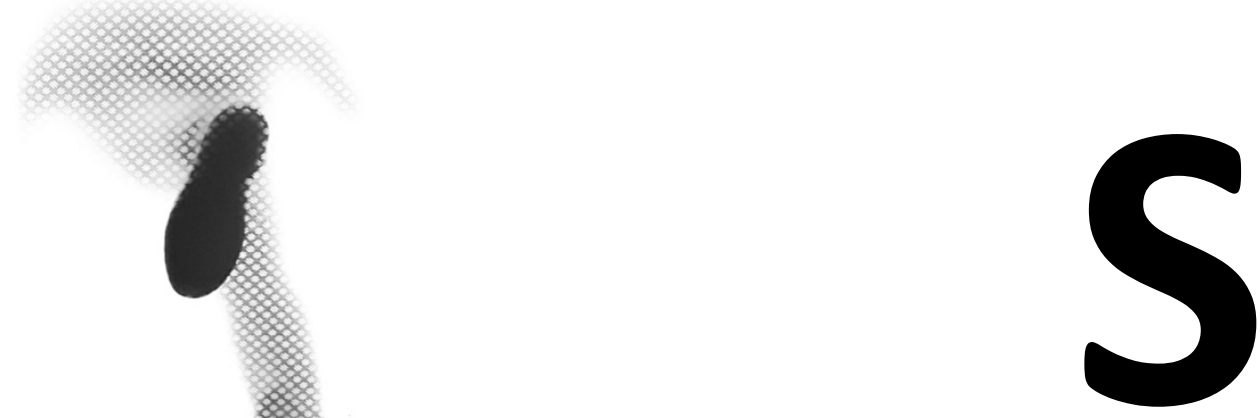

SAMENVATTING 
Door, onder andere, een vergrijzende populatie en steeds ruimere operatie-indicaties, van hele fitte tot zeer fragiele personen, zijn gewrichtsvervangende operaties één van de meest uitgevoerde electieve operaties wereldwijd en deze zullen de komende decennia verder toenemen in aantal. Een totale heup prothese (THP) wordt beschouwd als een veilige en effectieve chirurgische ingreep om de pijn in de heup te reduceren en het fysiek functioneren te verbeteren. Echter, een dergelijke operatie is niet zonder risico's noch een garantie voor een goed eindresultaat. Daarbij komt dat de context waarin het zorgsysteem functioneert de afgelopen decennia is veranderd, wat geresulteerd heeft in een herinrichting van de zorg. Een voorbeeld van een dergelijke herinrichting van zorg is het centraliseren van (complexe) operaties, waarbij een minimaal aantal verrichtingen per arts per jaar vereist zijn om de behandeling te mogen uitvoeren. Daarnaast wordt gesleuteld aan het begrip 'gezondheid', onder andere door het begrip anders uit te leggen: van "een status van compleet welbevinder" naar "de mogelijkheid zich aan te passen en om te gaan met uitdagingen tijdens het leven". Ook in de maatschappij zijn veranderingen gaande; de samenleving transformeert van een verzorgingsstaat naar een participatie-samenleving waarin burgers meer en meer voor zichzelf zorgen, samen met hun naasten.

Ingebed in de voornoemde ontwikkelingen maakten ook de klinische zorgpaden voor en na een THP de afgelopen decennia veranderingen door. De tijd-contingente aanpak van Joint Care ${ }^{\circledR}$, geïntroduceerd in 1997, heeft plaats gemaakt voor de Fast-Track principes met Evidence Based Medicine gerichte interventies om de negatieve gevolgen van de operatie zo veel mogelijk te reduceren. De nieuwste behandelmethode is een combinatie van Fast-Track principes, waarbij patiënt specifieke waarden en functionele doelen centraal staan. Met andere woorden: welke activiteiten wil een patiënt postoperatief zelfstandig uit kunnen voeren in zijn of haar eigen leefsituatie en hoe kunnen Fast-Track principes bijdragen dit sneller te realiseren. Deze evolutie in de zorg, van pakweg de afgelopen 20 jaar, laat een verschuiving zien van een populatie gerichte aanpak naar een meer persoonsgerichte behandeling, wat in z'n algemeenheid passend lijkt gezien de eerder beschreven veranderingen in het zorgsysteem en de maatschappij. Daarbij kan de patiënt niet los gezien worden van zijn of haar context; belangrijke aspecten hierin zijn de aanwezigheid van (betrokken) mantelzorgers en de materiele (dus ook financiële) mogelijkheden van de patiënt.

Om een centrale rol te kunnen spelen in de nieuwe inrichting van de zorg heeft de patiënt (en zijn behandelteam) relevante informatie nodig over de verwachte uitkomsten en consequenties van de beschikbare behandelopties. Daarbij kunnen de 4 pijlers van "P4-Medicine" - Predictie, 
rekening houdend met de voorkeuren en prioriteiten van de individuele patiënt op een specifiek moment in de tijd. Voor de leesbaarheid van het proefschrift is het zorgproces dat een patiënt doorloopt voor en na een THP onderverdeeld conform de 4 fases van het "continuum of care" model (zie Figuur 1): indicatie, opname, operatie en ontslag.

Figuur 1. Continuum of care model.

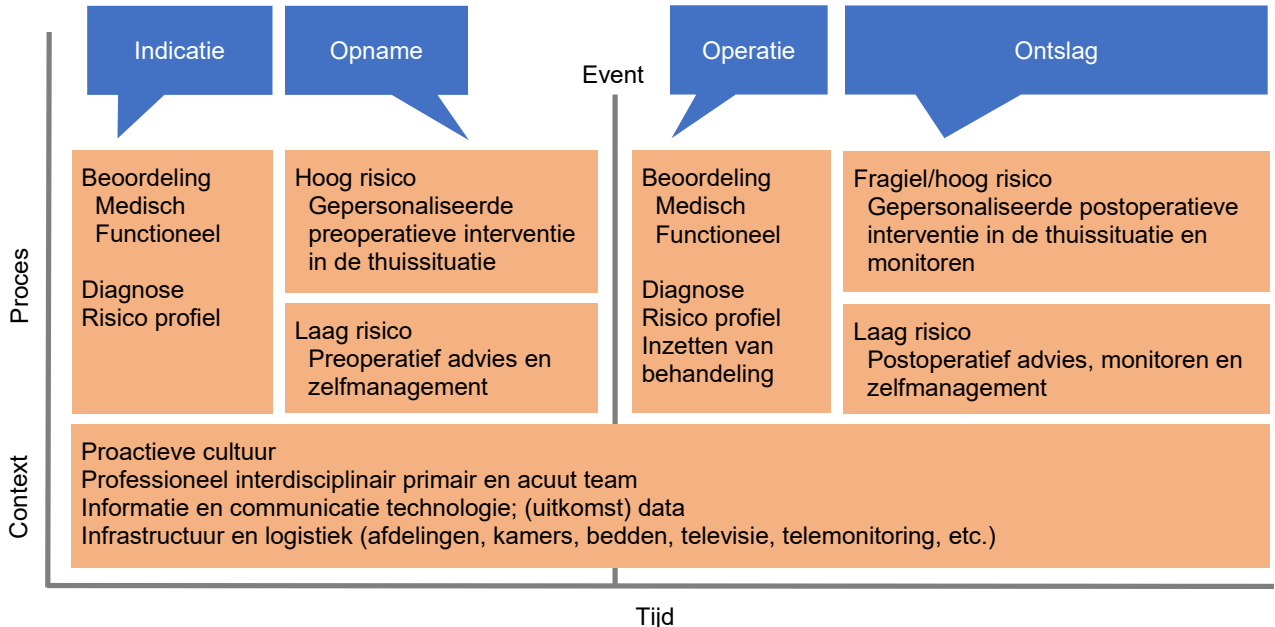

Het doel van de onderzoeken, die ten grondslag lagen aan dit proefschrift, was het optimaliseren van de uitkomsten voor individuele patiënten die opgaan voor een THP. Hierbij staan het vergroten van het inzicht in herstel en het ontwikkelen van klinische (meet)instrumenten centraal. De opgedane kennis kunnen de patiënt en de zorgprofessionals ondersteunen bij het maken van zorg gerelateerde beslissing en het monitoren van herstel.

\section{INDICATIE \& OPNAME}

\section{WELKE GROEPEN PATIËNTEN KUNNEN WE PREOPERATIEF ONDERSCHEIDEN EN WELKE FACTOREN ZIJN VOORSPELLEND VOOR HUN HERSTEL TIJDENS DE ZIEKENHUIS OPNAME (H2-4)}

Aandoeningsspecifieke zorgpaden zijn, in de regel, ontwikkeld vanuit cohortonderzoeken en logistiek-organisatorisch perspectief en daarmee in de basis gericht op de "gemiddelde" patiënt. Meer en meer komen we er achter dat dié gemiddelde patiënt niet bestaat, hetgeen leidde tot de 
ontwikkeling van personalized medicine. Om de zorg beter aan te laten sluiten bij de individuele patiënt is personalisatie van zorg noodzakelijk. Een eerste stap hierin is het onderzoeken of, uit de veelheid van patiënten, verschillende specifieke en vooral ook klinisch relevante patiëntprofielen te onderscheiden zijn. Als voorbereiding op deze stap wordt in hoofdstuk 2 een systematische literatuur studie besproken met de vraag "Welke preoperatieve patiënt gerelateerde factoren zijn voorspellend voor de opnameduur en het functioneel herstel van activiteiten tijdens de ziekenhuisopname van patiënten die opgaan voor een THP?". Een opvallende conclusie van deze review is dat de aandacht vooral uit ging naar persoonsfactoren, omgevingsfactoren en functies/structuren conform de International Classification of Functioning Disability and Health (ICF), met daarentegen geen of zeer geringe aandacht voor activiteiten en participatie van de patiënt. Deze uitkomst suggereert dat binnen de geïncludeerde studies het biomedisch perspectief de boventoon voert. Leeftijd, geslacht en comorbiditeit van de patiënt zijn de meest onderzochte factoren in de geïncludeerde artikelen binnen deze systematische review, waarbij de ASA-score en de aanwezigheid van long- of hartproblemen een sterke associatie laten zien met het tempo en de kwaliteit van herstel. Daarbij wordt het herstel van de patiënt na een THP voornamelijk geobjectiveerd middels de opnameduur. Dit terwijl de opnameduur beïnvloed wordt door onder meer 1) medisch herstel, 2) functioneel herstel en 3) logistiek. Wanneer men alleen de opnameduur als uitkomstmaat gebruikt, is niet meer te achterhalen waar eventuele aanpassingen in de behandeling nog bij kunnen dragen aan de verdere optimalisatie van de zorg en van het herstel. Immers de informatie omtrent het herstel van activiteiten en de logistiek ontbreekt. Een bredere kijk op het objectiveren van het postoperatief herstel is daarom van essentieel belang en komt verder in het proefschrift aan bod in hoofdstuk 5 (Monitoren van het functioneel herstel in de klinische fase).

Met de inzichten verworven in hoofdstuk 2 is, met gegevens uit de reguliere praktijk van twee ziekenhuizen, onderzocht of verschillende patiëntprofielen preoperatief te onderscheiden zijn binnen de totale populatie van patiënten die opgaan voor een THP. Uiteindelijk bleken vier patiëntprofielen - "Fit", "Pijn", "Comorbiditeit" en "Fragiel" - te onderscheiden op basis van de preoperatieve persoonskenmerken, elk met specifieke patronen van functioneel herstel en opnameduur $(\mathrm{H} 3)$. Hier zijn de fitte patiënten jonger en vertonen de beste preoperatieve functionele status en herstellen het snelst, in tegenstelling tot de fragiele oudere patiënten met een slechte preoperatieve functionele status en het langzaamste postoperatief herstel.

De opgedane kennis van de voorspellende waarde van de klassieke patiënt karakteristieken $(\mathrm{H} 2)$ en de voorspellende waarde van de preoperatieve functionele status van de patiënt $(\mathrm{H} 3)$, vormen 
de opmaat voor Hoofdstuk 4, waarin de ontwikkeling van een predictiemodel voor vertraagd herstel van fysieke activiteiten tijdens de ziekenhuisopname wordt beschreven. In Hoofdstuk 4 wordt beschreven dat door de toevoeging van een preoperatieve functionele maat (Timed Up and Go (TUG)), naast de gangbare patiëntkarakteristieken, het risicomodel significant beter presteert. Het uiteindelijke risico model bestaat uit 6 factoren - leeftijd, geslacht, BMI, ASA-score, Charnley-score en de TUG - waarbij de TUG (zie Figuur 2) de één na best voorspellende factor is van het risicomodel, waarmee het belang van de preoperatieve functionele status van de patiënt wordt onderschreven. De kennis dat de functionele status van de patiënt mede voorspellend is voor de snelheid van herstel, biedt een ingang om te onderzoeken of de functionele status van de patiënt preoperatief verbeterd kan worden tijdens de "wachtlijstperiode" om zo het postoperatief herstel positief te beïnvloeden.

Figuur 2. Timed Up and Go

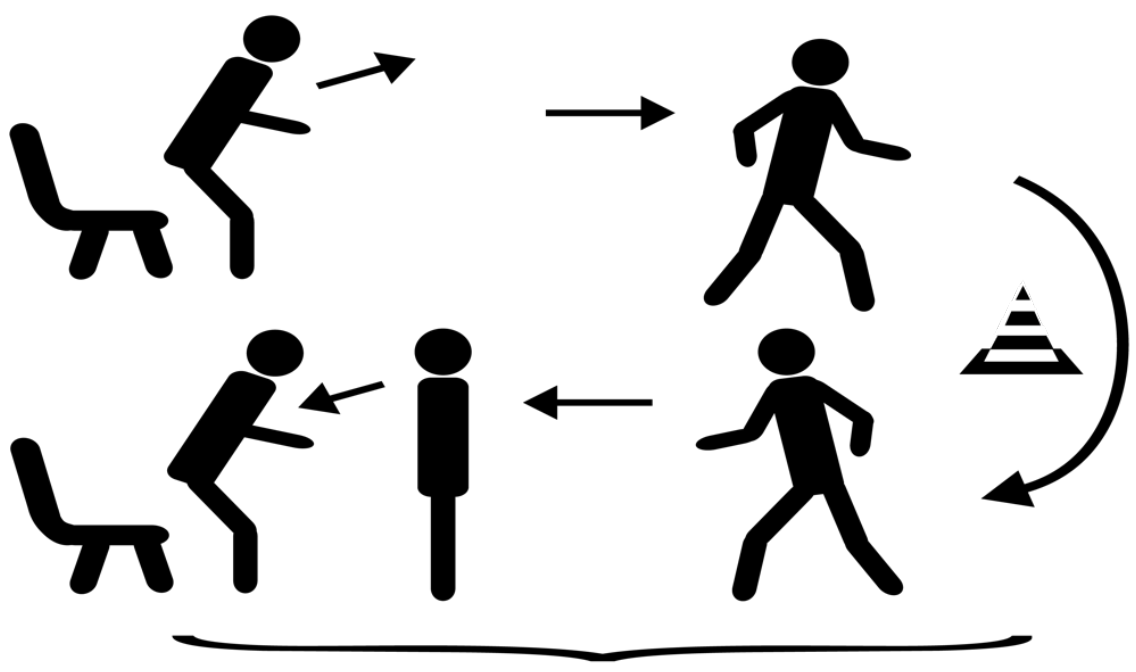

$3 m$

Opstaan uit de stoel, 3 meter lopen; om de pion draaien, terug lopen en weer gaan zitten.

\section{OPERATIE}

\section{MONITOREN VAN HET FUNCTIONEEL HERSTEL IN DE KLINISCHE FASE (H5)}

Hoofdstuk 2 liet een grote variatie in opnameduur zien binnen en tussen de verschillende onderzoeken. Wat induceert deze verschillen? Zoals eerder beschreven (bij INDICATIE \& OPNAME) 
wordt de opnameduur onder andere beïnvloed door het medisch herstel, functioneel herstel en logistiek. In hoofdstuk 5 wordt beschreven hoe het functioneel herstel van de patiënt tijdens de ziekenhuisopname kan worden geobjectiveerd. De mate van het functioneel herstel - zelfstandig kunnen uitvoeren van een aantal essentiële basale activiteiten - kan gebruikt worden door de zorgprofessional bij de beoordeling of de patiënt thuis zelfstandig kan functioneren zonder 24 uurs zorg.

Om het postoperatieve functioneel herstel van patiënten te kunnen monitoren is het meetinstrument "lowa Levels of Assistance Scale (ILAS)" als basis gebruikt. Met de ILAS kunnen zorgprofessionals, binnen dit proefschrift de ziekenhuisfysiotherapeuten, de activiteiten van lig naar zit, zit naar stand, lopen en traplopen beoordelen op zelfstandigheid van de patiënt. Echter, de ervaring, van verschillende ziekenhuisfysiotherapeuten uit meerdere ziekenhuizen in Nederland, was dat de activiteit van zit naar lig voor een deel van de patiënten een moeilijke activiteit betrof die toegevoegd moest worden aan de ILAS. Op basis van deze klinische ervaring is daarom de ILAS gemodificeerd en zo ontstond de mILAS. Vervolgens is in hoofdstuk 5 onderzocht of de moeilijkheid van de toegevoegde activiteit - zit naar lig - verschilt ten opzichte van de andere items van de mILAS. Uit de analyse bleek dat, in de eerste dagen na de operatie, de activiteit van zit naar lig gemiddeld het moeilijkste item was van de mILAS, wat de eerdere genoemde ervaringen van ziekenhuisfysiotherapeuten onderschrijft. Wanneer de patiënt zelfstandig de 4 of 5 items van de mILAS (voor sommige patiënten is traplopen, het $5^{\text {de }}$ item, niet noodzakelijk in de thuissituatie) kan uitvoeren, is de patiënt functioneel gezien klaar voor ontslag.

\section{ONTSLAG}

\section{EVALUEREN VAN HET HERSTEL MET BEHULP VAN REFERENTIEDATA (H6)}

Patiënten en behandelaren ontbreekt het aan evidence-based referentiegegevens om de kwaliteit van het postoperatieve fysieke herstel van de patiënt te beoordelen. Daardoor is het lastig vertraagd en/of slecht herstel vroegtijdig op te merken en zodoende bijtijds de therapie aan te passen of de patiënt terug te verwijzen voor aanvullende diagnostiek en/of interventies. Hoofdstuk 6 beschrijft het proces om te komen tot dergelijke referentiegegevens. Met gegevens uit verschillende fysiotherapiepraktijken in de Verenigde Staten is een referentiecurve ontwikkeld die het herstel van de flexie mobiliteit (buigen van de knie) in de tijd weergeeft voor patiënten na een totale knie operatie, welke ook als blauwdruk zou kunnen dienen voor het monitoren van patiënten na THP. Dergelijke referentiecurves kunnen door fysiotherapeuten gebruikt worden om 
van de individuele patiënt preciezer te monitoren door de uitkomsten te vergelijken met de gemiddelde variatie in herstel van eerder behandelde patiënten. Tevens kunnen de referentiecurves gebruikt worden om in de preoperatieve oriëntatiefase te beoordelen of de verwachtingen van zowel de patiënt als de behandelaar ten aanzien van het functioneel herstel reëel zijn in vergelijking met eerder behandelde (nagenoeg identieke) patiënten.

\section{DISCUSSIE (H7)}

Hoofdstuk 7 bevat de discussie en reflecteert op de resultaten en methodologie van de verschillende hoofdstukken en gaat in op de praktische toepasbaarheid van de uitkomsten die dit proefschrift biedt in zowel de klinische praktijk als in onderzoek.

In dit proefschrift is enkel gebruik gemaakt van gegevens uit de dagelijkse praktijk van drie verschillende Nederlandse ziekenhuizen en meerdere Amerikaanse particulieren fysiotherapiepraktijken. Dit proefschrift laat zien dat onderzoek met data vanuit de dagelijkse praktijk goed mogelijk is en past zowel bij de embedded scientist als de action research aanpak. Door gebruik te maken van de beschikbare gegevens uit de dagelijkse praktijk heeft deze aanpak een geringe impact voor de patiënt terwijl de reguliere zorg evalueert met de uitkomsten die generaliseerbaar lijken.

De 4p's van P4Medicine - Predictie, Preventie, Personalisatie en Participatie - staan als "kapstok" centraal in dit poefschrift om de reguliere zorg rondom de patiënt die opgaat voor een THP verder te personaliseren. Om tot een goed eindresultaat te komen is participatie van de patiënt gedurende het gehele behandeltraject essentieel, hiervoor zal de zorg zo veel mogelijk op de individuele patiënt afgestemd moeten worden en daarvoor is een betrokken patiënt noodzakelijk. Zo kan predictie bijdragen aan het vormen van reële verwachting van de patiënt en de zorgprofessionals omtrent de uitkomsten op korte (opnameduur) en lange termijn (herstel van activiteiten de eerste maanden na de operatie). Daarbij kan het - voor een selecte groep hoog risico patiënten - mogelijk zinvol zijn om een preventieve interventie te overwegen om de functionele status te vergroten om zo de negatieve gevolgen van de operatie beter te kunnen doorstaan. Daarnaast is het monitoren van herstel essentieel om de mate en snelheid van herstel te objectiveren, zeker als hierbij referentiecurves worden gebruikt met gegevens van patiënten 
die al eerder zijn behandeld. Alleen wanneer de totale behandeling goed afgestemd is op en met de individuele patiënt (personalisatie) is de kans het grootst dat de patiënt zich ten volle zal inzetten om een goed resultaat te behalen. Deze holistische en persoonlijke aanpak van de behandeling is ook door te voeren in vervolg onderzoek binnen THP en andere patiëntpopulaties.

\section{CONCLUSIE}

Voor een optimaal eindresultaat na een THP operatie is personalisatie van zorg essentieel. Elke patiënt is immers uniek en behoeft een op maat gemaakt behandelplan waarbij predictie, preventie en participatie essentiële onderdelen zijn om gezamenlijk te komen tot een zo optimaal mogelijk eindresultaat. Dit proefschrift realiseert die behoeft 


$$
\text { I D }
$$


En als laatste en meest gelezen hoofdstuk; het DANKWOORD. Voor de mensen die beginnen bij dit hoofdstuk, laat het u inspireren om ook de voorgaande hoofdstukken te lezen. Te beginnen met de Nederlandse samenvatting wat met weinig medische voorkennis goed te volgen moet zijn. Mocht $u$ het dan nog niet beu zijn en tijd over hebben, start dan bij hoofdstuk 1. Want dit proefschrift is de afronding van bijna 10 jaar noeste arbeid wat ik met veel plezier ben aangegaan en waarbij ik met vele interessante, slimme, inspirerende en aardige mensen heb mogen samenwerken die ik daarvoor graag wil bedanken. Mocht u niet persoonlijk genoemd worden in dit hoofdstuk en $U$ meent hier wel recht op te hebben... hierbij alvast mijn oprechte excuses.

\section{THUIS}

Laat ik beginnen met de belangrijkste personen.... Het thuisfront. Lieve Maartje, Thomas en Merel, zonder jullie steun was het mij nooit gelukt op deze beproeving te volbrengen. leder op jullie eigen manier hebben jullie mij geholpen en dat waardeer ik uit de grond van mijn hart! En wat ongezellig was het soms als ik weer veel achter de computer zat niet deel kon nemen aan het gezinsleven. Heb vaak gehoord dat ik te veel achter de computer zat en dat jullie dat niet echt gezellig vonden. Daarbij komt nog dat ik de studie een jaar moest pauzeren om een ander gevecht aan te gaan. Ik dacht in het begin nog dat ik tijdens de behandeling dit proefschrift wel kon afmaken, maar dat bleek ijdele hoop. Ook in deze zware periode zijn jullie heel belangrijk voor mij geweest. We hebben deze bijzonder periode allemaal op onze eigen wijze beleefd en hierbij wil ik jullie bedanken voor alle onvoorwaardelijke steun en toewijding tijdens de goede en minder goede tijden. Dank jullie wel lieve schatten....

\section{Prof. DR. N.L.U. van MeEteren}

Beste Nico, door jou bevlogenheid om de (fysiotherapeutische) zorg te verbeteren heb je mij geïnspireerd om ook zelf nieuwe kennis te ontwikkelen. Na fysiotherapiewetenschap hebben we met meerdere (inmiddels gepromoveerde) bevlogen collega's plannen gemaakt en uitgevoerd. Soms (of misschien vaker dan ik wil toegeven) was je vele stappen verder in het denkproces zodat ik bij anderen regelmatig na moest gaan wat nu precies bedoeld werd tijdens deze besprekingen. Maar altijd kwam ik geïnspireerd terug met weer meer vragen dan antwoorden. Dank Nico voor je inspiratie, je interesse, vooruitziende blik, en tomeloze inzet. Daarbij moet nog gezegd worden dat ik door jou niet meer spreek over een THP maar over een PERSOON met een THP. 
Beste Thomas, ik heb je zien ontwikkelen van een mede student bij fysiotherapiewetenschappen tot een volwaardige wetenschapper en zeer gewaardeerd copromotor. Met je met humor, analyses en breed netwerk heb je mij geholpen dit promotietraject te volbrengen. Ik keek elke keer weer uit naar ons wekelijks overleg waar ik mijn voortgang en tegenslagen met je kon delen. Je had altijd een luisterend oor en hielp met het gezamenlijk oplossen van de hobbels onderweg. Zelfs na het wisselen van baan wist je nog tijd vrij te maken ondanks dat je hier niet echt ruimte voor kreeg. Bedankt!!

\section{DR. SteVen VAn GaAlen}

Beste Steven, als orthopedisch chirurg in het Diakonessenhuis heb ik 8 jaar samengewerkt op het gebied van prothesiologie, rug chirurgie en later nog als copromotor totdat je vertrok naar Amsterdam waar je meer mogelijkheden kreeg om je verder te ontwikkelen. Jij heb mij met je orthopedische blik geholpen om ook verder te kijken dan de fysiotherapeutische mogelijkheden van de uitkomsten van dit proefschrift en het positioneren van mijn onderzoek binnen de maatschap orthopedie en het Diakonessenhuis.

\section{PA EN MA}

Lieve Pa en Ma, dank voor al jullie onvoorwaardelijk steun, liefde, vertrouwen en hulp als die nodig was wanneer er weer oppas nodig was voor Thomas en Merel. Ik kon en kan altijd op jullie hulp en steun rekenen en dat voelt als een warm bad daar ben ik jullie dankbaar voor.

\section{VRIENDEN EN FAMILIE}

Lieve vrienden en familie, ook jullie wil ik bedanken voor jullie steun en interesse voor mijn promotie. ledereen heeft op zijn eigen wijze bijgedragen aan dit proefschrift door advies, ontspanning, te fungeren als sparringpartner en relativering. Het was fijn om te ervaren dat jullie achter mij stonden waarbij jullie waardering en verwondering mij zeer hebben gesteund tijdens dit promotietraject.

\section{GeerT en ElLen}

Als pas afgestudeerde fysiowetenschappers zijn we alle drie zelfstandig onderzoek gaan doen binnen onze eigen ziekenhuizen wat uiteindelijk heeft geleid tot drie promoties. We hebben in deze periode vaak met elkaar samen gewerkt waarbij ik genoten heb van onze discussies, het delen van ervaringen en kennis. Er bestond geen competitie, althans zo heb ik het nooit ervaren, 
maar enkel respect voor elkaar. We zaten alle drie in het zelfde schuitje, al voer het ene schuitje net even wat harder dan de andere. Het was me een genoegen om met jullie samen gewerkt te hebben en ik hoop dat we in de toekomst dit verder kunnen voortzetten.

\section{COLLEGA'S AFDELING FYSIOTHERAPIE}

Ik wil jullie bedanken voor jullie waardering, aanmoedigingen, en steun tijdens mijn promotie periode. Het vieren van een publicatie was altijd een speciaal moment en daarnaast hebben jullie mij aan den lijve laten ondervinden dat het implementeren van de uitkomsten van mijn onderzoek(en) niet altijd zo makkelijk verliepen als dat ik gedacht had. Maar vooral jullie onophoudelijke vraag wanneer nu eindelijk de promotie plaats zou vinden en belangrijker wanneer het feest zou zijn hebben altijd een lacht om mijn gezicht gebracht al was het misschien niet altijd direct zichtbaar. Nu is het dan eindelijk zo ver, al is het nog maar de vraag of er een feestje mag worden gehouden met meer dan 30 personen met 1,5 meter afstand..... En de oefenzaal is voor mij echt GEEN optie!!

\section{VERPLEEGAFDELING ORTHOPEDIE}

Naast mijn directe fysiotherapie collega's wil ik ook alle medewerkers van de afdeling orthopedie bedanken voor alle steun en aanmoediging.

\section{CoAuteurs}

Alle coauteurs bedankt voor jullie inzet, toewijding en expertise bij het tot stand komen van de artikelen die hebben geleid tot dit proefschrift. Zonder jullie had ik dit nooit voor elkaar gekregen en dank voor alles wat jullie mij geleerd hebben.

\section{JEN AND ANDY}

Dear Jen, Andy, and other colleges at Denver University, thanks for the opportunity and hospitality to stay in Denver for four weeks to work together on my favorite Chapter \#7, Reference Curves. I learned a lot from you all in the field of physical therapy and the habits of Americans during the presidential election. Every time I think of Denver, I cannot stop smiling. Jen, I cannot thank you enough for letting me stay at your house. I felt really welcome and adopted by your family. You have a great husband and two great kids. And Andy, you are a great guy to work with and a marvelous dad, especially when you read Miffy to your kids. I have learned a lot of new stuff in $\mathrm{R}$ and the time that we spent during our road trip in the Mid-West was awesome. BOOM 

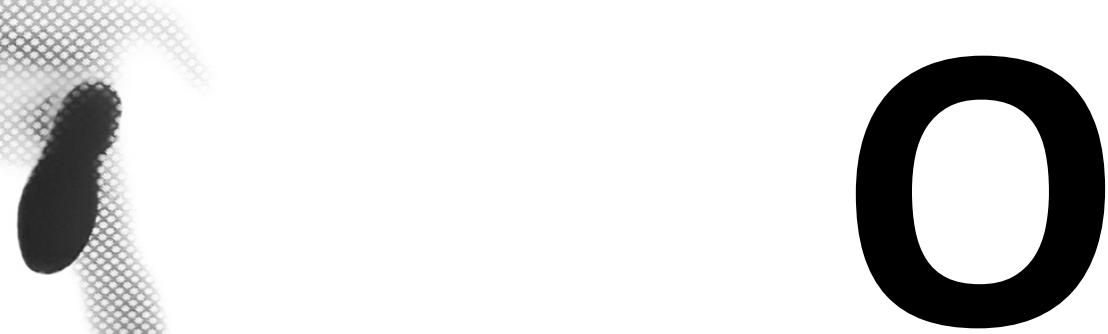

OVER DE AUTEUR 


\section{OVER DE AUTEUR}

Jordi Elings geboren op 22 mei 1979 te Wageningen. Na het afrondden van de HAVO aan 't Wagenings te Wageningen ging hij in 1996 fysiotherapie studeren aan de Hogeschool Utrecht en rondde de studie met goed gevolg af in 2000. Na 4 jaar werkzaam te zijn geweest als fysiotherapeut in het Diakonessenhuis te Utrecht startte hij de studie Master of Science Fysiotherapiewetenschappen aan de universiteit van Utrecht welke in 2007 werd afgerond. Tijdens de studie Fysiotherapiewetenschap kwam hij in aanraking met het (zelfstandig) uitvoeren van wetenschappelijk onderzoek bij patiënten na een orthopedische operatie. Het functioneel herstel tijdens de ziekenhuisopname van patiënten na een orthopedische operatie genoot zijn wetenschappelijke focus. Dit resulteerde in 2015 tot zijn eerste wetenschappelijke publicatie wat de voorbode was van zijn proefschrift welke hij begin 2021 afrond. Tijdens de studie heeft de auteur een wetenschappelijke stage van 4 weken gevolgd in Denver. Deze internationale samenwerking heeft geresulteerd in een wetenschappelijke publicatie waarbij hij als $2^{\text {de }}$ auteur is opgenomen.

Tijdens het promotietraject heeft hij zijn werkzaamheden moeten onderbreken in verband gezondheidsproblemen waarbij hij proefondervindelijk heeft kunnen ervaren wat de voordelen zijn van kennis rondom “Better in Better out' en het monitoren van (functioneel) herstel.

Naast de promotie is Jordi ook betrokken geweest bij regionale en landelijke initiatieven rondom "Better in Better out", de ontwikkeling van de KNGF-richtlijn artrose en onderzoek naar de invloed van de gebouwde omgeving op het beweeggedrag van patiënten die zijn opgenomen in het Diakonessenhuis. Voor de ontwikkeling van een regionaal netwerk rondom "Better in Better out" heeft hij een subsidie van $€ 35.000$ ontvangen vanuit de innovatiegelden van het Diakonessenhuis. Naast zijn reguliere werkzaamheden als fysiotherapeut heeft hij zijn kennis gedeeld als gastdocent master Geriatriefysiotherapie (HU) en kader opleiding Geriatrie (AMC), alsmede spreker op Internationale (Nederlandse Orthopeden vereniging, Building the Future of Health) en nationale congressen (KNGF, regionale genootschappen fysiotherapie, Geriatriedagen).

De auteur woont samen met Maartje van der Aa sinds 1998 en is de trotse vader van Thomas (13) en Merel (11) 